ANL- $721 \dot{4}$

Reactor Technology

(TID-4500)

AEC Research and

Development Report

ARGONNE NATIONAL LABORATORY 9.700 South Cass Avenue

CRSTI PRICKS

Argonne, Illinois 60439

$\mathrm{H} \cdot \mathrm{C}: 3.00$

MN .65

\title{
HYDRODYNAMICS OF A NEW CONCEPT OF PRIMARY CONTAINMENT BY ENERGY ABSORPTION
}

by

H. C. Sorensen and S. H. Fistedis

Reactor Engineering Division

\section{LEGAL NÓTICE}

This report was prepared as an account of Government sponsored work. Netther the United States, nor the Commission, nor any person acting on behalf of the Commlasidn:

A. Makes any warranty or representation, expressed or implied, with respect to the accuracy, completeness, or usefulness of the information contained in this report. or that the use of any information, apparatus, method, or process disclosed in thls report may not infringe privately owned rights; or

B. Assumes any llabilities with respect to the use of, or for damages resulting from the use of any information, apparatus, method, or process disclosed in thls report.

As used in the above. "person acting on behalf of the Commission" includes any employee or contractor of the Commission, or employee of such contractor, to the extent that such employee or contractor of the Commission, or employee of such contractor prepir disseminates, or provides access to, any information pursuant to his employment or contras, with the Commission, or his employment with such contractor.

L.. - - . . . .

$$
\text { -....... }
$$

December 1966 


\section{DISCLAIMER}

This report was prepared as an account of work sponsored by an agency of the United States Government. Neither the United States Government nor any agency Thereof, nor any of their employees, makes any warranty, express or implied, or assumes any legal liability or responsibility for the accuracy, completeness, or usefulness of any information, apparatus, product, or process disclosed, or represents that its use would not infringe privately owned rights. Reference herein to any specific commercial product, process, or service by trade name, trademark, manufacturer, or otherwise does not necessarily constitute or imply its endorsement, recommendation, or favoring by the United States Government or any agency thereof. The views and opinions of authors expressed herein do not necessarily state or reflect those of the United States Government or any agency thereof. 


\section{DISCLAIMER}

Portions of this document may be illegible in electronic image products. Images are produced from the best available original document. 
TABLE OF CONTENTS

Page

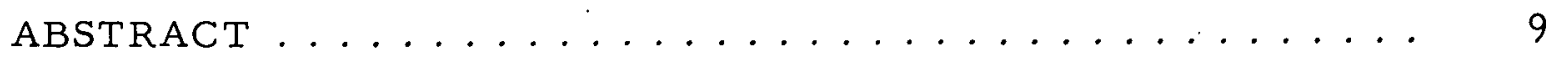

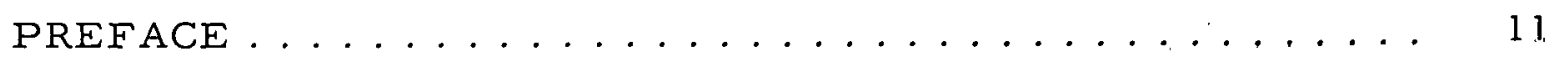

PART ONE. SOLUTION FOR THE IDEAL REACTOR SYSTEM

WITHOUT A REACTOR VESSEL ........... 13

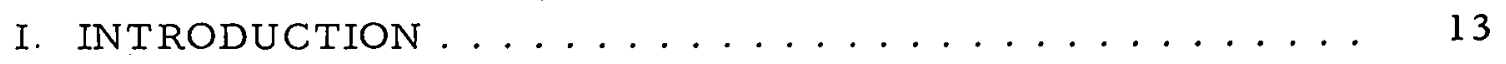

II. DEVELOPMENT OF THE THEORY $\ldots \ldots \ldots \ldots \ldots \ldots$

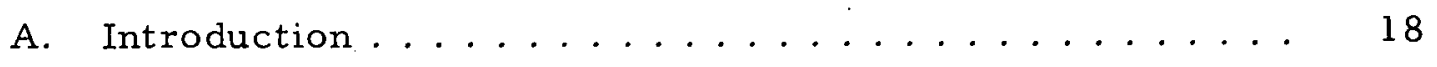

B. The Lagrangean Equations . . . . . . . . . . 18

C. The Jump Conditions at a Shock. . . . . . . . . 20

D. Effect of Dissipation ............... 21

E. Finite-difference Equations. . . . . . . . . . 22

F. Stability of the Finite-difference Equations . . . . . . . 24

G. Treatment at Interfaces . . . . . . . . . . . 24

III. SOLUTION OF A SAMPLE PROBLEM. . . . . . . . . . 26

A. Problem Layout . . . . . . . . . . . . 26

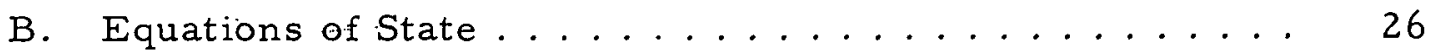

1. Products of Detonation. . . . . . . . . . 27

2. Water......................... 28

3. Argon. ..................... 29

C. Finite-difference Net and Equations . . . . . . . . . 31

1. TNT ......................... 33

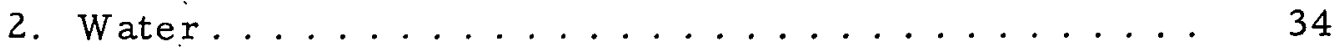

3. Argon....................... 34

D. Assumptions. ....................... 35

E. Boundary Conditions .................. 35

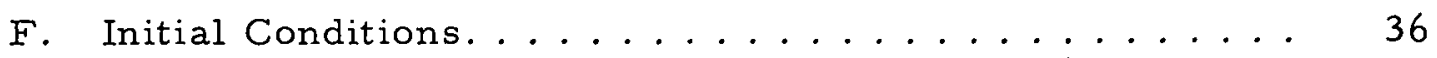

G. Flow Charts for Calculations in the Water........ 39

H. FORTRAN Names and Their Description.......... 41

I. List of Data Values Used... . . . . . . . . . . . 43 
TABLE: OF CONTENTS

$\underline{\text { Page }}$

J. FORTRAN IV Computer Statements ........... 44

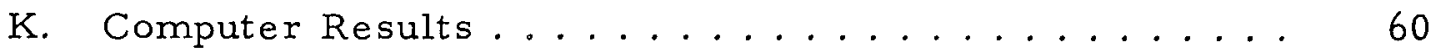

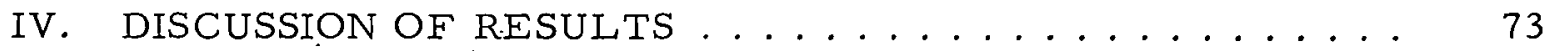

A. Comparison of the Computer Results for the Simulated Infinite Water Medium with Experimental

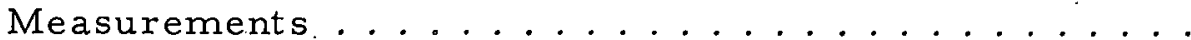

B. Comparison of the Computer Results for the.

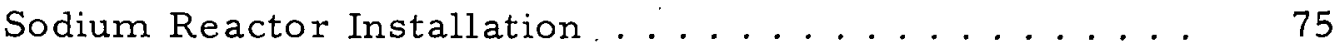

1. The Shock Wave................. 76

2. The Fluid Momentum due to the Passage of the

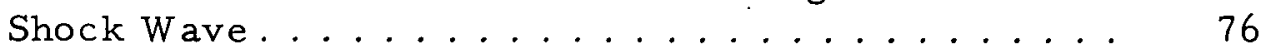

3. The Gas Bubble at High Temperature and Pressure Pushing on the Fluid ............. 77

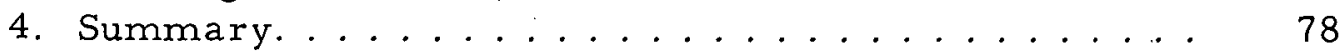

V. STRAIN-RATE CALCULATIONS ............. 79

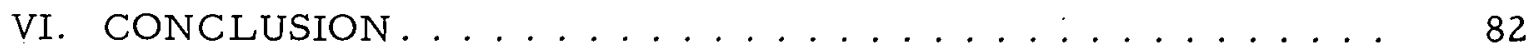

PART TWO. SOLUTION FOR THE IDEAL REACTOR SYSTEM WITH A REACTOR VESSEL . . . . . . . . . . 85

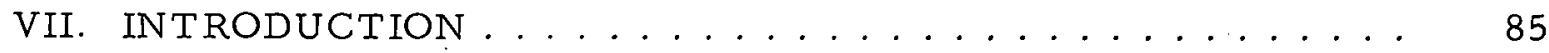

VIII. SOLUTION OF A SAMPLE PROBLEM. . . . . . . . . . . 86

A. Problem Layout . . . . . . . . . . . . 86

B. The Theory Associated with the Reactor Vessel ..... 86

C. Finite-difference Equations.............. 90

D. Initial Values ............................. 90

E. FORTRAN Names and Their Description. . . . . . . 94

F. Changes in Computer Program ............. 94

G. FORTRAN IV Computer Statements ............ 95

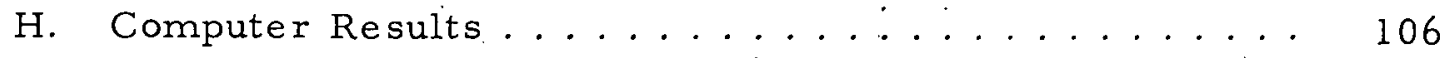


TABLE OF CONTENTS

Page

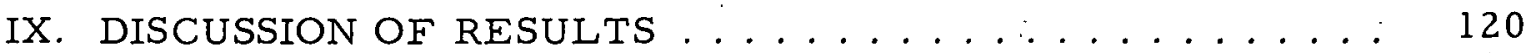

A. Comparison of Results................. 120

B. General Discussion of Results............. 121

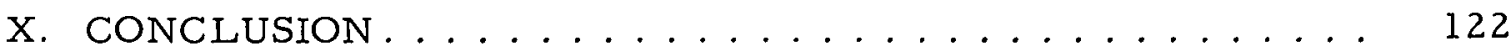

\section{APPENDIXES}

A. Tables of Experimental Data Extracted from

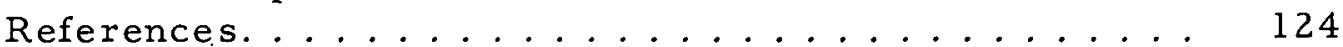

B. Description of the Miscellaneous Computer Programs. . 126

1. Least-squares Curve-fitting Program ........ 126

2. Program for CalComp 580 Plotter......... 126

3. Program for the Impulse .............. 126

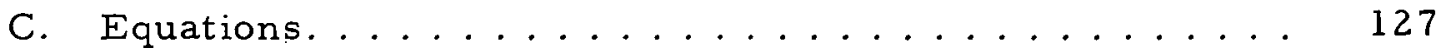

1. Equations for the Speed of Sound .......... 127

2. Equation for Determining the Shock Speed, $U_{S}$, in

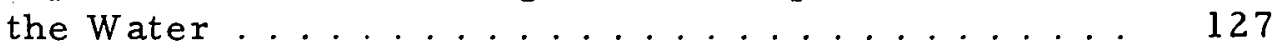

3. Equation for the Internal Energy of the Argon ..... 128

4. Transformation of the Equations for the Water. . . . 128

5. The Equation. for the Lagrangean Coordinates. . . . . 130

D. Comparison of Computer Results with Those Given by the Tait Equation. . . . . . . . . . . . . 132

E. Calculations for the Concrete Vessel .......... 133

1. Mass per Unit Area of the Inside Surface . . . . . . 133

2. Calculation for the Allowable Internal Pressure.... 133

F. Energy Calculations. . . . . . . . . . . . . 134

1. Energy Released by the Detonation of TNT . . . . . 134

2. Initial Kinetic Energy of the Concrete Mass. . . . . . 134

3. Comparison of Energies.............. 135

G. Miscellaneous Considerations ............ 136

1. Calculation of the Gas Constant, $\mathcal{R}$, for the Detonation

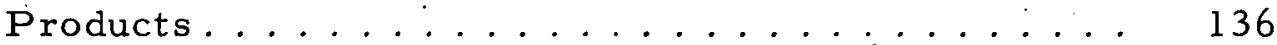

2. Calculations for the Allowable $\Delta t^{\prime}$ s at $t=0 \ldots 136$

3. Pictorial Representation for the $\Delta r^{\prime} s \ldots \ldots 137$

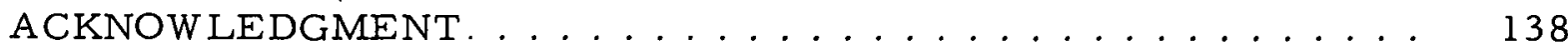

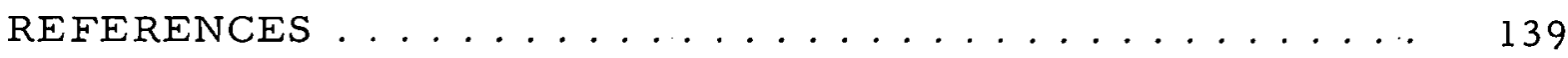


LIST OF FIGURES

No.

Title

$\underline{\text { Page }}$

1. Primary Containment Structure Showing the New Concept of Energy Absorption................ 15

2. Idealized Reactor System . . . . . . . . . . . . 16

3. Schematic Profile of a Shock Wave............. 17

4. Example Problem Layouts and Dimensions . . . . . . . . . 26

5. Finite-difference Net. . . . . . . . . . . . . . . ... 31

6. Simplified Flow Chart for Calculations in the Water . . . . . 39

7. More Detailed Flow Chart for Calculations in the Water. . . . 40

8. Graphical Representation of the Computer Results for the Simulated Infinite Water Medium . . . . . . . . . . . 69

9. Pressure-Time Curve for the Argon at the Water-Argon Interface . . . . . . . . . . . 70

10. Pressure-Time Curve for the TNT at the TNT-Water

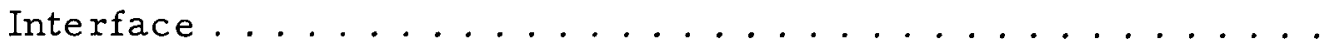

11. Pressure-Time Curve for the Inside Face of the Concrete Vessel ...................... 71

12. Location-Time Curve for the TNT-Water Interface. . . . . . 71

13. Location-Time Curve for the Water-Argon Interface...... 71

14. Pressure-Time Curve for the Water at the Water-Argon

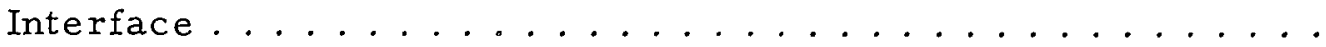

15. Pressure-Time Curve for the Water at the TNT-Water Interface. . . . . . . . . . . . 72

16. Maximum Pressure in the System Outside of the Gas Bubble. . 72

17. Pressure-Time Curve for the Center of the Gas Bubble..... 72

18. Total Energy of the System as a Function of Time. . . . . . . 72

19. Idealized Reactor System . . . . . . . . . . . . . . 85

20. Problem Layout and Dimensions . . . . . . . . . . 86

21. Pressure-Time Curve for the Inside Face of the Concrete

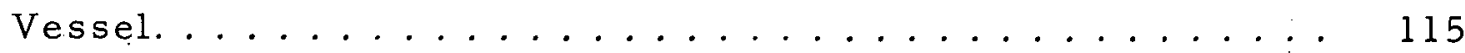

22. Location-Time Curve for the TNT-Water Interface...... 115

23. Location-Time Curve for the Reactor Vessel (Water-Argon Interface) . . . . . . . . . . . . 116 


\section{LIST OF FIGURES}

No.

Title

Page

24. Maximum Pressure in the System Outside of the Gas Bubble..

25. Pressure-Time Curve for the Water at the Reactor

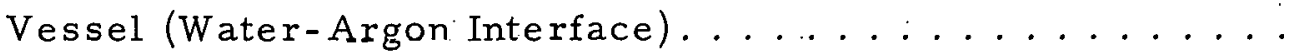

26. Pressure-Time Curve for the Water at the TNT-Water Interface . . . . . . . . . . . . .

27. Pressure-Time Curve for the Center of the Gas Bubble. . . .

28. Pressure-Time Curve for the TNT at the TNT-Water Interface

29. Total Energy of the System as a Function of Time. . . . . . 118

30. Energy Associated with the Fluid as a Function of Time. . . . 119

31. Energy Associated with the Reactor Vessel as a

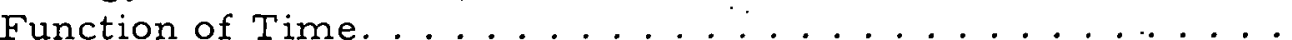

32. Pictorial Representation for $\Delta r^{\prime} s \ldots \ldots \ldots \ldots$ 


\section{LIST OF TABLES}

No.

Title

$\underline{\text { Page }}$

I. Densities of the Various Media ................ 26

II. Initial Values of the Parameters Required for the

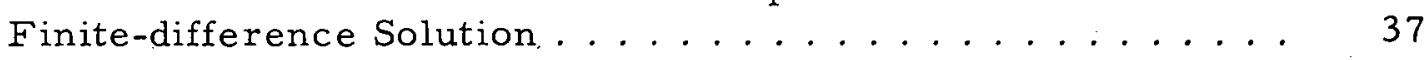

III. Computer Results for Peak-pressure Analy.sis . . . . . . . . . 60

IV. Tabulated Values of the Pressure and the Radial Coordinate at Several Critical Locations. . . . . . . . . 62

V. Peak Pressure in the Spherical Shock Wave from TNT. . . . 73

VI. Values of Various Hydrodynamical Parameters for TNT . . 75

VII. Strain-rate Classification for Metals ............ 81

VIII. Input Data for the Finite-difference Solution. . . . . . . . . 92

IX. Initial Values of the Parameters Required for the

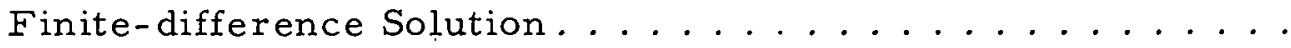

$X$. Tabulated Values of the Pressure and Radial Coordinate at Several Critical Locations, and a Record of the Energy in

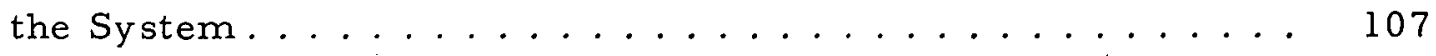

XI. Spherical Detonation Wave in TNT ............ 124

XII. Shock-wave and Thermodynamic Data for the Water Hugoniot

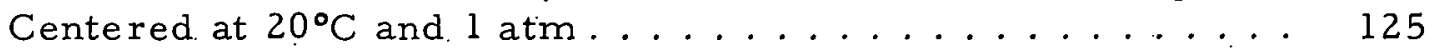

XIII. Pressure-Volume Data for Water.............. 132

XIV. Information about the Products of Detonation of TNT . . . . . 134 


\title{
HYDRODYNAMICS OF A NEW CONCEPT \\ OF PRIMARY CONTAINMENT \\ BY ENERGY ABSORPTION
}

by

H. C. Sorensen and S. H. Fistedis

\begin{abstract}
To determine the effect that the destructive component of a nuclear accident produces on a primary containment structure, a fluid dynamical analysis is made for an idealized reactor system having spherical symmetry. This primary containment structure reflects a new concept developed at Argonne National Laboratory:' It consists of the utilization of the concrete biological shield as an energy-absorbing device. For this purpose, unbonded, unstressed, high-strength steel strands are embedded in the biological shield. The new containment concept is based on the energyabsorbing. capability of the strands.

The partial differential equations describing the fluid motion are based upon the von Neumann-Richtmeyer artificial-viscosity technique and are presented in Lagrangean form. A numerical solution based upon finitedifference approximations of these partial differential equations is obtained by the use of a CDC-3600 digital computer. All computer programs used in obtaining the numerical solution are written in FORTRAN IV computer language.

Two solutions for an example problem are given. The solution for an ideal reactor system that does not include the reactor vessel is given in Part One, and the solution for the same ideal reactor system but with the reactor vessel included is given in Part Two. In each case, the effect that the destructive component produces on the concrete containment structure is determined from the computer results and is discussed. The results of the two solutions are then compared. Suggestions for improvements in. the analysis and suggestions for future work are also mentioned.
\end{abstract}




\section{PREFACE}

During the power excursion that results from the occurrence of a hypothetical core meltdown (accident) in a power reactor, a large amount of energy is deposited as heat in the materials of the core.* At the end of the excursion, the core is left at a very high temperature and pressure. This condition is the beginning of core disintegration: The material immediately surrounding the core is compressed.by the high pressure and is accelerated outward. The core expands in volume, accompanied by a rapid decrease in the core pressure. At the same time, a pressure wave forms and moves out into the surrounding medium. This pressure wave, after moving a short distance through the compressible medium, becomes a shock wave; i.e., it is characterized by a sharp front. As the shock wave moves through the compressible medium, there is an irreversible compression at the front, which continually deposits some of the energy of the shock wave in the material, raising the temperature slightly. This process causes an attenuation of the shock wave, so that it has less destructive capability when it finally reaches some important part of the containment structure.

For many hypothetical nuclear accidents, the local pressure produced by the energy deposited in the core is comparable to the pressure produced by the detonation of a TNT charge. Thus, it is common practice to analyze the destructiveness of a hypothetical nuclear accident on the basis of an equivalent TNT explosion. The size of the TNT charge is chosen such that the amount of energy released in its detonation is equivalent to that calculated for the accident.

Many people have investigated explosives, explosions, and shock waves. The list of investigators in these areas includes W. J. M. Rankine, H. Hugoniot, Lord Rayleigh, H. Jones, A. R. Miller, G. I. Taylor, W. G. Penney, P. W. Bridgman, H. K. Dasgupta, J. G. Kirkwood, H. A. Bethe, S. R. Brinkley, Jr., R. H. Cole, M. H. Rice, J. M. Walsh, J. von Neumann, R. D. Richtmeyer, P. D. Lax, H. L. Brode, L. D. Landau, K. P. Stanyukovich, R. Courant, and K. O. Friedrichs.

The analyses of shock waves in fluids have used a variety of mathematical methods and techniques. Penney ${ }^{21}$ and later Penney and Dasgupta ${ }^{22}$ used numerical methods to solve the differential equations for finite-amplitude spherical waves in TNT. They reduced the governing differential equations to a form convenient for step-by-step integration by the use of Riemann functions. This technique is called the method of characteristics.

Kirkwood and Bethe ${ }^{19}$ developed an analytical approach to shock-wave propagation in water. They considered the solution of the fundamental equations by the introduction of the enthalpy associated with the fluid.

\footnotetext{
* This account of what happens in a nuclear accident is condensed from Ref. 2 .
} 
Kirkwood and Brinkley ${ }^{20}$ developed an approach to the solution for shock waves of the basic hydrodynamic equations that is particularly convenient.for extending experimentally determined.shock-wave data obtained at a single distance, or over a limited.range, to other distances. They obtained the parameters of their theory from experimental data. These data were obtained at relatively large distances from the explosive charge where the pressures are relatively low. Then. they used their formulation to extrapolate for the pressures at points nearer.the charge.

Von Neumann and Richtmeyer ${ }^{16}$ developed another method for the analysis of fluid-dynamical problems involving shock waves. In this method, the equations of hydrodynamics are modified by the inclusion of additional terms that greatly simplify the procedures necessary for the stepwise numerical solution of the equations. The quantitative influence of these terms can be made as small as one wishes by choice of a sufficiently fine mesh for the numerical integration. The method uses an artifical viscosity as a mechanism for avoiding shock-front discontinuities, and it takes care of shocks automatically, whenever and wherever they occur. Brode ${ }^{3,4}$ used the von Neumann-Richtmeyer method for numerical solutions of spherical blast waves in air. This is the method employed in this work.

The concept of primary containment by energy absorption treated herewith was originally developed. by S. H. Fistedis. Part One of this report constitutes.the thesis of H. C. Sorensen. in partial fulfillment of the requirements of the degree of Doctor of Philosophy at the University of Nebraska. Part Two was subsequently completed. All work was performed at the Reactor Engineering.Division, Argonne National Laboratory. 


\section{PART ONE \\ SOLUTION FOR THE IDEAL REACTOR SYSTEM \\ WITHOUT A REACTOR VESSEL}

\section{INTRODUCTION}

The increasing demand for power has influenced and stimulated the development of atomic reactors. At present, electricity produced by atomic reactors is, in most cases, not competitive with that produced from fossil fuels. To become competitive, power reactors must accommodate larger and larger cores, thereby increasing their electrical output. As the production capability of.the reactor facility increases, the net cost per unit of output decreases.

Many difficult design problems are associated with the development of larger reactor cores. One such problem is the requirement for rendering: the facility safe with respect to the radiation exposure to the surrounding public. This requirement must be satisfied for normal operation of the facility as well as for abnormal reactor behavior.

To protect against radiation exposure to the reactor site personnel during normal operation, a radiation shield (also called a biological shield) is provided which prevents radioactive particles from escaping from the reactor cavity. The safety requirement for this type of reactor performance is easily satisfied.

Abnormal reactor behavior requires safety provisions in which those for the maximum credible accident (MCA) are included. The MCA is that particular accident (one of a large number of potential accidents examined in considering the safety of the reactor system) for which the consequences, as measured by the radiation exposure to the surrounding population, would not be exceeded by any other accident for which the occurrence during the lifetime of the facility would appear to be credible. The safety requirement for this type of reactor performance is not easily satisfied. If the MCA would.occur in a power reactor, an enormous amount of energy would be released in a very short time. This energy release could cause serious damage to the surrounding structure. As reactor cores become larger to produce more electricity, the amount of energy released by the MCA increases. Thus, the control of radiation exposure becomes more difficult. The control of the radiation released by a nuclear accident is referred to as containment.

Reactor containment is a general term which is defined ${ }^{6}$ to include all structures, systems, mechanisms, and devices that can be provided to attain, with a high degree of reliability, some specified attenuation in the radioactivity presumed to be released from the primary system in a reactor accident and which otherwise might be released to the surrounding environment. 
Containment is accomplished in two phases: The first is referred to as primary containment; the second is referred to as secondary containment. The objective of the first phase is to attenuate the destructive component, i.e., the energy release, of a nuclear accident and is performed by the primary containment system. The objective of the second phase is to control, within acceptable limits, the release to the environment of the radioactive products of a nuclear accident and is performed by the outer shell of the reactor plant.

In general, present design methods do not guarantee primary containment. However, safeguards are built into the reactor system to prevent rupture of the outer shell of the reactor plant, thereby insuring secondary containment. The outer shell is normally designed to withstand a certain static pressure, which is correlated to the magnitude of the MCA by $\mathrm{P}-\mathrm{V}-\mathrm{T}$ relations.

Every reactor requires a biological shield for normal operation. This biological shield is generally constructed of concrete (4-6. ft thick) and envelops the reactor cavity. The reactor cavity contains the reactor vessel, which in turn contains the reactor core. The nuclear accident begins in the core.

Primary containment is often achieved by placing concentric steel cylinders around the reactor vessel with a layer of crushable filler material separating adjacent steel cylinders. This primary-containment device is placed entirely within the reactor cavity. The destructive component of the accident is thereby attenuated.by the subsequent stretching of the steel cylinders and crushing of the filler material. A multitude of concentric cylinders can be an effective energy-absorbing. system. One serious objection to this method of energy absorption is the substantial expense involved in the construction. Another objection. is the lack of ascertainable margins of safety in design, since a local imperfection in a cylinder could initiate a tear in that cylinder; thus, failure of that cylinder would occur without significant energy absorption.

To reduce the cost of primary nuclear containment and to provide reliable safety factors for credible nuclear accidents, a new approach for primary nuclear containment by energy absorption' has been proposed.

This new approach uses high-strength steel strands placed in the concrete biological shield forming a basketlike configuration around the reactor cavity (see Fig. 1). The strands are placed in conduits to prevent bond with the concrete and are not prestressed. The energy-absorbing process is accomplished.by the plastic deformation that the strands are capable of exhibiting. This approach eliminates the necessity of the expensive multiple steel cylinders in the reactor cavity and extends the primary containment system to include the concrete biological shield, which heretofore has only played an effective role as a radiation shield. 


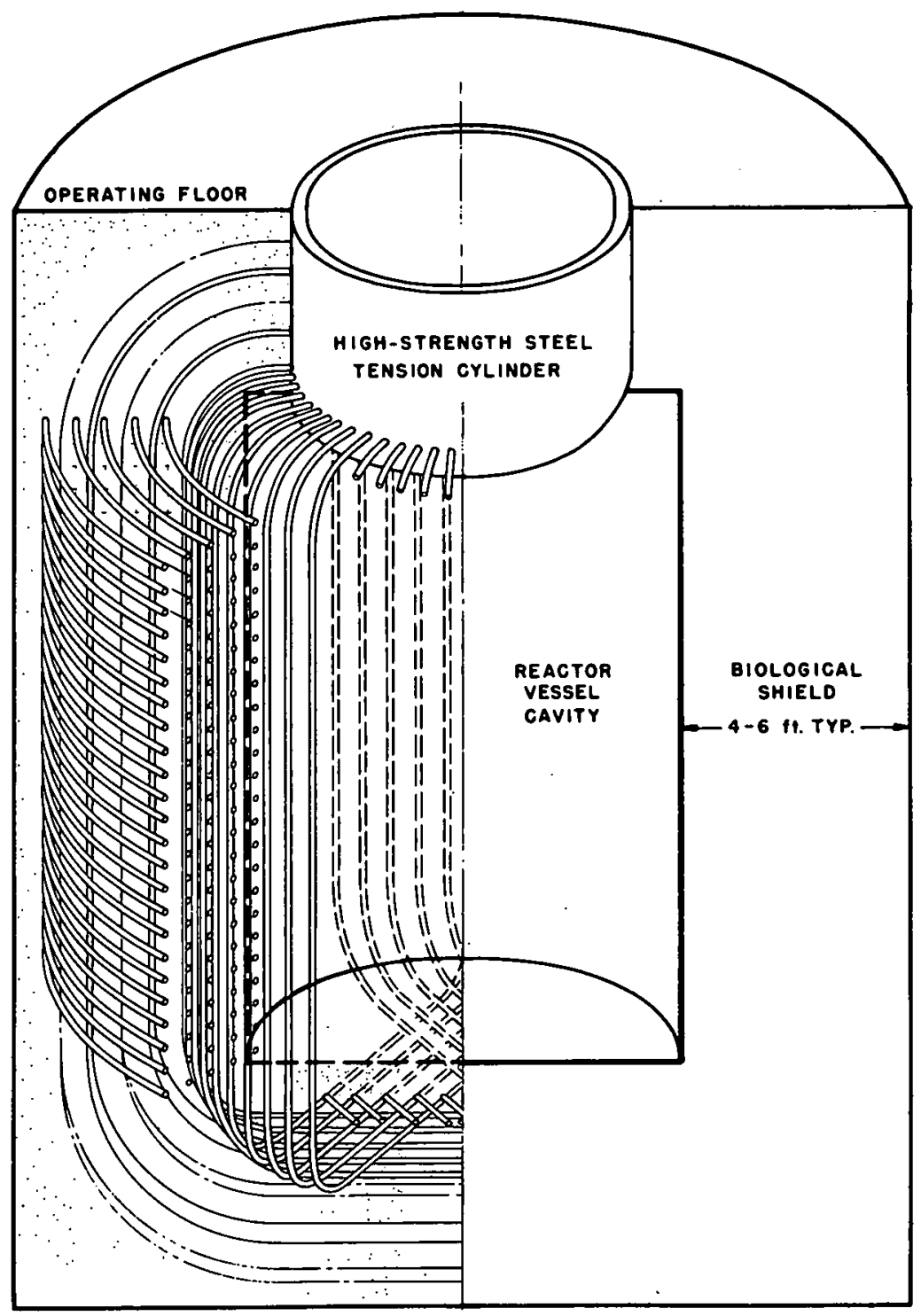

Fig. 1. Primary Containment Structure Showing the New Concept of Energy Absorption 1

The feasibility of this new approach for primary containment has been established on the basis of the mechanical properties of the strands measured under static conditions. This was done by equating the total energy released by the MCA to the total allowable strain energy of the strands. Equating the energies is a conservative basis for establishing the new concept because of the energy that dissipates during its transport to the containment structure. However, one factor necessary to establish the application of the new concept for primary containment is the rate of strain to which the strands are subjected. This is important because the total strain energy developed by the strands is dependent upon the strain rate.

The purpose of this investigation is to make a fluid dynamical analysis of the destructive component, i.e., the energy release, of a nuclear 
accident. This destructive component is assumed equivalent to that produced by the detonation of a charge of TNT. It is desired from the analysis to:

1. Obtain general information as to how the destructive component propagates and changes with time.

2. Determine the effect that the destructive component produces on the concrete primary-containment structure so that the required rate of strain for the strands can be calculated.

The system analyzed in this investigation is an idealized reactor system having spherical symmetry. It consists only of a reactor core, a liquid coolant surrounding the core, a layer of inert gas, and a concrete biological shield (see Fig. 2). The high-strength steel strands (omitted from Fig. 2) are assumed to be embedded in the concrete. This configuration results in a system of one space variable.

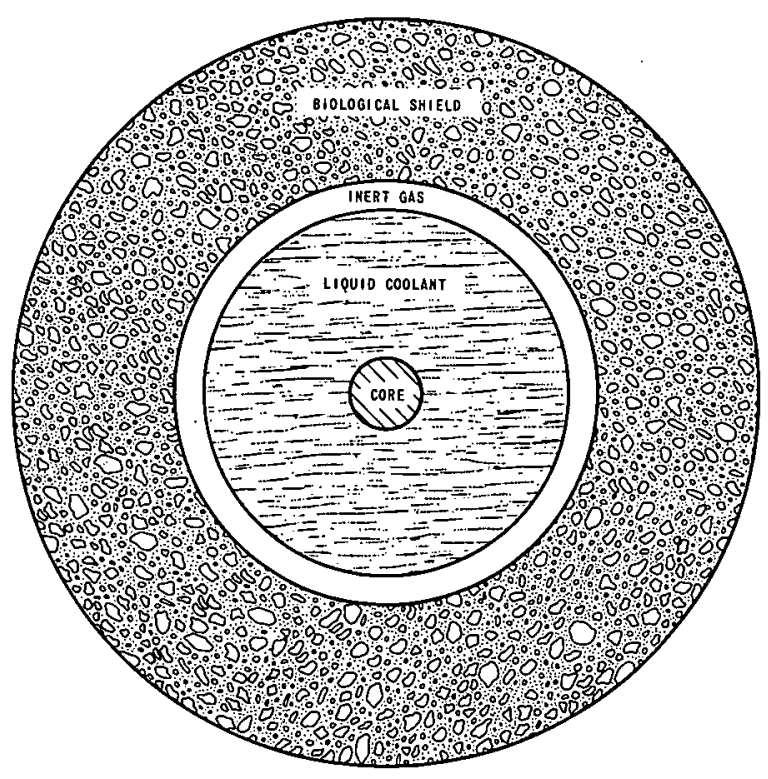

Fig. 2. Idealized Reactor System

$$
\begin{aligned}
& \frac{\partial \rho}{\partial t}+\operatorname{div}(\rho \bar{v})=0, \\
& \rho \frac{\partial \bar{v}}{\partial t}+\operatorname{grad} P=0,
\end{aligned}
$$

For an energy release due to the detonation of TNT inside a fluid, the destructive component can be separated into three elements. These three elements, in the order of appearance on the time scale, are:

1. The shock wave.

2. The fluid momentum due to the passage of the shock wave.

3. The expanding gas bubble at high temperature and pressure pushing on the fluid.

The Eulerian form of the basic equations ${ }^{5}$ describing the motion of an inviscid fluid (with no shock waves present) are

Motion (2)

and

$$
\frac{d E}{d t}-\frac{P}{\rho^{2}} \frac{d \rho}{d t}=0,
$$


where the velocity vector $\bar{v}$ has the components $u, v$, and $w$ in Cartesian coordinates. The density, $\rho$, is usually expressed in terms of the pressure, $P$, to obtain an additional equation called the equation of state of the fluid.

The front of the shock wave that is transmitted to the fluid medium surrounding the core is verified by experiment to be so steep that it can be considered a discontinuity. When a fluid particle is traversed by a shock wave, it suffers an almost discontin-

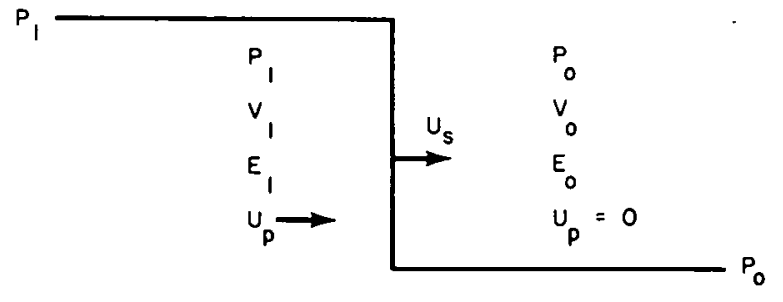

Fig. 3. Schematic Profile of a Shock Wave uous change in its thermodynamic state. The shock front propagates with a velocity, $U_{S}$, which is supersonic relative to the undisturbed medium; and a particle velocity, $U_{p}$, is imparted to the fluid behind the shock front (see Fig. 3). The basic equations for fluid flow do not apply in the region of the discontinuity.

The equations that do apply to such a discontinuity are obtained by considering regions immediately ahead of and behind the shock front. These. equations,* which are based on the conservation laws, are

$$
\begin{aligned}
& \mathrm{V}_{1} / \mathrm{V}_{0}=\left(\mathrm{U}_{\mathrm{s}}-\mathrm{U}_{\mathrm{p}}\right) / \mathrm{U}_{\mathrm{s}}, \\
& \mathrm{P}_{1}-\mathrm{P}_{0}=\mathrm{U}_{\mathrm{S}} \mathrm{U}_{\mathrm{p}} / \mathrm{V}_{0},
\end{aligned}
$$

Momentum (5)

and

$$
E_{1}-E_{0}=\frac{1}{2}\left(P_{1}+P_{0}\right)\left(V_{0}-V_{1}\right)
$$

where $P_{0}, V_{0}$, and $E_{0}$ and $P_{1}, V_{1}$, and $E_{1}$ denote pressure, specific volume, and specific internal energy ahead of and behind the shock front, respectively.

Taken together, Eqs. 1-6 completely describe the fluid motion considered in this investigation. These equations can be solved by finitedifference techniques.

* These three relations, called the Rankine-Hugoniot equations, are derived in any text on shock-wave hydrodynamics. See, for example, Ref. 7. 


\section{DEVELOPMENT OF THE THEORY*}

\section{A. Introduction}

Finite-difference methods for the calculation of time-dependent fluid flows have mostly been based on either the Eulerian or the Lagrangean form of the equations. In the Eulerian form, the independent space variables refer to a coordinate system fixed in space and through which the fluid is thought of as moving. The flow is characterized by a time-dependent velocity. field, which is to be found by solving the initial value problem. In the Lagrangean form, the independent space variables refer to a coordinate system fixed in the fluid and undergoing all the motion and distortion of the fluid. Therefore the particles of the fluid are permanently. identified by their Lagrangean variables, while their actual positions in space are among the dependent quantities to be solved. Although these forms are essentially equivalent, the Lagrangean form gives more information (it tells where each bit of fluid came from originally) and has the virtue that conservation of mass is automatic and exact, even in the finite-difference approximations. In some problems, this results in considerably greater accuracy. For these reasons, the Lagrangean form is generally preferred for problems in one space variable.

Fluid flows are frequently characterized by internal discontinuities, such as shocks, on which special boundary conditions (jump conditions) are required. These special boundary conditions are provided by the well-known Rankine-Hugoniot equations, but their application in practice is encumbered by the following difficulties: (1) The surfaces on which the conditions are to be applied are in motion through the fluid, and (2) the motion of these surfaces is not known in advance, but is determined by the equations themselves (the differential equations plus the jump conditions). Thus, in numerical work, a highly implicit situation prevails. The differential equations that apply to the smooth part of the flow, as for problems. without shocks or for the flow between shocks, will be described first.

\section{B. The Lagrangean Equations}

It is assumed that viscous forces, body forces (like gravity), heat conduction, and energy sources are absent. Certain artificial pseudoviscous forces in connection with shocks will be introduced later, and the possibility for heat conduction will be accomplished by leaving the energy equation in the system rather than eliminating it by use of the constancy of entropy along the world lines of fluid particles.

For spherical symmetry, let $r$ denote the radial coordinate of a small fluid element at time $t=0$, and let $R=R(r, t)$ be the radial

* This development is found in Ref. 14 , Chapter X, and is presented here in brief form to lend continuity to the subject matter. 
coordinate of the same fluid element at time $t$ in the motion, so that $r$ and $t$ are independent variables. Each bit of fluid is labeled with a certain value of $r$, called the Lagrangean coordinate, and retains that label as it moves about. The label $r$.could be chosen in many ways other than the one given above. For example, it could be defined as the radial coordinate at some other fixed time $t=t_{0}$. Furthermore, if $g(r)$ is any function with a continuous positive derivative, the variable $r^{\prime}=g(r)$ would also be suitable as a label. In other words, if $h(r)=g^{\prime}(r)$. is continuous and g.reater than 0 , then

$$
r^{\prime}=\int h(r) d r
$$

may be used in place of $r$ as the Lagrangean coordinate. A particular choice, which is convenient and will be used henceforth, is

$$
r^{\prime}=\frac{1}{\rho_{0}} \int \rho(r) d r,
$$

where $\rho(r)$ is the density at $t=0$, and $\rho_{0}$, is a constant having the dimensions of density. The symbol $r^{\prime}$ can be interpreted as the radial coordinate in a reference configuration of the system in which the various spherical shells of fluid have been moved in or out until they all have common density $\rho_{0}$. This is referred to as the standard reference configuration. Henceforth, $r$ will be written instead of $\mathrm{r}^{\prime}$.

The Lagrangean form of the differential equations governing a fluid motion with spherical symmetry is

$$
\begin{aligned}
& \frac{1}{\rho}=\frac{1}{\rho_{0}}\left[\frac{R(r, t)}{r}\right]^{2} \frac{\partial R}{\partial r}, \\
& \frac{\partial u}{\partial t}=-\frac{1}{\rho_{0}}\left[\frac{R(r, t)}{r}\right]^{2} \frac{\partial P}{\partial r}, \\
& \frac{\partial E}{\partial t}=\frac{P}{\rho^{2}} \frac{\partial \rho}{\partial t}, \\
& \frac{\partial R}{\partial t}=u,
\end{aligned}
$$

and

$$
P=f(E, \rho)
$$

where $u, P, \rho, E$, and $R$ represent fluid velocity, pressure, density, internal energy per unit mass, and the Eulerian coordinate, respectively, 
and are defined as functions of $\mathbf{r}$ and $t$. Equations 10 and 11 are to be thought of as abbreviations; their substitution into Eqs. 7, 8, and 9 gives three partial differential equations in the three dependent quantities, $R$, $\mathrm{u}$, and $\mathrm{E}$.

\section{The Jump Conditions at a Shock}

The motion of an ideal fluid is often characterized by lines or curves in the r, $t$-plane (more generally surfaces in the $\bar{R}, t$-space) on which certain of the dependent quantities are discontinuous, but possess one-sided limits on both sides. Even if the flow is smooth in the beginning, discontinuities may develop after a finite time, after which no smooth, single-valued solution of the system (Eqs. 7-11) exists. Examples are an interface, a contact discontinuity (where $\rho$ and $E$. are discontinuous, but $P$ and $u$ are continuous), a shock (where $\rho, E, P$, and $u$ are all discontinuous), and the head of a rarefaction wave (where only certain derivatives are discontinuous). At such discontinuities, the differential equations (which no longer make sense) must be supplanted by jump conditions, which serve as internal boundary conditions and are needed to make the solution unique.

For an interface, a contact discontinuity, or a rarefaction head, the only jump conditions needed are the continuity of certain variables, and no modification of the finite-difference representations of the system is required, although for an interface, modification may be desirable for increased accuracy. But when shocks are present, the unmodified difference equations do not give even approximately the right answers, except in certain limiting cases.

The Rankine-Hugoniot equations (jump conditions), together with the continuity of $R(r, t)$ across the shock, just provide the needed boundary conditions for the differential equations on each side and determine the motion of the shock front itself. These equations have been used directly in numerical calculations (unpublished work, Los Alamos) in a procedure called "shock fitting." The shock-fitting equations are implicit and must usually be solved by an iterative trial-and-error technique. The equations must be modified when the shock front passes a net point. The shock-fitting technique in general is rather complicated.

To get around these complications, von Neumann and Richtmeyer devised an approximate method of calculation for fluid dynamical problems, in which shocks are taken care of automatically, whenever and wherever they arise. The method is based upon certain physical notions concerning real (and therefore nonideal) fluids rather than on a direct attempt to incorporate the Rankine-Hugoniot conditions into the calculations. Specifically, dissipative mechanisms, like viscosity and heat conduction, have a smoothing effect on a shock, so that the surface of discontinuity is replaced by a thin transition layer in which quantities change rapidly but not discontinuously. The differential equations, with the dissipative mechanism 
included, apply in this layer as well as elsewhere, so that no boundary conditions at the shock front are needed. At the same time, the basic conservation laws on which the Rankine-Hugoniot conditions were based are retained, and the jump conditions still hold across the transition layer, in the approximation in which this layer is regarded as thin in comparison with other dimensions occurring in the problem.

D. Effect of Dissipation

Various investigators, including Lord Rayleigh, R. Beckèr (1922), and L. H. Thomas (1944), have studied the effect of dissipation on shocks. Becker studied the effect of heat conduction and viscosity. He showed that when heat conduction is allowed for, the temperature varies smoothly through the shock layer and that for shocks of strength less than a critical value, the pressure and density vary smoothly also. On the other hand, for stronger shocks, the transition of pressure and density from their initial to their final values is partly by a smooth variation and partly by a discontinuous jump. When viscosity is allowed for, however, all quantities vary smoothly through the shock region for a shock of any strength. In either case, the thickness of the transition zone is proportional to the coefficient of the dissipative mechanism, so that in the limit of no heat conduction and no viscosity, the variations approach the discontinuous ones of the Rankine-Hugoniot theory.

The idea of von Neumann and Richtmeyer was to introduce a purely artificial dissipative mechanism of such form and strength that the shock transition would be a smooth one extending over a small number (say three or four) of intervals $\Delta r$ of the space variable, and then to construct finitedifference equations with dissipation included, but without the necessity for shock fitting. In a calculation with such equations, the shocks show up automatically as near-discontinuities, across which quantities have very nearly the correct jumps and which travel with very nearly the correct speed through the fluid.

A mechanism like viscosity is more suitable for the dissipative mechanism than one like heat conduction because with viscosity, all quantities vary smoothly. However, Becker showed that with ordinary viscosity, in which the stress is proportional to the rate of shear, and which is, therefore, represented by linear terms in the differential equations, the thickness of the transition layer varies with shock strength, approaching zero for a very strong shock and infinity for a very weak one. But von Neumann and Richtmeyer want the thickness to be about the same--namely, about 3-4 $\Delta \mathrm{r}-$ for all shocks; they therefore add quadratic terms to the differential equations. This is equivalent to using a small viscosity coefficient for weak shocks and a large one for strong shocks.

By adding these terms, von Neumann and Richtmeyer achieve a thickness of the transition layer that is independent of the shock strength. 
Other features of the added terms insure that the thickness is also independent of the pressure and the density of the material into which the shock is running.

The differential equations of the von Neumann-Richtmeyer pseudoviscous method in Lagrangean formulation for spherical symmetry are

$$
\begin{aligned}
& V=\frac{1}{\rho_{0}}\left[\frac{R(r, t)}{r}\right]^{2} \frac{\partial R}{\partial r} \\
& \frac{\partial u}{\partial t}=-\frac{1}{\rho_{0}}\left[\frac{R(r, t)}{r}\right]^{2} \frac{\partial(P+Q)}{\partial r} \\
& \frac{\partial E}{\partial t}=-(P+Q) \frac{\partial V}{\partial t} \\
& \frac{\partial R}{\partial t}=u
\end{aligned}
$$

and

$$
P=F(E, V) \text {, }
$$

where $\mathrm{V}=1 / \rho$ is the specific volume, and $Q$, the pseudoviscous pressure, is given by

$$
Q= \begin{cases}\frac{\left(\rho_{0} \ell\right)^{2}}{V}\left(\frac{\partial V}{\partial t}\right)^{2}, & \text { if } \frac{\partial V}{\partial t}<0 \\ 0, & \text { if } \frac{V}{\partial t} \geq 0\end{cases}
$$

where $l$ is a constant having the dimension of length.

One method for the solution of fluid dynamical problems involving shocks is to solve Eqs. $12-1.7$ by a numerical technique.

E. Finite-difference Equations

Finite-difference systems may be obtained in a variety of ways. In the pseudoviscous terms, von Neumann and Richtmeyer replaced $l$ by a $\Delta r(r / R)^{2}$, where a is a dimensionless constant around 1.5 to 2.0 , thus giving the shocks a thickness around 3 to 5 times $\Delta r$, i.e., insuring that all shocks cover the same number of net points (namely, about 3-5). If the mesh size is variable, this will give the shocks a greater thickness in the coarse part of the net than in the fine part. 
The finite-difference form of Eqs. 12-17 used in this. instance is

$$
\begin{aligned}
& : v_{j+\frac{1}{2}}^{n+1}=\frac{1}{\rho_{0}} \frac{\left(R_{j+1}^{n+1}\right)^{3}-\left(R_{j}^{n+1}\right)^{3}}{r_{j+1}^{3}-r_{j}^{3}} \\
& \frac{u_{j}^{n+1}-u_{j}^{n}}{\Delta t}=-\frac{1}{\rho_{0}} \frac{\left(P_{j+\frac{1}{2}}^{n}-P_{j-\frac{1}{2}}^{n}\right)+\left(Q_{j+\frac{1}{2}}^{n}-Q_{j-\frac{1}{2}}^{n}\right)}{\Delta r_{j}}\left(\frac{R_{j}^{n}}{r_{j}}\right)^{2}, \\
& E_{j+\frac{1}{2}}^{n+1}-E_{j+\frac{1}{2}}^{n}+\left(\frac{P_{j+\frac{1}{2}}^{n+1}+P_{j+\frac{1}{2}}^{n}}{2}+Q_{j+\frac{1}{2}}^{n+1}\right)\left(V_{j+\frac{1}{2}}^{n+1}-V_{j+\frac{1}{2}}^{n}\right)=0, \quad \text { Energy (20) } \\
& \frac{R_{j}^{n+1}-R_{j}^{n}}{\Delta t}=u_{j}^{n+1}, \\
& P_{j+\frac{1}{2}}^{n+1}=f\left(E_{j+\frac{1}{2}}^{n+1}, v_{j+\frac{1}{2}}^{n+1}\right),
\end{aligned}
$$

and

$$
Q_{j+\frac{1}{2}}^{n}=\left\{\begin{array}{l}
\frac{2\left(a \rho_{0} \Delta r_{j+\frac{1}{2}}\right)^{2}}{v_{j+\frac{1}{2}}^{n}+v_{j+\frac{1}{2}}^{n-1}}\left(\frac{v_{j+\frac{1}{2}}^{n}-v_{j+\frac{1}{2}}^{n-1}}{\Delta t}\right)^{2}\left(\frac{2 r_{j+1}}{R_{j+1}^{n}+R_{j+1}^{n-1}}\right)^{4}, \\
0, \quad \text { if } v_{j+\frac{1}{2}}^{n}-v_{j+\frac{1}{2}}^{n-1}<0 \\
\text { otherwise. }
\end{array}\right.
$$

Pseudoviscous Pressure (23)

The system as a whole is correct to $0\left[(\Delta t)^{2}\right]+0\left[(\Delta r)^{2}\right]$. The superscript $\mathrm{n}$ represents the time step, and the subscript $\mathrm{j}$ represents the net point. The notation $r_{j}$ denotes the $j$ th net point of the Lagrangean net. The symbols $\Delta \mathrm{r}_{\mathrm{j}}$ and $\Delta \mathrm{r}_{\mathrm{j}+\frac{1}{2}}$ are defined as

$$
\Delta r_{j}=\frac{r_{j+1}-r_{j-1}}{2},
$$

and

$$
\Delta r_{j+\frac{1}{2}}=r_{j+1}-r_{j}
$$


The above set of equations constitutes a system of open-ended, initial-value, finite-difference equations. If all the quantities are known at $t=t^{n}$ along. with the appropriate boundary conditions, the solution can be propagated outward with time.

F. Stability of the Finite-difference Equations

The stability condition that guarantees convergence for the finitedifference equations is

$$
\frac{c \Delta t}{R_{j+1}^{n}-R_{j}^{n}} \leq 0.3
$$

and must be satisfied for all $\mathrm{n}$ and $\mathrm{j}$, where $\mathrm{c}$ is the speed of sound.in the medium.

G. Treatment at Interfaces

If an interface between two fluids comes at an index, say $\mathrm{j}=\mathrm{J}$, the finite-difference equations may be used just as they are, keeping in mind only to use the appropriate equation of state on each side of the interface. However, this may lead to inaccuracies, and it is better to give special treatment to interfaces. The inaccuracies result in several ways: (1) If the densities of the two fluids are very different (as for a gas and a liquid), we may wish to use quite different increments, $\Delta r$, on the two sides of the interface with consequent bad centering of the difference equations; and (2) although the pressure gradient, $\partial \mathrm{P} / \partial \mathrm{r}$, varies continuously across the interface (this is a consequence of the particular definition of the Lagrangean variable adopted here), the derivative of the pressure gradient may not, so that $\partial P / \partial r$ may not be given to the second-order accuracy by the centered difference quotient. To improve the accuracy of the solution at the interface, the expression

$$
\begin{aligned}
\left.\frac{\partial P}{\partial r}\right|_{r=r_{J}} \approx & \left\{3\left[\left(P_{j+\frac{1}{2}}^{n}-P_{j-\frac{1}{2}}^{n}\right)+\left(Q_{j+\frac{1}{2}}^{n}-Q_{j-\frac{1}{2}}^{n}\right)\right]\right. \\
& \left.-\frac{1}{3}\left[\left(P_{j+\frac{3}{2}}^{n}-P_{j-\frac{3}{2}}^{n}\right)+\left(Q_{j+\frac{3}{2}}^{n}-Q_{j-\frac{3}{2}}^{n}\right)\right]\right\} /\left(\Delta_{1} r+\Delta_{2} r\right)
\end{aligned}
$$

where $\Delta_{1} r$ and $\Delta_{2} r$ are the increments of $r$ used on the left and right sides of the interface, respectively, can be used in.place of 


$$
\left.\frac{\partial P}{\partial r}\right|_{r=r_{J}} \approx \frac{\left(P_{j+\frac{1}{2}}^{n}-P_{j-\frac{1}{2}}^{n}\right)+\left(Q_{j+\frac{1}{2}}^{n}-Q_{j-\frac{1}{2}}^{n}\right)}{\Delta r_{j}}
$$

in Eq. 19.

Equation 25 can be used even if the two fluids are identical, so that the interface is not a real one but only a point at which the increment $\Delta r$ is changed. 


\section{SOLUTION OF A SAMPLE PROBLEM}

A. Problem Layout

The idealized reactor system analyzed in this problem simulates a typical sodium-reactor installation. The core is a spherical charge of TNT. The charge radius, $a_{0}$, is $30 \mathrm{~cm}$, and the charge density is $1.5 \mathrm{gm} /$ $\mathrm{cm}^{3}$. Thus, the analysis for this problem is based on the destructive component (energy release) of $375 \mathrm{lb}$ of TNT. The liquid coolant in a sodium

TABLE I. Densities of the Various Media

\begin{tabular}{lcc}
\hline Medium & Density, $\mathrm{gm} / \mathrm{cm}^{3}$ & Conditions \\
\hline TNT & 1.51 & \\
Water & 0.9982 & $20^{\circ} \mathrm{C}$ and 1 atm \\
Argon & 0.00169 & $15^{\circ} \mathrm{C}$ and 1 atm \\
Concrete & 2.663 & \\
\hline
\end{tabular}

reactor would be sodium. However, the properties of water and sodium are very much alike. Since more experimental data are available for water than for sodium, water is used as the coolant in this example. The inert gas is argon, and the biological shield is concrete. The densities of the various media are given in Table $\mathrm{I}$.
Solutions for this problem are to be obtained for two different sets of dimensions. The first set (see Fig. 4A) simulates an infinite fluid medium surrounding the charge. The value of the peak pressure at the shock front as it propagates will be determined for this system by the numerical method. Values of the peak pressure at several positions of the shock front will be compared against experimentally measured peak pressures at corresponding positions. This comparison will provide a check on the method used in the numerical solution.

The second set of dimensions (see Fig. 4B) is representative of a typical sodium reactor installation. The effect that the destructive component produces on the concrete' containment structure will be determined for this idealized reactor system. The strain rate for the steel strands will then be calculated for this system.

B. Equations of State

The solution of fluid dynamical problems requires the use of an equation
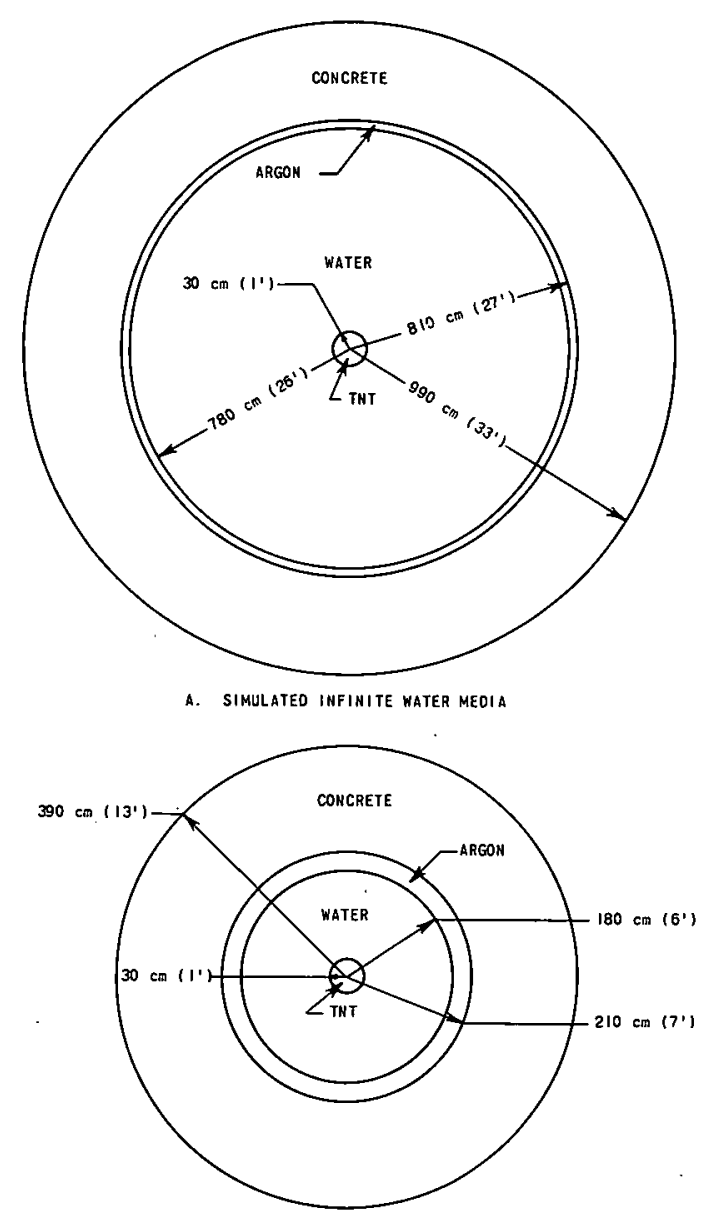

B. SimUlateo SODIUM reactor InStallation

Fig. 4. Example Problem Layouts and Dimensions 
of state for the fluid medium of the form $P=f(E, V)$. This problem has three different fluid media and therefore requires an equation of state for each.

\section{Products of Detonation}

The equation of state for the products of detonation of TNT is taken as that of Jones and Miller. ${ }^{10}$ This is a virial equation in powers of the pressure in the form

$$
P \frac{V^{\prime}}{N^{\prime}}=R T+b P+c P^{2}+d P^{3}
$$

where $v^{\prime}$ is the volume and $N^{\prime}$ the number of moles at temperature $T$ and pressure $P$ of the gaseous products of the detonation of one mole of explosive. The symbol $R$ represents the gas constant. At the detonation wave front, for a density of the solid TNT equal to $1.5 \mathrm{gm} / \mathrm{cm}^{3}$, the pressure is $15.9 \mathrm{x}$ $10^{10}$ dyne $/ \mathrm{cm}^{2}$, the molar volume is $117 \mathrm{~cm}^{3}$, the density is $1.95 \mathrm{gm} / \mathrm{cm}^{3}$, and the temperature is $3400^{\circ} \mathrm{K}$. The values of the virial coefficients are

$$
\begin{aligned}
& b=25.4, \\
& c=-0.104,
\end{aligned}
$$

and

$$
\mathrm{d}=2.33 \times 10^{-4},
$$

where $1000 \mathrm{~kg} / \mathrm{cm}^{2}$ is taken as the unit of pressure.

The internal energy $E$ in kcal per mole of TNT is represented by the equation*

$$
E=0.0875 T-7.46+N^{\prime} E_{1} \text {, }
$$

where $\mathrm{N}^{\prime}$ is the total number of moles of the gaseous products (a number that varies from 5.8 at the detonation front to 7.0 when the composition of the gaseous products becomes fixed) per mole of $T N T$, and $E_{1}$ is the energy per mole of gaseous products and is given in kcal by

$$
E_{1}=-\frac{1}{2} c P^{2}-\frac{2}{3} d P^{3}
$$

If we convert the units and note that $v^{\prime} / N^{\prime}$ is specific volume, the resulting equations for the gaseous explosion products used in this treatise are

\footnotetext{
* This is the equation for internal energy per mole of TNT as given by Jones and Miller ${ }^{10}$ and modified by Brode. ${ }^{3}$
} 


$$
P V=R T+0.6490 P-\left(0.2712 \times 10^{-11}\right) P^{2}+\left(0.6199 \times 10^{-23}\right) \mathrm{P}^{3}
$$

and

$$
\begin{aligned}
E= & \left(0.1614 \times 10^{8}\right) \mathrm{T}-0.1376 \times 10^{10}+\left(0.1356 \times 10^{-11}\right) \mathrm{P}^{2} \\
& -\left(0.4133 \times 10^{-23}\right) \mathrm{P}^{3},
\end{aligned}
$$

where $P, V, Q, T$, and $E$ represent the pressure (dyne/ $\mathrm{cm}^{2}$ ), the specific volume $\left(\mathrm{cm}^{3} / \mathrm{gm}\right)$, the gas constant (dyne $\left.-\mathrm{cm} / \mathrm{gm}-{ }^{\circ} \mathrm{K}\right)$, temperature $\left({ }^{\circ} \mathrm{K}\right)$, and the internal energy per unit mass of TNT (dyne-cm/gm), respectively. Equations 29-30 combine to give the required function $P=f(E, V)$ for the products of detonation.

\section{Water}

The equation of state for water is taken as that of Rice and Walsh. ${ }^{13}$ This equation is of the form

$$
\mathrm{H}(\mathrm{P}, \mathrm{V})=\mathrm{H}_{\mathrm{h}}(\mathrm{P})+\xi(\mathrm{P})\left[\mathrm{V}-\mathrm{V}_{\mathrm{h}}(\mathrm{P})\right]
$$

where $\mathrm{H}_{\mathrm{h}}$ and $\mathrm{V}_{\mathrm{h}}$ are the specific enthalpy and specific volume for a state on the Hugoniot curve (pressure-volume curve centered at $P_{0}, V_{0}$ ) and are considered as functions only of pressure.

equations, *

The values of $\mathrm{H}_{\mathrm{h}}$ and $\mathrm{V}_{\mathrm{h}}$ are obtained from the Rankine-Hugoniot

$$
\begin{aligned}
& \mathrm{V}_{1} / \mathrm{V}_{0}=\left(\mathrm{U}_{\mathrm{s}}-\mathrm{U}_{\mathrm{p}}\right) / \mathrm{U}_{\mathrm{s}}, \\
& \mathrm{P}_{1}-\mathrm{P}_{0}=\mathrm{U}_{\mathrm{s}} \mathrm{U}_{\mathrm{p}} / \mathrm{V}_{0},
\end{aligned}
$$

and

$$
H_{1}-H_{0}=\frac{1}{2}\left(P_{1}-P_{0}\right)\left(V_{0}+V_{1}\right)
$$

and an analytical fit to the experimental Hugoniot curve data for water, initially at $20^{\circ} \mathrm{C}$ and 1 atm, given by

$$
U_{S}-1.483=25.306 \log _{10}\left(1+U_{p} / 5.190\right)
$$

where $U_{s}$ and $U_{p}$ are the shock velocity and the particle velocity, respectively, in $\mathrm{km} / \mathrm{sec}$.

\footnotetext{
* These equations are presented here again for continuity and to indicate the form of Eq. 34 . Equation 34 is identical to Eq. 6 by the thermodynamic relationship $\mathrm{H}=\mathrm{E} . \because \mathrm{PV}$.
} 
Equation 31 is based upon the assumption that the thermodynamic variable $(\partial \mathrm{H} / \partial \mathrm{V})_{\mathrm{p}}$ may be approximated as a function only of pressure for sufficiently high pressures; i.e.,

$$
(\partial \mathrm{H} / \partial \mathrm{V})_{\mathrm{p}} \equiv \mathrm{C}_{\mathrm{p}} /(\partial \mathrm{V} / \partial \mathrm{T})_{\mathrm{p}} \equiv \xi(\mathrm{P})
$$

where $C_{p}$ is the specific heat at constant pressure. This assumption allows $\xi(P)$ to be obtained directly from experimental data ${ }^{18}$ for $(\Delta H / \Delta V)_{p}$. The analytical fit for $\xi(\mathrm{P})$ for the pressure range $25-250$ kilobars $(\mathrm{kb}) *{ }^{*}$ is of the form

$$
\log _{10} \xi=2.17943+0.0030338 \mathrm{P}
$$

for $\xi$ and $P$ in $\mathrm{kb}$.

The uncertainty in $(\Delta \mathrm{H} / \Delta \mathrm{V})_{\mathrm{p}}$ for a given pressure in the range $100-230 \mathrm{~kb}$ is estimated at $\pm 15 \%$. However; Walsh and Rice ${ }^{18}$ state that this large uncertainty, a consequence of taking differences between nearly equal experimental quantities, does not lead to large errors in the calculated $P$, $V$ curves since $(\Delta \mathrm{H} / \Delta \mathrm{V})_{\mathrm{p}}$ is used only to evaluate small offsets from the measured Hugoniot curve.

On the basis of the above statement, it is assumed that Eq. 31 is applicable for the entire pressure range $0-250 \mathrm{~kb}$ without appreciably changing the uncertainty associated with the function $\xi(P)$.

The internal energy of the water is determined from the thermodynamic relationship

$$
E=H-P V,
$$

where the internal energy and the enthalpy are in cal/gm, the pressure in $\mathrm{kb}$, and the volume in $\mathrm{cm}^{3} / \mathrm{gm}$. Equations 31-37 combine to give the required function $P=f(E, V)$ for the water.

\section{Argon}

The equation of state of argon is taken as that of BeattieBridgman. ${ }^{8}$ This equation is of the form

$$
P=\frac{R T\left(1-\frac{c}{V T^{3}}\right)}{V^{2}}\left[V+B_{0}\left(1-\frac{b}{V}\right)\right]-\frac{A_{0}}{V^{2}}\left(1-\frac{a}{V}\right),
$$

where $a, A_{0}, b, B_{0}$, and $c$ are arbitrary constants evaluated from experimental data. For argon, these constants are

$*_{1 \mathrm{~kb}}=986.9 \mathrm{~atm}=10^{9}$ dynes $/ \mathrm{cm}^{3}$. 


$$
\begin{aligned}
a & =0.02328, \\
A_{0} & =1.2907, \\
b & =0, \\
B_{0} & =0.03931,
\end{aligned}
$$

and

$$
c=5.99 \times 10^{-4}
$$

for the pressure in atmospheres, the specific volume in liters per gm-mole, and the temperature in ${ }^{\circ} \mathrm{K}$. The gas constant $R$ is 0.08206 atm-liters per $\mathrm{gm} / \mathrm{mole}-{ }^{\circ} \mathrm{K}$.

The equation of state reduces to

$$
P V^{2}=R T\left(V+B_{0}\right)\left(1-\frac{C}{V T^{3}}\right)-A_{0}\left(1-\frac{a}{V}\right)
$$

and the values of the constants, in the cgs system, are

$$
\begin{aligned}
a & =0.58282, \\
A_{0} & =8.3583 \times 10^{5}, \\
B_{0} & =0.98413, \\
c & =0.01500,
\end{aligned}
$$

and

$$
R=2.078 \times 10^{6},
$$

i.e., for the pressure in dyne $/ \mathrm{cm}^{2}$, the specific volume in $\mathrm{cm}^{3} / \mathrm{gm}$, the temperature in ${ }^{\circ} \mathrm{K}$, and $R$ in dyne $-\mathrm{cm} / \mathrm{gm}-{ }^{\circ} \mathrm{K}$.

This equation of state is good to within $15 \%$ of experimental data $^{9}$ for the pressure range $0-250$ atm. An order-of-magnitude check of Eq. 39 reveals the term c/VT ${ }^{3} \leqslant \leqslant 1$. Thus, the equation of state for argon used in this analysis is

$$
P V^{2}=R T\left(V+B_{0}\right)-A_{0}\left(1-\frac{a}{V}\right)
$$

The relationship for the internal energy of the argon is found by thermodynamics and has the form

$$
d E=C_{v} d t+\frac{A_{0}}{V}\left(1-\frac{a}{V}\right) d V
$$


where $C_{V}$, the specific heat at constant volume, has the value $3.137 \mathrm{x}$ $10^{6} \mathrm{dyne}-\mathrm{cm} / \mathrm{gm}-{ }^{\circ} \mathrm{K}$ and is assumed to be constant since the specific heats of monatomic gases are practically independent of temperature. ${ }^{12}$ Equations 40-4l combine to give the required function $P=f(E, V)$ for the argon.

C. Finite-difference Net and Equations

The parameters in the differential equations have reference to a particular particle of fluid. However, in this finite-difference approximation, the parameters have reference to a finite zone of fluid. The parameters for pressure, specific volume, specific enthalpy, specific internal energy, speed of sound, temperature, and the pseudoviscous pressure are presumed evaluated at the center of each $z$ one; the value of each of these parameters is considered to be representative of all fluid particles in that zone. The parameters for the Lagrangean coordinate, the Eulerian coordinate, and the velocity are evaluated at the zone interfaces; the value of each of these parameters is considered to be representative of all fluid particles within one-half the adjacent zone thicknesses.

The finite-difference net used in this problem is shown in Fig. 5. Each zone represents a spherical shell of fluid. The first zone of fluid (in the TNT) is designated as zone one, and the center of spherical symmetry is designated as interface one.

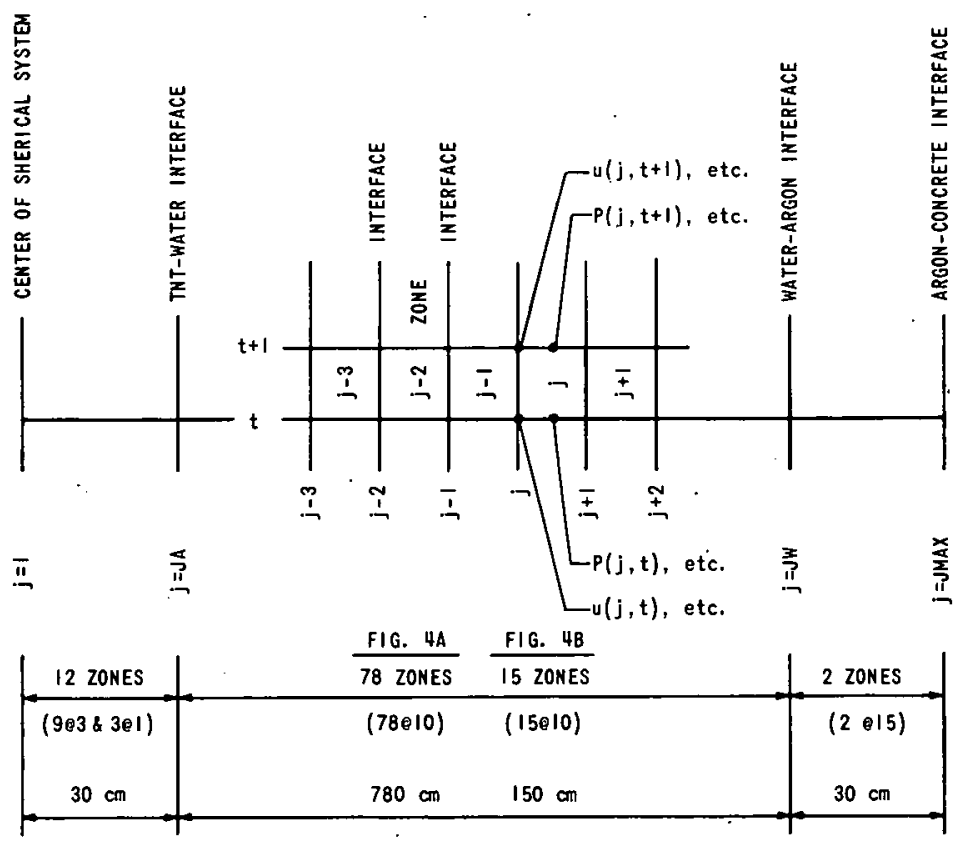

Fig. 5. Finite-difference Net 
The finite-difference equations (Eqs. 18-23) for this type of net designation become

$$
\begin{aligned}
& \frac{u(j, t+1)-u(j, t)}{\Delta t}=-V_{0}\left[\frac{P(j, t)-P(j-1, t)+Q(j, t)-Q(j-1, t)}{\Delta r(j)}\right]\left[\frac{R(j, t)}{r(j)}\right]^{2}, \\
& \frac{R(j, t+1)-R(j, t)}{\Delta t}=u(j, t+1) \\
& V(j, t+1)=V_{0}\left[\frac{R(j+1, t+1)^{3}-R(j, t+1)^{3}}{r(j+1)^{3}-r(j)^{3}}\right], \\
& Q(j, t+1)=\left\{\begin{array}{l}
\frac{4[\Delta r(j) Q]^{2}}{V_{0}^{2}[V(j, t+1)+V(j, t)]}\left[\frac{V(j, t+1)-V(j, t)}{\Delta t}\right]^{2} \\
\left.\qquad \frac{2 r(j+1)}{R(j+1, t+1)+R(j+1, t)}\right]^{4} \text { if }[V(j, t+1)-V(j, t)]<0 \\
0 \quad \text { otherwise }
\end{array}\right.
\end{aligned}
$$

$E(j, t+1)-E(j, t)+\left[\frac{P(j, t+1)+P(j, t)}{2}+Q(j, t+1)\right][V(j, t+1)-V(j, t)]=0$,

and

$P(j, t+1)=f[E(j, t+1), V(j, t+1)]$,

where $V_{0}=1 / \rho_{0}$ and $a^{2}$ has been replaced by 2.0. The terms $\Delta r(j)_{u}$ and $\Delta r(j)_{Q}$ are defined for proper centering* as

$$
\Delta r(j)_{u}=[r(j+1)+r(j-1)] / 2
$$

in Eq. 42 and

$$
\Delta r(j)_{Q}=r(j+1)-r(j)
$$

in Eq. 45.

\footnotetext{
* See Appendix $G$ for a pictorial representation for the $\Delta \mathrm{r}$ 's.
} 
At an interface between two different media, the following equation is used in place of Eq. 42 :

$$
\begin{aligned}
\frac{u(j, t+1)-u(j, t)}{\Delta t}= & -V_{0}\left\{\frac{3[P(j, t)-P(j-1, t)+Q(j, t)-Q(j-l, t)]}{\Delta r(j-l)+\Delta r(j+l)}\right. \\
& \left.-\frac{\frac{1}{3}[P(j+1, t)-P(j-2, t)+Q(j+1, t)-Q(j-2, t)]}{\Delta r(j-l)+\Delta r(j+l)}\right\}\left[\frac{R(j, t)}{r(j)}\right]^{2},
\end{aligned}
$$

where

$$
\Delta r(j+1)=[r(j+2)+r(j)] / 2
$$

and

$$
\Delta r(j-1)=[r(j)+r(j-2)] / 2
$$

Equations $42-47$ or 48 and 43-47, as applicable, are solved in the order presented, and the solution is propagated outward in time. These six equations are solved at each zone or zone interface, as applicable, for time $t+l$ from values known at time $t$. These newly calculated values are then reassigned as the values for time $t$, and the process is repeated.

Equations 46 and 47 constitute a system of two simultaneous equations involving two unknowns, $P(j, t+1)$ and $E(j, t+1)$, and are therefore solved by an iterative process until an acceptable solution is obtained. The initial value for $P(j, t+1)$ in this iterative process is either $P(j, t)$ or $[P(j, t)+P(j-1, t+1)] / 2$. The former value was used for the solution in the water and the argon, the latter value for the solution in the TNT.

The equations of state for the various fluid media written in finitedifference form are as follows:

1. $\underline{\text { TNT }}$

$$
\begin{aligned}
{[P(j, t+1)][V(j, t+1)] .=} & R[T(j, t+1)]+(0.6490)[P(j, t+1)] \\
& -\left(0.2712 \times 10^{-11}\right)[P(j, t+1)]^{2} \\
& +\left(0.6199 \times 10^{-23}\right)[P(j, t+1)]^{3}
\end{aligned}
$$

where $Q R$ is the gas constant, * and the temperature is obtained from the equation

\footnotetext{
* See Appendix $G$ for the calculation of the value for $\mathcal{R}$.
} 


$$
\begin{aligned}
T(j, t+1)= & \left\{E(j, t+1)+0.1376 \times 10^{10}-\left(0.1356 \times 10^{-11}\right)[P(j, t+1)]^{2}\right. \\
& \left.+\left(0.4133 \times 10^{-23}\right)[P(j, t+1)]^{3}\right\} /\left(0.1614 \times 10^{8}\right) .
\end{aligned}
$$

$$
\begin{aligned}
& \text { 2. Water* } \\
& \mathrm{H}(\mathrm{j}, \mathrm{t}+\mathrm{l})=\mathrm{H}_{\mathrm{h}}(\mathrm{j}, \mathrm{t}+\mathrm{l})+\xi(\mathrm{j}, \mathrm{t}+\mathrm{l})\left[\mathrm{V}(\mathrm{j}, \mathrm{t}+\mathrm{l})-\mathrm{V}_{\mathrm{h}}(\mathrm{j}, \mathrm{t}+\mathrm{l})\right] 23.8892,
\end{aligned}
$$

where the following equations are necessary to obtain a solution:

$$
\begin{aligned}
& E(j, t+1)=H(j, t+1)-[P(j, t+l)][V(j, t+1)](23.8892), \\
& U_{p}=4.53493\left(1.0953^{U_{S}}-1.1444\right) \\
& U_{s}\left(1.0953^{U_{S}}-1.1444\right)=0.02209[P(j, t+1)] \\
& V_{h}(j, t+1)=1.0018\left(1-U_{p} / U_{s}\right) \\
& H_{h}(j, t+1)=11.9446\left[1.0018+V_{h}(j, t+1)[P(j, t+1)]\right.
\end{aligned}
$$

and

$$
\xi(j, t+1)=151.16\left\{10^{0.0030338[P(j, t+1)]}\right\} .
$$

The units for Eqs. 51-57 are different than the cgs units used for the finitedifference equations (Eqs. 42-47) and therefore must be converted as necessary.

$$
\begin{aligned}
& \text { 3. Argon } \\
& \begin{aligned}
{[P(j, t+1)][V(j, t+1)]^{2} } & =R[T(j, t+1)]\left[V(j, t+1)+B_{0}\right] \\
& -A_{0}\left[1-\frac{a}{V(j, t+1)}\right],
\end{aligned}
\end{aligned}
$$

where $Q$ is the gas constant, $a, A_{0}$, and $B_{0}$ are the empirical constants, and the temperature is obtained from the equation

\footnotetext{
*: The equations presented here are variations of Eqs. 31-37. See Appendix C for the appropriate transformations.
} 


$$
\begin{aligned}
C_{V}\left[T(j, t+1)-T_{0}\right]= & {\left[E(j, t+1)-E_{0}\right]-\frac{A_{0}}{V(j, t+1)}\left[1-\frac{a}{V(j, t+1)}\right] } \\
& {\left[V(j, t+1)-V_{0}\right] . }
\end{aligned}
$$

D. As sumptions

The assumptions made concerning the solution of the problem are as follows:

1. The equations of state for the products of detonation and the argon are assumed to be valid for the entire range of pressures encountered in the analysis.

2. The detonation of the TNT is assumed to be initiated at the center of the spherical charge.

3. The equation of state for the water [i.e., $P=f(E, V)]$, which is given by Eqs. 31-37, is assumed valid for the pressure range $0-250 \mathrm{~kb}$. If in the iterative procedure required for the numerical solution the function $\mathrm{f}(\mathrm{E}, \mathrm{V})$ is less than zero, the equation of state for the water is taken as $\mathrm{P}=0$ on the following basis: Water can support a small negative pressure (i.e., tensile stress); if the magnitude of the negative pressure applied to the water exceeds the limiting value, separation of the water occurs. Since the magnitude of the limiting negative pressure for the water is small, it is taken as zero for this problem.

4. The concrete containment vessel is assumed to be infinitely rigid until after the major portion of the impulse has been applied. This assumption provides the basis for the second boundary condition necessary for the finite-difference solution.

5. Minute cracks are assumed to be present in the concrete vessel. The basis for this assumption is as follows: The operating temperature of the reactor is relatively high. Shrinkage of the concrete will occur, especially under the influence of this high operating temperature. The minute cracks are presumed to be due to the shrinkage of the concrete. As a result of this assumption, the energy required to cause the concrete to crack into chunks is considered to be negligible.

E. Boundary Conditions

The boundary conditions for this problem are as follows:

1. The particle velocity at the center of the sphere must be zero; i.e., $u(1, t)=0$ for all $t$.

2. The particle velocity at the concrete boundary must be zero; i.e., $u(J M A X, t)=0$ for all $t$. 
F. Initial Conditions

The numerical solution of the differential equations requires that initial values for all the parameters of the corresponding finite-difference equations be known at time $t_{0}$. For this problem, the initial values are prescribed at time $t_{0}=0$, which corresponds to the instant the detonation wave reaches the surface of the spherical charge of TNT. The parameters for which the initial values must be known are $\Delta t, R, u, V, Q, E, P$, and $r$, which represent the time increment, the Eulerian coordinate, the particle velocity, the specific volume, the pseudoviscous pressure, the specific internal energy, the pressure, and the Lagrangean coordinate, respectively. The initial values of these parameters required for the numerical solution of this problem are given in Table II and were obtained as follows:

\section{1. $\Delta t$ (designated as DELT in Table II)}

The allowable value of $\Delta t$ (DTTEST, Table II) was determined for each zone in the finite-difference net from the stability equation (Eq.. 24)..* The minimum allowable $\Delta t$ was used as a basis of establishing the initial value of $\Delta t$.

\section{2. $R$ (designated as $R R$ in Table II).}

The initial values of the Eulerian coordinate are taken as the initial radii of the zone interfaces defined by the finite-difference net.

\section{3. u, V, E, P (same designation in Table II)}

The initial values of these parameters for the products of detonation were obtained from the conditions in the detonation wave prescribed by Taylor as shown in Table XI in Appendix A. The computer was used to calculate the values for $E$ in the detonation products from Eqs. 49 and 50 .

The initial values of these parameters for the water and the argon are taken as follows:

$\begin{array}{ll}\text { Water } & \text { Argon } \\ \mathrm{u}_{0}=0 & \mathrm{u}_{0}=0 \\ \mathrm{P}_{0}=\begin{array}{l}1 \text { atm }=1.013274 \mathrm{x} \\ 10^{6} \text { dynes } / \mathrm{cm}^{2}\end{array} & \mathrm{P}_{0}=1 \text { atm }=1.013274 \mathrm{x} \\ 10^{6} \text { dynes } / \mathrm{cm}^{2} \\ \mathrm{~V}_{0}=1.0018 \mathrm{~cm}^{3} / \mathrm{gm} & \mathrm{V}_{0}=591.5974 \mathrm{~cm}^{3} / \mathrm{gm}\end{array}$

\footnotetext{
* See Appendix $G$ for these calculations:
} 
TABLE II. Initial Values of the Parameters Required for the Finite-difference Solution

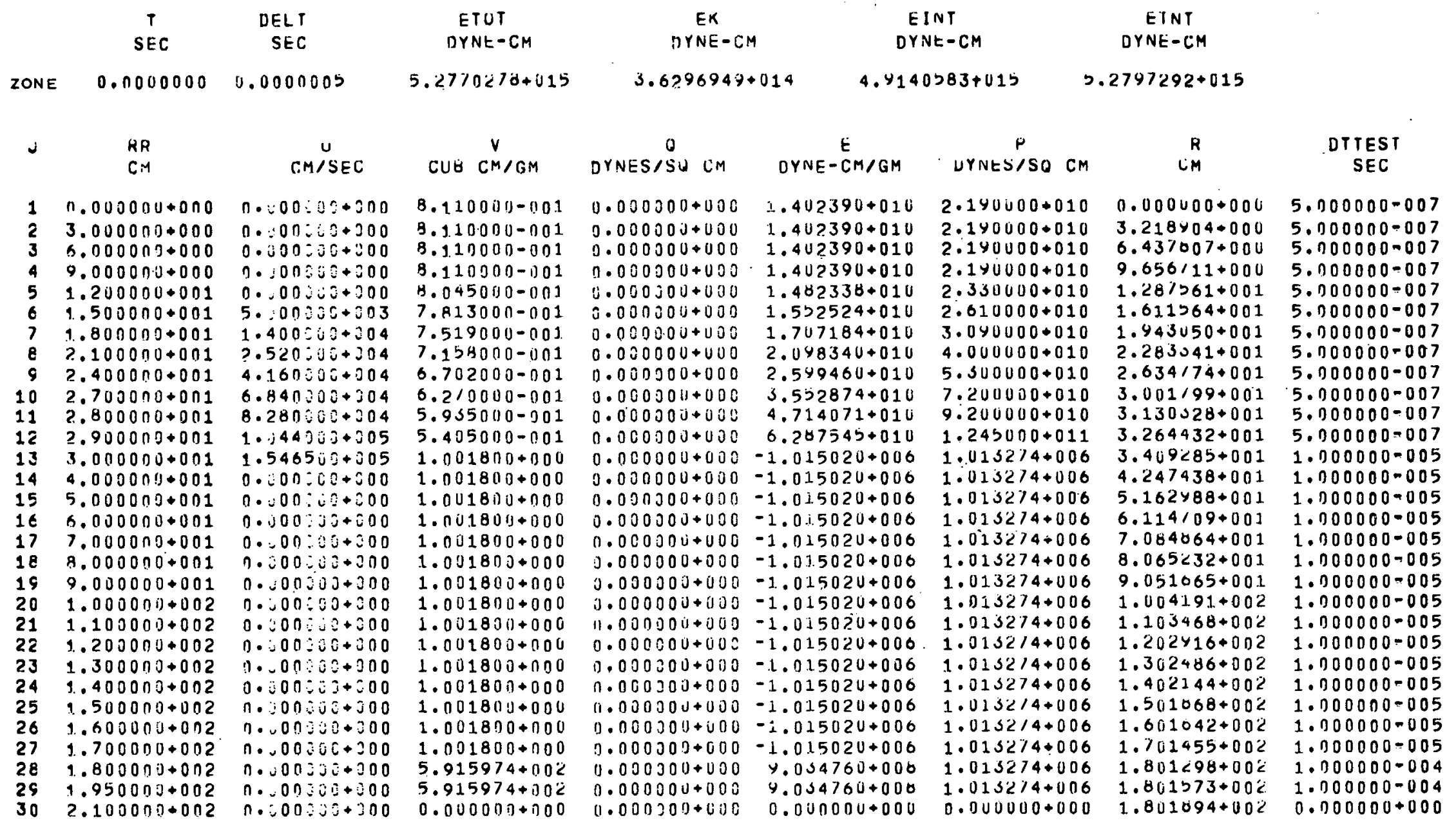




$$
\begin{aligned}
\underline{\text { Water }} \\
\mathrm{T}_{0}=293^{\circ} \mathrm{K} \\
\mathrm{c}_{0}=145,000 \mathrm{~cm} / \mathrm{sec} \\
\mathrm{E}_{0}=-1.015020 \times 10^{6} \text { dyne }-\mathrm{cm} / \mathrm{gm} \\
\mathrm{H}_{0}=0
\end{aligned}
$$

$$
\begin{aligned}
& \text { Argon } \\
& \mathrm{T}_{0}=288^{\circ} \mathrm{K} \\
& \mathrm{C}_{0}=33,100 \mathrm{~cm} / \mathrm{sec} \\
& \mathrm{E}_{0}=9.034760 \times 10^{8} \mathrm{dyne}-\mathrm{cm} / \mathrm{gm} \\
& \mathrm{C}_{\mathrm{V}}=3.137 \times 10^{6} \mathrm{dyne}-\mathrm{cm} / \mathrm{gm}-{ }^{\circ} \mathrm{K}
\end{aligned}
$$

where $c_{0}$ is the speed of sound in the medium under these conditions, and $E_{0}$ has been calculated from the appropriate relationship.

4. Q (same designation in Table II).

The initial values for the pseudoviscous pressure are taken as zero on the following basis: As the detonation wave propagates through the explosive, it leaves the gaseous products immediately behind the front in a highly compressed state, i.e., a low specific volume. As the front continues outward, the gas away from the front expands rapidly. Because of the everincreasing radius of the shock front, the specific volume of the gaseous products away from the front at time $t+l$ is greater than at time $t$. Therefore, the definition for $Q$ applies everywhere in the gaseous products except at the detonation front. Since the detonation process causes energy to be released in the wave front, it is ambiguous to assume dissipation occurs there. Thus, the initial value of $Q$ everywhere in the gaseous products is taken as zero on the basis of the definition.

The definition of $Q$ also applies to the water and the argon, which, at time $t=0$, have not been effected by the detonation process.

\section{5. $\mathrm{r}$ (designated as $\mathrm{R}$ in Table. II)}

The values of the Lagrangean coordinate represent the locations of the zone interfaces of the finite-difference net designation in the standard reference configuration. The common specific volume used for obtaining the Lagrangean coordinates is taken as that for the water given on page 36 , i.e., $V_{0}=1.0018 \mathrm{~cm}^{3} / \mathrm{gm}$. The computer was used to calculate the values of the Lagrangean coordinates.*

The values given in Table II for ETOT, EK, EINT, and ETNT represent the total energy of the system, the total kinetic energy of the system, the total internal energy of the system, and the total energy of the gaseous explosion products, respectively, at time $t=0$. These values were calculated by the use of the computer and are given for reference.

\footnotetext{
* See Appendix $C$ for the derivation of the formula.
} 


\section{.G. Flow Charts for Calculations in the Water}

The simplified and more detailed flow charts for calculations in the water are shown in Figs. 6 and 7, respectively.

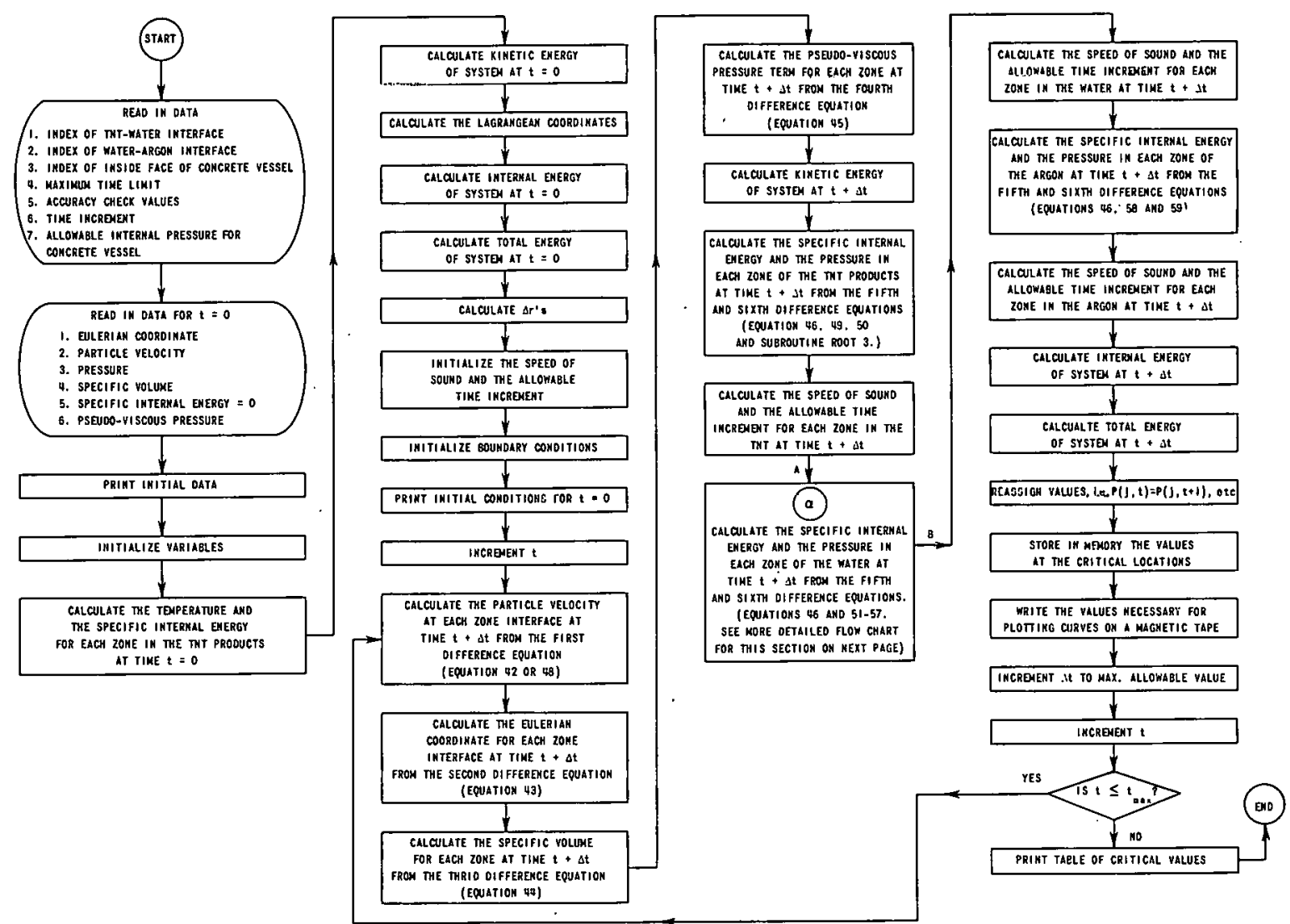

Fig. 6. Simplified Flow Chart for Calculations in the Water 


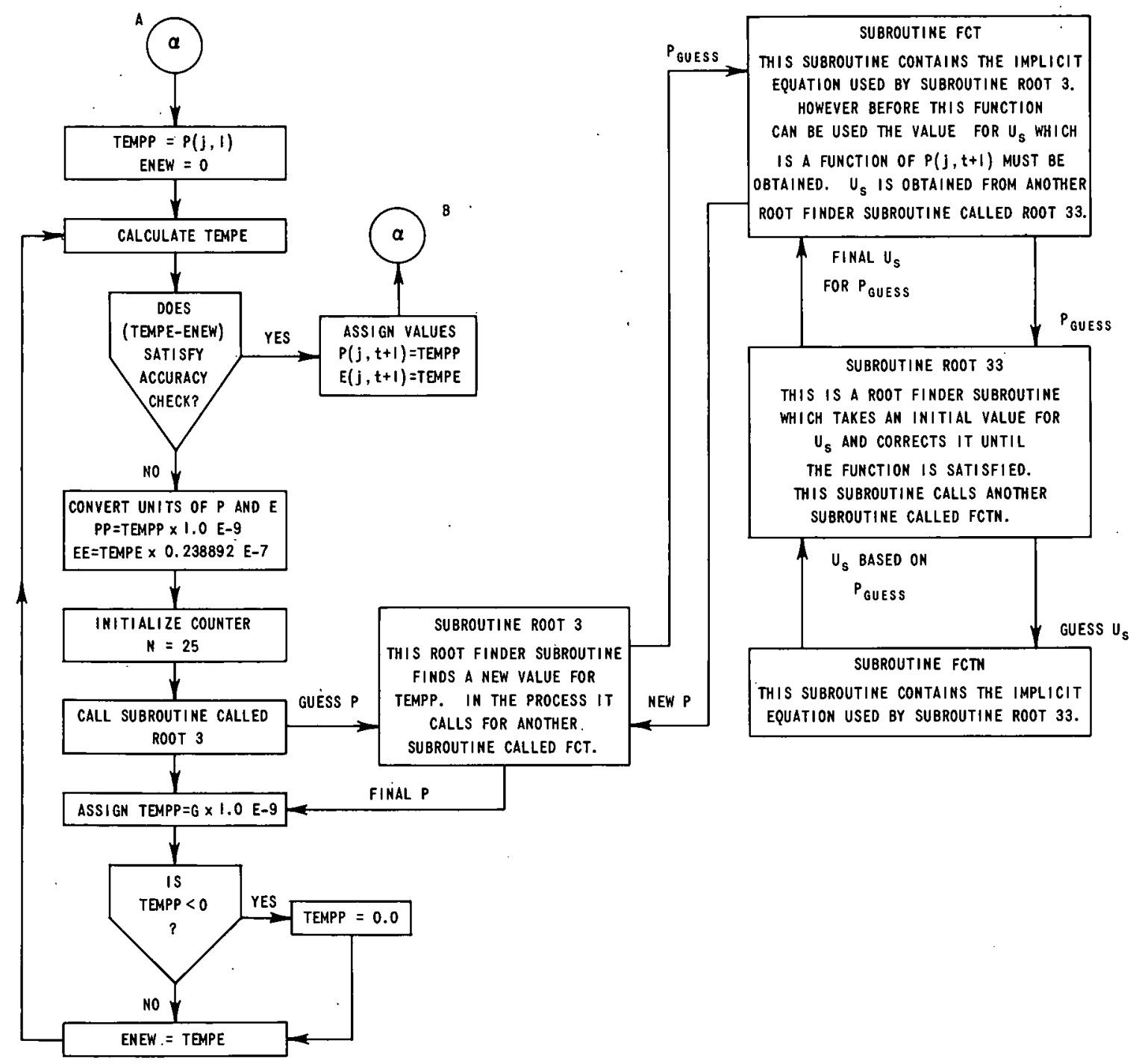

Fig. 7. More Detailed Flow Chart for Calculations in the Water 
H. FORTRAN Names and Their Description

FORTRAN Name

1. $\mathrm{AIPCC}$

2. DELRQ(J)

3. DELRU(J)

4. DELT

5. $\operatorname{DTtEST}(\mathrm{J})$

6. EINT

7. $E(J, 1)$

8. $E K$

9. EMASS

10. ENEW

11. ENTH

12. ENTHH

13. $\mathrm{EP}$

14. EPS, EPS 1

15. ETNT

16. ETOT

17. IMAX

18. J

19. JA

20. JMAX

21. JW

22. $\mathrm{KK}$ $\underline{\text { Description }}$

Allowable internal pressure at the inside face of the concrete, $\mathrm{kb}$

The value of $\Delta r(j)$ used in the formula to find $Q$

The value of $\Delta r(j)$ used in the formula to find $u$

Time increment, sec

The allowable value of $\Delta t$ resulting from the stability conditions for $z$ one $J$

Internal energy, dyne-cm

Specific internal energy of the fluid in zone $J$ at time $t$, dyne $-\mathrm{cm} / \mathrm{gm}$

Kinetic energy, dyne-cm

Mass of the fluid in zone $\mathrm{J}, \mathrm{gm}$

Test value for the accuracy check

Specific enthalpy of the water, cal/gm

Specific enthalpy of the water for the Hugoniot curve, cal/gm

Accuracy check value (relative quantity)

Accuracy check values, dyne $-\mathrm{cm} / \mathrm{gm}$

Total energy of the TNT products, dyne-cm

Total energy of the system, dyne $-\mathrm{cm}$

Maximum number of records written on magnetic tape and maximum number of lines of printout in the final table Index for zones and $z$ one interfaces Index of the TNT-water interface Index of the argon-concrete interface Index of the water-argon interface Index indicating the $z$ one of maximum pressure outside of the gas bubble 
FORTRAN Name

23. NPLIM

24. $\mathrm{P}(\mathrm{J}, \mathrm{l})$

25. PTEST

26. $Q(J, 1)$

27. $\mathrm{R}(\mathrm{J})$

28. $R R(J, 1)$

29. $\operatorname{SOS}(\mathrm{J})$

30. $\mathrm{T}$

31. TEM(J)

32. TEMPE

33. TEMPP

34. TMAX

35. $\mathrm{Tl}(\mathrm{I})$

36. VEL

37. $\mathrm{VH}$

38. $V(J, 1)$

39. $\operatorname{VMAX}(\mathrm{J})$

40. $\operatorname{VOL}(\mathrm{J}), \operatorname{VOL} 1(\mathrm{~J})$, $\operatorname{VOL2}(\mathrm{J})$

41. XI
Description

Program control value

Pressure at the center of zone $J$ at time $t$, dyne $/ \mathrm{cm}^{2}$

Auxiliary name used to determine the maximum pressure in the system outside the gas bubble

Pseudoviscous pressure term in zone $\mathrm{J}$ at time $t$, dynes $/ \mathrm{cm}^{2}$

The Lagrangean coordinate of the interface at index $\mathrm{J}$

Eulerian coordinate for interface $\mathrm{J}$ at time $t, \mathrm{~cm}$

Speed of sound in the fluid media in zone J

Time, sec

Temperature in zone $\mathrm{J},{ }^{\circ} \mathrm{K}$

Temporary value of the specific internal energy used in calculations

Temporary value of the pressure used in calculations

Upper limit on time, sec

Time at index I

Average velocity of the fluid particles in zone $\mathrm{J}$

Specific volume of the water for the Hugoniot curve, $\mathrm{cm}^{3} / \mathrm{gm}$

Specific volume of the fluid in zone $J$ at. time $t, \mathrm{~cm}^{3} / \mathrm{gm}$

Maximum value of the specific volume in zone $J$ that results in a positive pressure in that zone

Auxiliary values at index $\mathrm{J}$

FORTRAN name for $\xi$, kb 
FORTRAN Name

42. DELTAT, ARGUE

43. K, JAM, JWM, JMAXM, JCUR

44. LAST, IS 3, IFSW, IS2

45. N, I, KL, KLL

46. $\mathrm{Tl}(\mathrm{I}), \mathrm{Pl}_{1}(\mathrm{I}), \mathrm{P}_{2}(\mathrm{I})$, P3(I), P4(I), P5(I), P6(I), RR7(I), RR8(I), PMAX(I), KKP(I), ETOTAL

47. $\mathrm{U}(\mathrm{J}, 2), \mathrm{RR}(\mathrm{J}, 2)$, $\mathrm{V}(\mathrm{J}, 2), \mathrm{Q}(\mathrm{J}, 2)$, $P(J, 2), E(J, 2)$

48. AAR3, ARG, AR 1, AR2, AR 3, AR4, AR 44, B, $\mathrm{CC} 1, \mathrm{CC} 2, \mathrm{CC} 3, \mathrm{DISC}$, DSQ, EE, El, PCP, PP, RAD, RAD 1, RAD2, RAD 3, R1, R2, R3, TEMP, TEMP1, TEMP2, TEMPT, VSQ, VTEST
Description

Auxiliary names used to obtain the maximum allowable $\Delta t$

Control values of the index

Program control values

Indices used as counters

Auxiliary names used to obtain the values of the parameters at critical locations

Same description as for $U(J, 1)$,* etc., except applicable for time $t+\Delta t$

Auxiliary names

I. List of Data Values Used

FORTRAN Name Value (Fig. 4A) Value (Fig. 4B)

$\begin{array}{llll}\text { 1. } & \text { AIPCC } & 0.0992 \mathrm{~kb} & 0.0992 \mathrm{~kb} \\ \text { 2: } & \text { DELT } & 0.0000005 \mathrm{sec} & 0.0000005 \mathrm{sec} \\ \text { 3. } & \text { EP } & 0.00005 & 0.00005 \\ 4: & \text { EPS } & 100,000.0 \mathrm{dyne}-\mathrm{cm} / \mathrm{gm} & 100,000.0 \mathrm{dyne}-\mathrm{cm} / \mathrm{gm} \\ \text { 5. } & \text { JA } & 13 & 13 \\ 6: & \text { JW } & 88 & 28 \\ \text { 7. } & \text { JMAX } & 90 & 30 \\ \text { 8. } & \text { TMAX } & 0.004000 \mathrm{sec} & 0.022000 \mathrm{sec}\end{array}$

$*_{U(J, 1)}$ :. velocity in zone $\mathrm{J}$ at time 1. 


\section{J. FORTRAN IV Computer Statements}

\section{H.C.SORENSEN EXPLOSION ANALYSIS}

NUMERICAL ANALYSIS OF A TNT BLAST WAVE IN A LIMITED NON-HOMOGENEOUS FLUID MEDIUM. THF ANALYSIS IS BASED UPON THE VON NEUMANN-RICHTMEYER PSEUDO-VISCOUS METHOD.

THIS COMPUTER SOLUTION IS PERFORMED JN THE CDC 3600 COMPUTER. THIS PROGRAM USFS FOUR SUBROUTINES WHICH ARE CALLED ROOT3. FCT, ROOT33, AND FCTN.

COMMON AR1, AR2, AR3, AR4, IFSW,PP, US, UP, VH, ENTHH, XI, ENTH, EE, V,J,EP, KL $1, K L L$

DIMENSION $P(50,2), V(50,2), E(50,2), O(50,2), U(50,2), R R(50,2), T E M(50)$ 1,R $(50), \operatorname{DELRU}(50), \operatorname{DFLRO}(50), \mathrm{SOS}(50), \mathrm{DTTEST}(50), \operatorname{VOL}(50), \operatorname{VOL} 1(50)$, 2VOL2 $(50), \operatorname{VMAX}(50)$

COMMON/A/P1 $(4000), P 2(4000), P 3(4000), P 4(4000), P 5(4000), K K P(4000)$ COMMON/9/PG $(4000), R R 7(4000), R R 8(4000), T 1(4000), P M A X(4000)$ 


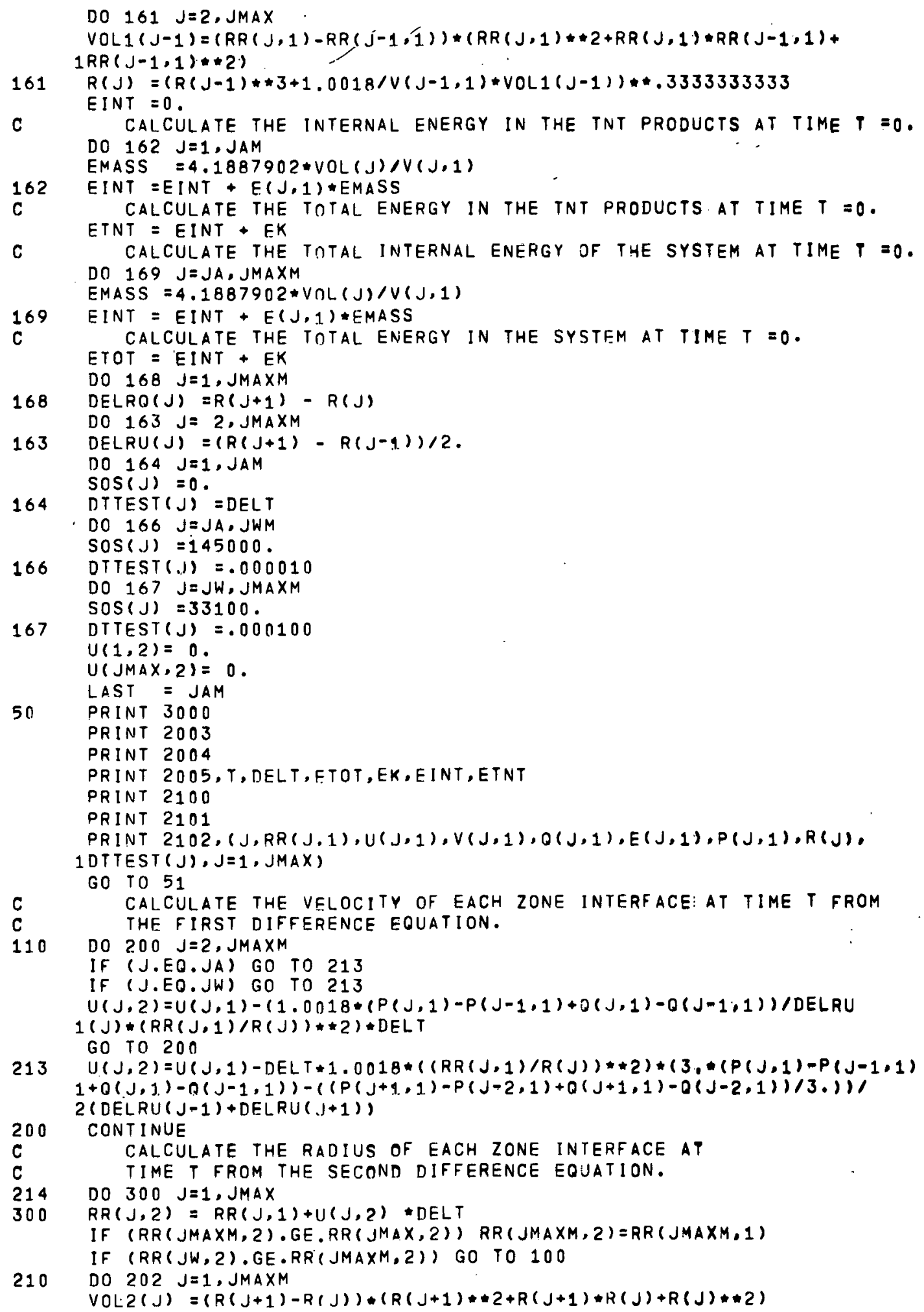




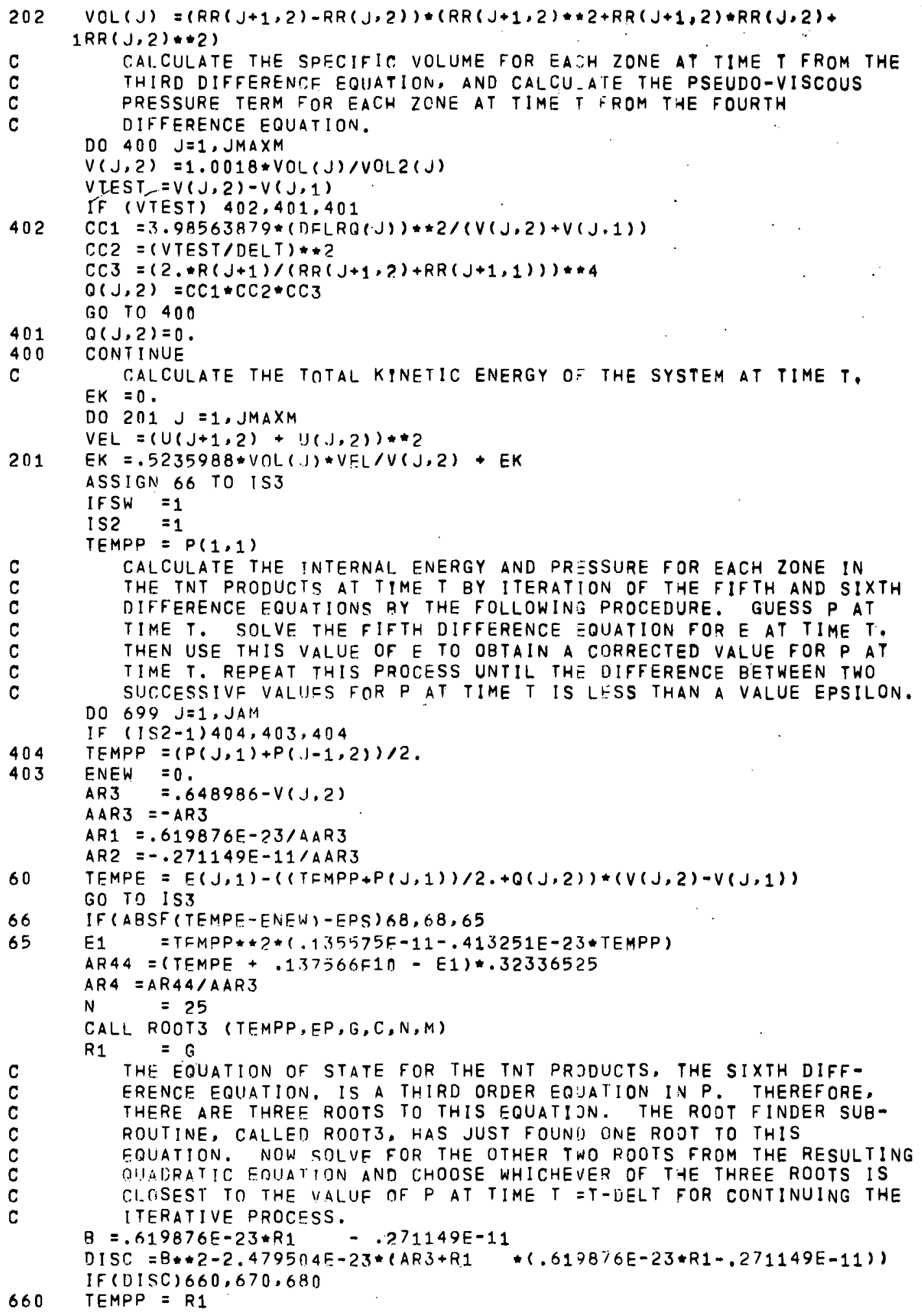




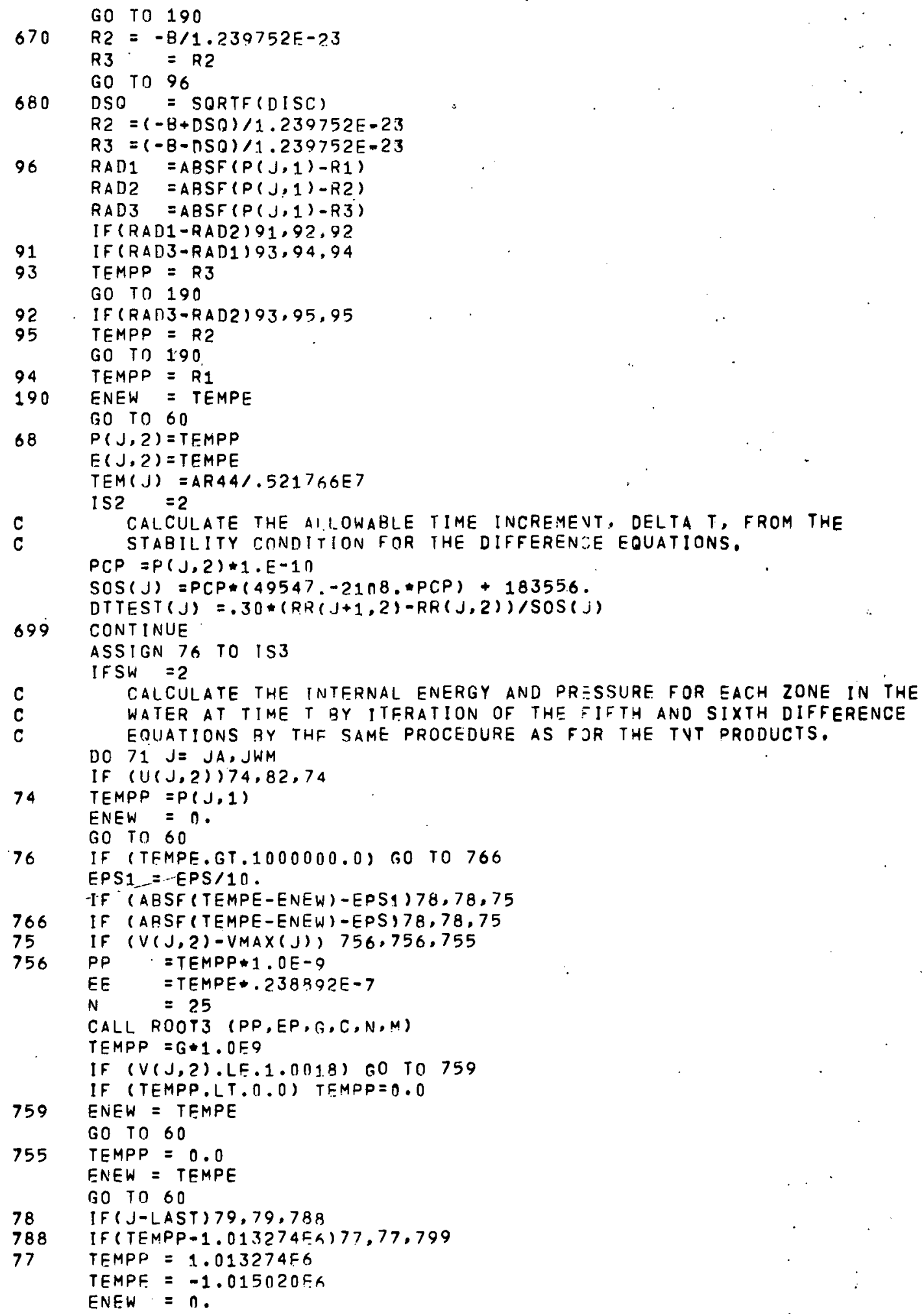




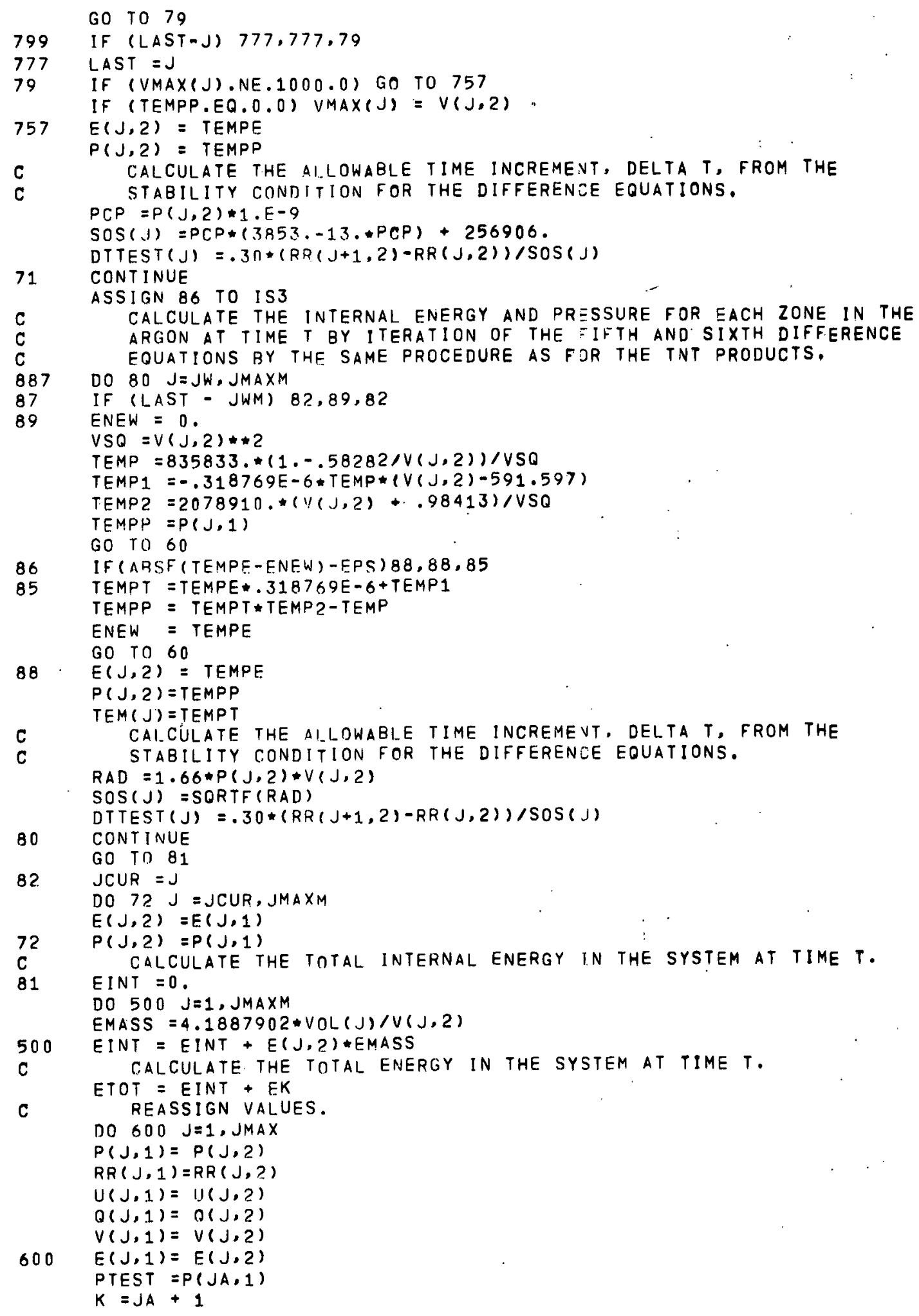




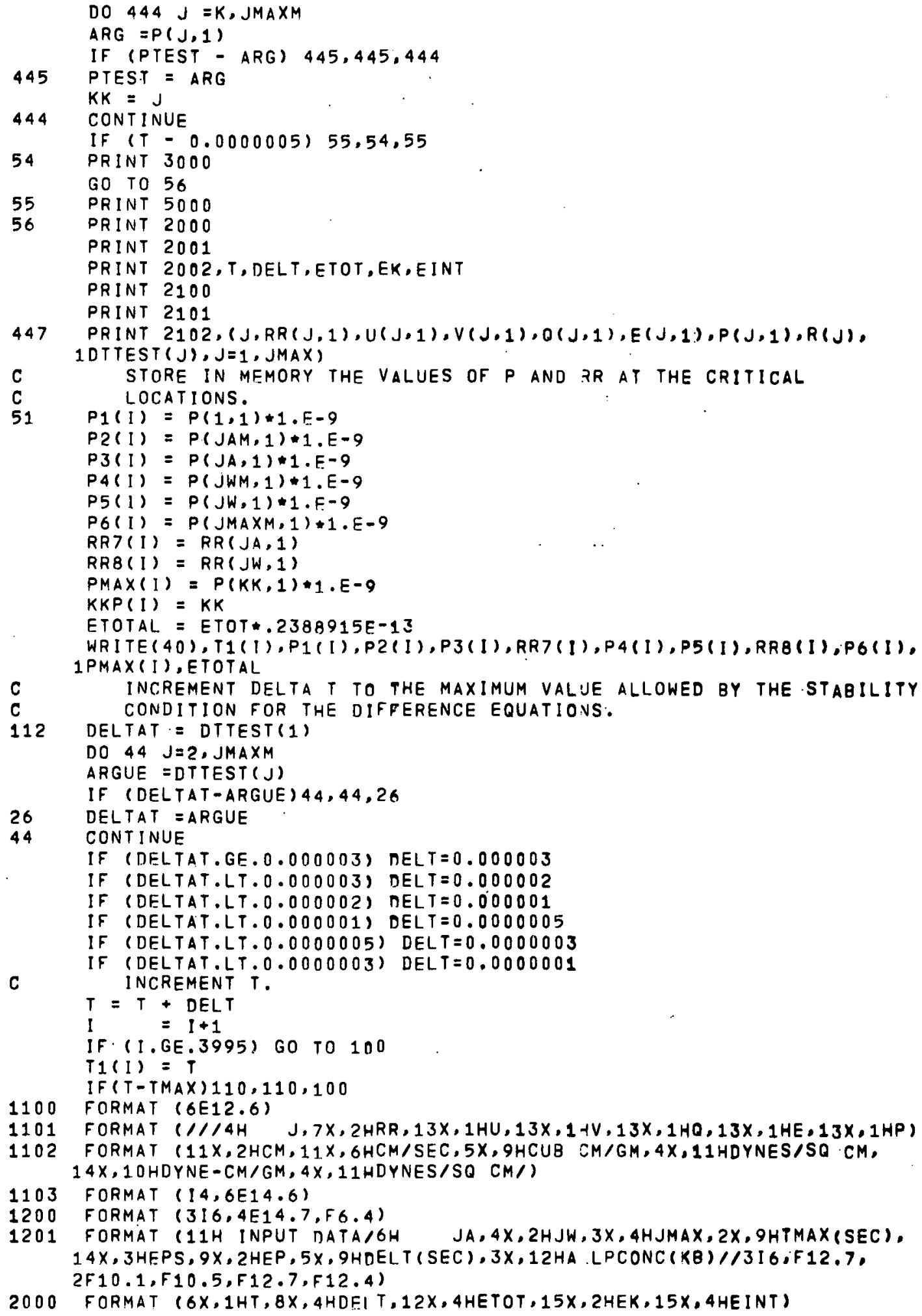




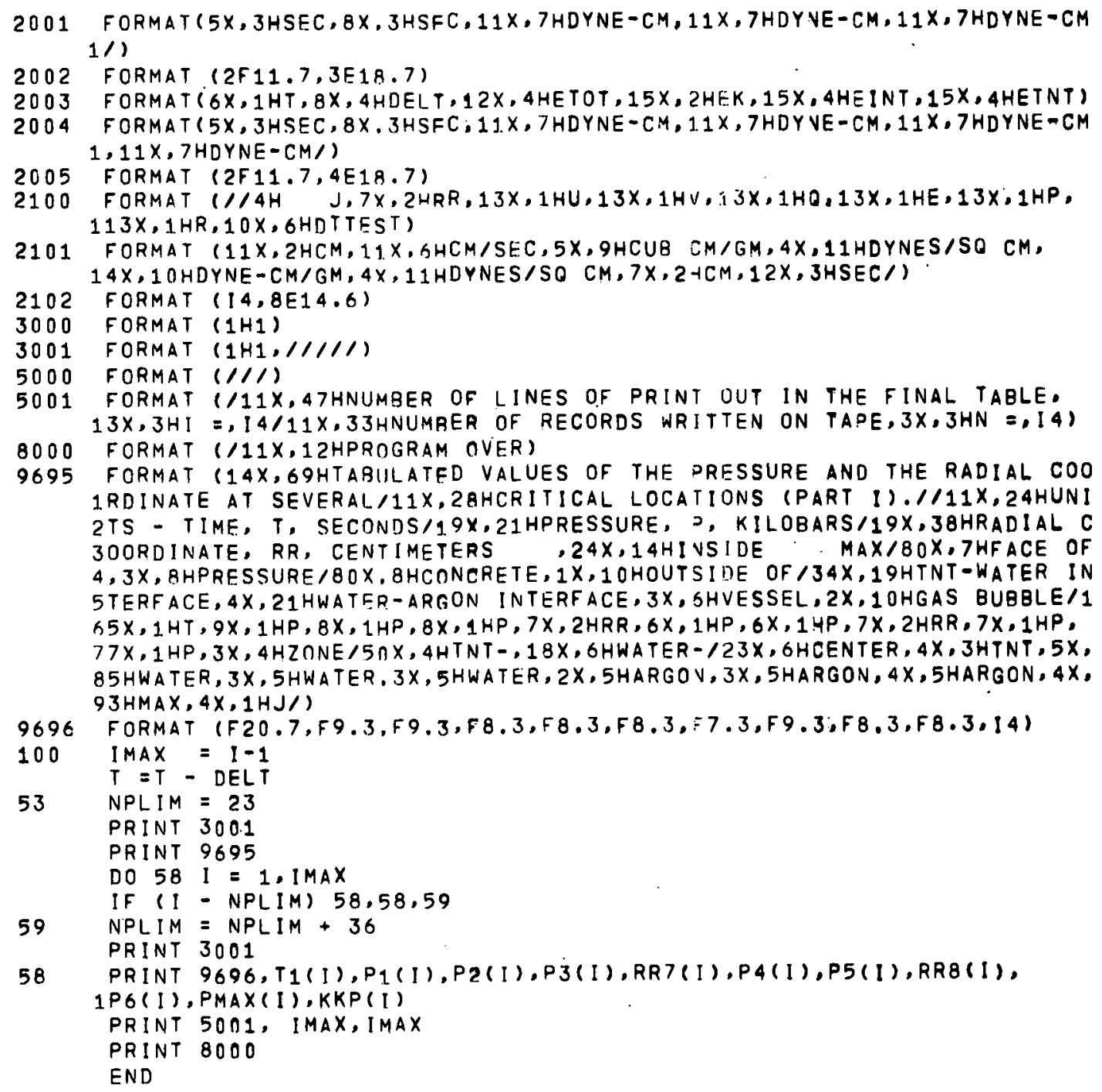


SUBROUTINE ROOT3 (A, EPS, G, C, N, M)

COMMON AR1, AR2, AR3, AR4, IFSW,PP,US,UP, VH,ENTHH, XI,ENTH,EE, V,J,EP,KL $1, K L L$

DIMENSION $V(50,2)$

C THIS SUBROUTINE IS A FORTRAN TRANSCRIPTION OF ACM. ALGORITHM NO.
C 26(COMM. ACM $4(1960) 603)$. IT COMPUTES A VALUE OF G = Y SATISFYING THE EQUATION $Y=$ FCT $(Y)$. THE ITERATION WILL CONVERGE TO Y PROVIDING THAT AT SOME TIME IN THE ITERATION A G IS. REACHED. SUCH THAT ABS(G-Y) $\triangle A B S(D(D F C T / D Y) / D Y)$ IS LESS THAV 2*ABS((DF/DY)-1.), WHERE THE DERIVATIVES ARE EVALUATED AT $Y$. INPUT INCLUDES: A SUBROUTINE, FCT $(X, Y)$, WHICH PLACES THE VALUE OF FCT $(X)$ IN Y; AN INITIAL APPROXIMATION TO THE ROOT, A: a TOLERANCE FOR THE RELATIVE ERROR IN G. EPS; A MAXIMUM NUMBER OF ITERATIONS TO BE PERFORMED. N. THE SUBROUTINE CHANGES $N$ TO THE NUMBER OF ITERATIONS ACTUALLY PERFORMED. OUTPUT INCLUDFS: THE NUMBER OF ITERATIONS PERFORMED, N: THE REQUIRED ROOT, G; THE VALUE $C=F C T(G)$ - G; A PARAMETER INDICATING THE SUCCESS OF THE PROCEDURE, M. IF THE TOLERANCE WAS NOT MET, M IS NEGATIVE. THE NUMBER ABS $(M)=1$ GIVES THE NUMBER OF TIMES THAT THE CORRECTION TO G EXCEEDED THE PRECEOING ONE, IF FCT (Y) -Y HAS THE SAME VALUE FOR TWO SUCCESSIVE APPROXIMATIONS TO G. THEN $H=1$, AND WE PRINT CYCLE AND EXIT. IF $(K L-2) 11,12,11$

12 PRINT $101, \mathrm{~J}$

101 FORMAT $(/ 5 X, 4 H J 1=, 13,5 X, 98 H I F$ JI EQUALS $J$, THE COYPUTED RESULTS A IRE ACCEPTABLE. THIS MFANS THAT THE ROOT, G, OBTAINED BY. THE/3X, 2113HSUBROUTINE HAS BEEN CORRECTED BY IHE PARENT ROUTINE AND THE PA 3RENT ROUTINE HAS CALLED THE SUBROUTINE AGAIN IN ITS/3X,1IJHATTEMPT 4 TO FIND A SATISFACTORY AOOT. IF JI DOES NOT EOUAL J, THE ROOT, G 5, OBTAINED BY THE ROOT. FINDER SUBROUTINE/3X,68HMAY OR MAY NOT BE A 6CCEPTABLE AND FURTHER INVESTIGATION IS NARRANTED./)

$11 \mathrm{KL}=1$

$M=1$

$J J=0$

$C=0$

CALL FCT $(0, \ldots)$

IF (F) $2,1,2$

$1 G=0$.

-GO TO 50

2 CALL FCT $(A, G)$

$C=G-A$

$D=C$

$B=C$

If (C) $3,50,3$

3 DO $40 \quad J J=1, N$

CALL FCT $(G, F)$

$C=F-Q$

IF (ABSF (C)-.000009)50,50.10

10 IF (ABSF (C) - $A B S F(G) * F P S) 50,50,4$

$4 H=B / C$

If $(H-1) 5,6,$.

6 PRINT $99, \mathrm{~J}$

PRINT $100, A, G, F, H$

99 FORMAT ( $18 \mathrm{H}$ CYCLE $3,8 X, 3 \mathrm{HJ}=, 14)$

100 FORMAT $(16 \mathrm{H} \quad \mathrm{A}=. F 15,7,4 \mathrm{X}, 3 \mathrm{HG}=, E 15,7,4 \mathrm{X}, 3 \mathrm{HF}=, E 15,7,4 \mathrm{X}, 3 \mathrm{HH}=$, 1E15.7)

$K L=K L+1$

GO TO 49

5 If (H) $7,7,8$

8 If $(H-2) 9,7,$,

$9 M=M+1$

$7 D=D /(H-1$,

$B=C$

40

$G=G+D$

$49 M=-M$

$J J=N$

$50 \mathrm{~N}=J \mathrm{~J}$

RETURN

END 
SUBROUTINE FCT $(X, Y)$

COMMON AR1,AR2,AR3, AR4, IFSW,PP,US,UP,VH,ENTHH,X:I,ENTH,EE,V,J,EP,KL

$1, K L L$

DIMENSION $V(50,2)$

IF $($ IFSW-1) 1;1,2

$1 \quad Y=(A R 1 * X+A R 2) \star X \star X+A R 4$

GO TO 3

$2 \quad N N=50$

PPP $=X$

$U S=1.75073+.05486 \$ P P P-.00022 *(P P P * 2)$

If (US -1.483 ) $6,7,5$

$6 \quad U S=1.483$

GO TO 7

5 CALL ROOT33 (US,EP, GG,CC,NN,MM,PPP)

US $=G G$

$7 \quad$ UP $=4.5349294 *(1.095275 * 0 \mathrm{US}-1.14445)$

$V H=1.0018 *(1.0-U P / U S)$

ENTHH $=11.9446 *(1.0018 * V H) * X$

EXP $=.0030338 * X$

$X I=151.16 * 10 * *$ EXP

ENTH $=E N T H H+X I *(V(J, 2)-V H) * 23.8892$

3

$Y=(E N T H-E E) /(V(J, 2) * 23.8892)$

RETURN

END 


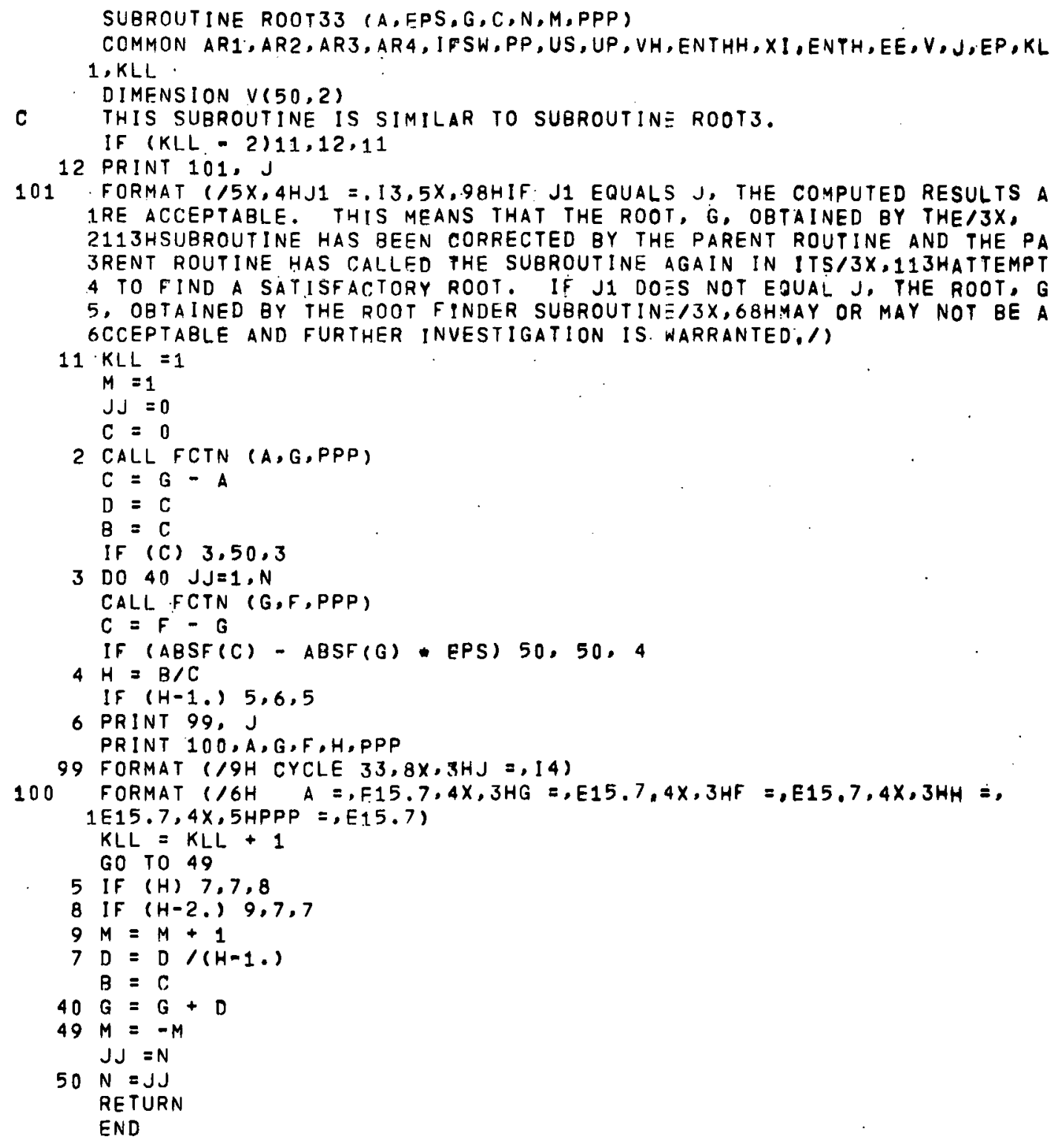

SUBROUTINE FCTN (X,Y,PPP)

COMMON AR1, AR2, AR3, AR4, IFSW,PP, US, UP, VH, ENTHH,XI,ENTH,EE,V,J,EP,KL $1, K L L$

DIMENSION $V(50,2)$

$Y=(.022090746 * P P P+1.14445 * X) /(1.095275 * * X)$

RETURN

END 


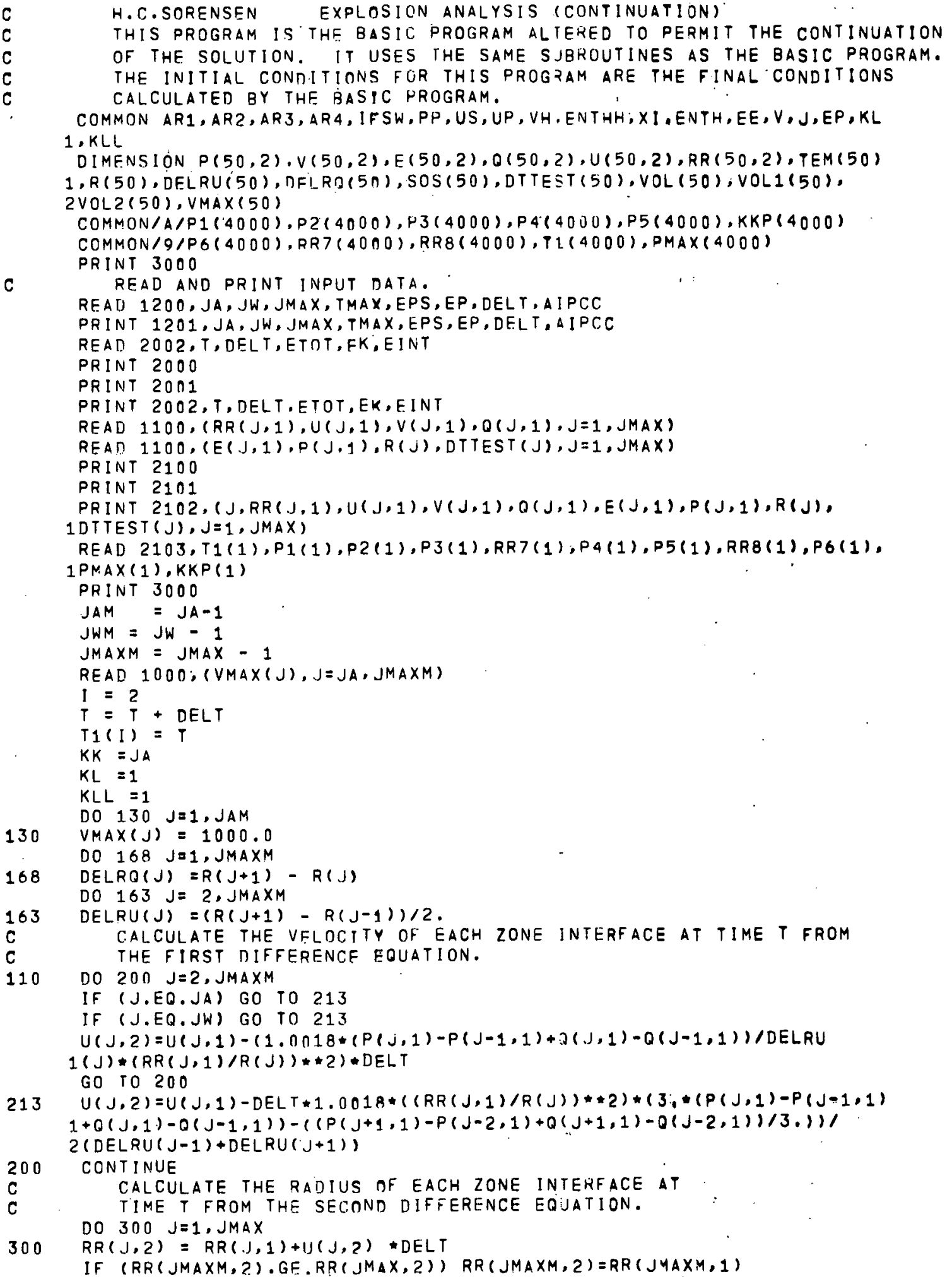


IF (RR (JW, 2) .GE,RR (JMAXM.2)) GO TO 100

DO $202 J=1$. JMAXM

VOL2 $(J)=(R(J+1)-R(J)) *(R(J+1) *+2+R(J+1) * R(J)+R(J) * 2)$

$\operatorname{VOL}(J)=(R R(J+1,2)-R R(J, 2)) \star(R R(J+1,2) \star * 2+R R(J+1 ; 2) \notin R R(J, 2)+$ $\operatorname{IRR}(J, 2) * 2)$

CALCULATE THE SPECIFIC VOLUME FOR EACH ZONE AT TIME T FROM THE

THIRO DIFFERENCF EOUIATION, AND CALCU. ATE THE PSEUDO-VISCOUS

PRESSURE TERM FOR EACH ZONE AT TIME T FROM THE FOURTH

DIFFERENCE EQUATION.

DO $4 \cap O J=1, J M A X M$

$V(J, 2)=1.0018 * V O L(J) / V O I .2(J)$

$V T E S T=V(J, 2)-V(J, 1)$

IF (VTEST) $402,401,401$

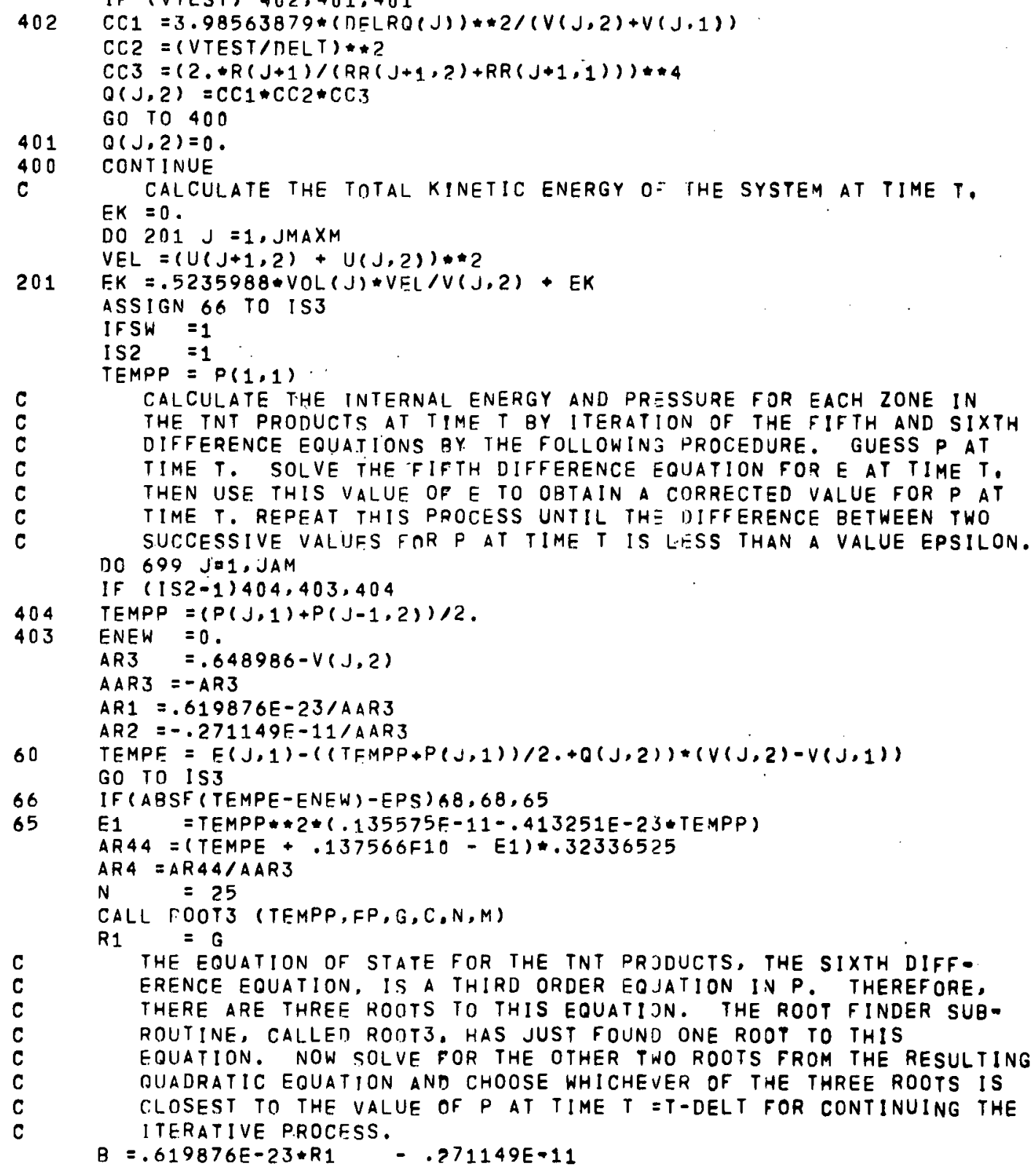




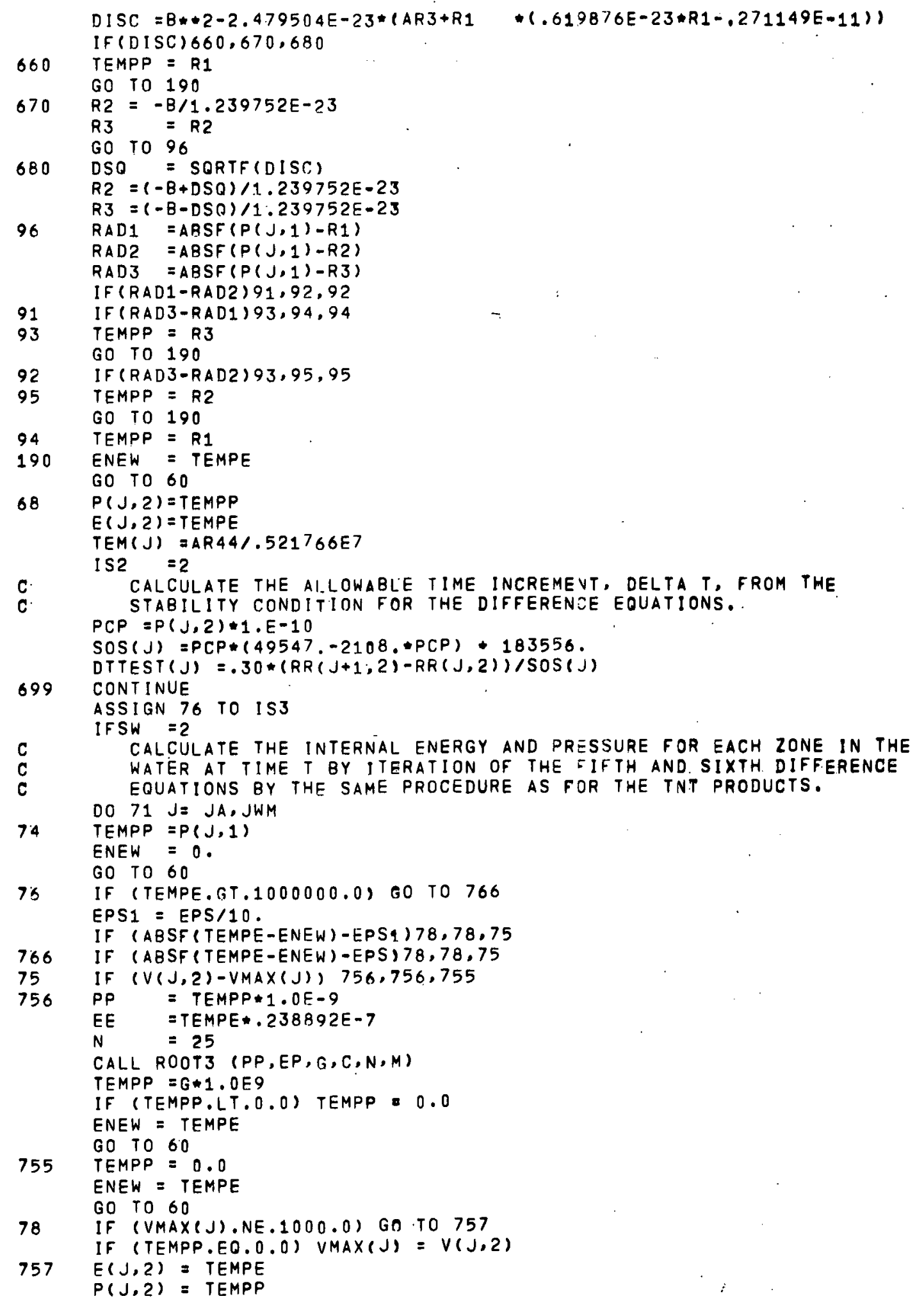




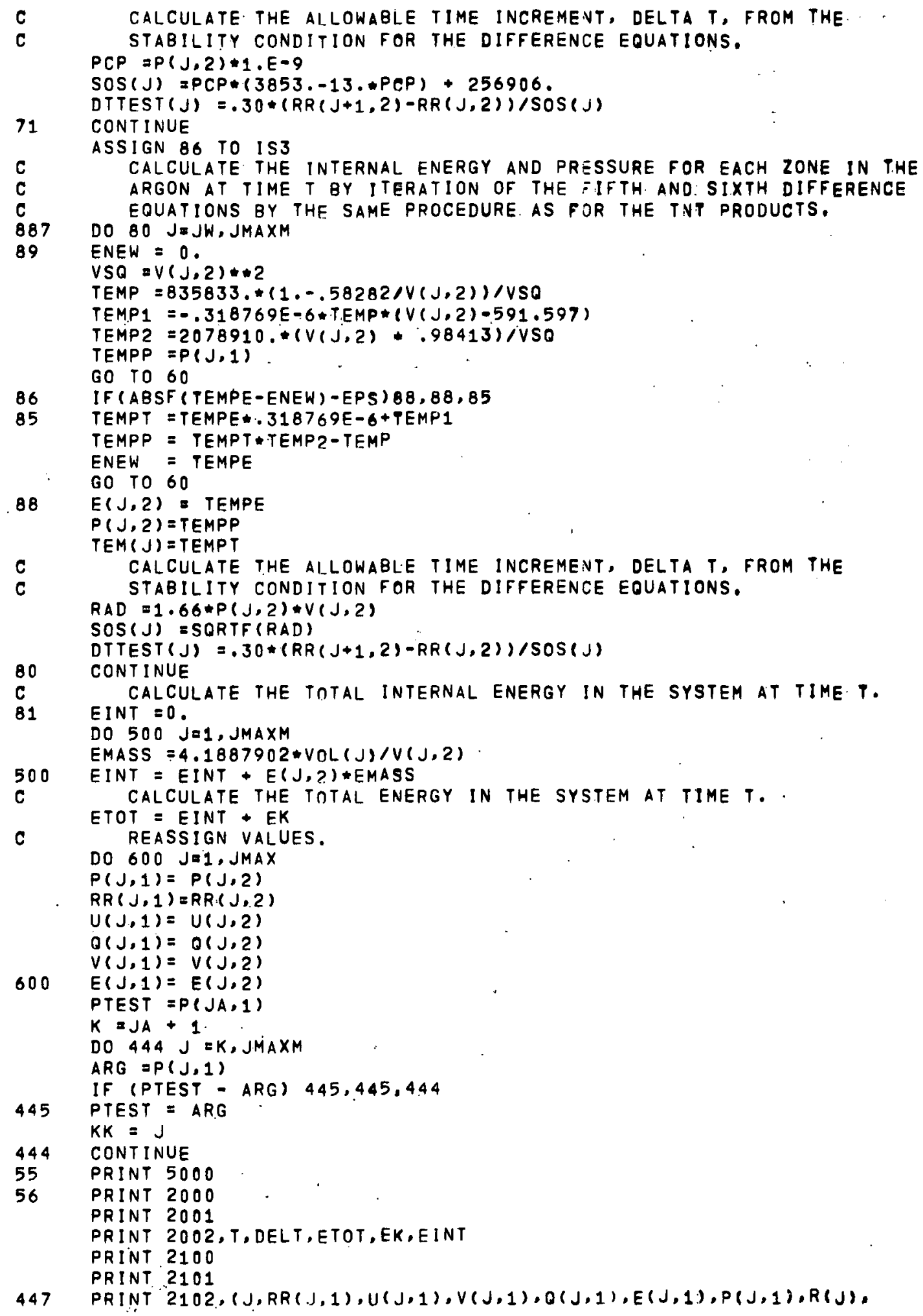




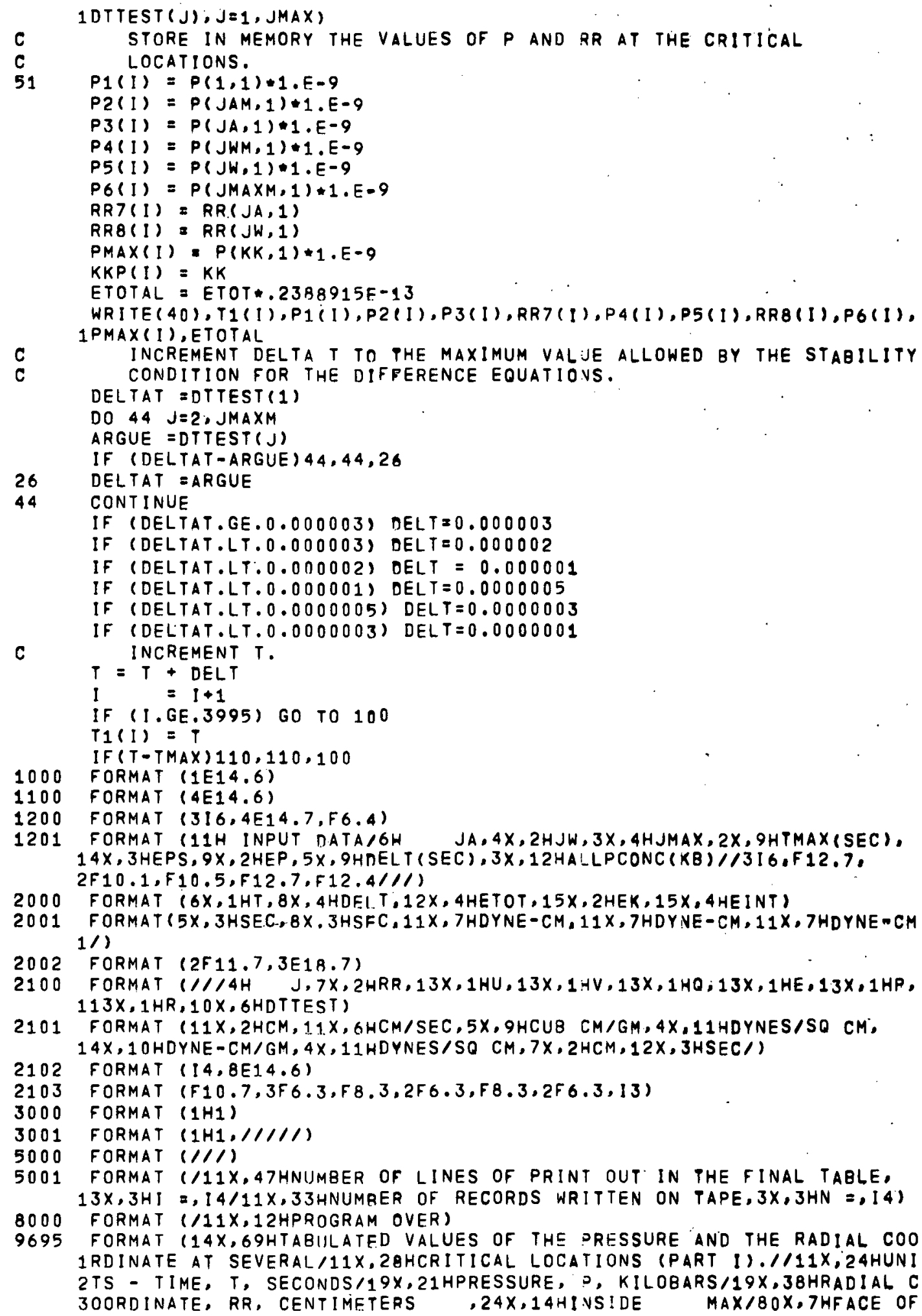


4,3X,8HPRESSURE $/ 80 X, 8 H C O N C R E T E, 1 X, 10 H O U T S I D E$ OF $/ 34 X, 19 H T N T$-WATER IN 5 TERF ACE, $4 X, 21$ HWATER-ARGON INTERFACE, $3 X, 6 H V E S S E L, 2 X, 1$ OHGAS - 8 UBBLE/1. $65 X, 1 H T, 9 X, 1 H P, 8 X, 1 H P, 8 X, 1 H P, 7 X, 2 H R R, 6 X, 1 H P, 6 X, 1 H P, 7 X, 2 H R R, 7 X, 1 H P$, $77 X, 1 H P, 3 X, 4 H Z O N E / 50 X, 4 H T N T-, 18 X, 6 H W A T E R-/ 23 X, 6 H C E N T E R, 4 X, 3 H T N Y, 5 X$, 85HWATER, 3X, 5HWATER, 3X, 5HWATER, $2 X$, 5HARGON, 3X, 5HAROON, $4 X, 5 H A R G O N, 4 X$, $93 H M A X, 4 X, 1 H J /)$

9696. FORMAT (F20.7.,F9.3,F9.3,F8.3,F8.3,F8.3, $7.3, F 9.3, F 8,3, F 8.3,14)$

100 IMAX $=1-1$

$T=T-D E L T$

NPLIM $=23$

PRINT 3001

PRINT 9695

DO $581=1$, IMAX

IF (I - NPLIM) $58,58,59$

$59 \quad$ NPLIM $=$ NPLIM +36

PRINT 3001

58 PRINT $9696, T 1(I), P 1(I), P 2(I), P 3(I), R R 7(I), P 4(I), P 5(I), R R 8(I)$, $1 P 6(I), P M A X(I), K K P(I)$

IMAXM = IMAX - 1

PRINT 5001, IMAX, IMAXM

PRINT 8000

END 
K. Computer Results

For each increment in time, the finite-difference equations (Eqs. $42-$ 47 ) were solved for all points in the finite-difference net. Table II represents a typical set of computer output data. A set of data similar to Table II was printed for each time increment. It was impractical to include all the computer output obtained during the solution of this problem.

The appropriate information about the peak pressure in the shock front obtained for the simulated infinite-wate $r$-medium layout is presented in tabular form in Table III. The information in columns 1,2 , and 3 of Table III was extracted from the actual computer output for this layout.

For the simulated sodium reactor installation layout, only values of the pressure and the radial coordinate at several critical locations in the finite-difference net are presented. A sample of the tabulated computer results for this layout is given in Table IV.

The order of these computer results is as follows:

1. Tabulated computer results for the simulated infinite water medium (Table III).

2. Graphical representation of the computer results for the simulated infinite water medium (Fig. 8).

3. A sample of the tabulated computer results for the simulated sodium reactor installation ( $T$ able IV).

4. Graphical representation of the computer results for the simulated sodium-reactor installation (Figs. 9-18).

TABLE III. Computer Results for Peak-pressure Analysis

\begin{tabular}{ccccc}
\hline $\begin{array}{c}\text { Peak } \\
\text { Pressure } \\
P_{\mathrm{m}}, \mathrm{kb}\end{array}$ & $\begin{array}{c}\text { Time } \mathrm{P}_{\mathrm{m}} \\
\text { Occurred, } \\
\text { sec }\end{array}$ & $\begin{array}{c}\text { Location of } \\
\text { Peak Pressure, } \\
\mathrm{R}, \mathrm{cm}\end{array}$ & $\begin{array}{c}\text { Reduced } \\
\text { Radius, } \\
\text { R/a }\end{array}$ \\
\hline 62.184 & 0.0000055 & 31.7605 & 0.9446 & 1.059 \\
42.598 & 0.0000105 & 33.2910 & 0.9011 & 1.110 \\
33.404 & 0.0000175 & 34.9995 & 0.8572 & 1.167 \\
28.442 & 0.0000235 & 36.5528 & 0.8207 & 1.218 \\
24.914 & 0.0000295 & 38.0820 & 0.7878 & 1.269 \\
16.962 & 0.0000625 & 47.6551 & 0.6295 & 1.589 \\
12.400 & 0.0001045 & 57.4176 & 0.5225 & 1.914 \\
9.610 & 0.0001495 & 67.1947 & 0.4465 & 2.240 \\
7.649 & 0.0001955 & 76.9436 & 0.3899 & 2.565 \\
6.374 & 0.0002455 & 86.7915 & 0.3457 & 2.893 \\
5.330 & 0.0002975 & 96.6564 & 0.3104 & 3.222 \\
4.614 & 0.0003505 & 106.5312 & 0.2816 & 3.551 \\
4.005 & 0.0004035 & 116.3906 & 0.2578 & 3.880 \\
3.548 & 0.0004605 & 126.3269 & 0.2375 & 4.211 \\
3.174 & 0.0005155 & 136.2160 & 0.2202 & 4.541
\end{tabular}


TABLE III. (Contd.)

\begin{tabular}{|c|c|c|c|c|}
\hline $\begin{array}{c}\text { Peak } \\
\text { Pressure, } \\
P_{\mathrm{m}}, \mathrm{kb}\end{array}$ & $\begin{array}{l}\text { Time } P_{m} \\
\text { Occurred, } \\
\text { sec }\end{array}$ & $\begin{array}{c}\text { Location of } \\
\text { Peak Pressure,* } \\
\text { R, cm }\end{array}$ & $a_{0} / R$ & $\begin{array}{c}\text { Reduced } \\
\text { Radius, } \\
\text { R/ao }\end{array}$ \\
\hline 2.864 & 0.0005755 & 146.1831 & 0.2052 & 4.873 \\
\hline 2.605 & 0.0006325 & 156.0993 & 0.1922 & 5.203 \\
\hline 2.387 & 0.0006925 & 166.0547 & 0.1807 & 5.535 \\
\hline 2.1 .99 & 0.0007525 & 176.0063 & 0.1704 & 5.867 \\
\hline 2.041 & 0.0008145 & 185.9781 & 0.1613 & 6.199 \\
\hline 1.896 & 0.0008765 & 195.9477 & 0.1531 & 6.532 \\
\hline 1.771 & 0.0009365 & 205.8960 & 0.1457 & 6.863 \\
\hline 1.660 & 0.0010005 & 215.8830 & 0.1390 & 7.196 \\
\hline 1.566 & 0.0010625 & 225.8498 & 0.1328 & 7.528 \\
\hline 1.479 & 0.0011245 & 235.8166 & 0.1272 & 7.861 \\
\hline 1.401 & 0.0011865 & 245.7838 & 0.1221 & 8.193 \\
\hline 1.330 & 0.0012505 & 255.7668 & 0.1173 & 8.526 \\
\hline 1.265 & 0.0013145 & 265.7490 & 0.1129 & 8.858 \\
\hline 1.206 & 0.0013785 & 275.7307 & 0.1088 & 9.191 \\
\hline 1.155 & 0.0014425 & 285.7119 & 0.1050 & 9.524 \\
\hline 1.104 & 0.0015065 & 295.6916 & 0.1015 & 9.856 \\
\hline 1.057 & 0.0015705 & 305.6733 & 0.0981 & 10.189 \\
\hline 1.015 & 0.0016345 & 315.6548 & 0.0950 & 10.522 \\
\hline 0.975 & 0.0016995 & 325.6423 & 0.0921 & 10.855 \\
\hline 0.939 & 0.0017635 & 335.6240 & 0.0894 & 11.187 \\
\hline 0.905 & 0.0018285 & 345.6110 & 0.0868 & 11.520 \\
\hline 0.873 & 0.0018935 & 355.5989 & 0.0844 & 11.853 \\
\hline 0.843 & 0.0019585 & 365.5863 & 0.0821 & 12.186 \\
\hline 0.815 & 0.0020235 & 375.5738 & 0.0799 & 12.519 \\
\hline 0.788 & 0.0020895 & 385.5663 & 0.0778 & 12.852 \\
\hline 0.764 & 0.0021545 & 395.5539 & 0.0758 & 13.185 \\
\hline 0.740 & 0.0022195 & 405.541 .6 & 0.0740 & 13.518 \\
\hline 0.718 & 0.0022845 & 415.5340 & 0.0722 & 13.851 \\
\hline 0.697 & 0.0023505 & 425.5220 & 0.0705 & 14.184 \\
\hline 0.678 & 0.0024165 & 435.5144 & 0.0689 & 14.517 \\
\hline 0.659 & 0.0024825 & 445.5067 & 0.0673 & 14.850 \\
\hline 0.641 & 0.0025485 & 455.4991 & 0.0659 & 15.183 \\
\hline 0.624 & 0.0026145 & 465.4915 & 0.0644 & 15.516 \\
\hline 0.608 & 0.0026795 & 475.4802 & 0.0631 & 15.849 \\
\hline 0.593 & 0.0027455 & 485.4728 & 0.0618 & 16.182 \\
\hline 0.578 & 0.0028115 & 495.4654 & 0.0605 & 16.516 \\
\hline 0.564 & 0.0028775 & 505.4581 & 0.0594 & 16.849 \\
\hline 0.551 & 0.0029445 & 515.4544 & 0.0582 & 17.182 \\
\hline 0.538 & 0.0030105 & 525.4472 & 0.0571 & 17.515 \\
\hline $0: 526$ & 0.0030765 & 535.4401 & 0.0560 & 17.848 \\
\hline 0.514 & 0.0031425 & 545.4331 & 0.0550 & 18.181 \\
\hline 0.503 & 0.0032085 & 555.4261 & 0.0540 & 18.514 \\
\hline 0.492 & 0.0032755 & 565.4225 & 0.0531 & 18.847 \\
\hline 0.482 & 0.0033415 & 575.4157 & 0.0521 & 19.181 \\
\hline 0.472 & 0.0034085 & 585.4120 & 0.0512 & 19.514 \\
\hline 0.462 & 0.0034745 & 595.4053 & 0.0504 & 19.847 \\
\hline 0.453 & 0.0035405 & 605.3988 & 0.0496 & 20.180 \\
\hline
\end{tabular}

$* R$, the location of the peak pressure, is the average of the Eulerian coordinates of the two interfaces for the zone in which the peak pressure occurs and $a_{0}=30 \mathrm{~cm}$. 
TABLE IV. Tabulated Values of the Pressure and the Radial Coordinate at Several Critical Locations

UNITS - TIME, T, SECONDS

PPESSURE, P, KILIJAARS

RADIAL COORIINATE, RR, CENTIMETERS

INSIDC MAX

FACE OF PRFSSURE

CONCRETE OUTSINE OF

VESSEL GAS BURRLE

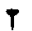

0.0000000

0.0000005

0.0000010

0.0000015

0.0000020

$0.00000>5$

$0.0 \cap 00030$

0.0100035

0.0000040

$0.0 \cap 00045$

0.0000050

0.0000055

0.0000000

0.0000065

D. 0000070

0.0000075

0.0000080

0.0000085

0.0000090

0.0000095

0.00001 in 5

0.000011 .5

0,0000125

0.0000135

$0.000 n 145$

0.0000155

0.0000165

0.0000275

0.0000185

0.0000205

0.0000225

$0.000 \cap 245$

0.00002 .5

0.0701295

0.0000305

$0.0 \cap 1 \cap 325$

0.0000345

0.01100365

0.00003 .5

0.0000405

0.0000425

0.0000445

0.0000465

0.0000485

0.0000505

0.0000525

0.0000545

0.0000585

0.0000585

0.0000605

0.0000615

0.0000625

0.0000635

0.0000645

0.0000655

0.0000645

0.1000675

0.0000685

0.0000695 $p$

TNT=WATER INTERFACE

$P$ P TNT.

CFNTER TNT WATER WATER

21.900

$124 \cdot 5 n n$

0.00130 .000

WATER=ADGON INTERFACE

$\begin{array}{ccc}P & P & \text { RR } \\ & & \\ \text { WATER ARGON WATER- } & \text { ARGDN }\end{array}$

21.000

29.900

29.000

21.000

21.900

29. 900

21.900

29.900

21.000

$31.00 n$

21.900

21.900

21.000

$29.00 \mathrm{n}$

21,000

21.900

21.900

21.000

21. 900

21.901

21.901

29.001

21.002

29.904

21.905

21.907

21.911

21.924

21.945

21. 98 ?

27. 109

22.211

27.345

27.50 .3

27.706

22.945

23.216

2.7 .513

23. 825

24.143

24.456

24.757

$25.14 n$

25.312

25.588

25.896

26.278

26.504

26.767

27,077

27.443

27.870

28,366

$2 A, 942$

29.591

30.321
113.998

102.827

$91.9 ?$ ?

81. $6 \mathrm{nz}$

72.227

63.929

56.731

50.574

45.356

40.955

37.248

34.120

31.470

29.216

27.296

$25.6 ? 4$

24,193

22.978

$21,8 ? 8$

20.058

18.654

17,522

16.595

15.828

15.186

14.64 ?

13.78 .5

13.193

12.750

12.415

12.15 A

11.962

11.81 ?

$11.69 \mathrm{R}$

11.610

$11.5,32$

11.447

$11.34 \mathrm{~B}$

11.230

1i.091

10.927

10.735

10.513

11.256

$0.9 \times 6$

9.645

$9.3 \cap n$

B.934

B. 750

Q.5A2

A. 372

H. 181

7.988

7.796

$7.6 \mathrm{nd}$

7.415

1.228
14.180

$5.203 \quad 31.553$

$5.701 \quad 31.650$

$9.378 \quad 36.573$

0.0010 .001

180.000

0.001 ก.n01 180.000

$0.001 \quad n .001 \quad 180.000$

0.001 ก, nO1 180.0nO

$0.001 \quad n .001 \quad 180.000$

0.001 ก.n01 180.0nn

0.001 n. 01 1A0.000

0.001 ก., 01 180.0nO

$0.001 \quad n .001 \quad 180.000$

$0.001 \quad 0.001 \quad 180.000$

$0.001 \quad 0.001 \quad 180.000$

$0.001 \quad n, 001 \quad 180.000$

0.001 i.n01 180.000

$0.001 \quad n, 001 \quad 180,000$

$0.003 \quad 0.001 \quad 180.000$

$0,001 \quad n, 001 \quad 180,000$
$2 ? .133$
$0.163 \quad 30.084$

$0.348 \quad 310.172$

$0.554 \quad 30.264$

$0.783 \quad 30.359$

$1.0 .34 \quad 30.456$

$1.307 \quad 30.555$

1.59 A 31.655

$1.917 \quad 30.755$

$2.256 \quad 30.856$

$2.617 \quad 30.957$

$2.999 \quad 31.058$

$3.400 \quad 31.158$

$3.822 \quad 31.258$

$4.264 \quad 31.357$

$4.722 \quad 31.455$

$0.216 \quad 31.746$

$6.746 \quad 31.841$

$7.827 \quad 32.027$
$8.969 \quad 32.210$

8.969

10.149

11.361

12.595

1.3.8.39

$15.07 \mathrm{~B}$

16.299

17.489

19.572

21.356

22.757

23.707

32.210

32.389

$32: 564$

$3 ? .136$

32.903

33.067

33.227

33.383

33.680

34.229

24.162

34.481

34.940

23.517

32.467

21.035

35.146

35.339

.35 .519

$49.337 \quad 35.687$

17.498

35,845

$15.633 \quad .75 .997$

$13.834 \quad 36.143$

$12.169 \quad 36.287$

10.678

36.429

$8.272 \quad 36.719$

$7.347 \quad 36.869$

$6.601 \quad 37.024$

$6.010 \quad 31.184$

$5.560 \quad 37.349$

$5.371 \quad 37.434$

$5.214 \quad 37.519$

$5,087 \quad 37.607$

$4.989 \quad 37.695$

$4.921 \quad 37.786$

$4,881 \quad 37.877$

$4.868 \quad 37.970$

$4.883 \quad 38.065$

$4,925 \quad 38.160$
33.962 
TABLE IV. (Contd.)

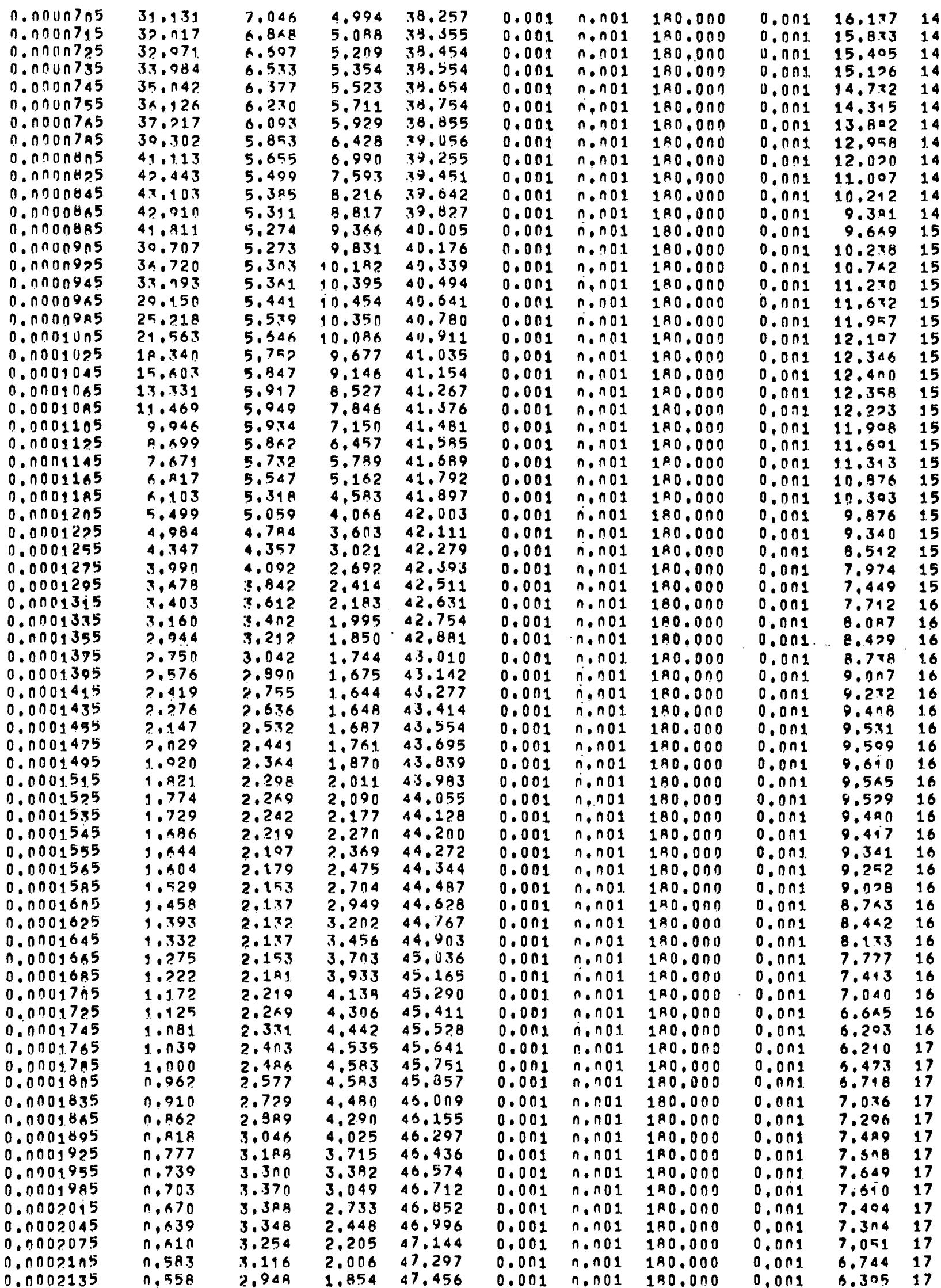


TABLE IV. (Contd.)

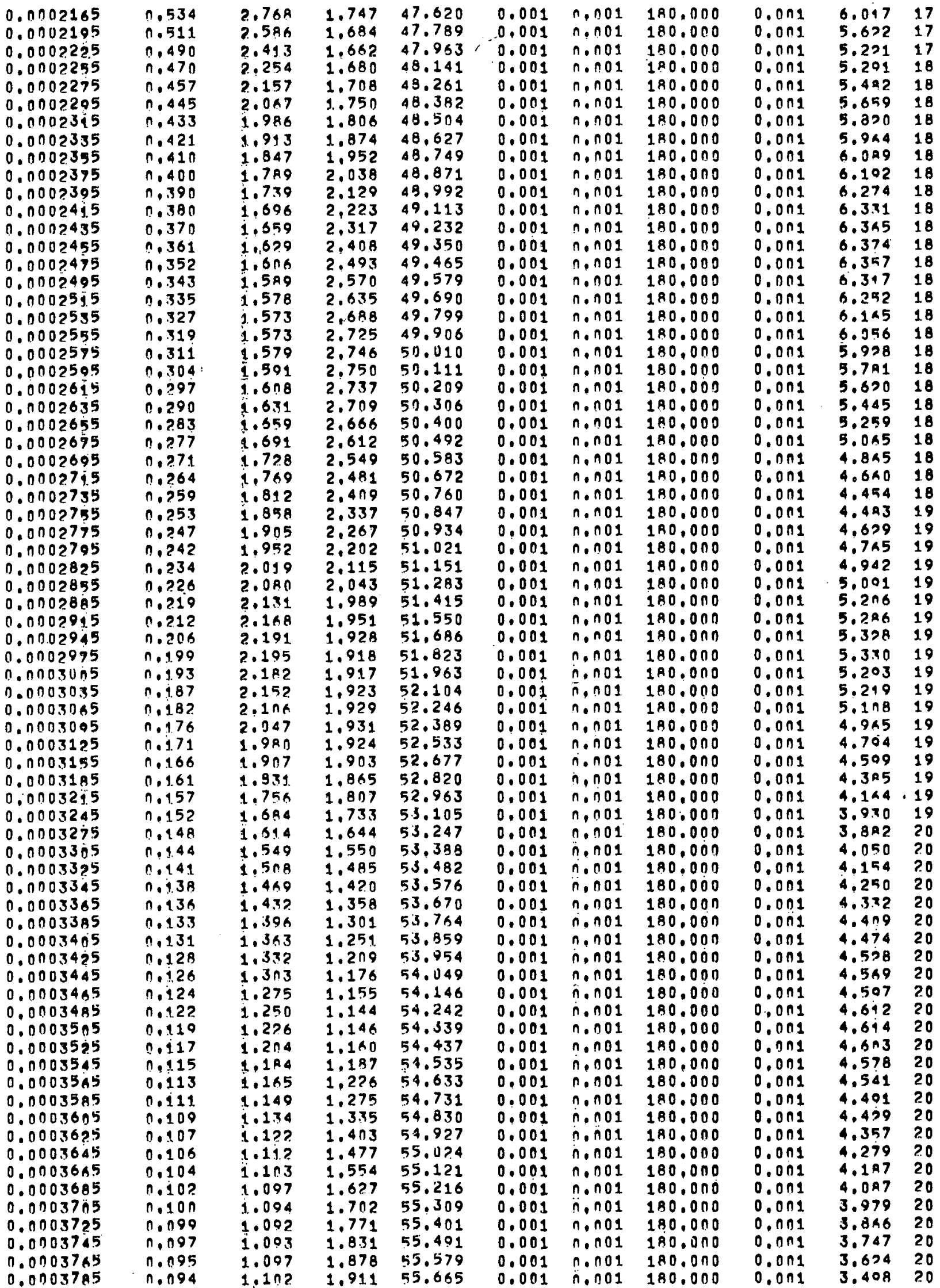


TABLE IV. (Contd.)

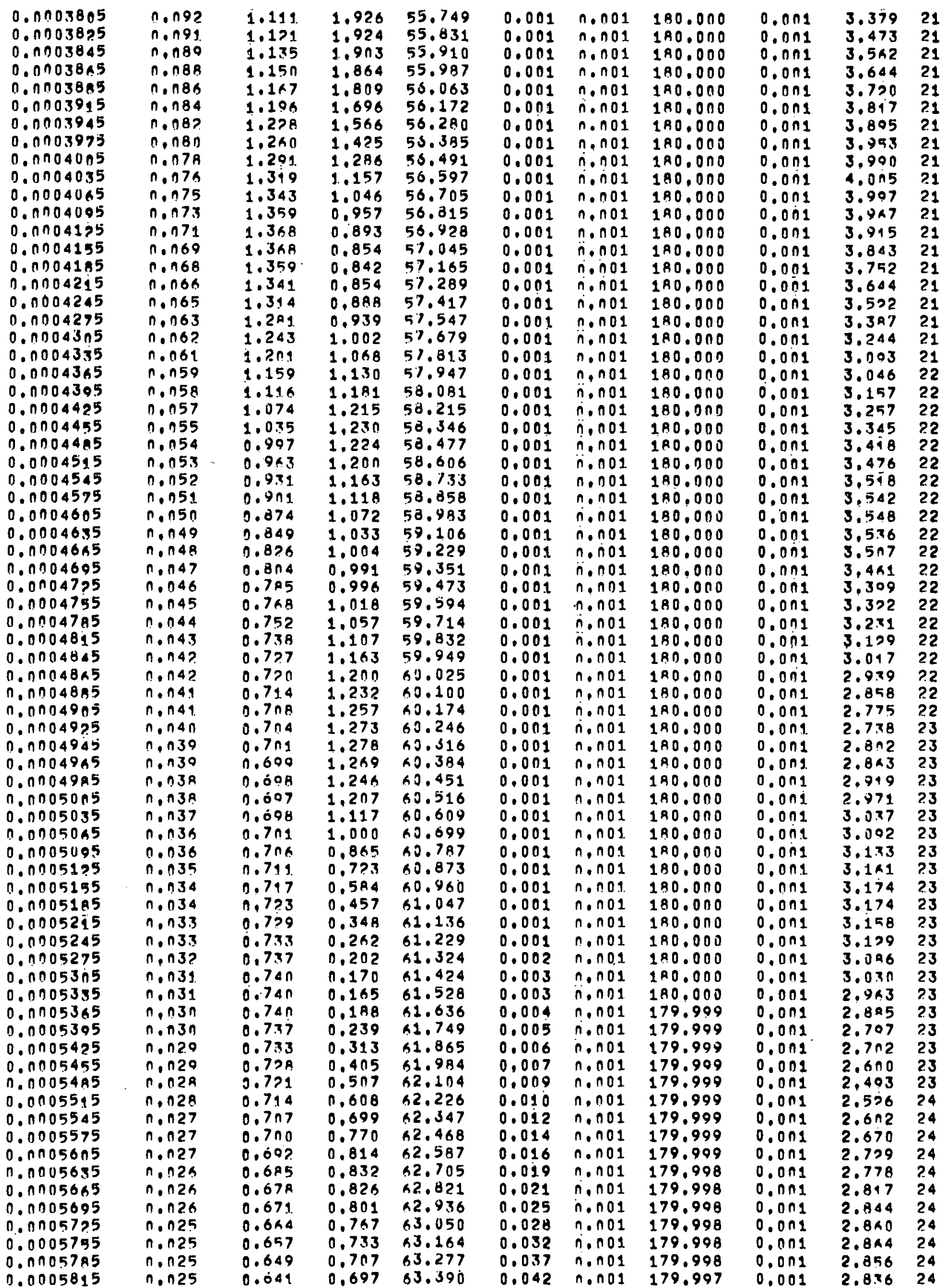


TABLE IV. (Contd.)

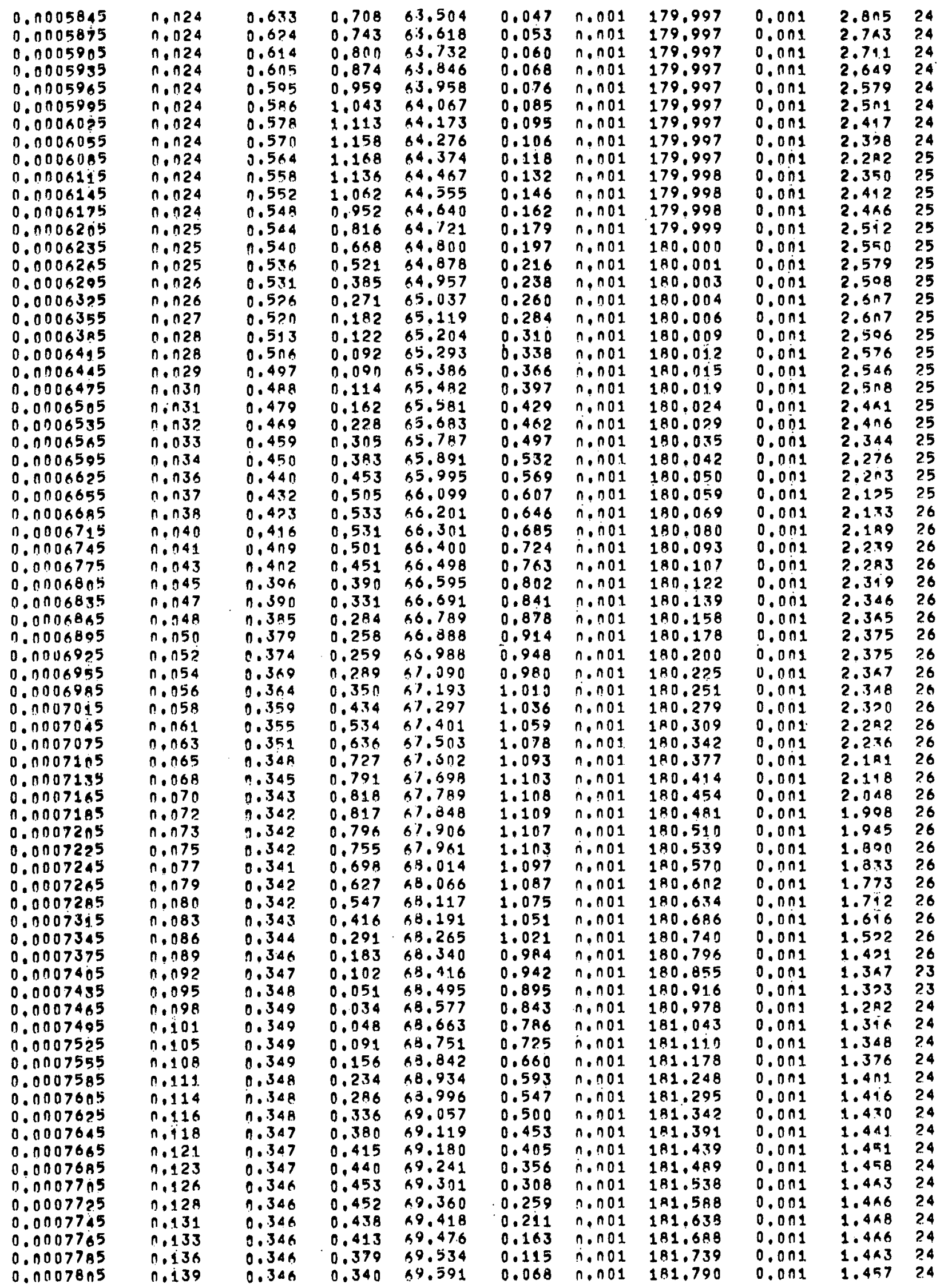


TAB LE IV. (Contd.)

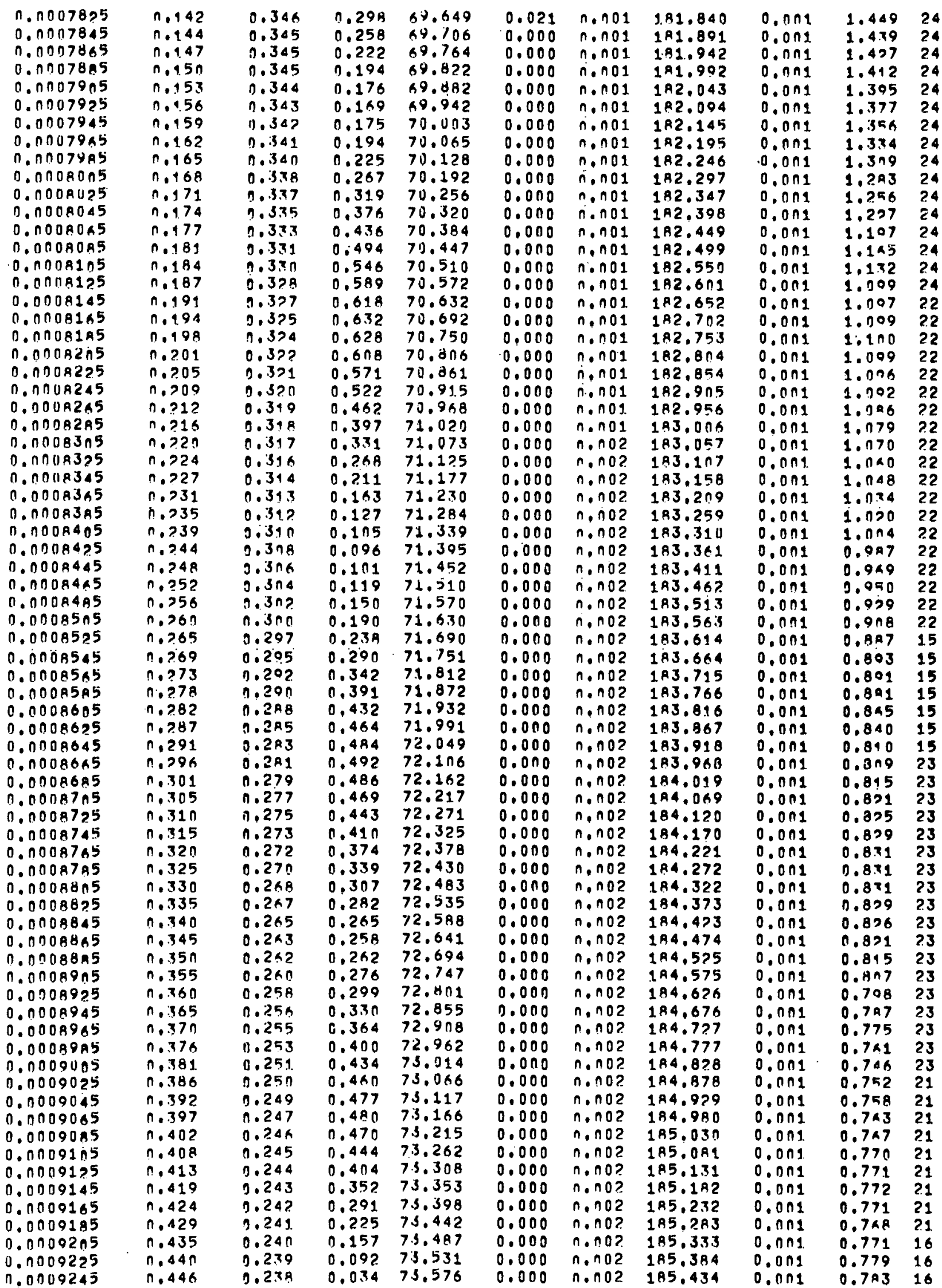


TAB LE IV. (Contd.)

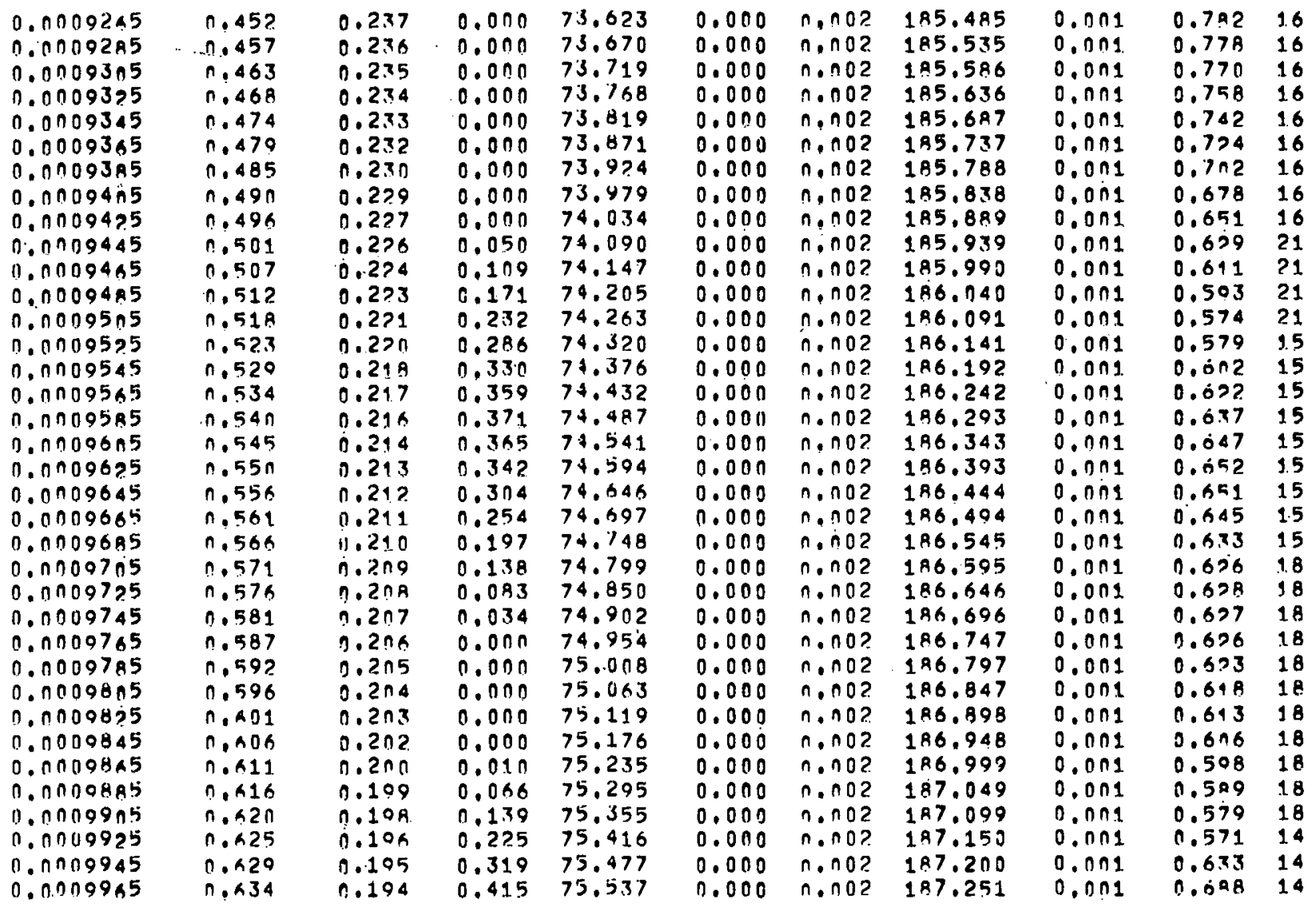



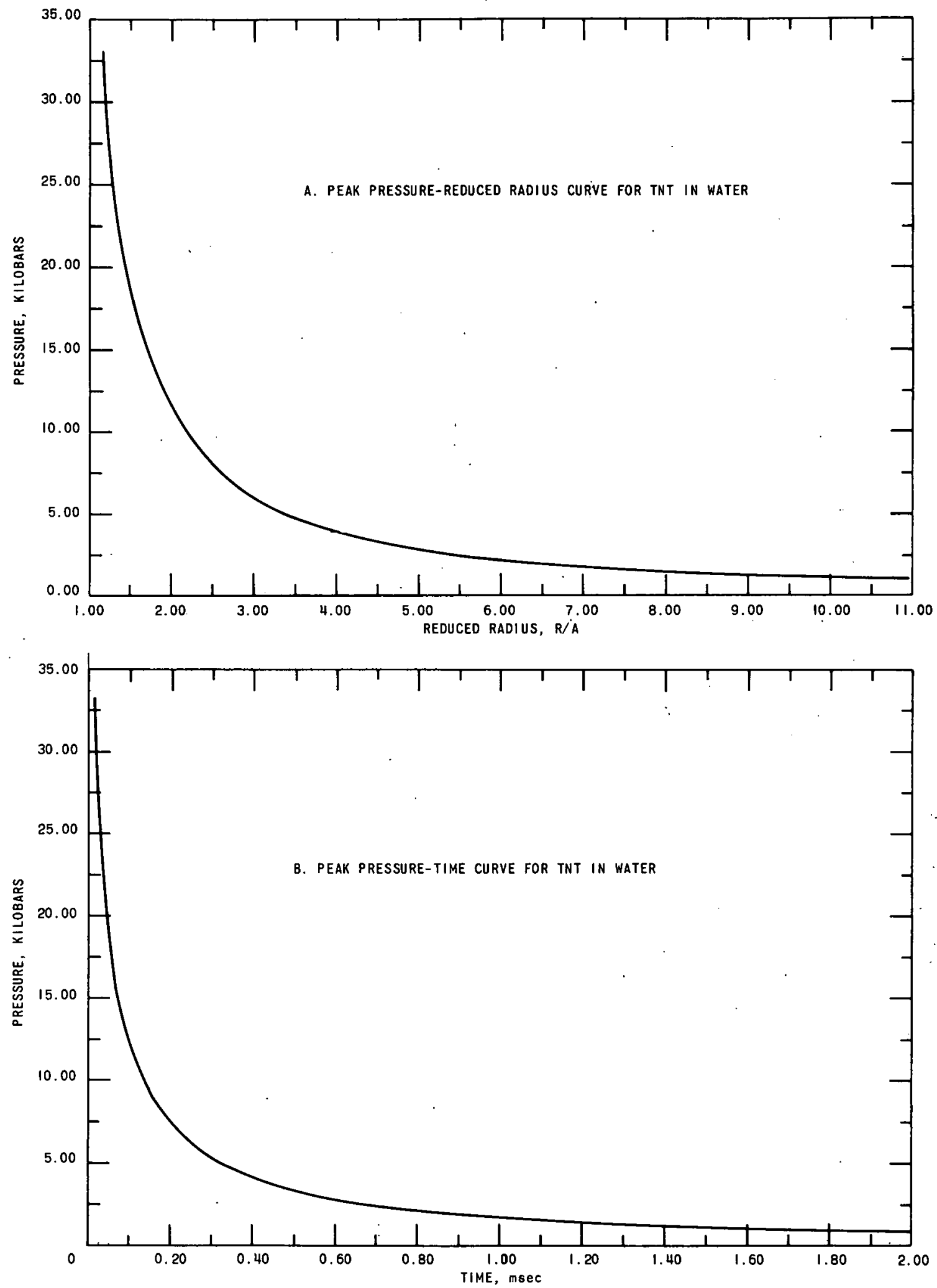

Fig. 8. Graphical Representation of the Computer Results for the Simulated Infinite Water Medium 


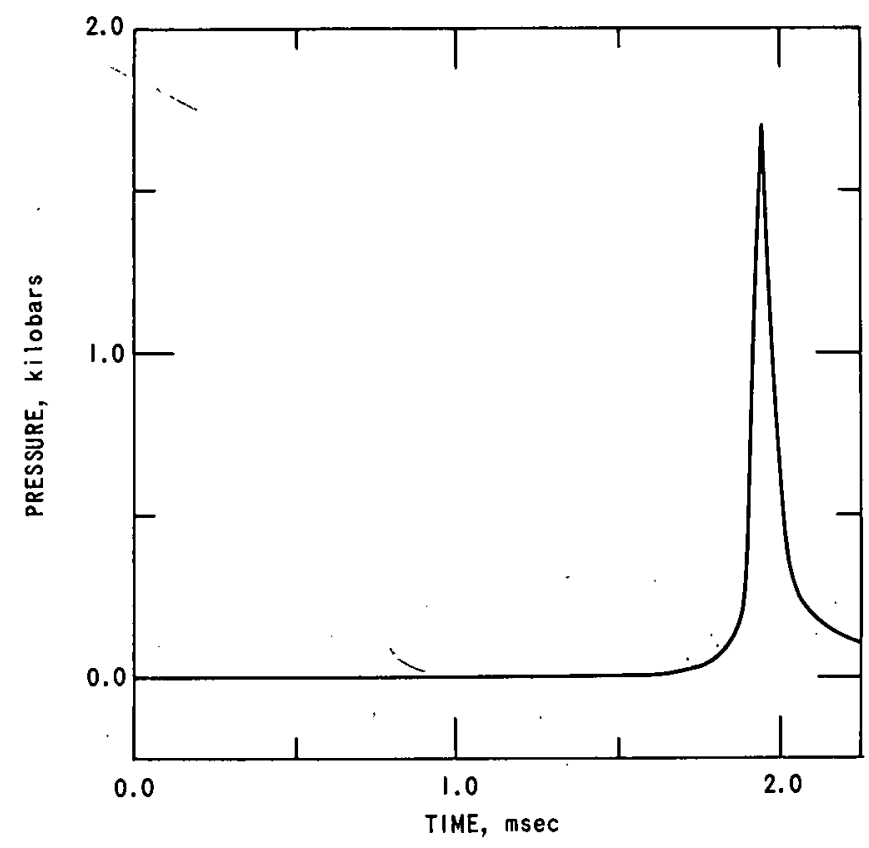

Fig. 9

Pressure-Time Curve for the Argon at the Water-Argon Interface

Fig. 10

Pressure-Time Curve for the TNT at the TNT-Water Interface

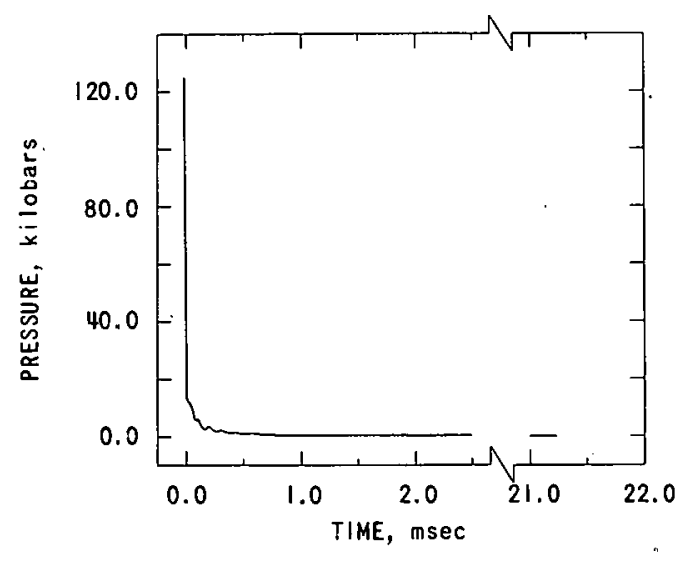




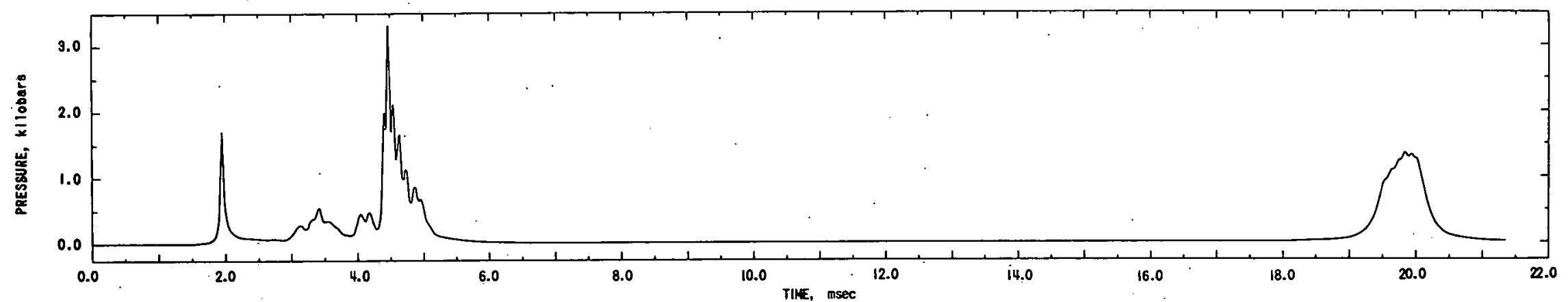

Fig. 11. Pressure-Time Curve for the Inside Face of the Concrete Vessel

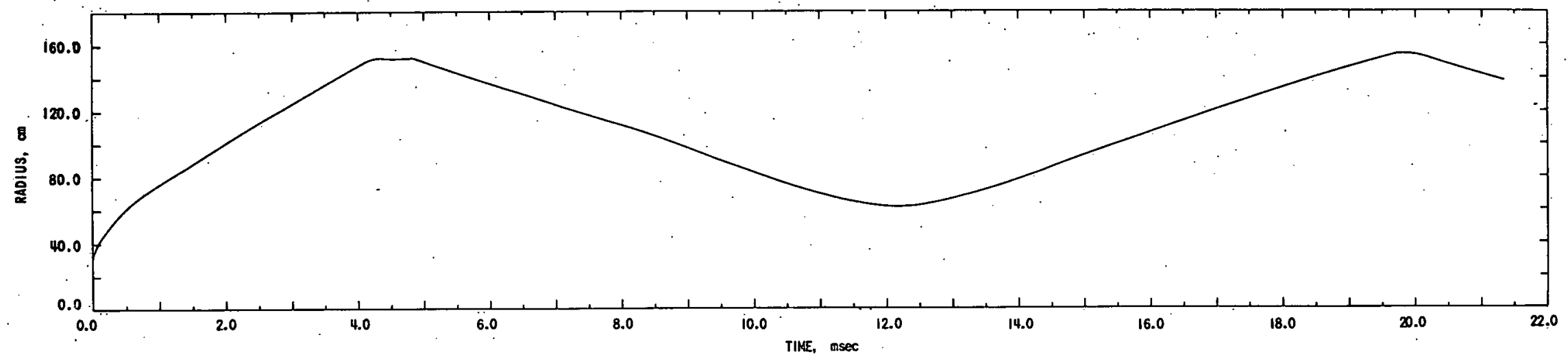

Fig. 12. Location-Time Curve for the TNT-Water Interface

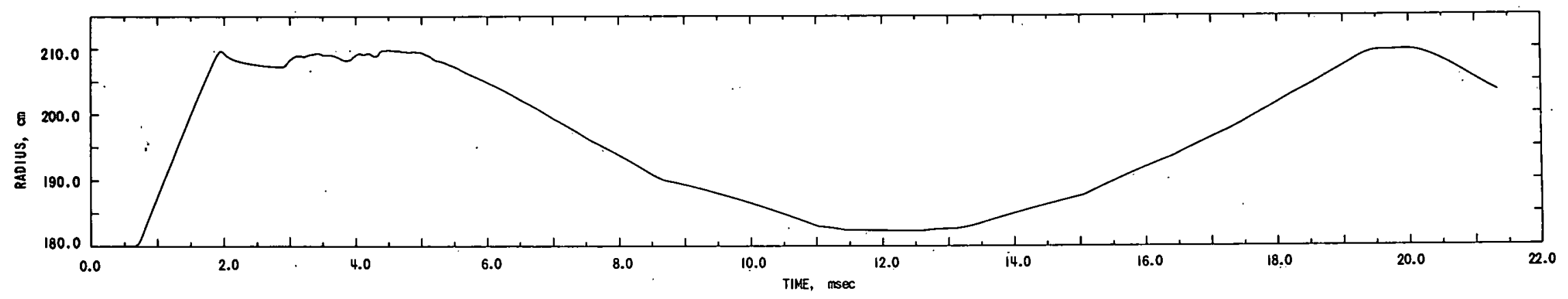

Fig. 13. Location-Time Curve for the Water-Argon: Interface 


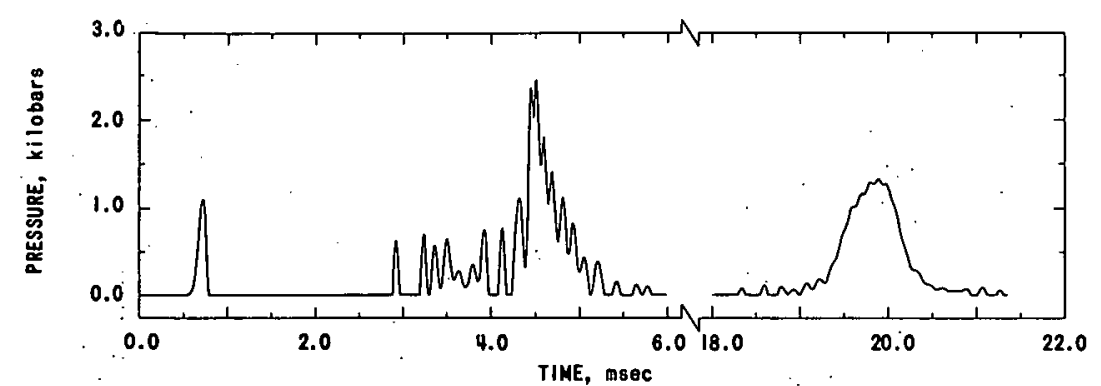

Fig. 14. Pressure-Time Curve for the Water at the Water-Argon Interface

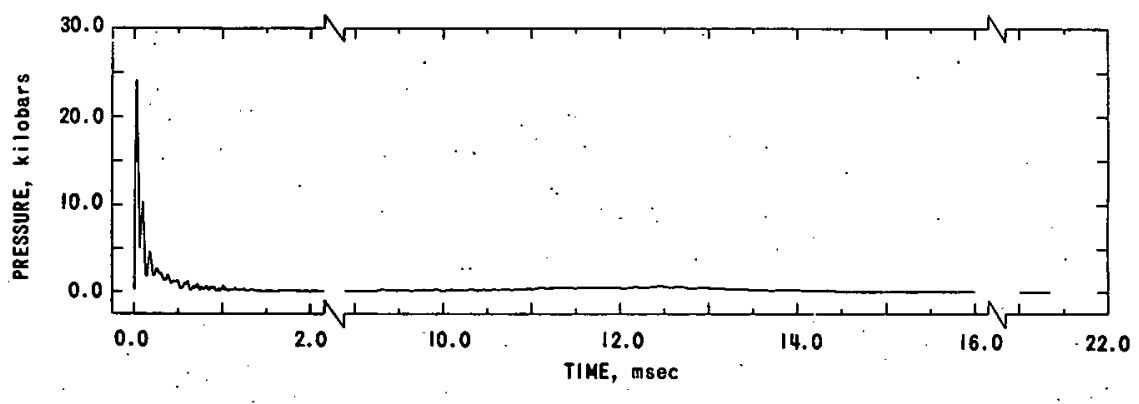

Fig. 15. Pressure-Time Curve for the Water at the TNT-Water Interface

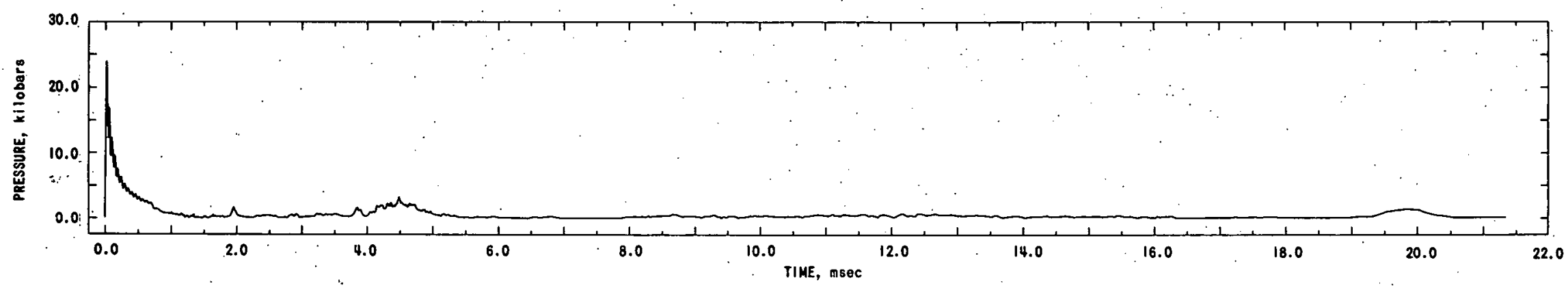

Fig. 16. Maximum Pressure in the System Outside of the Gas Bubble

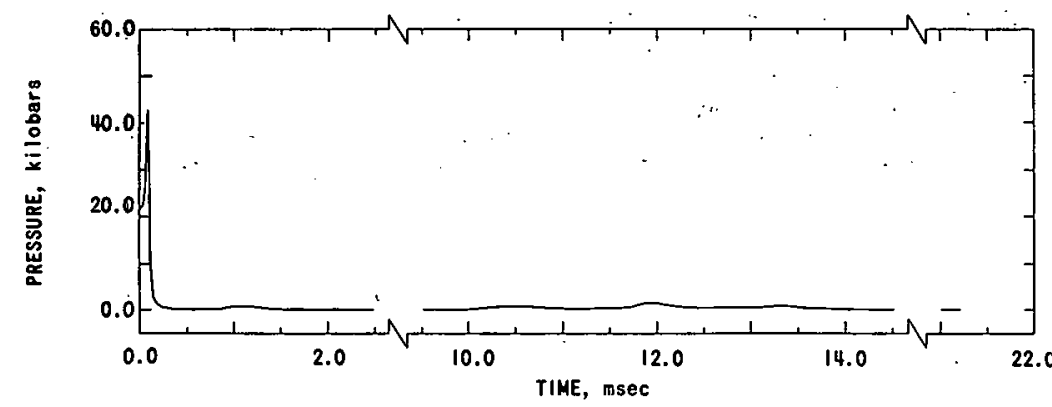

Fig. 17. Pressure-Time Curve for the Center of the Gas Bubble

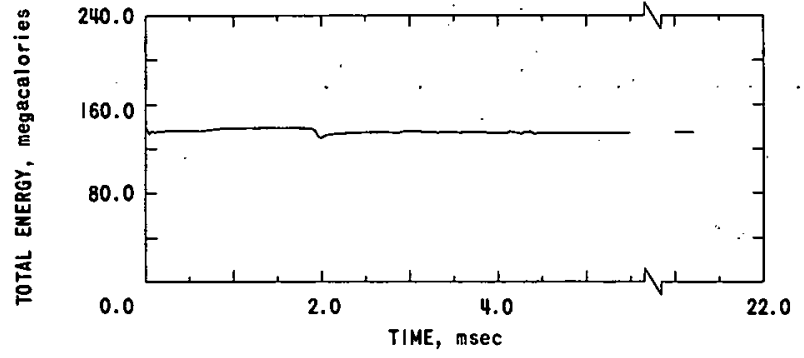

Fig. 18. Total Energy of the System as a Function of Time 


\section{DISCUSSION OF RESULTS}

A. Comparison of the Computer Results for the Simulated Infinite Water Medium with Experimental Measurements

To be useful, any new theoretical analysis should be verified experimentally. Experimental measurements of shock-wave pressures have been performed. However, the measurement of shock-wave pressures in the near proximity of the charge is prohibited by the very high pressures there.

One set of experimental data in connection with the KirkwoodBrinkley theory is presented in Table V. The Kirkwood-Brinkley theory was formulated on the basis of these experimental measurements. Peak pressures in the shock front at distances closer to the charge were then extrapolated by use of their formulation. The values of the peak pressure at various locations, which were calculated by the use of this theory, are given in Table $\mathrm{V}$ for reference. The value of the measured pressure given for 25 charge radii appears to be in error. By noticing that the trend of the difference between two successive values of the measured pressure is decreasing, a more appropriate value* for the peak pressure measured at 25 charge radii would be 5,440 psi. Therefore, the peak pressure at this location is not used for comparison.

TABLE V. Peak Pressure in the Spherical Shock Wave from TNT ${ }^{a}$

\begin{tabular}{|c|c|c|c|c|c|}
\hline \multirow{2}{*}{$\begin{array}{c}\text { Distance, } \\
\text { Charged Radii }\end{array}$} & \multicolumn{2}{|c|}{$\begin{array}{c}\text { Kirkwood-Brinkley } \\
\text { Theory } \\
\text { Peak Pressure } \\
\text { psi }\end{array}$} & \multirow{2}{*}{$\begin{array}{c}\text { Penney-Dasgupta } \\
\text { Theory } \\
\text { Peak Pressure, } \\
\text { psi } \\
\text { Calculated }\end{array}$} & \multirow{2}{*}{$\begin{array}{c}\text { Pseudoviscous } \\
\text { Method } \\
\text { Peak Pressure, } \\
\text { psi } \\
\text { Calculated }\end{array}$} & \multirow{2}{*}{$\begin{array}{c}\% \text { Difference for } \\
\text { Pseudoviscous } \\
\text { Method and } \\
\text { Measured } \\
\text { Pressure }\end{array}$} \\
\hline & Calculated & Measured & & & \\
\hline 1 & 460,000 & & 761,000 & $(1,512,000)$ & \\
\hline 2 & 167,000 & & 141,000 & 168,000 & \\
\hline 3 & 91,400 & & 67,000 & 87,130 & \\
\hline 5 & 42,800 & & 30,700 & 40,030 & \\
\hline 7 & 26,600 & & 19,600 & 25,020 & \\
\hline 10 & 16,400 & 16,250 & 12,600 & $15 ; 700$ & 3.5 \\
\hline 15 & 9,670 & 9,640 & 7,830 & 9,460 & 1.9 \\
\hline 20 & 6,720 & 6,720 & 5,690 & 6,640 & 1.2 \\
\hline 25 & 1,090 & 1,090 & 4,470 & $(5,530)$ & \\
\hline
\end{tabular}

${ }^{a}$ The pressures given in this table can be compared on the basis of the similarity principle (see Ref. 5).

b These data were obtained from Ref. 5, page 145, Table 4.2.

Values from the Penney-Dasgupta theory are also given in Table V for reference. These values, obtained by the use of the formula

$$
P_{m}(p s i)=103,000\left(\frac{a_{0}}{R}\right) e^{2 a_{0} / R},
$$

\footnotetext{
*Extrapolated by simple proportion.
} 
agreed closely to the values of the peak presisure in the shock front determined in their step-by-step solution over the range $a_{0}<R<6 a_{0}$.

The values of the peak pressure in the shock front given in Table V for the von Neumann-Richtmeyer pseudoviscous method* were evaluated on the basis of linear interpolation of the computer results given in Table III, except the values of the peak pressure for 1 and 25 charge radii. These two values were extrapolated by the use of the equation

$$
\begin{aligned}
P_{m} & =\exp \left[-102.82\left(\frac{a_{0}}{R}\right)^{6}+367.79\left(\frac{a_{0}}{R}\right)^{5}-504.75\left(\frac{a_{0}}{R}\right)^{4}+345.27\left(\frac{a_{0}}{R}\right)^{3}\right. \\
& \left.=129.58\left(\frac{a_{0}}{R}\right)^{2}+30.744\left(\frac{a_{0}}{R}\right)-2.0076\right],
\end{aligned}
$$

which is an analytic fit** to the data in columns 1 and 4 of Table III.

Another analytic fit was obtained for the data.in columns. 1 and 2 of Table III of the form

$$
\begin{aligned}
P_{m} & =\exp \left[0.0031079(\ln t)^{4}+0.10858(\ln t)^{3}+1.310(\ln t)^{2}\right. \\
& \quad+5.9200(\ln t)+6.6053] .
\end{aligned}
$$

Equations 61 and 62 are presented graphically in Figs. 8A and 8B, respectively. These two figures may be used together to predict, for a particular distance from the charge, the magnitude of the peak pressure in the shock front and the time at which this peak pressure will occur.

The maximum difference between the measured peak pressures and the peak pressures determined by the pseudoviscous method is $3.5 \%$. There is also very good agreement between the values calculated from the pseudoviscous method and the values calculated from the Kirkwood-Brinkley theory, except in the vicinity of the TNT boundary, where the value calculated by the Penney-Dasgupta theory is closer to the value calculated by the pseudoviscous method. In his book, Underwater Explosions, ${ }^{5}$ Cole states that the Penney-Dasgupta theory seems to be more reliable than the Kirkwood-Brinkley theory for calculations at distances within several charge radii and that the low peak pressures predicted by Penney and Dasgupta are attributed to the low energy release they assumed in the initial conditions $(800 \mathrm{cal} / \mathrm{gm}){ }^{\dagger}$

$*_{1 \mathrm{~kb}}=14,505 \mathrm{psi}$.

** See Appendix B for a description of the computer program.

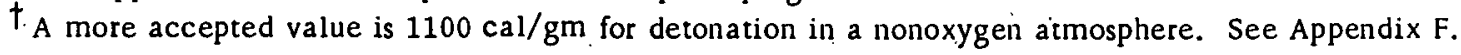


Penney* (1943) suggested that calculations of shock waves could profitably be made by using. step-by-step calculations out to a few charge radii to provide initial conditions for use of the Kirkwood-Brinkley propagation theory (or some alternative theory) at greater distances. This is precisely what is achieved by the pseudoviscous method alone.

The peak pressure transmitted to the water can only be compared in a qualitative sense. One set of data for comparison is given in Table VI. Since the peak pressure in the transmitted wave is directly related to the peak pressure in the detonation wave, the magnitude of the peak pressure in the transmitted wave obtained from the pseudoviscous method seems to be appropriate by comparison.

TABLE VI. Values of Various Hydrodynamical Parameters for TNT

\begin{tabular}{lccc}
\hline \multicolumn{1}{c}{ Parameter } & $\begin{array}{c}\text { Ref. 17, } \\
\text { Page 115 }\end{array}$ & $\begin{array}{c}\text { Pseudo- } \\
\text { viscous } \\
\text { Method }\end{array}$ & $\begin{array}{c}\text { \% Difference } \\
\text { on Basis } \\
\text { of Col. } 1\end{array}$ \\
\hline $\begin{array}{l}\text { Density of Packed TNT, } \\
\text { gm/cm }\end{array}$ & 1.60 & 1.51 & 5.6 \\
$\begin{array}{c}\text { Peak Pressure in Detonation } \\
\text { Wave, kb } \\
\text { Peak Pressure in Transmitted } \\
\text { Wave, kb }\end{array}$ & 190 & 150 & 21.0 \\
\hline
\end{tabular}

aObtained from Eq. 61 for $a_{0} / R=1$.

On the basis of the above comparisons, the results obtained by the pseudoviscous method for the simulated infinite water medium are acceptable.

B. Computer Results Obtained for the Simulated Sodium Reactor Installation

The computer results for the simulated sodium-reactor installation are presented graphically in Figs. 9-18. These figures show how the values of the pressure and the radial coordinate at several critical locations, which are a result of the destructive component, vary with time. However, the effect that the destructive component produces on the concrete containment structure can be determined completely from Figs. 9 and 11. The destructive component consists of the following three elements: (1) the shock wave, (2) the fluid momentum due to the passage of the shock wave, and (3) the gas bubble at high temperature and pressure pushing on the fluid. These components are described in the following paragraphs.

* See Ref. 5, page 141. 


\section{The Shock Wave}

The shock wave is the fastest element of the destructive component and would, therefore, reach the concrete structure first. However, as the shock wave propagates outward through the water, the magnitude of the peak pressure in the front is decreased by dissipation. The peak pressure in the front, when it passes through the zone in the water adjacent to the water-argon interface, is $1.109 \mathrm{~kb}$ and occurs at time $\mathrm{t}=718.5 \mu \mathrm{sec}$. As the shock wave encounters the water-argon interface, a wave of compression is transmitted into the argon, and a rarefaction wave is reflected back into the water. However, when a compressive wave is transmitted from a liquid to a gas, a large attenuation of the peak pressure in the shock front takes place. In this problem, the magnitude of the peak pressure in the shock front of the compressive wave transmitted to the argon is so small that the shock wave is considered to be completely attenuated upon its passage into the argon. This result can be verified in the following manner:

The time interval between the occurrence of the peak pressure in the shock front in two adjacent zones in the water near the water-argon interface is less than $65 \mu \mathrm{sec}$ (see Table III for values near $R=180$ ). The speed of sound in water is about four times the speed of sound in argon (both at standard conditions). In this problem, the widths of the argon zones in the finite-difference net are 1.5 times the widths of the water zones. If a shock wave of appreciable magnitude is transmitted into the argon, a noticeable increase in the pressure should result in the zone of argon adjacent to the water-argon interface. This noticeable increase in the pressure should start to occur at approximately $390 \mu \mathrm{sec}(65 \times 4 \times 1.5)$ later than when the maximum pressure occurs in the zone of water adjacent to water-argon interface $(718.5 \mu \mathrm{sec}$ as given above), i.e., at time $t=$ $1.1 \mathrm{msec}$. Figure 9 shows the pressure-time curve for the zone of argon adjacent to the water-argon interface, and no noticeable pressure increase is indicated at time $t=1.1 \mathrm{msec}$. In fact, the first visible increase in the pressure occurs at time $t>1.5 \mathrm{msec}$. The pressure peak at approximately $2.0 \mathrm{msec}$, seen in Fig. 9, is a result of the next element of the destructive component.

Therefore, it is concluded for this particular problem that the shock wave has been completely attenuated during its passage through the water and the argon. Thus, the concrete containment structure is not subjected to a shock wave.

\section{The Fluid Momentum due to the Passage of the Shock Wave}

The second element of the destructive component to be considered is the fluid momentum due to the passage of the shock wave. As the shock wave propagates outward into the undisturbed water, it.imparts 
an outward velocity to the water particles behind the shock front. When the shock front reaches the water-argon interface, a rarefaction wave is reflected back into the water, i.e., toward the center of the system. This rarefaction wave gives the water particles behind its front an additional outward velocity.

The passage of the rarefaction wave leaves the water in a very undesirable state as the outer water particles are moving outward faster than those closer to the center of the system. This causes the water particles to separate and, therefore, void spaces to occur in the fluid. (Assumption 5* was used to describe this state of the liquid.) This state continues in the water until the outer particles are slowed down by the pressure increase in the argon. This allows the lagging water particles to "catch up."

The effect of this fluid motion on the concrete containment structure can be interpreted from Fig. 11 , the pressure-time curve for the inside of the concrete vessel. The pressure peak that occurs at approximately $2.0 \mathrm{msec}$ is a result of the initial rapid outward motion of the water particles due to the rarefaction wave. The pressure peak at approximately $4.5 \mathrm{msec}$ is a result of the total outward flow of the fluid particles due to the passage of the shock wave and the rarefaction wave. As a result of this initial outward flow of the fluid, an impulse is produced on the concrete containment structure.

3. The Gas Bubble at High Temperature and Pressure Pushing on the Fluid

The slowest element of the destructive component is the gas bubble. In the production of an impulse on the concrete structure, the outward-flowing fluid particles are slowed down. As the pressure in the argon increases, all the fluid particles are given a velocity back toward the center of the sphere. This motion of the fluid particles causes the heretofore expanding sphere of hot gas to decrease in volume. The inward flow of the fluid particles continues until the pressure in the gas bubble increases to a point where it again reverses the direction of the fluid flow. This second outward motion of the fluid particles results in an additional impulse produced on the concrete structure. A third pressure peak, seen in Fig. 11 at approximately $20.0 \mathrm{msec}$, is a result of this second outward flow of the fluid and, in this case, is caused by the expanding gas bubble. Pulsations of the gas bubble would continue until a quasistatic state of internal pressure would result. The additional impulse on the concrete containment vessel due to each pulsation would decrease. The final effect of the gas bubble on the containment structure would be equivalent to a spherical pressure vessel under the action of a static internal pressure. Because of the cracking

* See page 35 . 
of the concrete, this idealized quasistatic condition would never be realized. The motion of the gas bubble interface is described in Fig. 12, and the motion of the water-argon interface is described in Fig. 13.

\section{Summary}

Since the shock wave is attenuated, the only remaining effect of the destructive component that the concrete containment vessel must resist is the impulse. The specific impulse per unit area of concrete at the inside surface is.given by

$$
I=\int_{t_{0}}^{t_{1}} P(t) d t
$$

where $P(t)$ is the pressure at the inside face of the concrete as a function: of time. The magnitude of this impulse is related to the area under the pressure-time curve for the inside face of the concrete vessel shown in Fig. 11. Since the magnitude of the impulse can be determined, we can calculate the maximum strain rate to which the high-strength steel strands embedded in the concrete will be subjected. Correlation between the impulse and the strain rate is given in Chapter V.

Figure 18 shows the total energy in the system as a function of time. Since the idealized reactor system analyzed in this study is a closed system, the total energy in the system should remain constant. Constancy of the energy is shown in this figure to the degree of accuracy of the finitedifference system; it indicates that this conservation law is satisfied in the finite-difference solution.

Figures 10 and $14-17$ are given for reference to show how the pressures at various critical locations vary with time. 


\section{STRAIN-RATE CALCULATIONS}

The assumption that the concrete containment vessel is infinitely rigid during the action of the impulse appears to be justified because of the short duration over which the major part of the impulse occurs, i.e., $20 \mathrm{msec}$ (see Fig. 11). It does not seem feasible that the huge concrete mass could respond in such a short time. Thus, the maximum strain rate that the steel strands would "see" can be calculated from the impulse obtained from Fig. 11. by

The linear impulse is related to the change in the linear momentum

$$
I=\int_{t_{0}}^{t_{1}} \sum F_{r} d t=m\left(v_{r}-v_{0}\right)
$$

Since force equals pressure times area, the impulse per unit area can be written

$$
I=\int_{t_{0}}^{t_{1}} P_{r}(t) d t=m\left(v_{r}-v_{0}\right),
$$

where the value of the integral is related. to the area under: the curve shown in Fig. 11. For the concrete mass initially at rest, i.e., $v_{0}=0$,

$$
I=m v_{r},
$$

where $I, m$, and $v_{r}$ are the impulse per unit area, mass per unit area, and radial velocity; respectively. The unit area. is taken as a unit area on the inside surface of the concrete vessel. By rearrangement of the terms in Eq. 66, the resulting radial velocity of the concrete mass is

$$
\mathrm{v}_{\mathbf{r}}=\frac{\mathrm{I}}{\mathrm{m}}
$$

The steel strands embedded in the concrete form circular hoops. The time rate of change of the circumference of any particular strand in terms of the time rate of change of the radius is given by

$$
\frac{d C}{d t}=2 \pi \frac{d r}{d t}
$$

where $C$ and. $r$ are the circumference and radius, respectively. 
Since $v_{r}=d r / d t$, the instantaneous change in the circumference is

$$
\mathrm{d} \dot{C}=2 \pi \frac{\mathrm{I}}{\mathrm{m}} \mathrm{dt}
$$

Strain., $\epsilon$, may be defined as the total change in length divided by the length over which the change occurred. In this case,

$$
\epsilon=\frac{\Delta \mathrm{C}}{\mathrm{C}_{0}}
$$

where $C_{0}$ is the original circumference of the steel strand. The instantaneous.time rate of change of the strain is given by

$$
\frac{d \epsilon}{d t}=\lim _{\Delta t \rightarrow 0} \frac{1}{C_{0}} \frac{\Delta C}{\Delta t}=\frac{1}{C_{0}} \frac{d C}{d t}
$$

Substituting Eq. 69 into Eq. 71 and simplifying, the strain rate for any steel strand is given by

$$
\dot{\epsilon}=\frac{\mathrm{I}}{\mathrm{m} \mathbf{x} \mathrm{r}_{0}}
$$

where $\ddot{\epsilon}$ represents the time derivative of strain and $r_{0}$ is the initial hoop radius of the steel strand.

For this problem, the values for the impulse per unit area* and mass per unit area** are

$$
I=2,607,150 \mathrm{gm}-\mathrm{cm} / \mathrm{sec} / \mathrm{cm}^{2}
$$

and

$$
\mathrm{m}=1007,59 \mathrm{gm} / \mathrm{cm}^{2}
$$

If $r_{0}$ is taken as the smallest possible value, i.e., $r_{0}=210 \mathrm{~cm}$, then, by neglecting the energy absorbed in cracking the concrete, the maximum possible strain rate to which any strand will be subjected is

$$
\dot{\epsilon}_{\max }=\frac{2,607,150}{1007.59 \times 210}=12.32 \mathrm{sec}^{-1}
$$

\footnotetext{
* See Appendix B.

** See Appendix E.
} 
Strain rates for metals can be categorized into four classes as shown in Table VII. (The conventional rate of strain for static testing is $10^{-3} \sec ^{-1}$.)

TABLE VII. Strain-rate Classification for Metalsa

\begin{tabular}{cl}
$\begin{array}{c}\text { Strain Rate, } \\
\sec ^{-1}\end{array}$ & \multicolumn{1}{c}{ Classification } \\
\hline$<10^{0}$ & Low rate of strain \\
$10^{0}-10^{3}$ & Moderate rate of strain \\
$10^{3}-10^{4}$ & High rate of strain \\
$>10^{4}$ & Very high rate of strain \\
\hline
\end{tabular}

a This table and the ensuing discussion is based upon information from Ref. 6, pp. 6.108-6.117.
The maximum strain rate for the strands determined in this analysis is $12.32 \mathrm{sec}^{-1}$. This is classified in the extreme lower range of moderate rate of strain. To our knowledge, no experimental tests have been performed on high-strength.steel strands at this strain rate. However, Klinger ${ }^{11}$ conducted low strain-rate experiments on the high-strength steel SAE 4340 in the range from the annealed condition. (119,000 psi) to a nominal ultimate strength of $220,000 \mathrm{psi}$. His results indicate that, in general, the strength properties increase.with increasing strain rate. Moreover, the strain-rate effect becomes markedly less as the strength level of the steel is increased. In fact, the 220,000-psi steels (same ultimate stress range as for the steel strands) showed either no change or a slight loss in strength $(<3 \%)$ with increasing strain rate. No significant effect on the total elongation at any strength level was noted. The range of strain rates for his tests was $10^{-5} \sec ^{-1}<\dot{\epsilon}<10^{1} \sec ^{-1}$.

Thus, the static properties of the steel strands could be used as a good approximation for the design of the concrete containment structure. However, experimental verification of the mechanical properties of the steel strands at the design strain rate would be warranted. 


\section{CONCLUSION}

In this study, we attempted ${ }^{1}$ to determine the effect that the destructive component produces on the concrete containment vessel so that the strain rate for the strands could.be calculated, and ${ }^{2}$ to obtain an insight as to how the destructive component changes with time. It is concluded that these objectives have been achieved. The pressure-time curve for the inside face of the concrete vessel, necessary for determining the strain rate to which the steel strands are subjected, was obtained by numerical integration of the differential equations using the von Neumann-Richtmeyer artificial-viscosity technique.

An important factor that influences the results of this problem is the thickness of the layer of inert gas. This gas layer is important because of its role in attenuating the shock wave. It is also effective in controlling the peak pressure at the inside face of the concrete by a buffering action. If the layer of inert gas is very thin, the effectiveness of the layer is reduced. Therefore, a relatively: thick layer of gas should be provided because it is essential that the shock wave be eliminated. If a strong shock wave is transmitted to the concrete, serious damage to the structure could occur before the energy-absorbing capability of the strands is developed.

The finite-difference solution was propagated outward in time until the pressure-time curve for the inside face of the concrete vessel (Fig. 11) exhibited the effect of a bubble pulsation. This noticeable effect occurred at about $20 \mathrm{msec}$. By comparison of the pressure peaks at 4.5 and $20 \mathrm{msec}$, it was concluded that the magnitudes of the pressure peaks of subsequent pulsations would be small. Therefore, the contribution to the total impulse from all subsequent pulsations was considered negligible. Thus, the computer solution was terminated.

In the process of achieving primary containment, the energy associated with the destructive component is absorbed by the stretching of the steel strands. For the required elongation of the strands to occur, the concrete must be allowed to break up. However, the concrete must not become rubble for its entire thickness as this would deter. the effectiveness of the energy-absorbing capability of the strands.

The Rice and Walsh equation of state for water, which was used in the analysis, is relatively simple in form, but requires a rather complicated computer sequence to obtain.the results. Except near the charge surface, the magnitude of the peak pressure in the shock front was found to be within the pressure range where the Tait equation of state* is applicable. As the Tait equation of state is simpler than the equation of state by Rice and Walsh, the computer time required for the solution could have been reduced by a combination of the se two equations of state.

\footnotetext{
* See Appendix D for the applicable pressure range.
} 
The pressures in the argon obtained in this analysis were above the range of experimental verification for the equation of state used for the argon. This makes the pressure-time curve for the inside face of the concrete somewhat questionable, as equations of state used for calculations outside the range of experimental verification may not yield reliable results. However, the results obtained indicate the range of pressures for which equations of states are required; i.e., $P>3500$ atm. The pressures in the argon could have been reduced.by using a.thicker layer of the gas, but this would have resulted in more computer time required for the solution.

It is readily apparent from this study that the von NeumannRichtmeyer artifical-viscosity technique offers a very effective method for solving hydrodynamic problems involving shock phenomena. This method offers: these features: ${ }^{3}$

1. No limiting physical as sumptions need be imposed on the differential equations to reduce them to ordinary equations or to make them more simply integrable; rather, one deals with the partial differential equations without similarity restrictions.

2. Shock waves are handled automatically, and no special computational technique is required if the problem contains multiple shocks or when shocks impinge on the origin; i.e., there are no floating boundary conditions to be satisfied separately.

3. The complexity of the computations is not seriously increased by allowing. for the computation of detailed equations of state from either tabular data or analytic fits:

4. The method is adaptable to large ranges in.time and space variables; i.e., expansions around singular points are nowhere necessary. 


\author{
PART T.WO \\ SOLUTION FOR THE IDEAL REACTOR \\ SYSTEM WITH A REACTOR VESSEL
}

\title{
VII. INTRODUCTION
}

The problem solved in Part One was for an ideal reactor system that did not include a reactor vessel. However, a reactor vessel is always a component of an integral reactor system.

Often the reactor-vessel material is Type $212 \mathrm{~B}$ carbon steel or Type 304 stainless steel (both ductile materials). As toughness (i.e., the material's ability to resist energy load up to fracture) is a function of the ductility of the material, the energy-absorbing capability of a reactor vessel made of either of these two materials is substantial.

The purpose of Part Two is to treat the problem of Part One with the reactor vessel included (see Fig. 19) in order to:

1. Determine the energy-absorbing capability of the reactor vessel.

2. Determine the net effect that the destructive component produces on the concrete containment structure so that the rate of strain for the steel strands can be calculated.

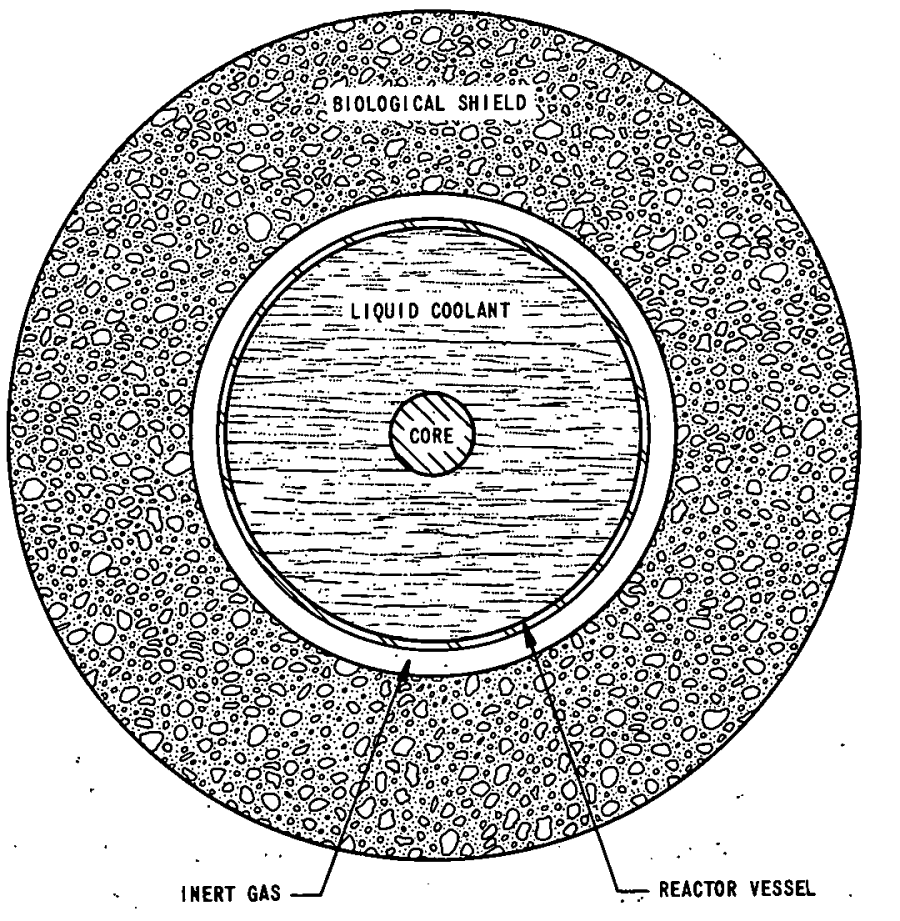

Fig. 19

Idealized Reactor System

The theory in Part One is applicable to Part Two except as noted. The results obtained for this problem will be compared to the results obtained for the problem in Part One. 


\section{SOLUTION OF A SAMPLE PROBLEM}

A. Problem Layout

The problem layout for this solution is given in Fig. 20. The reactor-vessel material is Type 304 stainless steel.

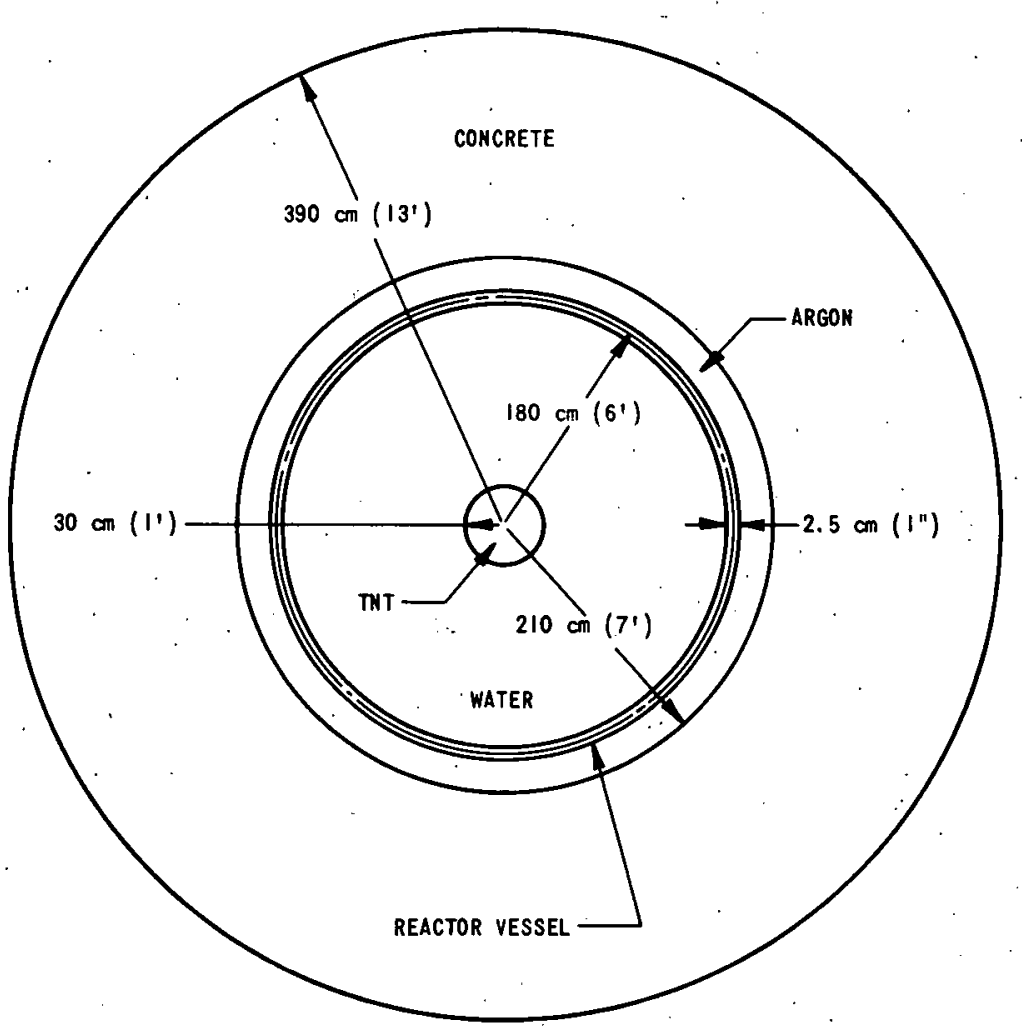

Fig. 20. Problem Layout and Dimensions

B. The Theory Associated with the Reactor Vessel*

The reactor vessel is considered to be a thin spherical shell under internal and external pressure and is analyzed by membrane theory. Thus, the stress in the shell is the same at all points, and the stress at any point is the same in all directions.

The energy-absorbing process of the reactor vessel is achieved by large plastic deformation; therefore the elastic behavior of the material is neglected. The material is categorized as a strain-hardening material; i.e., an increase in the stress is required for continued plastic deformation. Several empirical formulas (strain-hardening laws) have been proposed for fitting uniaxial true stress-strain curves. For Type 304 stainless steel, a very close fit for all pertinent portions of the true stress-strain curve is

*See Ref. 6, pp. 6.92-6.195 for more detailed information. 
provided by

$$
\ddot{\sigma}=\sigma_{0}(1+\lambda \epsilon) \text {, }
$$

where $\sigma$ is the true stress, $\epsilon$ is the effective strain, $\sigma_{0}$ is the initial yield stress, and $\lambda$ is a nondimensional hardening constant.

However, the reactor vessel is in a state of biaxial stress, not uniaxial stress. Therefore, Eq. 73 does not apply directly, but can be converted to a similar expression that applies to the biaxial state of stress by various yield criteria and flow rules. It is common practice to obtain the yield condition for biaxial states of stress from the familiar concept of the yield point under uniaxial stress. This can be accomplished by the use of the von Mises octahedral shear stress yield criterion,

$$
\tau_{\text {oct }}: \leq \sigma_{0} \text {, }
$$

where $\sigma_{0}$ is the current tensile yield stress. For biaxial states of stress, $\sigma_{3}$ is zero, and the yield criterion reduces to

$$
\left(\sigma_{1}^{2}-\sigma_{1} \sigma_{2}+\sigma_{3}^{2}\right)^{1 / 2} \leq \sigma_{0} \text {. }
$$

For the reactor vessel, where $\sigma_{1}=\sigma_{2}=\sigma$, the yield criterion reduces to

$$
\sigma \leq \sigma_{0} \text { : }
$$

Equation 76 gives the result that the yield stress for the spherical shell is identical to the yield stress for simple tension; i.e.,

$$
\sigma_{0_{\text {biaxial }}}=\sigma_{0_{\text {uniaxial }}}
$$

The effective strain, $\epsilon$, for biaxial states of stress can be obtained for a von Mises material from the relationship

$$
\epsilon=\frac{2}{3^{1 / 2}}\left(\epsilon_{1}^{2}+\epsilon_{1} \epsilon_{2}+\epsilon_{2}^{2}\right)^{1 / 2}
$$

which was obtained from the flow rule and where $\epsilon_{1}$ and $\epsilon_{2}$ are the strains in the two orthogonal directions. For the reactor vessel, where $\epsilon_{1}=\epsilon_{2}=\epsilon_{\mathrm{c}}$, the effective strain becomes

$$
\epsilon=2 \epsilon_{c},
$$

where $\epsilon_{c}$ is the circumferential strain in the spherical shell. 
Thus, the true stress-strain relationship for the biaxial state of stress for the spherical reactor vessel is obtained by substituting Eqs. 77 and 79 into Eq: 73. This relationship is

$$
\sigma=\sigma_{0}\left(1+2 \lambda \epsilon_{c}\right)
$$

where

$$
\begin{aligned}
& \sigma=\text { true stress in the shell, } \\
& \sigma_{0}=\text { yield stress for the material in simple tension, } \\
& \lambda=\text { strain-hardening constant, }
\end{aligned}
$$

and

$$
\epsilon_{\mathrm{c}}=\text { circumferential strain in the shell. }
$$

The treatment of the reactor vessel in the solution of the problem is somewhat complex. To solve the problem directly by the von NeumannRichtmeyer technique, an equation of state for the reactor vessel material is needed. An equation of state for the material under biaxial tension is not available. Therefore, the spherical shell is considered as an interface of finite thickness with a velocity obtained from an equation of motion different from Eq. 42. After the reactor vessel attains a certain specified limiting circumferential strain, the vessel is assumed to disintegrate instantaneously. From this point, the solution is propagated with the equations used in Part One.

The equation of motion for a thin spherical shell under an internal pressure where the motion is resisted by the stress in the shell is

$$
\frac{\mathrm{du}}{\mathrm{dt}}=\frac{\mathrm{l}}{\rho \mathrm{rh}}(\operatorname{Pr}-2 \sigma \mathrm{h}) \text {, }
$$

where

$$
\begin{aligned}
& u=\text { the velocity of the shell, } \\
& \rho=\text { density of the shell, } \\
& \mathrm{h}=\text { thickness of the shell, } \\
& \mathrm{r}=\text { radius of the shell, } \\
& P=\text { internal pressure on the shell, }
\end{aligned}
$$

and

$\sigma=$ stress in the shell. 
As plastic deformation is assumed to produce no volume change of the solid material in the shell, the density of the material remains constant. Consequently, the thickness of the shell can be determined for any position of the shell by the expression

$$
h=\left(\frac{r_{0}}{r}\right)^{2} h_{0},
$$

where

$$
\begin{aligned}
& \mathrm{h}_{0}=\text { initial thickness of the shell, } \\
& \mathrm{r}_{0}=\text { initial radius of the shell, } \\
& \mathrm{r}=\text { current radius of the shell, }
\end{aligned}
$$

and

$\mathrm{h}=$ current thickness of the shell.

A step-by-step numerical solution is to be obtained. Thus, Eq. 81 , in incremental form, becomes

$$
\frac{\Delta \mathrm{u}}{\Delta \mathrm{t}}=-\frac{1}{\rho \mathrm{rh}}[\mathrm{r}(\Delta \mathrm{P})+2 \sigma \mathrm{h}]
$$

where $\Delta P$ is the resultant between the pressure outside the shell, $P_{0}$, and the pressure inside the shell, $P_{i}$; i.e.,

$$
\Delta P=P_{0}-P_{i}
$$

The energy associated with the reactor vessel is obtained by the use of the work-energy principle,

$$
\Delta \mathrm{U}=\Delta \mathrm{E}
$$

where $\Delta U$ is the net work done on the system by all the external active forces, and $\triangle \mathrm{E}$ is the total change in the energy. For the thin spherical shell (reactor vessel), the work-energy principle can be written in incremental form as

$$
\Delta E=-4 \pi r^{2}(\Delta P)(\Delta r)
$$

where $r$ is the radius of the shell and $\Delta r$ is the incremental change in the radius. 
C. Finite-difference Equations

The finite-difference equations associated with the reactor vessel are as follows:

$$
\begin{aligned}
& \Delta P=P(j, t)-P(j-1, t), \\
& \epsilon_{c}=[R(j, t)-R(j, 0)] / R(j, 0), \\
& \sigma=\sigma_{0}\left(1+2 \lambda \epsilon_{c}\right), \\
& h=h_{0}[R(j, 0) / R(j, t)]^{2}, \\
& u(j, t+1)=u(j, t)-\frac{\Delta t}{\rho h[R(j, t)]}\{\Delta P[R(j, t)]+2 \sigma h\},
\end{aligned}
$$

and

$$
\Delta E=-4 \pi[R(j, t)]^{2}(\Delta P)[R(j, t+1)-R(j, t)] .
$$

The indexed terms given in Eqs. 87-92 are referenced to Fig. 5 and are applicable only for the value $j=J W$, which is the index of the reactor vessel (or water-argon interface).

D. Initial Values

The reactor vessel is made of Type 304 stainless steel. The mechanical properties of a materialdepend upon the strain rate to which the material is subjected. It is required to know the appropriate dynamic tensile properties of the stainless steel. However, since the dynamic properties of Type 304 stainless steel are not adequately known, the static tensile properties are used as a first approximation.

In general,* for austenitic stainless steels, the dynamic ultimate tensile strengths remain the same as static ultimate tensile strengths; the total elongation decreases slightly and the yield stress increases considerably with increasing strain rate. Thus, as toughness is related to the area under the stress-strain curve, the use of the static properties is a conservative approximation.

The static tensile properties for Type 304 stainless steel used in this sample problem are as follows:** 
Ultimate true stress $=149,000$ psi,

Ultimate true strain $=0.548 \mathrm{in} . / \mathrm{in}$.

Yield stress $=40,400$ psi,

and

Hardening constant $=4.9$.

The complete list of initial values for the reactor vessel is as follows:

Maximum allowable circumferential strain, $\epsilon_{\mathrm{c}_{\max }}=15 \%$;

Yield stress, $\sigma_{0}=2.78 \times 10^{9}$ dynes $/ \mathrm{cm}^{2}$;

Hardening constant, $\lambda=4.9$;

Initial shell radius, $R(j, 0)=180.0 \mathrm{~cm}$;

Initial shell thickness, $h_{0}=2.5 \mathrm{~cm}$;

and

Shell material density, $\rho=7.85 \mathrm{gm} / \mathrm{cm}^{3}$.

The input data and the initial conditions are listed in Tables VIII and IX, respectively. 
TABLE VIII. Input Data for the Finite-difference Solution

$\begin{array}{cccccccc}\text { JA } & \text { JW } & \text { JMAX } & \text { TMAX(SEC) } & \text { EPS } & \text { EPS1 } & \text { EP } & \text { DELT(SEC) } \\ 13 & 28 & 30 & 0.1000000 & 100000.0 & 0.00001 & 0.00005 & 0.0000005\end{array}$

RRO

LAMROA

$1.800000+002 \quad 4.900000+000$
SIGMAO

$2.780000+009$
HZERO

$2.500000+000$
RHO

$7.8500 n n+000$
ECIRCALL

$1.500000-001$
$J$

CM

$$
2
$$

3
$0.000000+000$ $3.000000 \div 000$ $6.000000+000$ $9.000000+000$ $1.200000 \div 001$ $1.500000+001$ $1.800000+001$ $2.100000+001$ $2.400000+001$ $2,700000+001$ $2.800000+001$ $2.900000+001$ $3.000000+001$ $4.000000+001$ 5. $000000+001$ $6.000000+001$ $7,000000 \div 001$ $8.000000+001$ $9.000000+001$ $1.000000+002$ $1.100000+002$ $1.200000+002$ $1.300000+002$ $1.400000+002$ $1.500000 \div 002$ $1.600000+002$ $1.700000+002$ $1.800000+002$ $1.950000+002$ $2.100000+002$

\section{$\stackrel{U}{C M}$ SEC}

$0.000000+000$ $0.000000+000$ $0.000000+000$ $0.000000+000$ $0.000000+000$ 5. $000300+003$ 1. $400000+004$ $2.520000+004$ $4.160000+004$ $6.840000+004$ 8. 280000+004 1. $044000+005$ $1.546500+005$ $0.000000+000$ $0.000000 * 000$ $0.000000+000$ $0.000000+000$ $0.000000+000$ 0. $000000+000$ $0.000300+000$ D. $000000+000$ $0.000000+000$ $0.000000+000$ $0.000000+000$ $0.000000+000$ $0.000000+000$ $0.000000+000$ $0.000000+000$ $0.000000+000$ $0.000000+000$

\section{CUB $\quad V M / G M$}

$8.110000-001$

$8.110000=001$

8.110000-001

$8.1100 \cap 0=001$

$8.045000=001$

$7.813000 \div 001$

$7.519000=001$

$7.158000=001$

$6.70>000=001$

$6.270000=001$

$5.9350 \cap 0=001$

$5.405000-001$

$1.001800+000$

$1.001800+000$

$1.001800+000$

$1.001800+000$

$1.001800+000$

$1.001800+000$

$1.001800+000$

$1.001800+000$

$1.001800+000$

$1.001800+000$

$1.001800+000$

$1.001800+000$

$1.001800+000$

$1.001800+000$

$1.0018 \cap 0+000$

$5.915974+002$

$5.915974+002$

$0.0000 \cap 0+000$

$\begin{array}{lc} & 0 \\ \text { OYNES/SO CM } & \text { DYNE }=C M / G M \\ 0.000000+000 & 0.00000 n+000 \\ 0.000000+000 & 0.00000 n+000 \\ 0.000000+000 & 0.00000 n+000 \\ 0.000000+000 & 0.00000 n+000 \\ 0.000000+000 & 0.00000 n+000 \\ 0.000000+000 & 0.00000 n+000 \\ 0.000000+000 & 0.00000 n+000 \\ 0,000000+000 & 0.00000 n+000 \\ 0.000000+000 & 0.00000 n+000 \\ 0.000000+000 & 0.00000 n+000 \\ 0.000000+000 & 0.00000 n+000 \\ 0.000000+000 & 0.00000 n+000 \\ 0.000000+000 & -1.01502 n+006 \\ 0.0000 .00+000 & -1.01502 n+006 \\ 0.000000+000 & -1.01502 n+006 \\ 0.000000+000 & -1.01502 n+006 \\ 0.000000+000 & -1.01 E 02 n+006 \\ 0.000000+000 & -1.01502 n+006 \\ 0.000000+000 & -1.01502 n+006 \\ 0.000000+000 & -1.01502 n+006 \\ 0.000000+000 & =1.01502 n+006 \\ 0.000000+000 & -1.01502 n+006 \\ 0.000000+000 & -1.01502 n+006 \\ 0.000000+000 & -1.01502 n+006 \\ 0.000000+000 & -1.01502 n+006 \\ 0.000000+000 & -1.01502 n+006 \\ 0.000000+000 & -1.01502 n+006 \\ 0.000000+000 & 9.03476 n+008 \\ 0.000000+000 & 9.03476 n+008 \\ 0.000000+000 & 0.00000 n+000\end{array}$

\section{DYNFS/SO T.M}

$2.190000+010$ 2. $190000+110$ $2.190000+n 10$ $2.190000+010$ $2.33 n 000+110$ $2.610000+010$ $3.090000+010$ $4.00 \cap 000+010$ $5.30 \cap 000+010$ $7.200000+010$ $9.200000+110$ $1.245000+011$ $1.0132 .74+006$ 1. $013274+006$ $1.013274+006$ $1.013274+0.06$ $1.01 \times 274+006$ $1.01,3274+006$ $1.013274+006$ $1.013274+006$ $1.013274+006$ $1.013274+0 \cap 6$ $1.013274+006$ 1. $01 \times 274+106$ 1. $01,3274+0 n 6$ $1.01 .3274+006$ $1.01 .3274+1 \cap 6$ $1.013274+006$ $1.01,3274+0 \cap 06$ $0.00 \cap 000+100$ 
TABLE IX. Initial Values of the Parameters Required for the Finite-difference Solution

\begin{tabular}{|c|c|c|c|c|c|c|c|}
\hline$\stackrel{\top}{S E C}$ & $\begin{array}{l}\text { DELT } \\
\text { SEC }\end{array}$ & $\begin{array}{c}\text { ETOT } \\
\text { DYNE-CM }\end{array}$ & $\begin{array}{c}\text { EK } \\
\text { OYNE-CM }\end{array}$ & $\begin{array}{c}E ! N T \\
\text { EYNE=CM }\end{array}$ & $\begin{array}{c}\text { ETNT } \\
\text { DYNE }=C H\end{array}$ & $\begin{array}{l}\text { ETVES } \\
\text { DYNE=CM }\end{array}$ & $\begin{array}{l}\text { ENERGY } \\
\text { DYNE=CM }\end{array}$ \\
\hline 0000000 & 0.0000005 & $5.2770278+015$ & $3.6296949+014$ & $4.9 .140583+015$ & $5.2797292+01.5$ & $000000000+000$ & $5.2770278 * 015$ \\
\hline
\end{tabular}

RR

CM

$\begin{array}{ll}0.000000+000 & 0.000000+000 \\ 3.000000+000 & 0.000000+000 \\ 6.000000+000 & 0.000000+000 \\ 9.000000+000 & 0.000000+000 \\ 1.200000+001 & 0.000000+000 \\ 1.500000+001 & 5.000000+003 \\ 1.800000+001 & 1.400000+004 \\ 2.100000+001 & 2.520000+004 \\ 2.400000+001 & 4.160000+004 \\ 2.700000+001 & 6.840000+004 \\ 2.800000+001 & 8.280000+004 \\ 2.900000+001 & 1.044000+005 \\ 3.000000+001 & 1.546500+005 \\ 4.000000+001 & 0.000000+000 \\ 5.000000+001 & 0.000000+000 \\ 6.000000+001 & 0.000000+000 \\ 7.000000+001 & 0.000000+000 \\ 8.000000+001 & 0.000000+000 \\ 9.000000+001 & 0.000000+000 \\ 1.000000+002 & 0.000000+000 \\ 1.100000+002 & 0.000000+000 \\ 1.200000+002 & 0.000000+000 \\ 1.300000+002 & 0.000000+000 \\ 1.400000+002 & 0.000000+000 \\ 1.500000+002 & 0.000000+000 \\ 1.600000+002 & 0.000000+000 \\ 1.700000+002 & 0.000000+000 \\ 1.800000+002 & 0.000000+000 \\ 1.950000+002 & 0.000000+000 \\ 2.100000+002 & 0.000000+000\end{array}$
CU8 CM/GM

$8.110 \overline{0} 00=0 \mathrm{O} 1$

$8,110000=001$

$8.110000=001$

$8.045000=001$

$7.813010=001$

$7.519000-001$

7.1580 ? $0=001$

$6.702000=001$

$6.270000=001$

5.935000 .001

$5.405000=001$

$1.0018 \cap 0+000$

$1.001800+000$

$1.001800+000$

$1.00 \overline{1} 800+000$

$1.001800+000$

$1.001800+000$

$1.001800+000$

$1.001800+000$

$1.001800+000$

$1.001810+000$

$1.009800+000$

$1.001800+000$

$1.0018 \cap 0+000$

$1.0018 \cap 0+000$

$1.0018 \cap 0+000$

$5.915974+002$

$5.915974+002$

$0.000000+000$

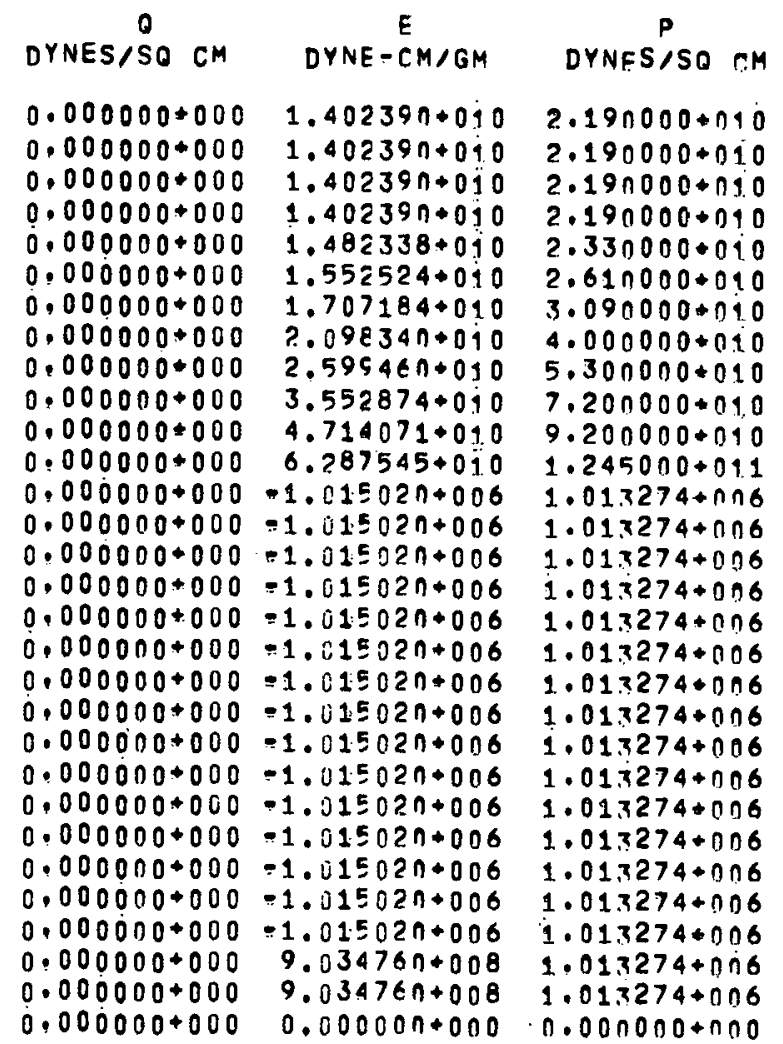

$R$
$C M$

DTTEST

SEC

$0.000000+000$

$3.218904 \div 000$

6.437807 .000

0.656711 .000

$1.287561+009$

$1.611564+001$

$1.043050+0$ की

$2.283341+001$

$2.634774+009$

$3.001799+001$

$3.13 n 328+001$.

$3.264432+001$

$3.409285+001$

$4.247438+009$

$5.16 ? 988+071$

$6.114709+001$

$7.084864+001$

$0.065232+009$

9. ก5 $1665+0$ กิ

1. $04191+042$

$1.10 .3468+0142$

$1.202916+002$

$1.30 ? 486+002$

1.402144 .002

$1.501868+002$

1.601642000

$1.601642+002$

$1.701455+002$
$1.801298+062$

$1.801298+062$
$1.801573+002$

$1.801 .894+012$
5.000000 .007

$5.000000=007$

$5.000000=007$

5.000000 .007

$5.000000=007$

$5.000000=007$

5.000000 .007

$5.000000=007$

$5.000000=007$

$5.000000-007$

$5.000000=007$

1.000000 .005

$1.000000=005$

$1.000000=005$

$1.000000-005$

$1.000000=005$

$1.000000=005$

$1.000000=005$

$1.000000=005$

$1.000000-005$

$.000000=005$

$1.000000=005$

$1.000000-005$

$1.000000-005$

$1.000000=004$

1.000000 .004

$0.000000+000$ 
E. FORTRAN Names and Their Description

FORTRAN Name

1. RRO

2. XLAMBDA

3. SIGMAO

4. HZERO

5. RHO

6. ECIRCALL

7. DELP

8. ECIRC

9. SIGMA

10. $\mathrm{H}$

11. ETVES, ETVESCAL

12. ЕTOT, ETOTAL

13. ENERGY, ENERCAL
Description

Initial radius of reactor vessel.

Hardening constant

Yield stress of reactor vessel

Initial thickness of reactor vessel

Density of reactor vessel material

Allowable circumferential strain

Resultant pressure on reactor vessel

Circumferential strain

True stress in reactor vessel

Thickness of reactor vessel

Energy associated with reactor vessel

Energy associated with fluid

Total energy of system

F. Changes in Computer Program

The computer program used for this solution is the program used in Part One with the following changes:

1. The Tait form of the equation of state* for water has been incorporated.

2. The equations associated with the reactor vessel have been incorporated.

3. The program has been revised to obtain all the output on magnetic tape.

4. The program has been refined to conserve computer time.

5. At the termination of the computer solution, the latest calculated values of all the parameters are punched on cards. These cards then become the input for the continuation program if the use of the continuation program becomes necessary.

*See Appendix D. 
G. FORTRAN IV Computer Statements

PROGRAM HCSTNT

COMMON AR1, AR2, AR3, ARA, IFSH,PP, US, UP, VH,ENTHH,XI,ENTH,EE,V,J,EP,KL 1,KLL

DIMENSION $P(50,2), V(50,2), E(50,2), 0(50,2), U(50,2), R R(50,2), T E M(50)$ 1.R $(50)$, DELRU $(50)$, DELRO $(50), S O S(50)$, DTTEST $(50), V O L(50), V O L 1(50)$, 2VOL2(50)

WRITE (39.3000)

C READ AND PRINT INPUT DATA. READ1200,JA, JH, JMAX,TMAX,EPS, EPS.1, EP, DELT WRITE (39,1201), JA, JW, JMAX, TMAX, EPS, EPS1, EP, DEL.T READ 4000, RRO, XLAMBDA,SIGMAO,HZERO,RHO, ECIRCALL WRITE (39,4001),RRO, XLAMBDA, SIGMAO,HZERO,RHO, ECIRCALL READ $1100,(R R(J, 1), U(J, 1), P(J, 1), V(J, 1), E(J, 1), 0(J, 1), J=1, J M A X)$ WRITE (39.1102)

WRITE(39,1103), (J,RR(J,1),U(J,1),V.(J,1), Q(J,1),E(J,1),P(J,1), $1 J=1, J M A X)$

$J A M=J A-1$

$J W M=J W-1$

JMAXM $=$ JMAX -1

$R(1)=0$.

$T=0$.

I. $\quad=1$

I $\operatorname{COUNT}=1$

$140=1$

ASSIGN 740 TO IS6

ASSIGN 510 TO IS7

ISB $=1$

PLAST $=0$.

$P X=0$.

$K K=J A$

$K L=1$

$K L L=1$

CALCULATE THE TEMPERATURE AND THE INTERNAL ENERGY FOR :EACH ZONE IN THE TNT PRODUCTS AT TIME T OO. THE TEMPERATURE, FOR A GIVEN PRESSURE AND VOLUME, IS OBTAINED FROM THE EQUATION OF STATE. THE INTERNAL ENERGY IS A FUNCTION OF THE TEMPERATURE AND PRESSURE.

DO $150 \mathrm{~J}=1$. JAM

TEM $(J)=(P(J, 1) *(V(J, 1)=.648986-P(J, 1) *(-.271149 E-11+.619876 E-23 * P$ $1(J, 1))) / .521766 E 7$

$E(J, 1)=.161355 E 8 * T E M(J)-.137566 E 10+P(J, 1) * * 2 *(.135575 E-11-.413251$

$1 E-23 \oplus P(J, 1))$

DO $151 J=J A, J W M$

$151 T \cdot E M(J)=293$.

DO $152 \mathrm{~J}=\mathrm{JW} . \mathrm{JMAXM}$

152 TEM $(J)=288$

DO $165 \mathrm{~J}=1$, JMAXM

$165 \operatorname{VOL}(J)=(R R(J+1,1)-R R(J, 1)) *(R R(J+1,1) \neq 2+R R(J+1,1) * R R(J, 1)+$ $1 R R(J, 1) *+2)$

C

c

CALCULATE THE TOTAL KINETIC ENERGY OF: THE SYSTEM AT TIME $Y=0$. THIS KINETIC ENERGY IS DUE ONLY TO THE MOTION OF. THE EXPLOSION PRODUCTS AS THE OTHER FLUIDS IN THE SYSTEM ARE AT REST.

EK $=0$.

DO $160 \mathrm{~J}=1$, JAM

VEL $=(U(J+1,1)+U(J, 1)) \star * 2$ 


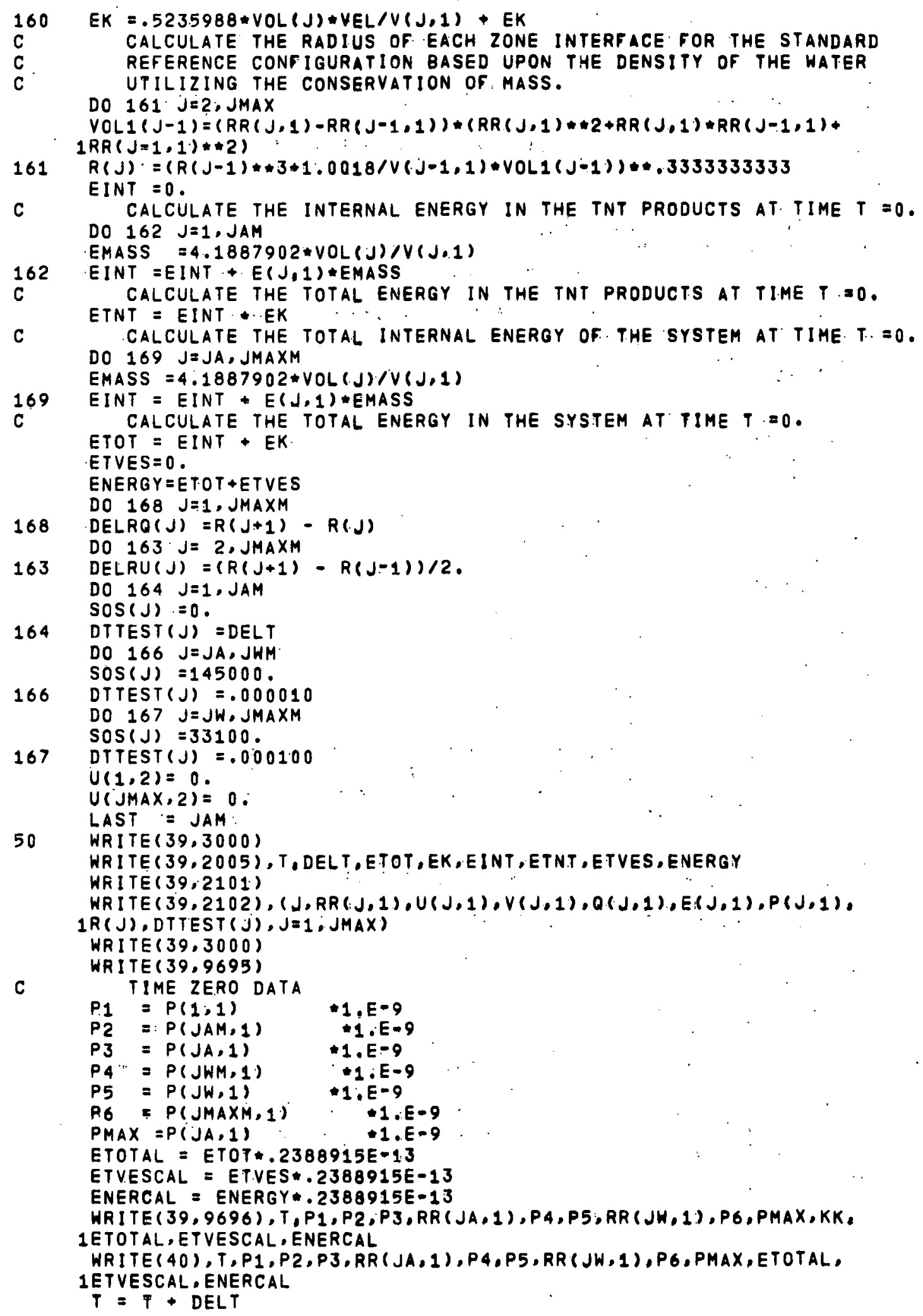




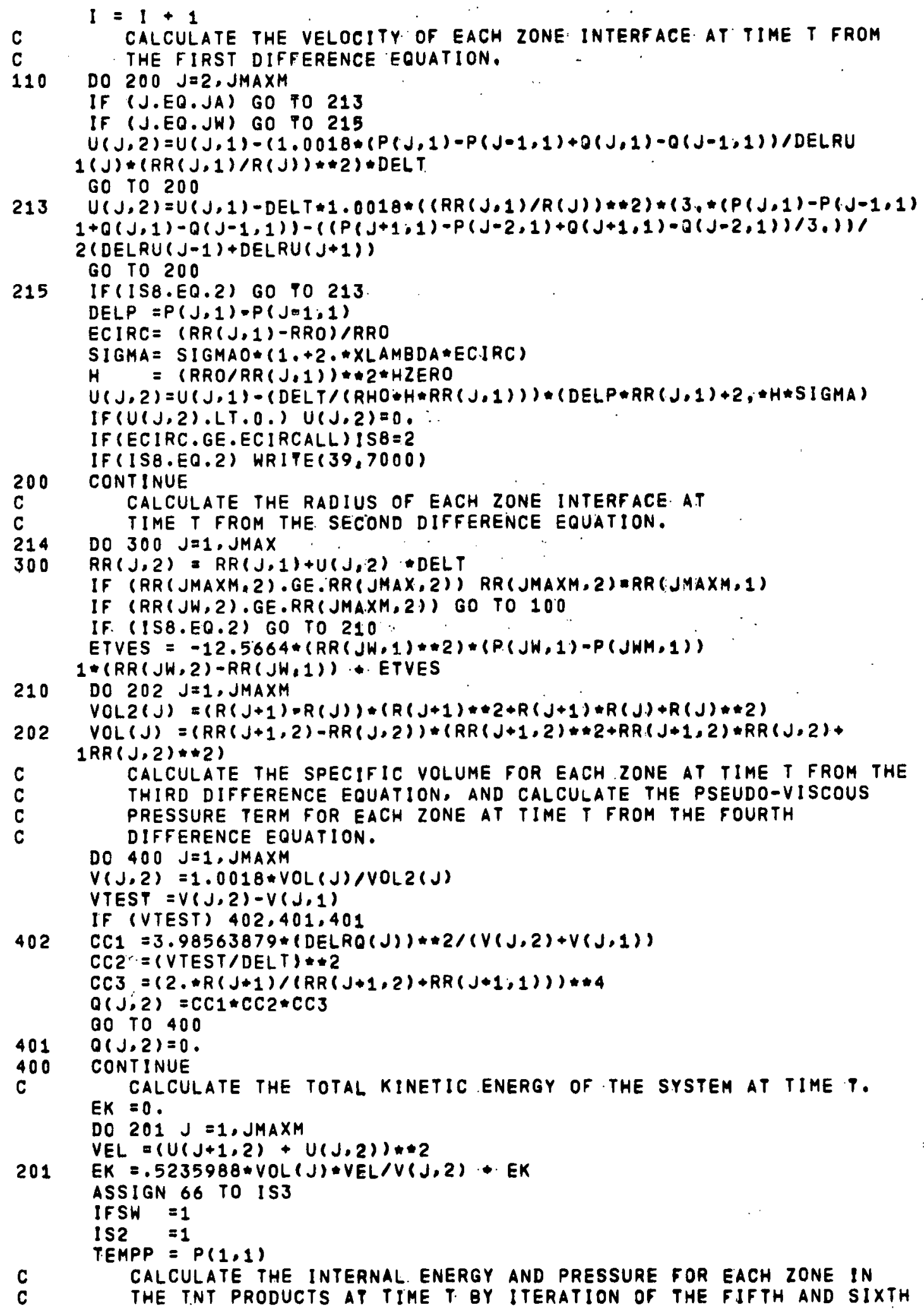




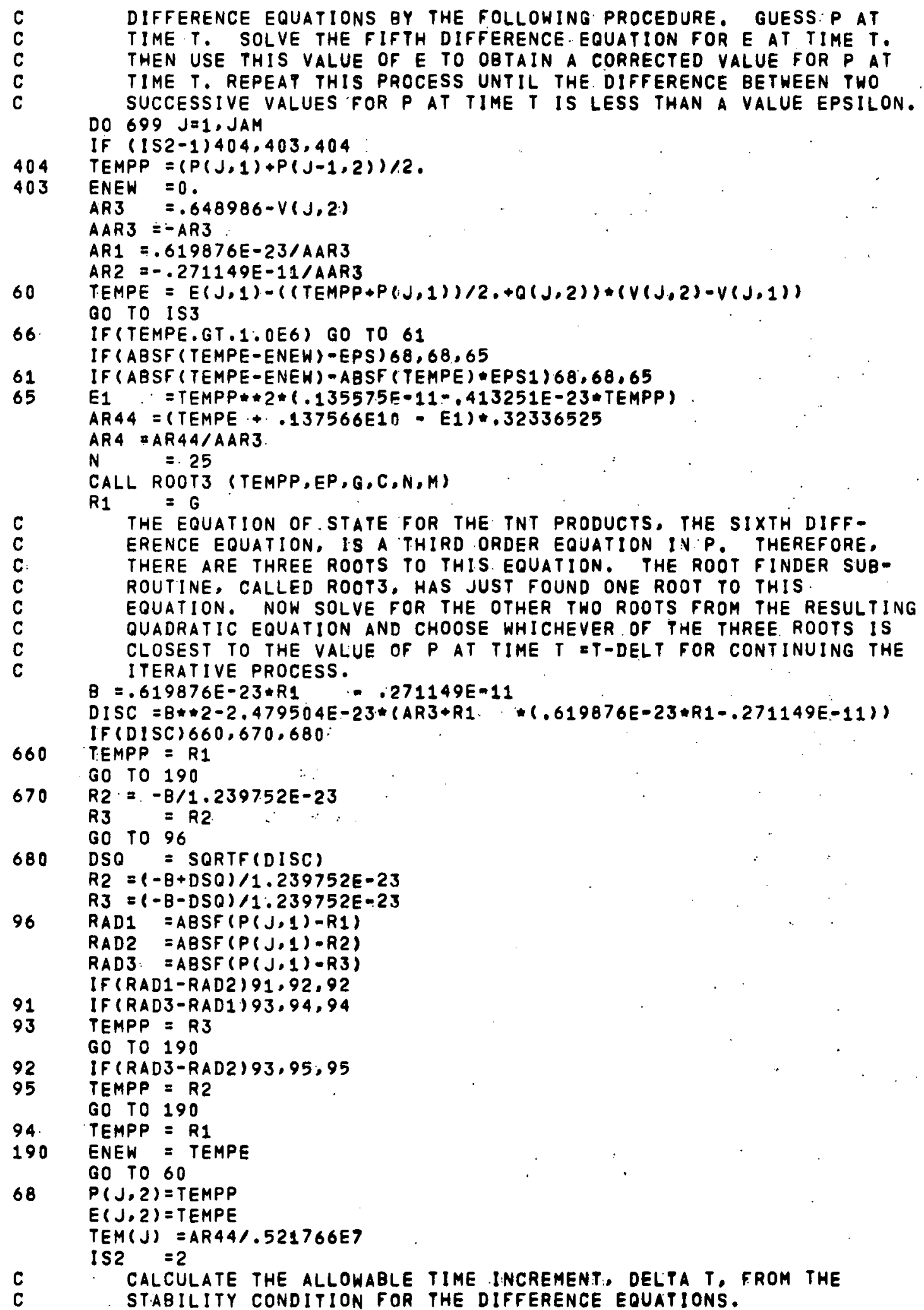




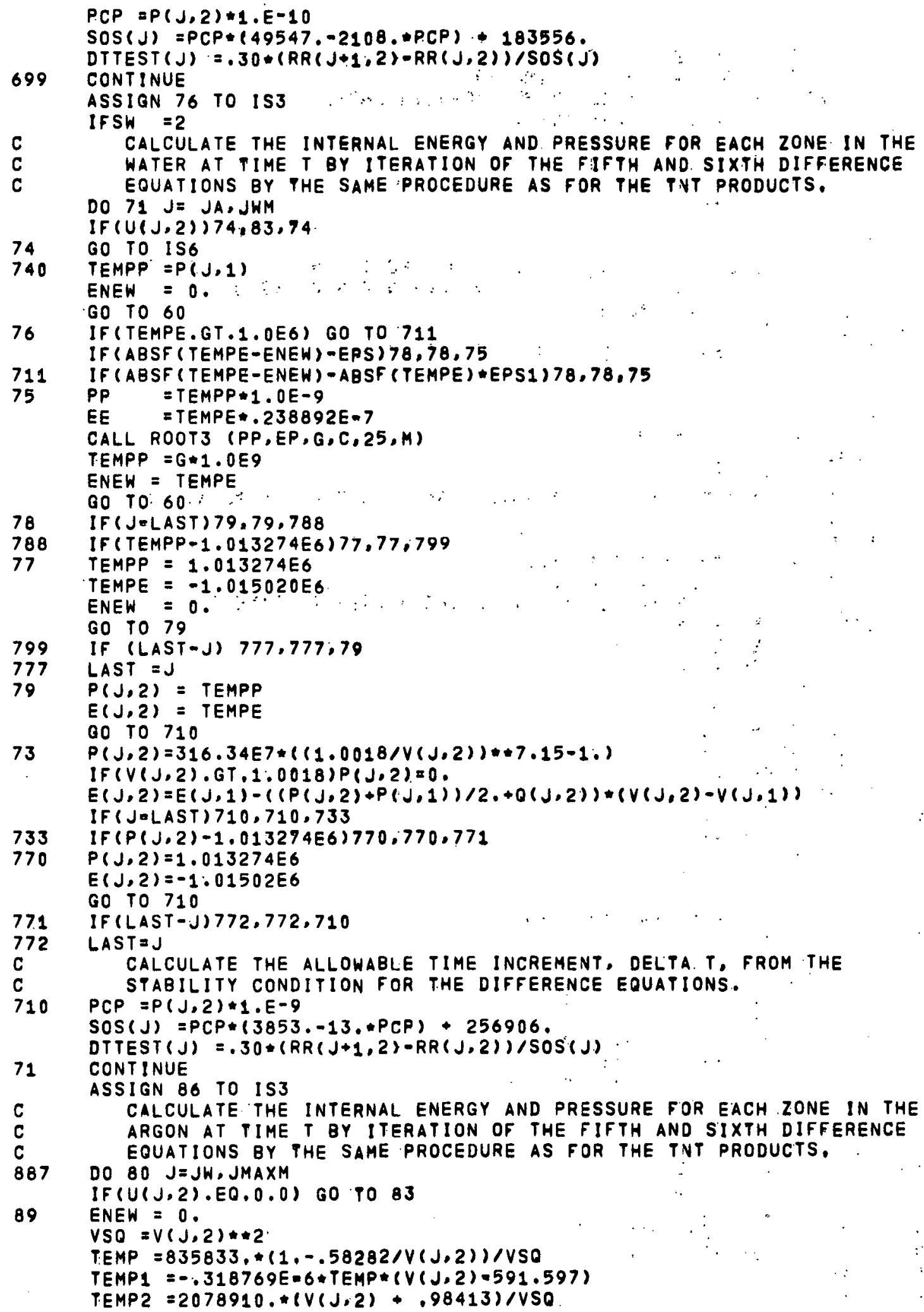




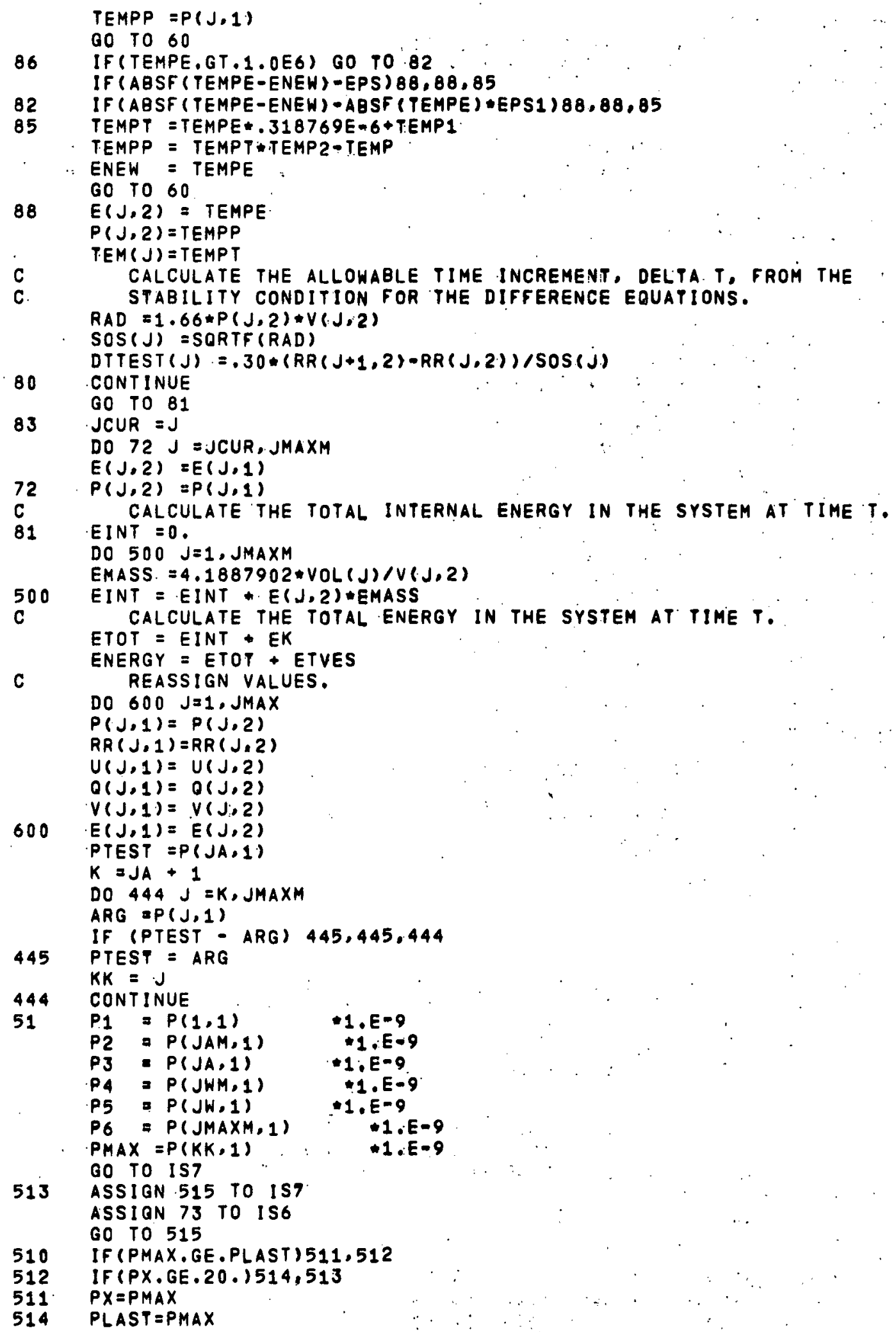




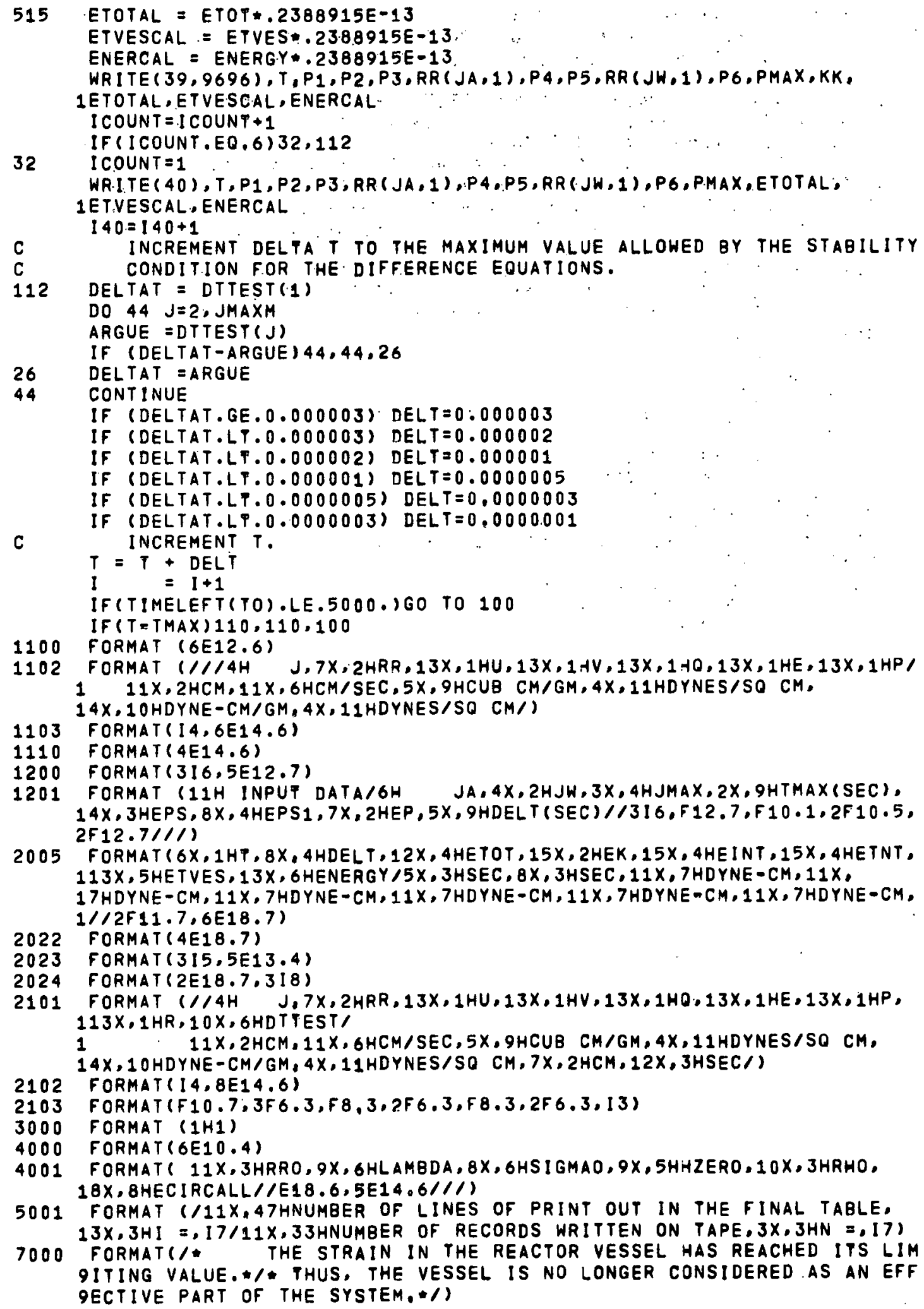
$13 x, 3 H I=, 17 / 11 x, 33 H N U M B E R$ OF RECORDS WRITTEN ON TAPE, 3X,3HN $=, 171$ 


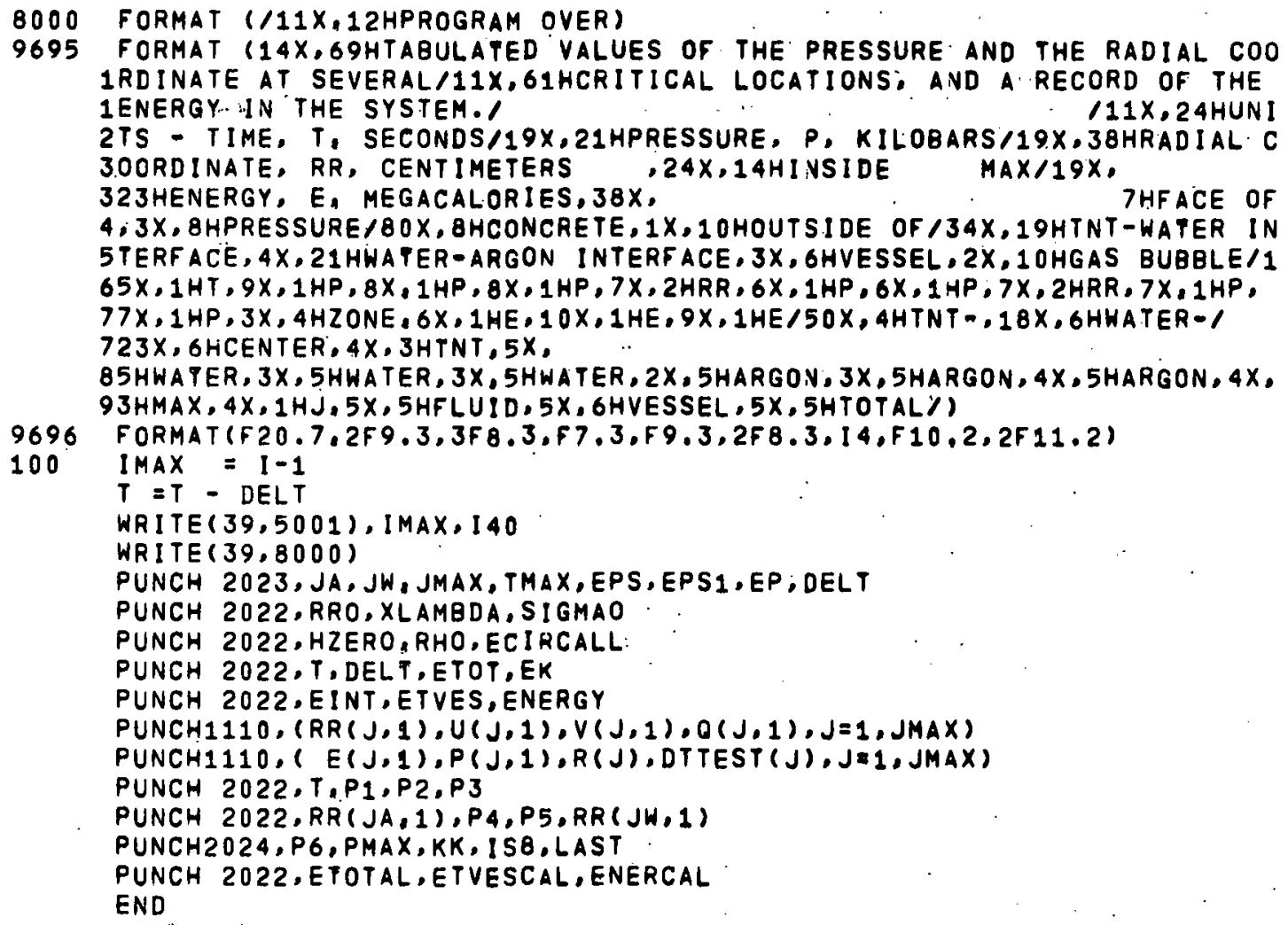


SUBROUTINE ROOTJ (A, EPS, G, C, N, M)

COMMON AR1, AR2, AR3, ARA,IIFSW,PP, US, UP, VH,ENTHH, X.I, ENTH, EE, V, J,EP, KL $1, K L L$

DIMENSION V(50,2)

THIS SUBROUTINE IS A FORTRAN TRANSCRIPTION OF ACM ALGORITHM NO. 26(COMM. ACM 4(1960)603). IT COMPUTES A VALUE OF $G=Y$ SATISFYING THE EQUATION Y = FCT $(Y)$. THE ITERATION WILL CONVERGE TO Y PROVIDING THAT AT SOME TIME IN THE ITERATION A G IS REACHED SUCH THAT ABS $(G-Y) * A B S(D(D F C T / D Y) / D Y)$ IS LLES THAN 2*ABS( THE DERIVATIVES ARE EVALUATED AT $Y$. INPUT INCLUDES: A SUBROUTINE, FCT $(X ; Y)$, WHICH. PLACES THE VALUE OF FCT $(X)$ IN $Y$; AN INITIAL APPROXIMATION TO THE ROOT, A: A TOLERANCE FOR THE RELATIVE ERROR IN G, EPS; A MAXIMUM NUMBER OF ITERATIONS TO BE PERFORMED, $N$. : THE SUBROUTINE CHANGES $N$ TO THE NUMBER OF ITERATIONS ACTUALLY PERFORMED.

OUTPUT INCLUDES: THE NUMBER OF ITERATIONS PERFORMED, N: THE REQUIRED ROOF, G: THE VALUE $C=$ FCT $(G)$ - G; A PARAMETER INDICATING THE SUCCESS OF THE PROCEDURE, M. IF THE TOLERANCE WAS NOT MET. M IS NEGATIVE. THE NUMBER ABS $(M)-1$ GIVES THE NUMBER OF TIMES THAT THE CORRECTION TO G EXCEEDED THE PRECEDING ONE. IF FCT(Y)-Y HAS THE SAME VALUE FOR TWO SUCCESSIVE APPROXIMATIONS TOO G. THEN $H=1$, AND WE PRINT CYCLE AND EXIT.

IF. $(K L-2) 11,12,11$

12 WRITE $(39,101), J$

101 FORMAT $(/ 5 X, 4 H J 1=, 13,5 X, 98 H I F$ JI. EOUALS J. THE COMPUTED RESULTS A 1RE ACCEPTABLE. THIS MEANS THAT THE ROOT, $G$, OBTAINED BY THE/3X, 2113 HSUBROUTINE HAS BEEN CORRECTED BY THE PARENT ROUTINE AND THE PA 3RENT ROUTINE HAS CALLED T.HE SUBROUTINE AGAIN IN ITS/3X.113HATTEMPT 4 TO FIND A SATISFACTORY ROOT. IF. JI DOES NOT EOUAL! J, THE ROOT, G 5, OBTAINED BY THE ROOT FINDER SUBROUTINE/3X,68HMAY OR MAY NOT BE A GCCEPTABLE AND FURTHER INVESTIGATION IS. WARRANTED,/)

$11 \mathrm{KL}=1$

$M=1$

$J J=0$

$C=0$

CALL FCT $(0, F)$

IF (F) $2,1,2$

$1 G=0$.

GO TO 50

2 CALL FCT $(A, G)$

$C=G-A$

$D=C$

$B=C$

If (C) 3.50 .3

3 DO $40 \quad J J=1, N$

CALL FCT $(G, F)$

$C=F-G$

IF (ABSF (C) -.000009)50.50.10

10 IF (ABSF (C) $\triangle A B S F(G)+E P S) 50,50,4$

$4 H=B / C$

If $(H-1) 5,6,$,

6

WRITE $(39.99) \mathrm{J}$

WRITE $(39,100) \quad A, G, F, H$

99 FORMAT (/8H CYCLE $3,8 X, 3 H J=, 14)$

100 FORMAT (/6H A $=, E 15,7,4 X, 3 H G=, E 15,7,4 X, 3 H F=, E 15,7,4 X, 3 H H=$, 1E15.7)

$K L=K L+1$

.6O TO 49

5 If $(H) 7,7,8$

8 If $(H-2) 9,7,$,

$9 M=M+1$

$7 D=D /(H-1$.

$B=C$

$B=0+D$

$49 M=-M$

$J J=N$

$50 \mathrm{~N}=J \mathrm{~J}$

RETURN

END 


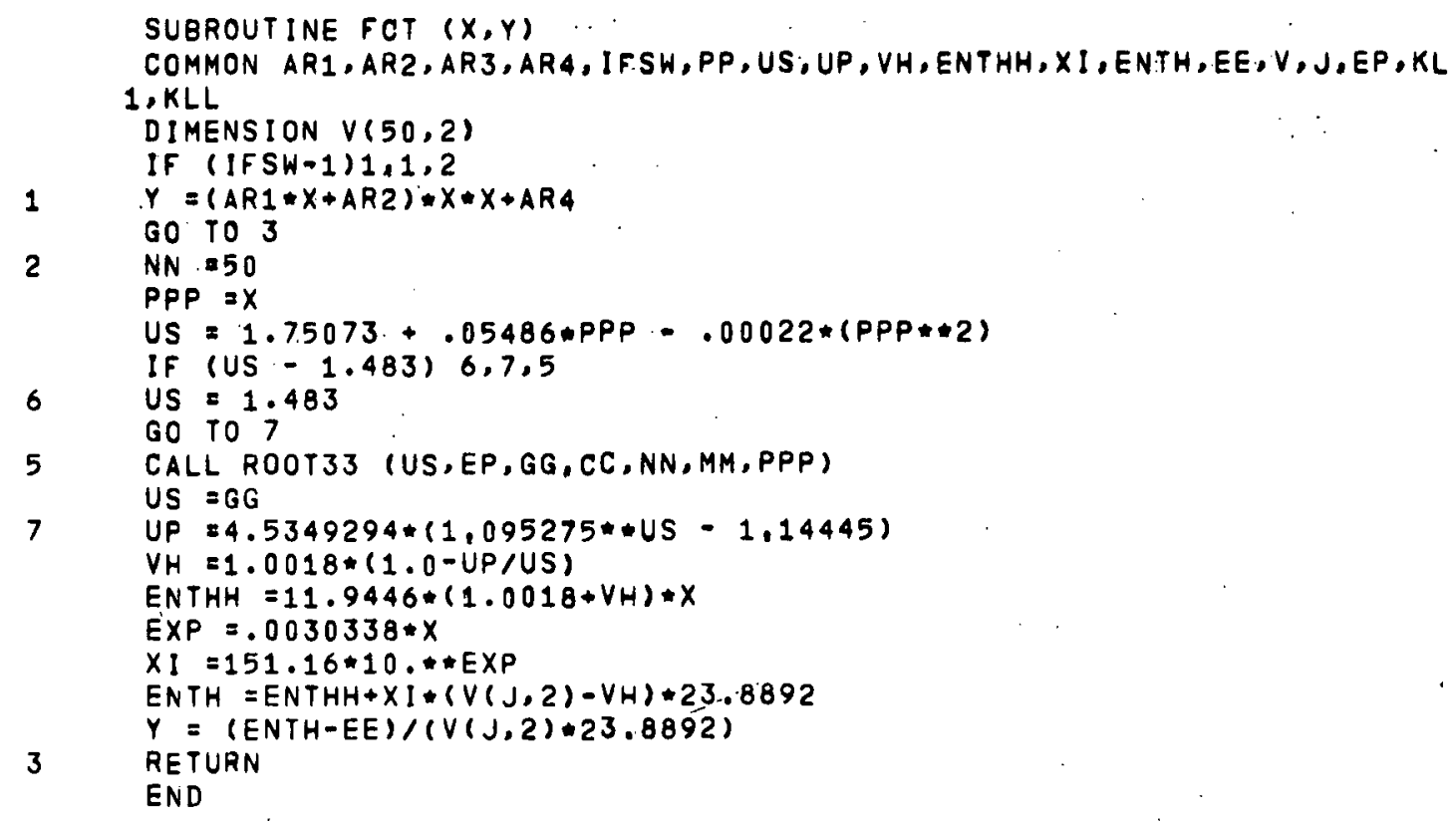




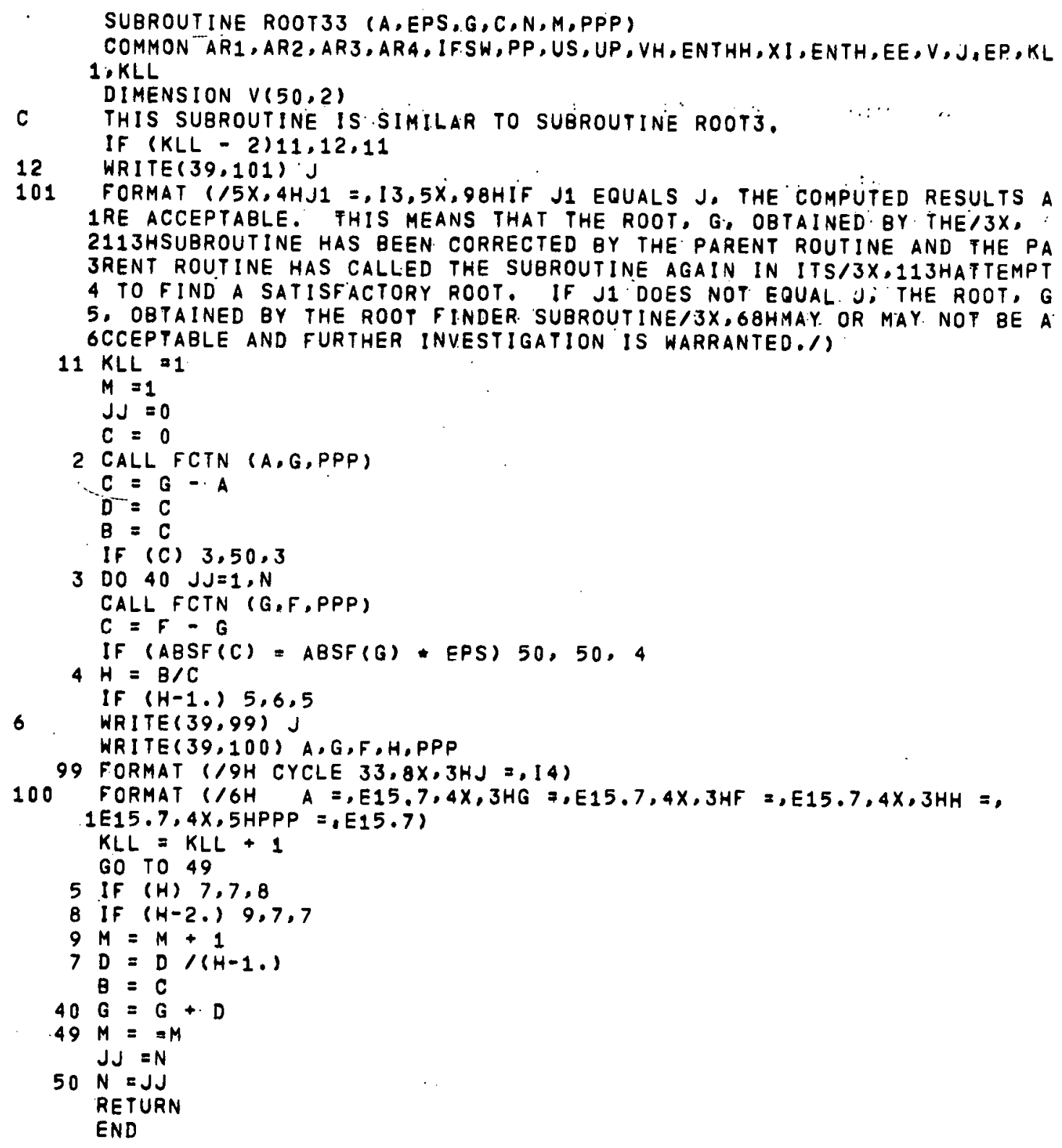

SUBROUTINE FCTN $(X, Y, P P P)$

COMMON AR1, AR2, AR3, AR4, IFSH,PP, US, UP, VH, ENTHH, XI,ENTH,EE, V, J,EP, KL 1. KLL

DIMENSION $V(50,2)$

$Y=(.022090746 * P P P+1.14445 * X) /(1.095275 * * X)$

RETURN

END 
H. Computer Results

The computer results for this solution are presented as follows:

1. A sample of the tabulated computer results obtained for various critical parameters (Table X).

2. Graphical representation of the computer results obtained for various critical parameters. (Figs. 21-31). 
TABLEX. Tabulated Values of the Pressure and Radial Coordinate at Several Critical Locations, and a Record of the Energy in the System

UNITS - TIME, T, SECONDS

PRESSURE, $P, K I L O R A R S$

RADIAL COORDINATE, RR, CENTIMETERS

ENERGY, E, MEGACALORIES

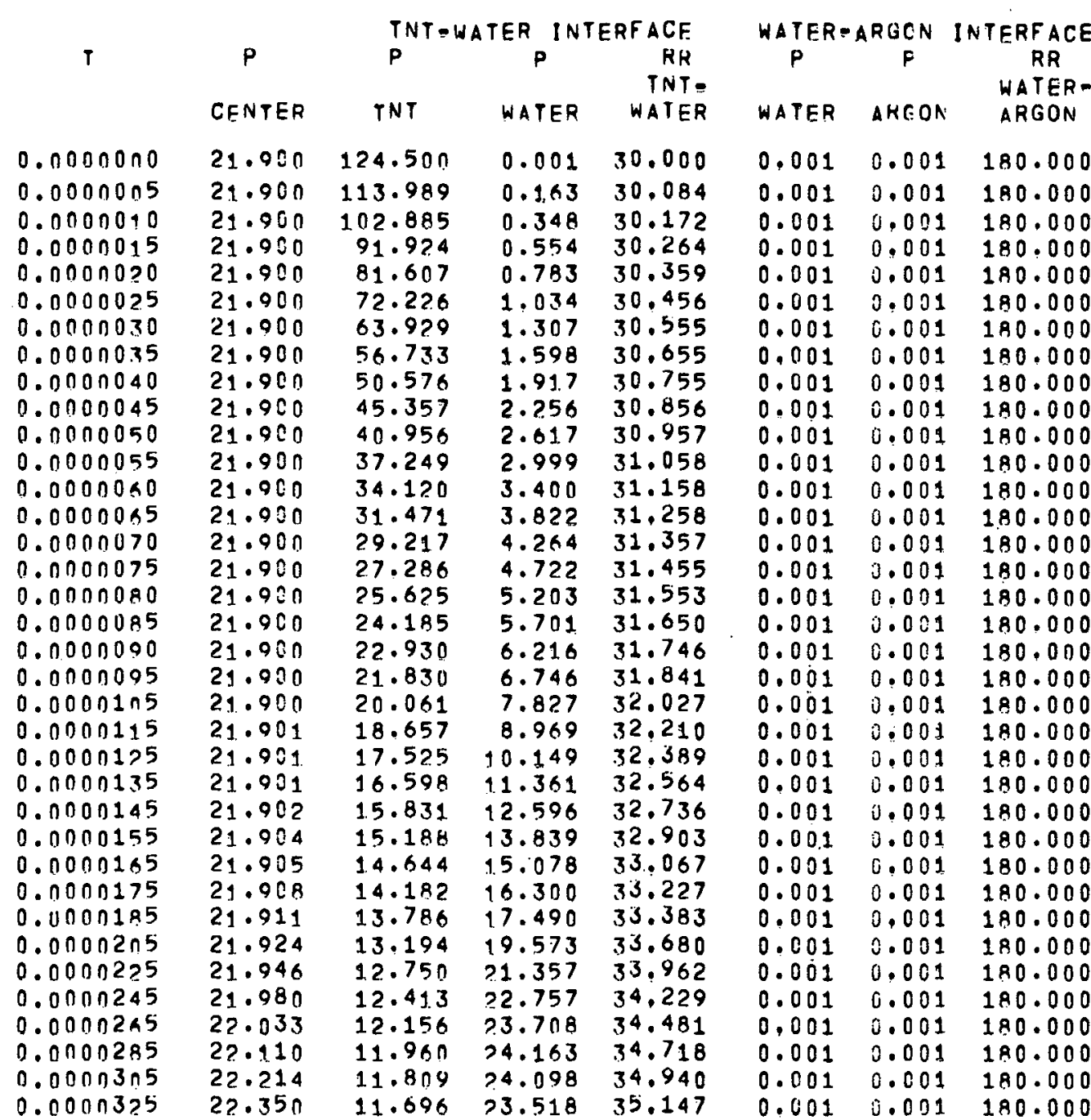

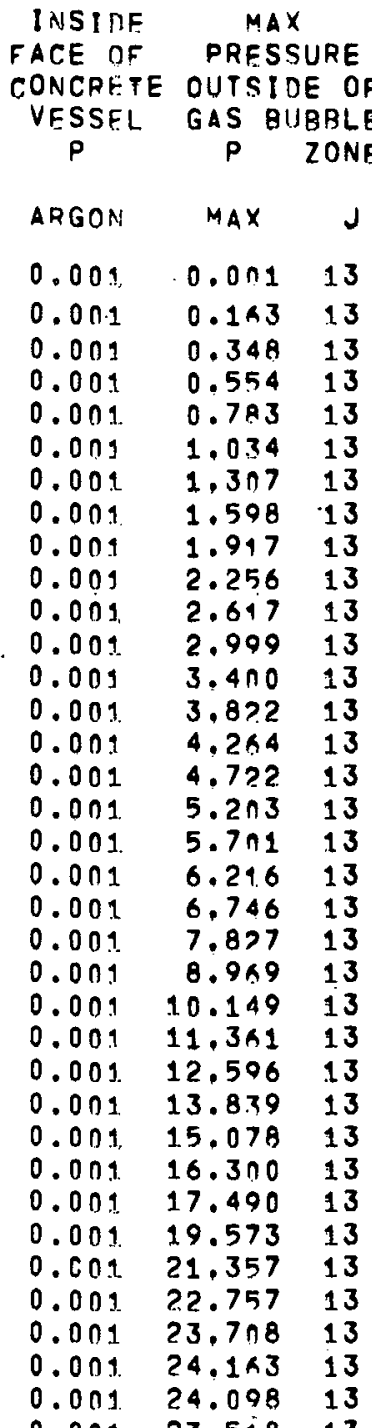

$E$
FLUID
136.06
137.25
137.15
137.11
137.15
137.23
137.36
137.51
137.68
137.84
138.00
138.15
138.29
138.42
138.53
138.63
138.72
138.79
1338.85
138.90
138.94
138.96
1338.93
1338.86
138.74
1338.58
1338.39
138.17
1337.94
137.38
136.84
136.30
135.77
135.23
134.67
134.10

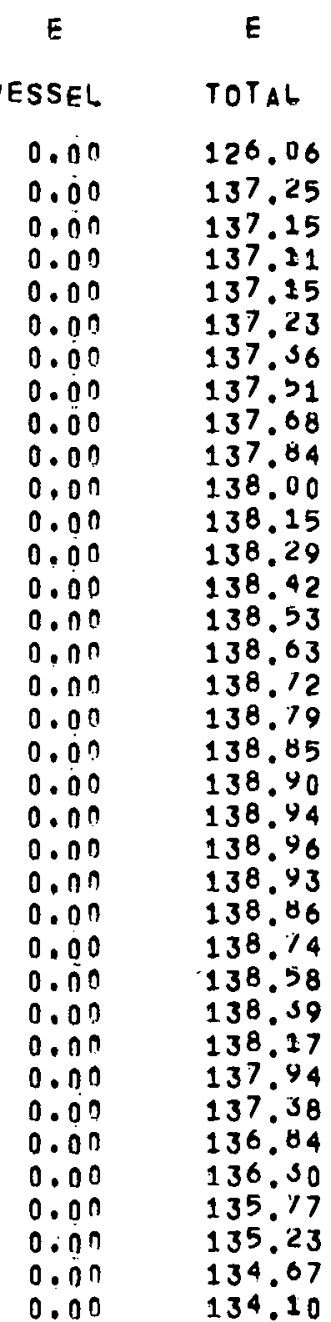


TABLE X (Contd.)

\begin{tabular}{|c|c|}
\hline $\begin{array}{l}0.0000345 \\
0.0000365 \\
0.0000385 \\
0.00000405 \\
0.00000425 \\
0.00000445 \\
0.00000465 \\
0.00000485 \\
0.00000505 \\
0.0000525 \\
0.00000545 \\
0.00000565 \\
0.0000585\end{array}$ & $\begin{array}{l}22.521 \\
22.713 \\
22.952 \\
23.223 \\
23.518 \\
23.830 \\
24.146 \\
24.458 \\
24.755 \\
25.036 \\
25.305 \\
25.577 \\
25.882\end{array}$ \\
\hline 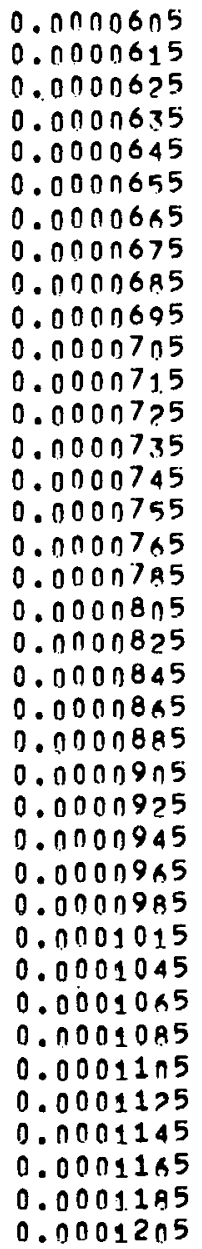 & $\begin{array}{l}26.269 \\
26.485 \\
26.748 \\
27.058 \\
27.423 \\
27.851 \\
28.348 \\
28.920 \\
29.572 \\
30.310 \\
31.123 \\
39.013 \\
32.971 \\
33.988 \\
35.049 \\
36.137 \\
37.731 \\
39.321 \\
41.133 \\
42.456 \\
43.099 \\
42.917 \\
41.911 \\
39.701 \\
36.709 \\
33.078 \\
29.132 \\
25.200 \\
19.745 \\
15.407 \\
13.148 \\
11.302 \\
9.798 \\
8.569 \\
7.557 \\
6.718 \\
6.016 \\
5.423\end{array}$ \\
\hline
\end{tabular}

$\begin{array}{rrr}11.609 & 72.467 & 35.339 \\ 11.530 & 71.034 & 35.519 \\ 11.446 & 19.336 & 35.687 \\ 11.348 & 17.496 & 35.845 \\ 11.230 & 1.5 .631 & 35.997 \\ 11.091 & 13.833 & 36.143 \\ 10.927 & 1.268 & 36.287 \\ 11.735 & 10.676 & 36.429 \\ 10.513 & 9.377 & 36.573 \\ 10.256 & 8.271 & 36.719 \\ 9.965 & 7.346 & 36.869 \\ 9.644 & 6.600 & 37.024 \\ 9.298 & 6.009 & 37.184 \\ 8.933 & 5.559 & 37.349 \\ 8.748 & 5.370 & 37.434 \\ 8.561 & 5.213 & 37.519 \\ 8.371 & 5.086 & 37.607 \\ 8.179 & 4.989 & 37.695 \\ 7.986 & 4.919 & 37.786 \\ 7.794 & 3.004 & 37.877 \\ 7.597 & 3.001 & 37.971 \\ 7.398 & 3.022 & 38.067 \\ 7.197 & 3.069 & 38.164 \\ 6.998 & 3.142 & 38.264 \\ 6.801 & 3.240 & 38.365 \\ 6.608 & 3.363 & 38.468 \\ 6.422 & 3.511 & 38.571 \\ 6.244 & 3.684 & 38.676 \\ 6.074 & 3.880 & 38.782 \\ 5.914 & 4.100 & 38.888 \\ 5.629 & 4.619 & 39.101 \\ 5.389 & 5.219 & 39.314 \\ 5.195 & 5.884 & 39.523 \\ 5.044 & 6.592 & 39.728 \\ 4.936 & 7.317 & 39.927 \\ 4.867 & 8.028 & 40.119 \\ 4.834 & 8.690 & 40.303 \\ 4.834 & 9.268 & 40.479 \\ 4.863 & 9.728 & 40.647 \\ 4.920 & 1.0 .040 & 40.805 \\ 4.999 & 10.184 & 40.956 \\ 5.158 & 9.991 & 41.162 \\ 5.335 & 9.419 & 41.351 \\ 5.447 & 8.909 & 41.471 \\ 5.540 & 8.303 & 41.584 \\ 5.602 & 7.635 & 41.694 \\ 5.621 & 6.942 & 41.800 \\ 5.588 & 6.252 & 41.904 \\ 5.498 & 5.589 & 42.008 \\ 5.351 & 4.969 & 42.111 \\ 5.154 & 4.403 & 42.216\end{array}$

$\begin{array}{llllll}0.001 & 0.001 & 180.000 & 0.001 & 22.467 & 13 \\ 0.001 & 0.001 & 180.000 & 0.001 & 21.034 & 13 \\ 0.001 & 0.001 & 180.000 & 0.001 & 19.336 & 13 \\ 0.001 & 0.001 & 180.000 & 0.001 & 17.496 & 13 \\ 0.001 & 0.001 & 180.000 & 0.001 & 15.631 & 13 \\ 0.001 & 0.001 & 180.000 & 0.001 & 13.833 & 13 \\ 0.001 & 0.001 & 180.000 & 0.001 & 12.188 & 13 \\ 0.001 & 0.001 & 180.000 & 0.001 & 12.046 & 14 \\ 0.001 & 0.001 & 180.000 & 0.001 & 13.083 & 14 \\ 0.001 & 0.011 & 180.000 & 0.001 & 14.053 & 14 \\ 0.001 & 0.001 & 180.000 & 0.001 & 14.925 & 14 \\ 0.001 & 0.001 & 180.000 & 0.001 & 15.649 & 14 \\ 0.001 & 0.001 & 180.000 & 0.001 & 16.262 & 14 \\ 0.001 & 0.001 & 180.000 & 0.001 & 16.680 & 14 \\ 0.001 & 0.001 & 180.000 & 0.001 & 16.846 & 14 \\ 0.001 & 0.001 & 180.000 & 0.001 & 16.982 & 14 \\ 0.001 & 0.001 & 180.000 & 0.001 & 17.030 & 14 \\ 0.001 & 0.001 & 180.000 & 0.001 & 17.048 & 14 \\ 0.001 & 0.001 & 180.000 & 0.001 & 17.015 & 14 \\ 0.001 & 0.001 & 180.000 & 0.001 & 16.585 & 14 \\ 0.001 & 0.001 & 180.000 & 0.001 & 16.445 & 14 \\ 0.001 & 0.001 & 180.000 & 0.001 & 16.253 & 14 \\ 0.001 & 0.001 & 180.000 & 0.001 & 16.013 & 14 \\ 0.001 & 0.001 & 180.000 & 0.001 & 15.728 & 14 \\ 0.001 & 0.001 & 180.000 & 0.001 & 15.401 & 14 \\ 0.001 & 0.001 & 180.000 & 0.001 & 15.039 & 14 \\ 0.001 & 0.001 & 180.000 & 0.001 & 14.646 & 14 \\ 0.001 & 0.001 & 180.000 & 0.001 & 14.227 & 14 \\ 0.001 & 0.001 & 180.000 & 0.001 & 13.789 & 14 \\ 0.001 & 0.001 & 180.000 & 0.001 & 13.335 & 14 \\ 0.001 & 0.001 & 180.000 & 0.001 & 12.377 & 14 \\ 0.001 & 0.001 & 180.000 & 0.001 & 11.419 & 14 \\ 0.001 & 0.001 & 180.000 & 0.001 & 10.490 & 14 \\ 0.001 & 0.001 & 180.000 & 0.001 & 9.609 & 14 \\ 0.001 & 0.001 & 180.000 & 0.001 & 8.947 & 15 \\ 0.001 & 0.001 & 180.000 & 0.001 & 9.532 & 15 \\ 0.001 & 0.001 & 180.000 & 0.001 & 10.088 & 15 \\ 0.001 & 0.001 & 180.000 & 0.001 & 10.600 & 15 \\ 0.001 & 0.001 & 180.000 & 0.001 & 11.058 & 15 \\ 0.001 & 0.001 & 180.000 & 0.001 & 11.448 & 15 \\ 0.001 & 0.001 & 180.000 & 0.001 & -9.502 & 15 \\ 0.001 & 0.001 & 180.000 & 0.001 & 11.7 \times 0 & 15 \\ 0.001 & 0.001 & 180.000 & 0.001 & 12.079 & 15 \\ 0.001 & 0.001 & 180.000 & 0.001 & 12.084 & 15 \\ 0.001 & 0.001 & 180.000 & 0.001 & 12.026 & 15 \\ 0.001 & 0.001 & 180.000 & 0.001 & 11.875 & 15 \\ 0.001 & .0 .001 & 180.000 & 0.001 & 11.637 & 15 \\ 0.001 & 0.001 & 180.000 & 0.001 & 11.320 & 15 \\ 0.001 & 0.001 & 180.000 & 0.001 & 10.934 & 15 \\ 0.001 & 0.001 & 180.000 & 0.001 & 10.494 & 15 \\ 0.001 & 0.001 & 180.000 & 0.001 & 10.012 & 15 \\ 0.001 & & & & & \end{array}$

133.55

133.05

132.66

i 32.40

132.29

132.32

132.47

132.73

133.05

133.44

133.85

134.26

134.67

35.04
135.22

135.38

135.53

135.66

135.77

135.87

335.98

136.07

136.13

136.18

136.20

136.21

136.21

136.19

136.17

136.15

136.11

136.08
136.09

136.11

136.13

136.15

136.15

136.14

136.10

136.03

35.84

135.58

135.39

35.20

335.00

i 34.82

134.66

134.53

134.44
134.39

$\begin{array}{ll}0.00 & 133.55 \\ 0.00 & 133.05 \\ 0.00 & 132.06 \\ 0.00 & 132.40 \\ 0.00 & 132.29 \\ 0.00 & 132.32 \\ 0.00 & 132.47 \\ 0.00 & 132.73 \\ 0.00 & 133.05 \\ 0.00 & 133.44 \\ 0.00 & 133.85 \\ 0.00 & 134.26 \\ 0.00 & 134.67 \\ 0.00 & 135.04 \\ 0.00 & 135.22 \\ 0.00 & 135.38 \\ 0.00 & 135.53 \\ 0.00 & 135.06 \\ 0.00 & 135.77 \\ 0.00 & 135.87 \\ 0.000 & 135.98 \\ 0.00 & 136.07 \\ 0.00 & 136.13 \\ 0.00 & 136.18 \\ 0.00 & 136.20 \\ 0.000 & 136.21 \\ 0.00 & 136.21 \\ 0.00 & 136.19 \\ 0.00 & 136.19 \\ 0.00 & 136.15 \\ 0.00 & 136.11 \\ 0.000 & 136.49 \\ 0.00 & 136.08 \\ 0.00 & 136.09 \\ 0.00 & 136.11 \\ 0.00 & 136.13 \\ 0.00 & 136.15 \\ 0.00 & 136.15 \\ 0.00 & 136.24 \\ 0.00 & 136.10 \\ 0.00 & 136.03 \\ 0.00 & 135.84 \\ 0.00 & 135.58 \\ 0.00 & 135.39 \\ 0.00 & 135.20 \\ 0.00 & 135.00 \\ 0.00 & 134.82 \\ 0.00 & 134.06 \\ 0.00 & 134.53 \\ 0.00 & 134.14 \\ 0.00 & 134.39 \\ & \end{array}$


TABLE X (Contd.)

\begin{tabular}{|c|c|c|c|c|}
\hline $\begin{array}{l}0.0001225 \\
0.0001245 \\
0.0001275 \\
0.0001375 \\
0.0001325 \\
0.0001345 \\
0.0001365 \\
0.0001385 \\
0.0001405 \\
0.0001425 \\
0.0001445 \\
0.0001445 \\
0.0001485 \\
0.0001535 \\
0.0001525 \\
0.0001545 \\
0.0001565 \\
0.0001585 \\
0.00001605 \\
0.0001625 \\
0.0001645 \\
0.0001665 \\
0.0001685\end{array}$ & $\begin{array}{l}4.918 \\
4.484 \\
3.942 \\
3.498 \\
3.244 \\
3.019 \\
2.818 \\
2.637 \\
2.475 \\
2.327 \\
2.194 \\
2.072 \\
1.960 \\
1.858 \\
1.764 \\
1.677 \\
1.597 \\
1.522 \\
1.453 \\
1.388 \\
1.328 \\
1.272 \\
1.219\end{array}$ & $\begin{array}{l}4.922 \\
4.667 \\
4.261 \\
3.873 \\
3.636 \\
3.419 \\
3.220 \\
3.040 \\
2.879 \\
2.736 \\
2.609 \\
2.497 \\
2.399 \\
2.315 \\
2.243 \\
2.184 \\
2.137 \\
2.101 \\
2.077 \\
2.063 \\
2.060 \\
2.069 \\
2.090\end{array}$ & $\begin{array}{l}3.895 \\
3.447 \\
2.892 \\
2.457 \\
2.221 \\
2.031 \\
1.884 \\
1.779 \\
1.714 \\
1.686 \\
1.696 \\
1.742 \\
1.824 \\
1.942 \\
2.092 \\
2.272 \\
2.480 \\
2.708 \\
2.953 \\
3.206 \\
3.459 \\
3.703 \\
3.929\end{array}$ & $\begin{array}{l}42.322 \\
42.431 \\
42.600 \\
42.775 \\
42.895 \\
43.018 \\
43.144 \\
43.273 \\
43.405 \\
43.540 \\
43.677 \\
43.817 \\
43.958 \\
44.101 \\
44.245 \\
44.389 \\
44.533 \\
44.675 \\
44.816 \\
44.954 \\
45.089 \\
45.220 \\
45.348\end{array}$ \\
\hline 0.0001705 & 1.169 & $2.12 ?$ & 4.128 & 45.471 \\
\hline $\begin{array}{l}0.0001725 \\
0.0001745 \\
0.0001765 \\
0.0001785 \\
0.0001805 \\
0.0001825 \\
0.0001845 \\
0.0001875 \\
0.0001905 \\
0.0001935 \\
0.0001945 \\
0.01001995 \\
0.01002025 \\
0.0002055 \\
0.00002085 \\
0.0002115 \\
0.0002145 \\
0.00002175 \\
0.0002205 \\
0.00002235 \\
0.00002245 \\
0.0002285 \\
0.0002305 \\
0.00002325 \\
0.00002345 \\
0.0002345 \\
0.0002385\end{array}$ & $\begin{array}{l}1.123 \\
1.079 \\
1.038 \\
0.099 \\
0.907 \\
0.927 \\
0.894 \\
0.847 \\
0.804 \\
0.764 \\
0.727 \\
0.893 \\
0.660 \\
0.630 \\
0.502 \\
0.575 \\
0.550 \\
0.527 \\
0.505 \\
0.484 \\
0.464 \\
0.452 \\
0.440 \\
0.428 \\
0.417 \\
0.406 \\
0.396\end{array}$ & $\begin{array}{l}2.166 \\
2.222 \\
2.291 \\
2.371 \\
2.462 \\
2.562 \\
2.670 \\
2.839 \\
3.007 \\
3.160 \\
3.283 \\
3.364 \\
3.391 \\
3.360 \\
3.271 \\
3.135 \\
2.966 \\
2.783 \\
2.597 \\
2.499 \\
2.255 \\
2.155 \\
2.064 \\
1.981 \\
1.906 \\
1.839 \\
1.780\end{array}$ & $\begin{array}{l}4.293 \\
4.417 \\
4.496 \\
4.529 \\
4.515 \\
4.455 \\
4.353 \\
4.118 \\
3.826 \\
3.504 \\
3.173 \\
2.855 \\
2.563 \\
2.308 \\
2.098 \\
1.936 \\
1.822 \\
1.754 \\
1.730 \\
1.747 \\
1.800 \\
1.851 \\
1.914 \\
1.987 \\
2.068 \\
2.155 \\
2.245\end{array}$ & $\begin{array}{l}45.590 \\
45.705 \\
45.816 \\
45.423 \\
46.026 \\
46.127 \\
46.224 \\
46.365 \\
46.502 \\
46.637 \\
46.773 \\
46.909 \\
47.049 \\
47.193 \\
47.342 \\
47.496 \\
47.657 \\
47.824 \\
47.996 \\
48.173 \\
48.353 \\
48.474 \\
48.595 \\
48.718 \\
48.840 \\
48.961 \\
49.082\end{array}$ \\
\hline
\end{tabular}

\begin{tabular}{|c|c|c|c|c|}
\hline $\begin{array}{l}0.001 \\
0.001 \\
0.001 \\
0.001 \\
0.001 \\
0.001 \\
0.0101 \\
0.001 \\
0.001 \\
0.001 \\
0.001 \\
0.001 \\
0.001 \\
0.001 \\
0.001 \\
0.001 \\
0.001 \\
0.001 \\
0.001 \\
0.001 \\
0.001 \\
0.001 \\
0.001 \\
0.001 \\
0.001\end{array}$ & 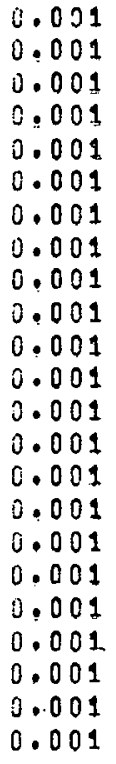 & $\begin{array}{l}180.000 \\
180.000 \\
180.000 \\
180.000 \\
180.000 \\
180.000 \\
180.000 \\
180.000 \\
180.000 \\
180.000 \\
180.000 \\
180.000 \\
180.000 \\
180.000 \\
180.000 \\
180.000 \\
180.000 \\
180.000 \\
180.000 \\
180.0000 \\
180.000 \\
180.000 \\
180.000\end{array}$ & 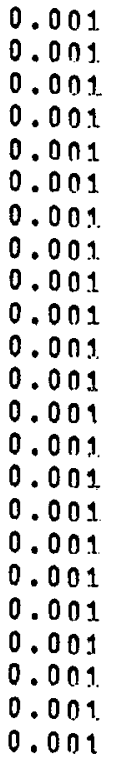 & $\begin{array}{l}8.977 \\
8.448 \\
7.661 \\
7.345 \\
7.713 \\
8.059 \\
8.375 \\
8.657 \\
8.898 \\
9.094 \\
9.240 \\
9.334 \\
9.374 \\
9.358 \\
9.288 \\
9.165 \\
8.993 \\
8.776 \\
8.519 \\
8.230 \\
7.914 \\
7.578 \\
7.278\end{array}$ \\
\hline 0.001 & 0.001 & 180.000 & 0.00 .9 & 6.871 \\
\hline $\begin{array}{l}0.001 \\
0.001 \\
0.001 \\
0.001 \\
0.001 \\
0.001 \\
0.001 \\
0.001 \\
0.001 \\
0.001 \\
0.001 \\
0.001 \\
0.001 \\
0.001 \\
0.001 \\
0.001 \\
0.001 \\
0.001 \\
0.001 \\
0.001 \\
0.001 \\
0.001 \\
0.001 \\
0.001 \\
0.001 \\
0.001 \\
0.001\end{array}$ & $\begin{array}{l}0.001 \\
0.001 \\
0.001 \\
0.001 \\
0.001 \\
0.001 \\
0.001 \\
0.001 \\
0.001 \\
0.001 \\
0.001 \\
0.001 \\
0.001 \\
0.001 \\
0.001 \\
0.001 \\
0.001 \\
0.001 \\
0.001 \\
0.001 \\
0.001 \\
0.001 \\
0.001 \\
0.001 \\
0.001 \\
0.001 \\
0.001\end{array}$ & $\begin{array}{l}180.000 \\
180.000 \\
180.000 \\
180.000 \\
180.000 \\
180.000 \\
180.000 \\
180.000 \\
180.000 \\
180.000 \\
180.000 \\
180.000 \\
180.000 \\
180.000 \\
180.000 \\
180.000 \\
180.000 \\
180.000 \\
180.000 \\
180.000 \\
180.000 \\
180.000 \\
180.000 \\
180.000 \\
180.000 \\
180.000 \\
180.000\end{array}$ & 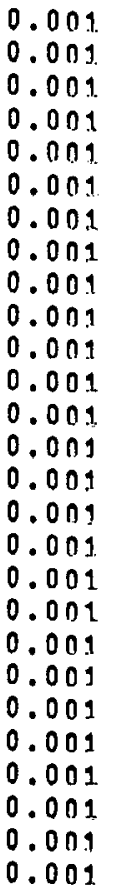 & $\begin{array}{l}6.512 \\
6.156 \\
6.042 \\
6.296 \\
6.535 \\
6.755 \\
6.952 \\
7.188 \\
7.358 \\
7.454 \\
7.475 \\
7.418 \\
7.287 \\
7.088 \\
6.830 \\
6.523 \\
6.180 \\
5.813 \\
5.432 \\
5.049 \\
5.277 \\
5.407 \\
5.573 \\
5.725 \\
5.860 \\
5.976 \\
6.071\end{array}$ \\
\hline
\end{tabular}

134.39
134.43
134.57
134.79
134.98
135.18
135.40
135.61
135.82
136.01
136.18
136.31
136.42
136.48
136.49
136.47
136.41
136.32
136.20
136.07
135.92
135.77
135.63
135.50
135.39
135.31
135.25
135.23
135.22
135.24
135.28
135.35
135.43
135.52
135.59
135.65
135.67
135.67
135.65
135.61
135.57
135.52
135.49
135.48
135.51
135.54
135.58
135.63
135.69
135.75
135.81


TABLE X (Contd.)

$\begin{array}{lllll}0.0002405 & 0.386 & 1.729 & 2.335 & 49.202 \\ 0.0002425 & 0.376 & 1.685 & 2.423 & 49.320 \\ 0.0002445 & 0.366 & 1.648 & 2.505 & 49.437 \\ 0.0002465 & 0.357 & 1.618 & 2.578 & 49.552 \\ 0.0002485 & 0.349 & 1.594 & 2.641 & 49.664 \\ 0.0002505 & 0.340 & 1.576 & 2.690 & 49.774 \\ 0.0002525 & 0.332 & 1.564 & 2.724 & 49.881 \\ 0.0002545 & 0.324 & 1.558 & 2.743 & 49.986 \\ 0.0002565 & 0.316 & 1.557 & 2.744 & 50.089 \\ 0.0002585 & 0.309 & 1.562 & 2.729 & 50.188 \\ 0.0002605 & 0.301 & 1.572 & 2.697 & 50.285 \\ 0.0002625 & 0.294 & 1.587 & 2.650 & 50.380 \\ 0.0002645 & 0.287 & 1.608 & 2.591 & 50.472 \\ 0.0002665 & 0.281 & 1.633 & 2.522 & 50.562 \\ 0.0002685 & 0.274 & 1.662 & 2.446 & 50.651 \\ 0.0002705 & 0.268 & 1.696 & 2.366 & 50.738 \\ 0.0002725 & 0.262 & 1.733 & 2.287 & 50.825 \\ 0.0002745 & 0.256 & 1.773 & 2.209 & 50.910 \\ 0.0002765 & 0.251 & 1.814 & 2.136 & 50.996 \\ 0.0002785 & 0.245 & 1.857 & 2.070 & 51.081 \\ 0.0002805 & 0.24 n & 1.900 & 2.012 & 51.166 \\ 0.0002825 & 0.235 & 1.942 & 1.962 & 51.252 \\ 0.0002855 & 0.227 & 2.001 & 1.910 & 51.382 \\ 0.0002885 & 0.220 & 2.052 & 1.878 & 51.514 \\ 0.0002915 & 0.213 & 2.094 & 1.867 & 51.647 \\ 0.0002945 & 0.206 & 2.123 & 1.872 & 51.782 \\ 0.0002975 & 0.200 & 2.139 & 1.890 & 51.919 \\ 0.0003005 & 0.194 & 2.139 & 1.916 & 52.058 \\ 0.0003035 & 0.188 & 2.124 & 1.944 & 52.198 \\ 0.0003065 & 0.182 & 2.095 & 1.968 & 52.338 \\ 0.0003095 & 0.177 & 2.054 & 1.983 & 52.480 \\ 0.0003125 & 0.171 & 2.001 & 1.983 & 52.621 \\ 0.0003155 & 0.166 & 1.942 & 1.963 & 52.762 \\ 0.0003185 & 0.162 & 1.877 & 1.920 & 52.903 \\ 0.0003215 & 0.157 & 1.810 & 1.855 & 53.042 \\ 0.0003245 & 0.152 & 1.742 & 1.770 & 53.182 \\ 0.0003275 & 0.148 & 1.675 & 1.670 & 53.320 \\ 0.0003305 & 0.144 & 1.610 & 1.561 & 53.459 \\ 0.0003325 & 0.141 & 1.569 & 1.489 & 53.551 \\ 0.0003345 & 0.139 & 1.528 & 1.419 & 53.644 \\ 0.0003345 & 0.136 & 1.489 & 1.353 & 53.736 \\ 0.0003385 & 0.133 & 1.451 & 1.294 & 53.830 \\ 0.0003405 & 0.131 & 1.415 & 1.242 & 53.923 \\ 0.0003475 & 0.129 & 1.381 & 1.201 & 54.018 \\ 0.0003445 & 0.126 & 1.348 & 1.170 & 54.113 \\ 0.0003465 & 0.124 & 1.318 & 1.152 & 54.209 \\ 0.0003485 & 0.122 & 1.288 & 1.147 & 54.305 \\ 0.0003505 & 0.120 & 1.261 & 1.155 & 54.402 \\ 0.0003525 & 0.117 & 1.236 & 1.177 & 54.500 \\ 0.0003545 & 0.115 & 1.212 & 1.213 & 54.598 \\ 0.0003565 & 0.113 & 1.191 & 1.260 & 54.696\end{array}$

$\begin{array}{lll}0.001 & 0.001 & 180.000 \\ 0.001 & 0.001 & 180.000 \\ 0.001 & 0.001 & 180.000 \\ 0.001 & 0.001 & 180.000 \\ 0.001 & 0.001 & 180.000 \\ 0.001 & 0.001 & 180.000 \\ 0.001 & 0.001 & 180.000 \\ 0.001 & 0.001 & 180.000 \\ 0.001 & 0.001 & 180.000 \\ 0.001 & 0.001 & 180.000 \\ 0.001 & 0.001 & 180.000 \\ 0.001 & 0.001 & 180.000 \\ 0.001 & 0.001 & 180.000 \\ 0.001 & 0.001 & 180.000 \\ 0.001 & 0.001 & 180.000 \\ 0.001 & 0.001 & 180.000 \\ 0.001 & 0.001 & 180.000 \\ 0.001 & 0.001 & 180.000 \\ 0.001 & 0.001 & 180.000 \\ 0.001 & 0.001 & 180.000 \\ 0.001 & 0.001 & 180.000 \\ 0.001 & 0.001 & 180.000 \\ 0.001 & 0.001 & 180.000 \\ 0.001 & 0.001 & 180.000 \\ 0.001 & 0.001 & 180.000 \\ 0.001 & 0.001 & 180.000 \\ 0.001 & 3.001 & 180.000 \\ 0.001 & 0.001 & 180.000 \\ 0.001 & 0.001 & 180.000 \\ 0.001 & 0.001 & 180.000 \\ 0.001 & 0.001 & 180.000 \\ 0.001 & 0.001 & 180.000 \\ 0.001 & 0.001 & 180.000 \\ 0.001 & 0.001 & 180.000 \\ 0.001 & 0.001 & 180.000 \\ 0.001 & 0.001 & 180.000 \\ 0.001 & 0.001 & 180.000 \\ 0.001 & 0.001 & 180.000 \\ 0.001 & 0.001 & 180.000 \\ 0.001 & 0.001 & 180.000 \\ 0.001 & 0.001 & 180.000 \\ 0.001 & 0.001 & 180.000 \\ 0.001 & 0.001 & 180.000 \\ 0.001 & 0.001 & 180.000 \\ 0.001 & 0.001 & 180.000 \\ 0.001 & 0.001 & 180.000 \\ 0.001 & 0.001 & 180.000 \\ 0.001 & 0.001 & 180.000 \\ 0.001 & 0.001 & 180.000 \\ 0.001 & 0.001 & 180.000 \\ 0.001 & 0.001 & 180.000\end{array}$

1.35 .87

135.93
35.97

136.01

136.03

136.04

136.04
136.03

136.00

135.96

135.91

35.84

135.77

135.70

135.62

135.54

35.48

135.41

135.36

135.32

135.29

135.28

135.28

135.29

135.34

135.40

135.48

135.57

135.66

135.74

135.80

135.85

135.87

135.86

135.83

135.78

135.72

135.66

135.60

135.56

135.54

135.52

135.51

135.50

35.51

135.53

135.55

135.58

i35.62

135.65

135.69

135.73

$\begin{array}{ll}0.00 & 135.87 \\ 0.00 & 135.93 \\ 0.00 & 135.97 \\ 0.00 & 136.01 \\ 0.00 & 136.03 \\ 0.00 & 136.04 \\ 0.00 & 136.03 \\ 0.00 & 136.00 \\ 0.00 & 135.96 \\ 0.00 & 135.91 \\ 0.00 & 135.84 \\ 0.00 & 135.77 \\ 0.00 & 135.70 \\ 0.00 & 135.02 \\ 0.00 & 135.54 \\ 0.00 & 135.48 \\ 0.00 & 135.41 \\ 0.00 & 135.36 \\ 0.00 & 135.32 \\ 0.00 & 135.29 \\ 0.00 & 135.28 \\ 0.00 & 135.28 \\ 0.00 & 135.20 \\ 0.00 & 135.34 \\ 0.00 & 135.40 \\ 0.00 & 135.48 \\ 0.00 & 135.57 \\ 0.00 & 135.06 \\ 0.00 & 135.14 \\ 0.00 & 135.80 \\ 0.00 & 135.85 \\ 0.00 & 135.87 \\ 0.00 & 135.06 \\ 0.00 & 135.83 \\ 0.00 & 135.18 \\ 0.00 & 135.12 \\ 0.00 & 135.06 \\ 0.00 & 135.00 \\ 0.00 & 135.06 \\ 0.00 & 135.54 \\ 0.00 & 135.02 \\ 0.00 & 135.51 \\ 0.00 & 135.00 \\ 0.00 & 135.51 \\ 0.00 & 135.53 \\ 0.00 & 135.55 \\ 0.00 & 135.08 \\ 0.00 & 135.02 \\ 0.00 & 135.05 \\ 0.00 & 135.09 \\ 0.00 & 135.10 \\ 0.00 & \end{array}$


TABLE X (Contd.)

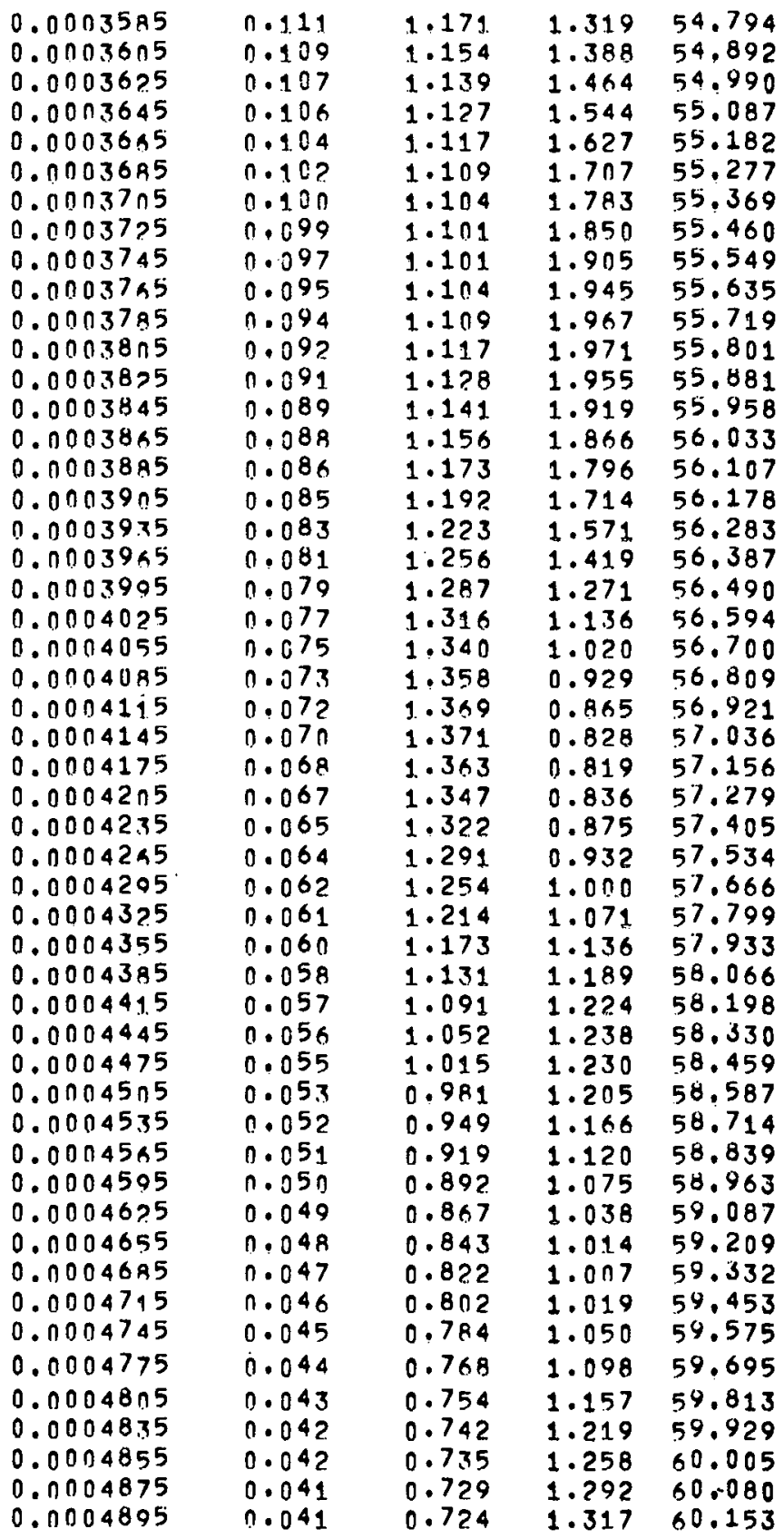

\begin{tabular}{|c|c|c|c|c|}
\hline $\begin{array}{l}0.001 \\
0.001 \\
0.001 \\
0.001 \\
0.001 \\
0.001 \\
0.001 \\
0.001 \\
0.001 \\
0.001 \\
0.001 \\
0.001 \\
0.001 \\
0.001 \\
0.001 \\
0.001 \\
0.001 \\
0.001 \\
0.001 \\
0.001 \\
0.001 \\
0.001 \\
0.001 \\
0.001 \\
0.001 \\
0.001 \\
0.001 \\
0.001 \\
0.001 \\
0.001 \\
0.001 \\
0.001 \\
0.001 \\
0.001 \\
0.001 \\
0.001 \\
0.001 \\
0.001 \\
0.001 \\
0.001 \\
0.001 \\
0.001 \\
0.001 \\
0.001 \\
0.001 \\
0.001 \\
0.001 \\
0.001 \\
0.001 \\
0.001 \\
.001\end{array}$ & $\begin{array}{l}0.001 \\
0.001 \\
0.001 \\
0.001 \\
0.001 \\
0.001 \\
0.001 \\
0.001 \\
0.001 \\
0.001 \\
0.001 \\
0.001 \\
0.001 \\
0.001 \\
0.001 \\
0.001 \\
0.001 \\
0.001 \\
0.001 \\
0.001 \\
0.001 \\
0.01 \\
0.01 \\
0.001 \\
0.001 \\
0.001 \\
0.001 \\
0.001 \\
0.001 \\
0.01 \\
0.01 \\
0.01 \\
0.01 \\
0.01 \\
0.01\end{array}$ & $\begin{array}{l}180.000 \\
180.000 \\
180.000 \\
180.000 \\
180.000 \\
180.000 \\
180.000 \\
180.000 \\
180.000 \\
180.000 \\
180.000 \\
180.000 \\
180.000 \\
180.000 \\
180.000 \\
180.000 \\
180.000 \\
180.000 \\
180.000 \\
180.000 \\
180.000 \\
180.000 \\
180.000 \\
180.000 \\
180.000 \\
180.000 \\
180.0000 \\
180.000 \\
180.000 \\
180.000 \\
180.000 \\
180.000 \\
180.000 \\
180.0000 \\
180.000 \\
180.000 \\
180.000 \\
180.000 \\
180.000 \\
180.000 \\
180.000 \\
180.000 \\
180.000 \\
180.000 \\
180.000\end{array}$ & 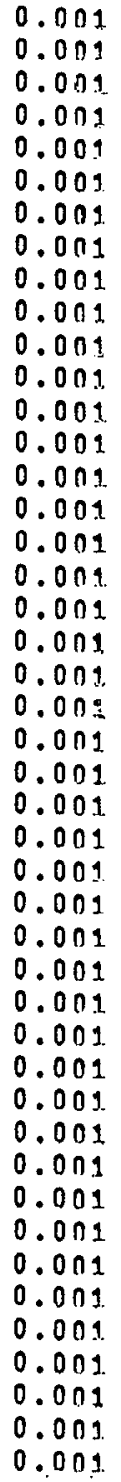 & $\begin{array}{l}4.442 \\
4.388 \\
4.373 \\
4.247 \\
4.163 \\
4.070 \\
3.970 \\
3.863 \\
3.751 \\
3.635 \\
3.51 .5 \\
3.393 \\
3.4 n 0 \\
3.488 \\
3.570 \\
3.646 \\
3.715 \\
3.8 n 1 \\
3.868 \\
3.916 \\
3.942 \\
3.948 \\
3.931 \\
3.894 \\
3.836 \\
3.759 \\
3.664 \\
3.555 \\
3.432 \\
3.298 \\
3.157 \\
3.009 \\
3.070 \\
3.173 \\
3.264 \\
3.343 \\
3.4 n 7 \\
3.456 \\
3.498 \\
3.5 n 4 \\
3.5 n 2 \\
3.493 \\
3.448 \\
3.396 \\
3.379\end{array}$ \\
\hline 0.001 & 0.001 & 180.000 & 0.001 & 3.249 \\
\hline $\begin{array}{l}0.001 \\
0.001 \\
0.001 \\
0.001 \\
0.001\end{array}$ & 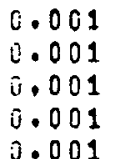 & $\begin{array}{l}180.000 \\
180.000 \\
180.000 \\
180.000\end{array}$ & $\begin{array}{l}0.001 \\
0.001 \\
0.001 \\
0.001 \\
0.001\end{array}$ & $\begin{array}{l}3.157 \\
3.054 \\
2.981 \\
2.9155\end{array}$ \\
\hline
\end{tabular}

135.77
135.81
135.83
135.86
135.87
135.88
135.87
135.87
135.85
135.82
135.79
135.76
135.72
135.68
135.64
135.60
135.57
135.52
135.48
135.46
135.46
135.47
135.49
135.52
135.57
135.61
135.67
135.72
135.76
135.80
135.82
135.84
135.84
135.83
135.82
135.80
135.77
135.76
135.74
135.74
135.73
135.74
135.74
135.74
135.74
135.73
135.72
135.71
135.70
135.68
135.67

0.00

0.0

$0.0 n$

0.00

0.00

0.00

0.00

0.00

0.00

0.00

0.00

0,00

0.01

0.00

0.00

0.00

0.00

0.00

0.00

0.00

0.00

0.00

0.00

0.00

0.0 n

0.0 ?

0.00

0.00

0.00

0.00

0.00

0.00

0.00

0.00

0,00

0.00

$0.0 n$

0.00

0.00

0.00

0.00

0,00

0.00

0.00

0.00

0.00

0.00

0.00

0.00

0.00

0.00
135.17

135.81

135.03

135.86

135.88

135.88

135.67

135.87

135.65

135.82

135.79

135.76

135.72

135.68

135.64

135.00

135.57

135.52

135.48

135.46

135.46

135.47

135.49

135.32

135.57

135.61

135.72

135.76

135.80

135.82

135.84

135.44

135.83

135.82

135.80

135.17

135.76

135.74

135.74

135.73

135.74

135.74

135.74

135.74

135.73

135.72

135.71

135.70

135.08 
TABLE X (Contd.)

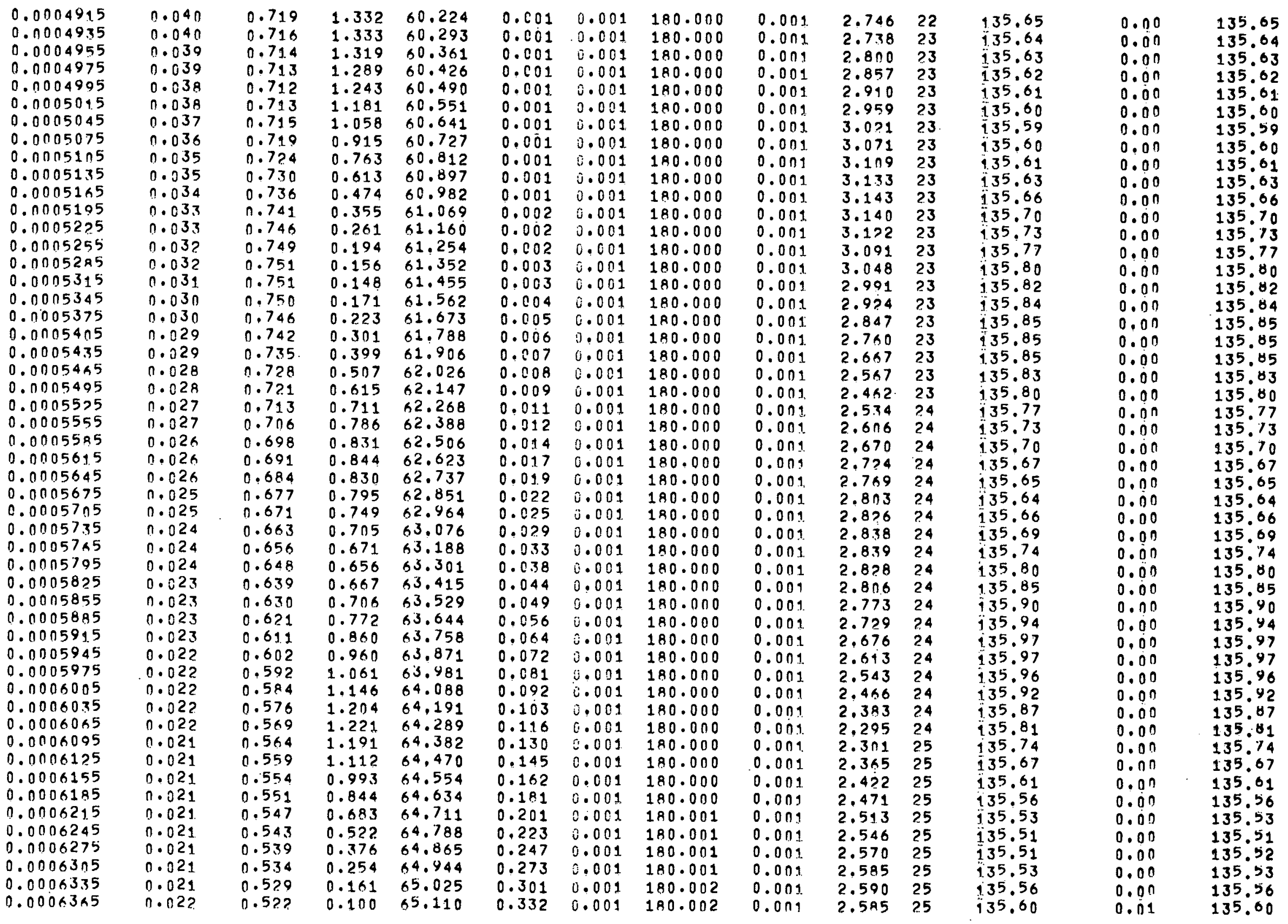


TABLE X (Contd.)

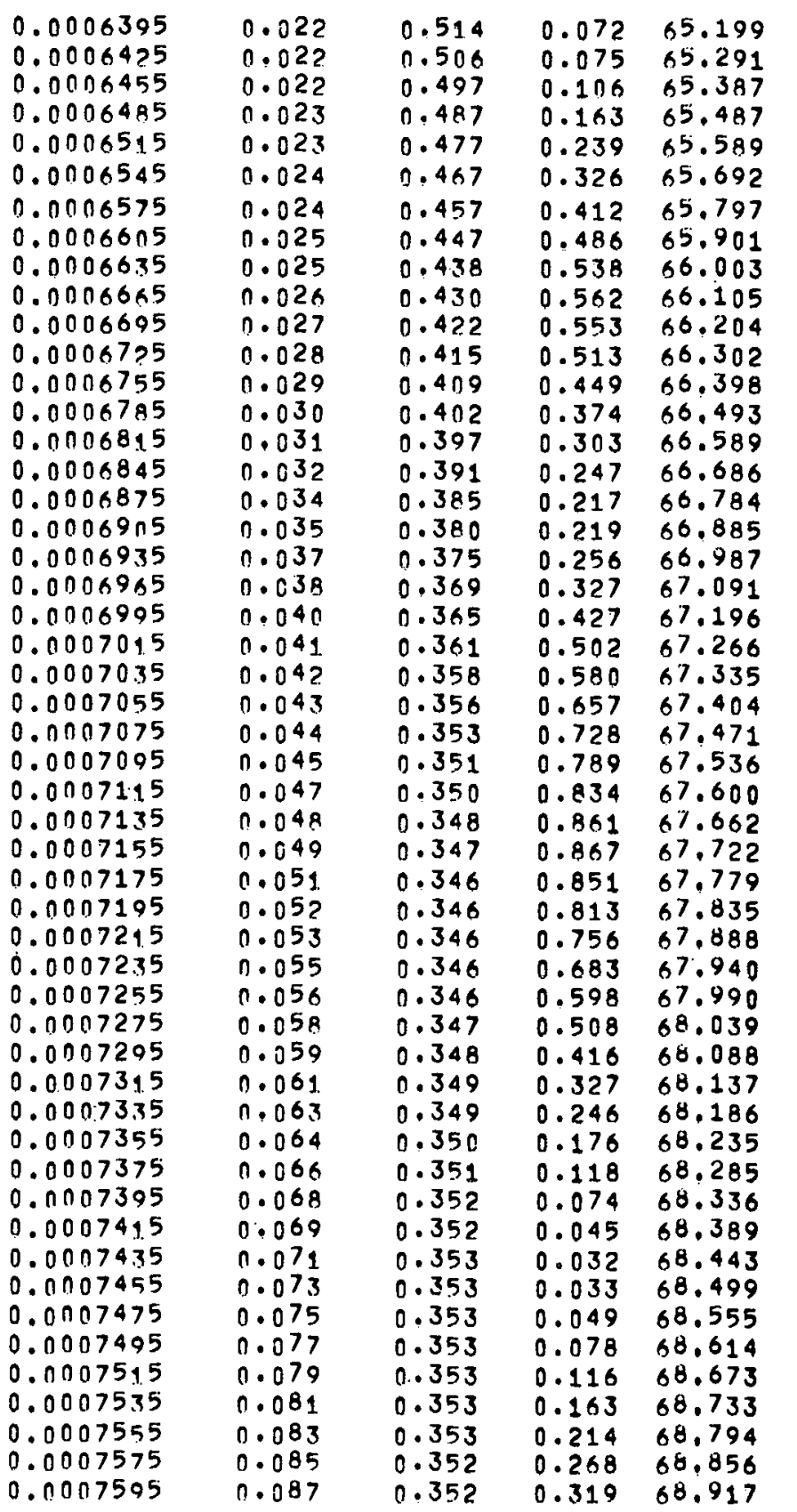

\begin{tabular}{|c|c|c|c|c|}
\hline $\begin{array}{l}0.365 \\
0.400 \\
0.438 \\
0.479 \\
0.523 \\
0.570\end{array}$ & 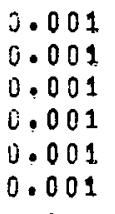 & $\begin{array}{l}180.003 \\
180.004 \\
180.005 \\
180.006 \\
180.007 \\
180.009\end{array}$ & $\begin{array}{l}0.0011 \\
0.0001 \\
0.001 \\
0.001 \\
0.001 \\
0.001\end{array}$ & $\begin{array}{l}2.571 \\
2.548 \\
2.515 \\
2.474 \\
2.476 \\
2.369\end{array}$ \\
\hline $\begin{array}{l}0.620 \\
0.673 \\
0.729 \\
0.789 \\
0.852 \\
0.918 \\
0.988 \\
1.061 \\
1.137 \\
1.216 \\
1.298 \\
1.383 \\
1.470 \\
1.559 \\
1.650 \\
1.712 \\
1.774 \\
1.836 \\
1.898 \\
1.960 \\
2.022 \\
2.084 \\
2.144 \\
2.204 \\
2.262 \\
2.319 \\
2.375 \\
2.428 \\
2.479 \\
2.528 \\
2.574 \\
2.616 \\
2.656 \\
2.691 \\
2.724 \\
2.752 \\
2.775 \\
2.795 \\
2.809 \\
2.819 \\
2.825 \\
2.825 \\
2.820 \\
2.810 \\
2.795\end{array}$ & $\begin{array}{l}0.001 \\
0.001 \\
0.001 \\
0.001 \\
0.001 \\
0.001 \\
0.001 \\
0.001 \\
0.001 \\
0.001 \\
0.001 \\
0.001 \\
0.001 \\
0.001 \\
0.001 \\
0.001 \\
0.001 \\
0.001 \\
0.001 \\
0.001 \\
0.001 \\
0.001 \\
0.001 \\
0.001 \\
0.001 \\
0.001 \\
0.01 \\
0.011 \\
0.01 \\
0.001 \\
0.001 \\
0.001 \\
0.001 \\
0.001 \\
0.001 \\
0.001 \\
0.001 \\
0.001 \\
0.001 \\
0.001 \\
0.001 \\
0.001 \\
0.001 \\
0.001 \\
0.001 \\
0.001\end{array}$ & $\begin{array}{l}180.011 \\
180.013 \\
180.015 \\
180.017 \\
180.020 \\
180.024 \\
180.027 \\
180.031 \\
180.036 \\
180.041 \\
180.046 \\
180.052 \\
180.059 \\
180.066 \\
180.074 \\
180.080 \\
180.086 \\
180.092 \\
180.099 \\
180.106 \\
180.113 \\
180.121 \\
180.129 \\
180.138 \\
180.147 \\
180.157 \\
180.167 \\
180.177 \\
180.188 \\
180.200 \\
180.211 \\
180.224 \\
180.237 \\
180.250 \\
180.264 \\
180.279 \\
180.294 \\
180.310 \\
180.326 \\
180.343 \\
180.360 \\
180.378 \\
180.396 \\
180.415 \\
180.435\end{array}$ & 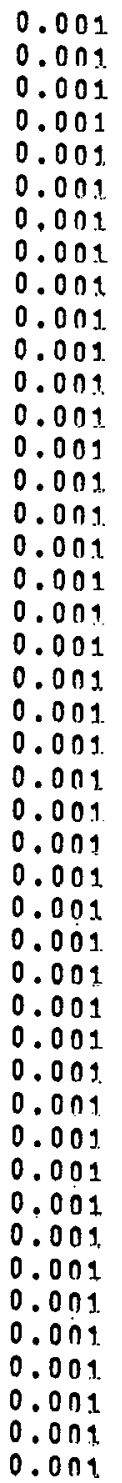 & $\begin{array}{l}2.307 \\
2.239 \\
2.166 \\
2.113 \\
2.175 \\
2.232 \\
2.283 \\
2.378 \\
2.367 \\
2.398 \\
2.423 \\
2.439 \\
2.449 \\
2.450 \\
2.444 \\
2.437 \\
2.426 \\
2.413 \\
2.396 \\
2.376 \\
2.354 \\
2.329 \\
2.302 \\
2.273 \\
2.262 \\
2.319 \\
2.375 \\
2.428 \\
2.479 \\
2.528 \\
2.574 \\
2.616 \\
2.656 \\
2.691 \\
2.724 \\
2.752 \\
2.775 \\
2.795 \\
2.879 \\
2.819 \\
2.825 \\
2.825 \\
2.870 \\
2.810 \\
2.795\end{array}$ \\
\hline
\end{tabular}

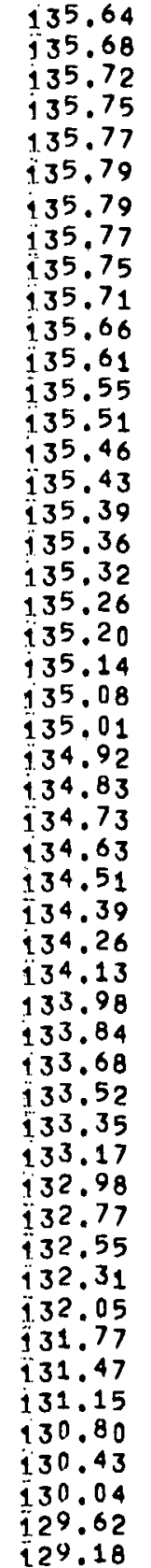


TABLE X (Contd.)

\begin{tabular}{|c|c|c|c|c|c|c|c|c|c|c|c|c|c|}
\hline $\begin{array}{l}0.0007615 \\
0.0007635 \\
0.0007655 \\
0.0007675 \\
0.0007695 \\
0.0007715 \\
0.0007735 \\
0.0007755 \\
0.0007775 \\
0.0007795 \\
0.0007815 \\
0.0007835 \\
0.0007855 \\
0.0007875 \\
0.0007895 \\
0.0007915 \\
0.0007935\end{array}$ & $\begin{array}{l}0.089 \\
0.092 \\
0.094 \\
0.096 \\
0.099 \\
0.101 \\
0.104 \\
0.106 \\
0.109 \\
0.111 \\
0.114 \\
0.117 \\
0.119 \\
0.122 \\
0.125 \\
0.128 \\
0.131\end{array}$ & $\begin{array}{l}0.351 \\
0.351 \\
0.350 \\
0.350 \\
0.350 \\
0.350 \\
0.349 \\
0.349 \\
0.349 \\
0.349 \\
0.348 \\
0.348 \\
0.347 \\
0.347 \\
0.346 \\
0.345 \\
0.343\end{array}$ & $\begin{array}{l}0.366 \\
0.406 \\
0.435 \\
0.453 \\
0.457 \\
0.447 \\
0.425 \\
0.392 \\
0.352 \\
0.307 \\
0.261 \\
0.220 \\
0.185 \\
0.159 \\
0.146 \\
0.146 \\
0.161\end{array}$ & $\begin{array}{l}68.978 \\
69.039 \\
69.100 \\
69.160 \\
69.219 \\
69.277 \\
69.335 \\
69.393 \\
69.450 \\
69.506 \\
69.563 \\
69.621 \\
69.679 \\
69.738 \\
69.797 \\
69.858 \\
69.920\end{array}$ & $\begin{array}{l}2.775 \\
2.749 \\
2.719 \\
2.684 \\
2.645 \\
2.601 \\
2.552 \\
2.500 \\
2.443 \\
2.383 \\
2.320 \\
2.253 \\
2.184 \\
2.113 \\
2.039 \\
1.963 \\
1.886\end{array}$ & $\begin{array}{l}0.0001 \\
0.0001 \\
0.0001 \\
0.0001 \\
0.0001 \\
0.0001 \\
0.001 \\
0.001 \\
0.001 \\
0.0001 \\
0.0001 \\
0.001 \\
0.001 \\
0.001 \\
0.001 \\
0.001 \\
0.001\end{array}$ & $\begin{array}{l}180.455 \\
180.476 \\
180.497 \\
180.519 \\
180.541 \\
180.564 \\
180.587 \\
180.611 \\
180.636 \\
180.660 \\
180.686 \\
180.712 \\
180.738 \\
180.764 \\
180.791 \\
180.819 \\
180.847\end{array}$ & 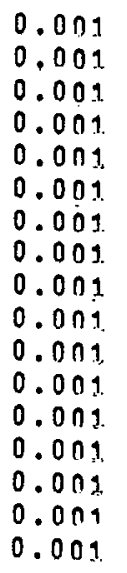 & $\begin{array}{l}2.775 \\
2.749 \\
2.719 \\
2.684 \\
2.645 \\
2.611 \\
2.552 \\
2.500 \\
2.443 \\
2.383 \\
2.320 \\
2.253 \\
2.184 \\
2.113 \\
2.039 \\
1.943 \\
1.896\end{array}$ & $\begin{array}{l}27 \\
27 \\
27 \\
27 \\
27 \\
27 \\
27 \\
27 \\
27 \\
27 \\
27 \\
27 \\
27 \\
27 \\
27 \\
27 \\
27\end{array}$ & $\begin{array}{l}128.72 \\
128.25 \\
127.76 \\
127.25 \\
126.74 \\
126.22 \\
125.69 \\
125.16 \\
124.64 \\
124.12 \\
123.61 \\
123.11 \\
122.62 \\
122.14 \\
121.67 \\
121.22 \\
120.78\end{array}$ & $\begin{array}{l}10.23 \\
10.79 \\
11.36 \\
11.94 \\
12.53 \\
13.12 \\
13.71 \\
14.31 \\
14.90 \\
15.50 \\
16.09 \\
16.67 \\
17.25 \\
17.82 \\
18.39 \\
18.93 \\
19.47\end{array}$ & $\begin{array}{l}138.95 \\
139.04 \\
139.12 \\
139.12 \\
139.27 \\
139.33 \\
139.40 \\
139.47 \\
139.54 \\
139.02 \\
139.90 \\
139.78 \\
139.87 \\
139.96 \\
140.06 \\
140.15 \\
140.25\end{array}$ \\
\hline $\begin{array}{l}0.0007955 \\
0.0007975 \\
0.0007995 \\
0.0008015 \\
0.0008035 \\
0.0008055 \\
0.0008075 \\
0.0008095 \\
0.0008115 \\
0.0008135 \\
0.0008155 \\
0.0008175 \\
0.0008195 \\
0.0008215 \\
0.0008235 \\
0.0008255 \\
0.0008275 \\
0.0008295 \\
0.0008315 \\
0.0008335 \\
0.0008355 \\
0.0008375 \\
0.0008395 \\
0.0008415 \\
0.0008435 \\
0.0008455 \\
0.0008475 \\
0.0008495 \\
0.0008515 \\
0.0008535\end{array}$ & $\begin{array}{l}0.134 \\
0.137 \\
0.140 \\
0.143 \\
0.146 \\
0.150 \\
0.153 \\
0.157 \\
0.160 \\
0.164 \\
0.167 \\
0.171 \\
0.174 \\
0.178 \\
0.182 \\
0.186 \\
0.190 \\
0.194 \\
0.198 \\
0.202 \\
0.206 \\
0.210 \\
0.215 \\
0.219 \\
0.223 \\
0.228 \\
0.232 \\
0.237 \\
0.242 \\
0.246\end{array}$ & $\begin{array}{l}0.342 \\
0.340 \\
0.339 \\
0.337 \\
0.335 \\
0.333 \\
0.331 \\
0.329 \\
0.327 \\
0.326 \\
0.324 \\
0.323 \\
0.322 \\
0.320 \\
0.319 \\
0.31 .8 \\
0.317 \\
0.316 \\
0.315 \\
0.313 \\
0.312 \\
0.310 \\
0.309 \\
0.307 \\
0.305 \\
0.303 \\
0.300 \\
0.298 \\
0.296 \\
0.293\end{array}$ & $\begin{array}{l}0.190 \\
0.231 \\
0.285 \\
0.346 \\
0.412 \\
0.478 \\
0.540 \\
0.593 \\
0.633 \\
0.657 \\
0.663 \\
0.649 \\
0.618 \\
0.571 \\
0.511 \\
0.444 \\
0.373 \\
0.303 \\
0.239 \\
0.184 \\
0.141 \\
0.111 \\
0.096 \\
0.095 \\
0.109 \\
0.137 \\
0.175 \\
0.223 \\
0.275 \\
0.328\end{array}$ & $\begin{array}{l}69.983 \\
70.047 \\
70.111 \\
70.176 \\
70.241 \\
70.305 \\
70.369 \\
70.431 \\
70.493 \\
70.553 \\
70.611 \\
70.668 \\
70.724 \\
70.778 \\
70.831 \\
70.883 \\
70.935 \\
70.986 \\
71.038 \\
71.090 \\
71.143 \\
71.197 \\
71.252 \\
71.308 \\
71.365 \\
71.423 \\
71.483 \\
71.542 \\
71.602 \\
71.663\end{array}$ & $\begin{array}{l}1.807 \\
1.727 \\
1.647 \\
1.566 \\
1.485 \\
1.404 \\
1.323 \\
1.242 \\
1.162 \\
1.083 \\
1.005 \\
0.928 \\
0.852 \\
0.778 \\
0.705 \\
0.034 \\
0.564 \\
0.496 \\
0.430 \\
0.366 \\
0.304 \\
0.244 \\
0.185 \\
0.129 \\
0.074 \\
0.022 \\
0.000 \\
0.000 \\
0.000 \\
0.000\end{array}$ & $\begin{array}{l}0.001 \\
0.001 \\
0.001 \\
0.001 \\
0.001 \\
0.001 \\
0.0191 \\
0.001 \\
0.001 \\
0.001 \\
0.001 \\
0.01 \\
0.011 \\
0.001 \\
0.001 \\
0.001 \\
0.001 \\
0.001 \\
0.001 \\
0.001 \\
0.001 \\
0.001 \\
0.001 \\
0.001 \\
0.001 \\
0.001 \\
0.001 \\
0.001 \\
0.001 \\
0.001\end{array}$ & $\begin{array}{l}180.875 \\
180.904 \\
180.933 \\
180.962 \\
180.991 \\
181.021 \\
181.051 \\
181.082 \\
181.112 \\
181.143 \\
181.174 \\
181.205 \\
181.237 \\
181.268 \\
181.300 \\
181.332 \\
181.364 \\
181.396 \\
181.428 \\
181.460 \\
181.493 \\
181.525 \\
181.557 \\
181.590 \\
181.622 \\
181.654 \\
181.687 \\
181.719 \\
181.751 \\
181.784\end{array}$ & 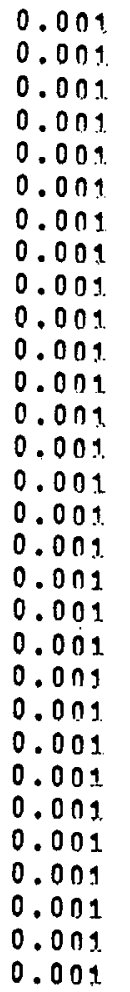 & $\begin{array}{l}1.807 \\
1.727 \\
1.647 \\
1.566 \\
1.495 \\
1.454 \\
1.487 \\
1.570 \\
1.552 \\
1.583 \\
1.613 \\
1.642 \\
1.669 \\
1.695 \\
1.799 \\
1.742 \\
1.742 \\
1.781 \\
1.707 \\
1.811 \\
1.823 \\
1.833 \\
1.840 \\
1.844 \\
1.846 \\
1.846 \\
1.843 \\
1.837 \\
1.829 \\
1.818\end{array}$ & $\begin{array}{l}27 \\
27 \\
27 \\
27 \\
27 \\
25 \\
25 \\
25 \\
25 \\
25 \\
25 \\
25 \\
25 \\
25 \\
25 \\
25 \\
25 \\
25 \\
25 \\
25 \\
25 \\
25 \\
25 \\
25 \\
25 \\
25 \\
25 \\
25 \\
25 \\
25\end{array}$ & $\begin{array}{l}120.35 \\
219.94 \\
119.53 \\
119.14 \\
118.77 \\
118.40 \\
118.05 \\
117.72 \\
117.40 \\
117.10 \\
116.82 \\
116.56 \\
116.33 \\
116.11 \\
115.92 \\
115.76 \\
115.62 \\
115.51 \\
115.42 \\
115.36 \\
115.32 \\
115.30 \\
115.30 \\
115.32 \\
115.35 \\
115.40 \\
115.45 \\
115.51 \\
115.55 \\
115.59\end{array}$ & $\begin{array}{l}19.99 \\
20.50 \\
20.99 \\
21.44 \\
21.92 \\
22.35 \\
22.77 \\
23.16 \\
23.54 \\
23.89 \\
24.32 \\
24.53 \\
24.82 \\
25.03 \\
25.33 \\
25.55 \\
25.75 \\
25.93 \\
26.08 \\
26.22 \\
26.34 \\
26.43 \\
26.51 \\
26.57 \\
26.61 \\
26.63 \\
26.64 \\
26.64 \\
26.64 \\
26.64\end{array}$ & $\begin{array}{l}140.54 \\
140.44 \\
140.53 \\
140.01 \\
140.09 \\
140.76 \\
140.02 \\
140.69 \\
140.94 \\
140.99 \\
141.05 \\
141.09 \\
141.14 \\
141.19 \\
141.25 \\
141.31 \\
141.37 \\
141.43 \\
141.30 \\
141.58 \\
141.66 \\
141.73 \\
141.81 \\
141.89 \\
141.96 \\
142.03 \\
142.09 \\
142.15 \\
142.19 \\
142.23\end{array}$ \\
\hline
\end{tabular}

NUMBER OF LINFS OF PRINT OUT IN THE FINAL TABLE $1=389$

NUMBER OF RECORDS WRITTEN ON TAPE $N=78$

0.00 .2

$1.818 \quad 25 \quad 115.59$

PROGRAM OV'- 


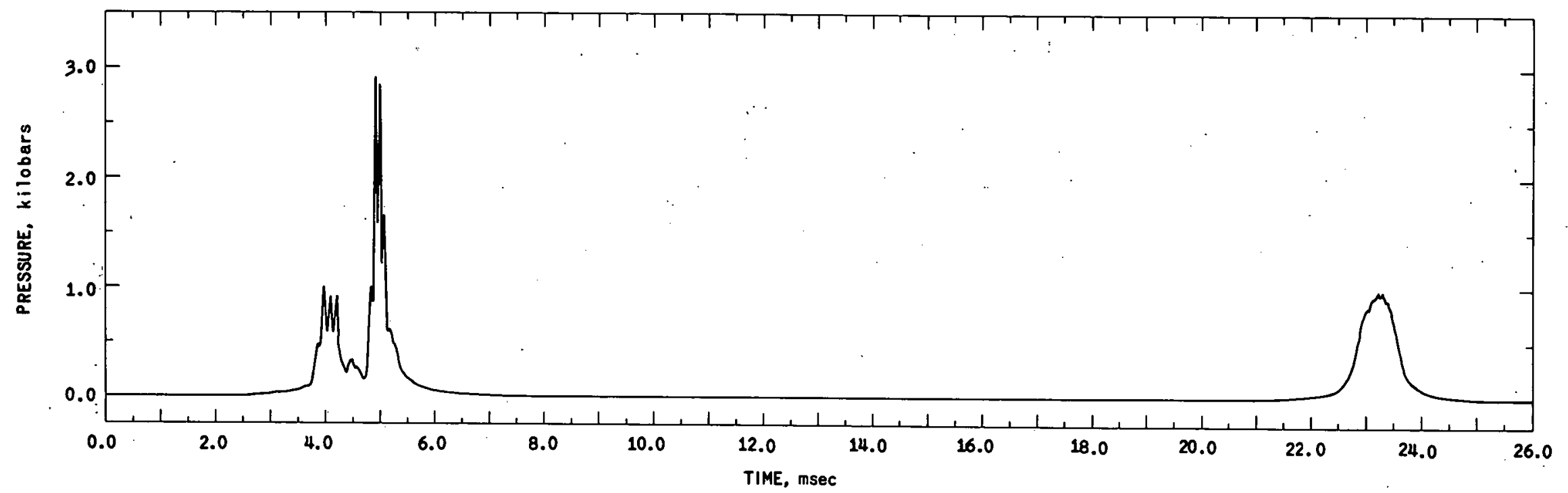

Fig. 21. Pressure-TimeCurve for the Inside Face of the Concrete Vessel

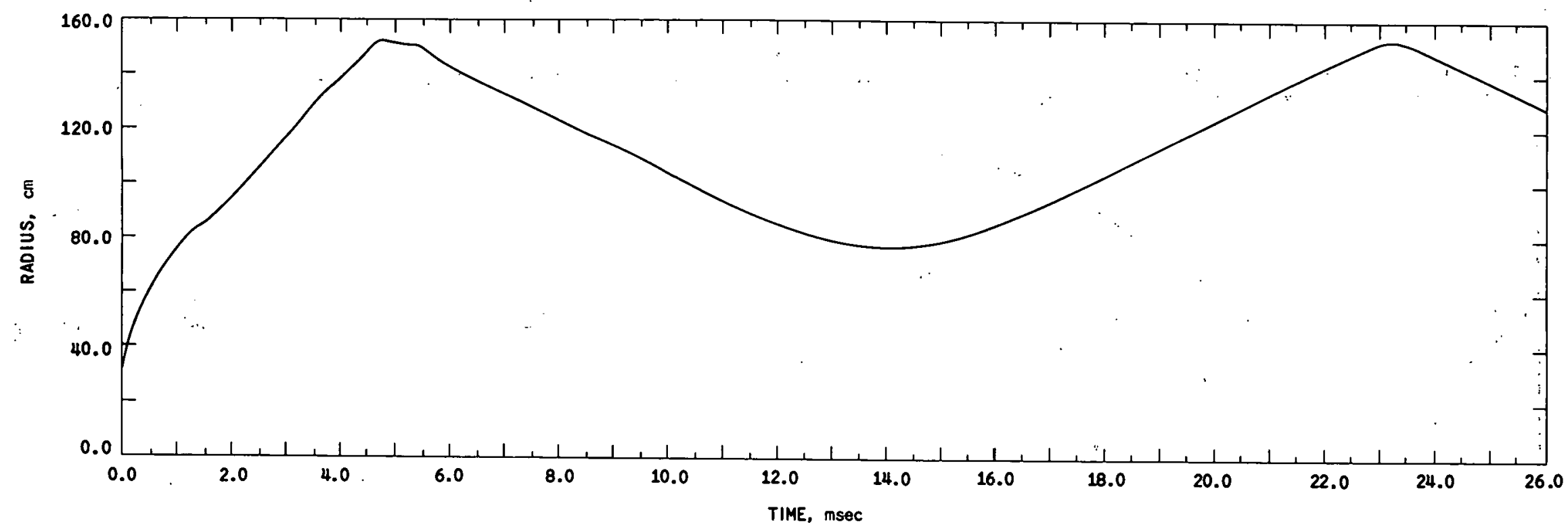

Fig. 22. Location-Time Curve for the TNT-Water Interface 


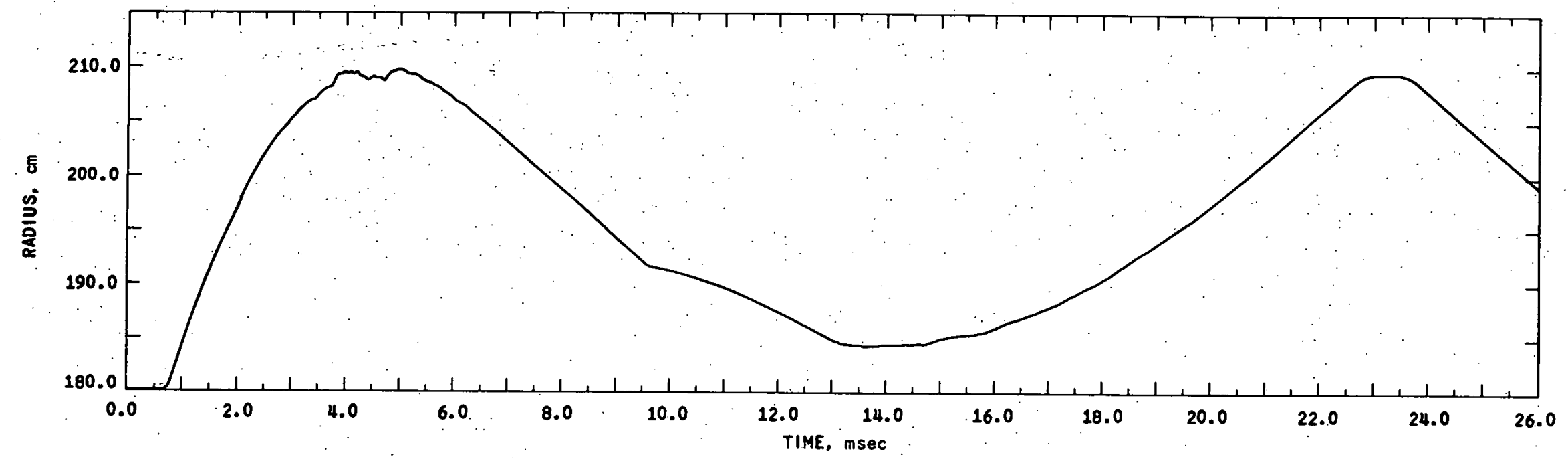

Fig. 23. Location-Time Curve for the Reactor Vessel (Water-Argon Interface)

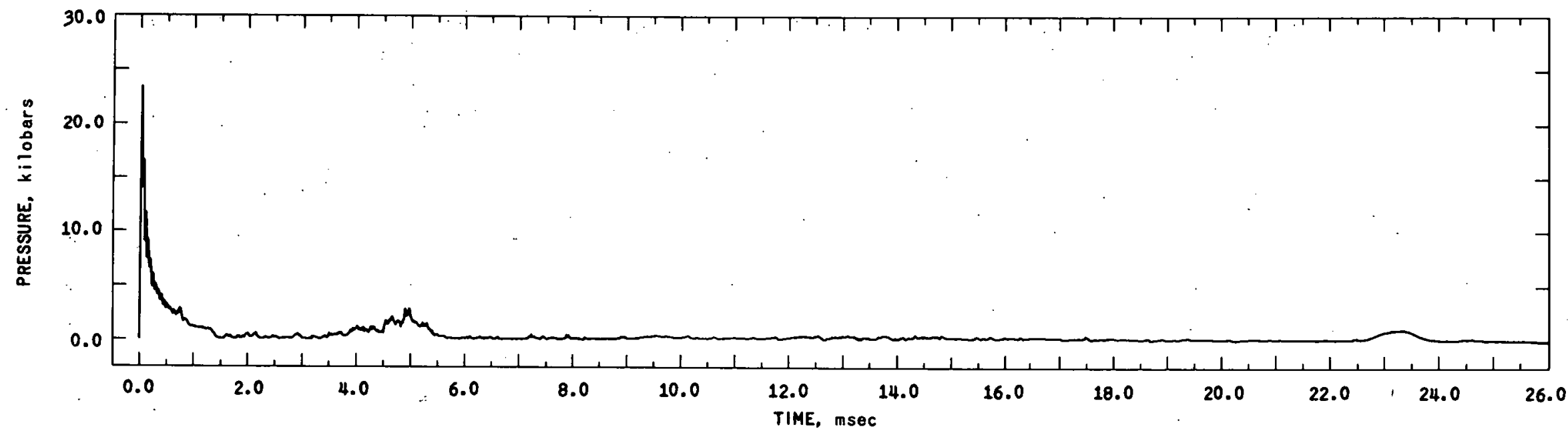

Fig. 24. Maximum Pressure in the System Outside of the Gas Bubble 


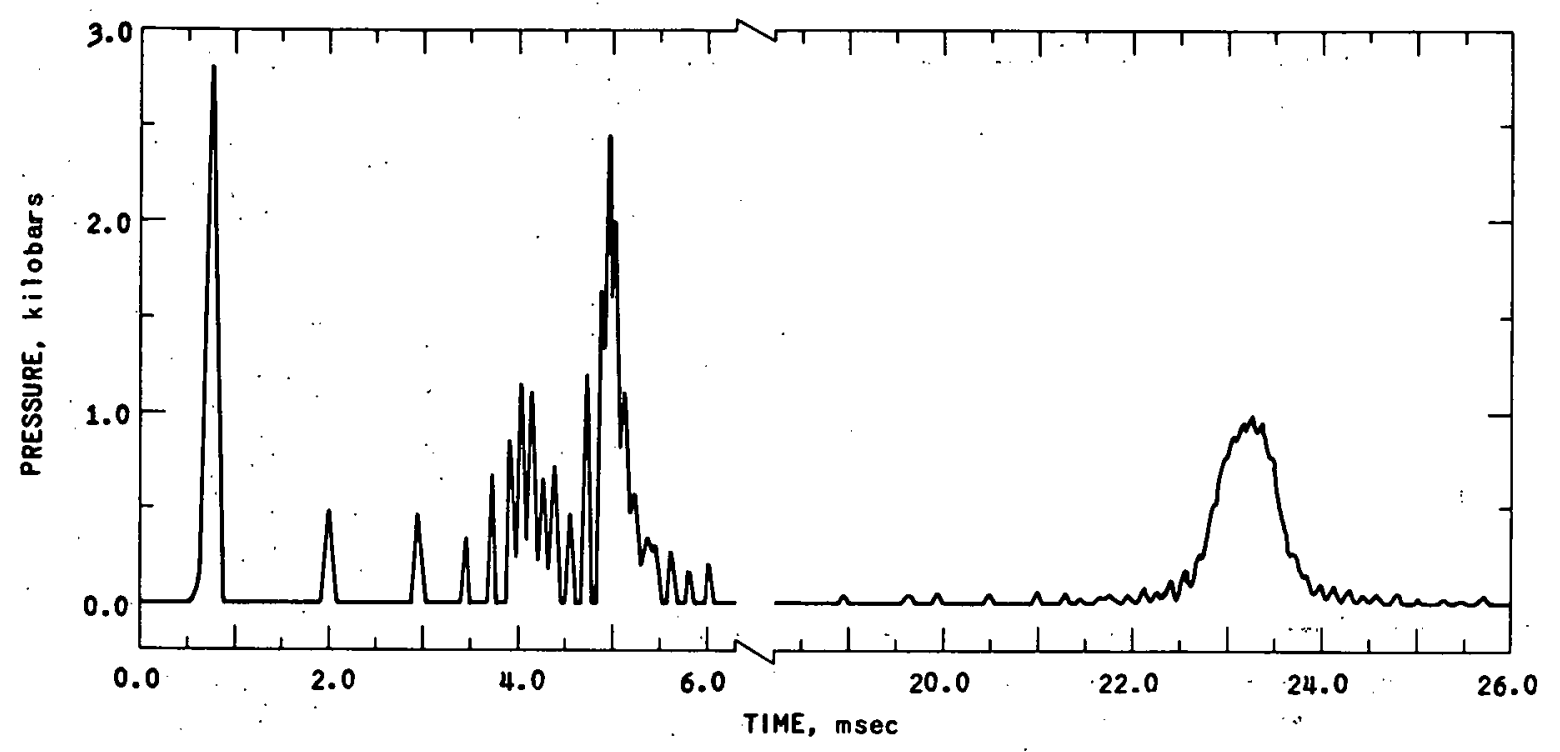

Fig. 25. Pressure-Time Curve for the Water at the Reactor Vessel (Water-Argon)

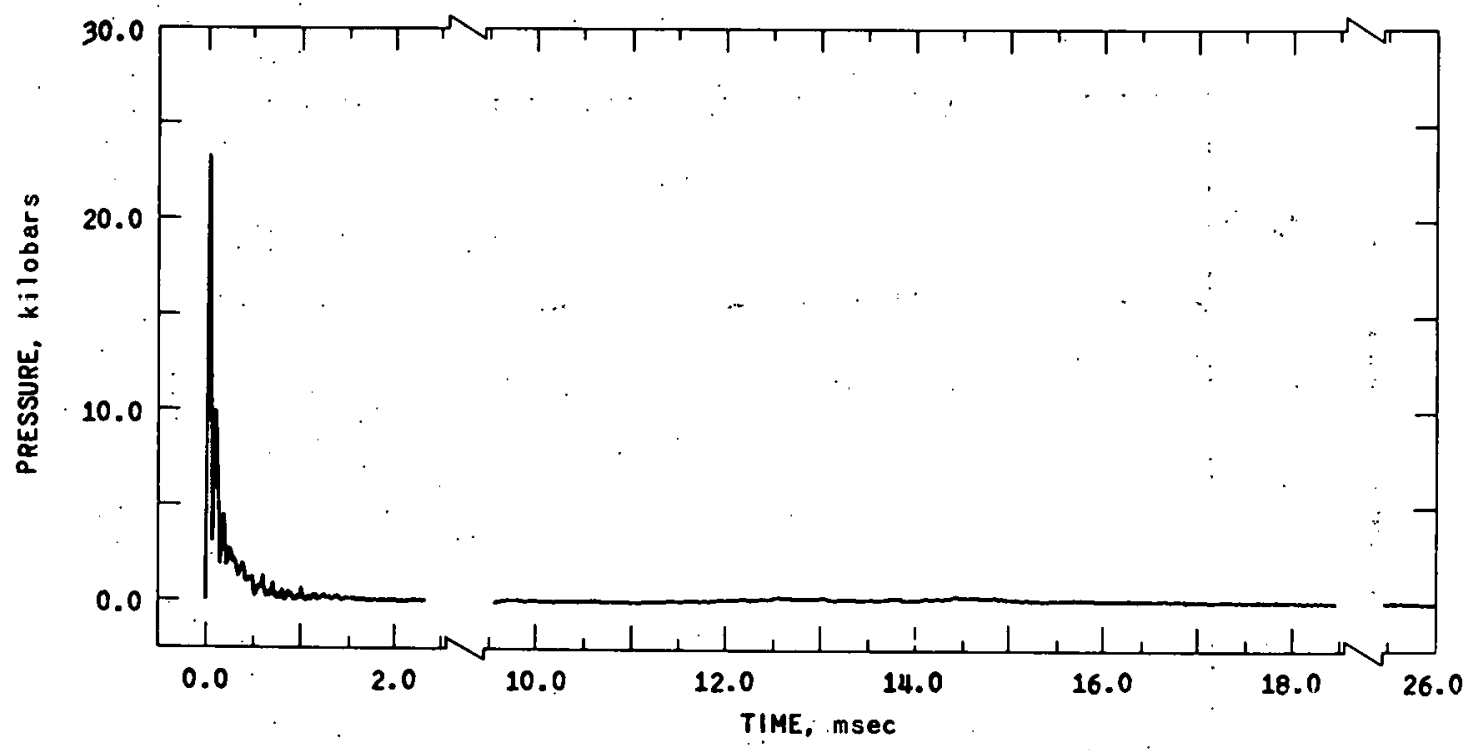

Fig. 26. Pressure-Time Curve for the Water at the TNT-Water Interface 


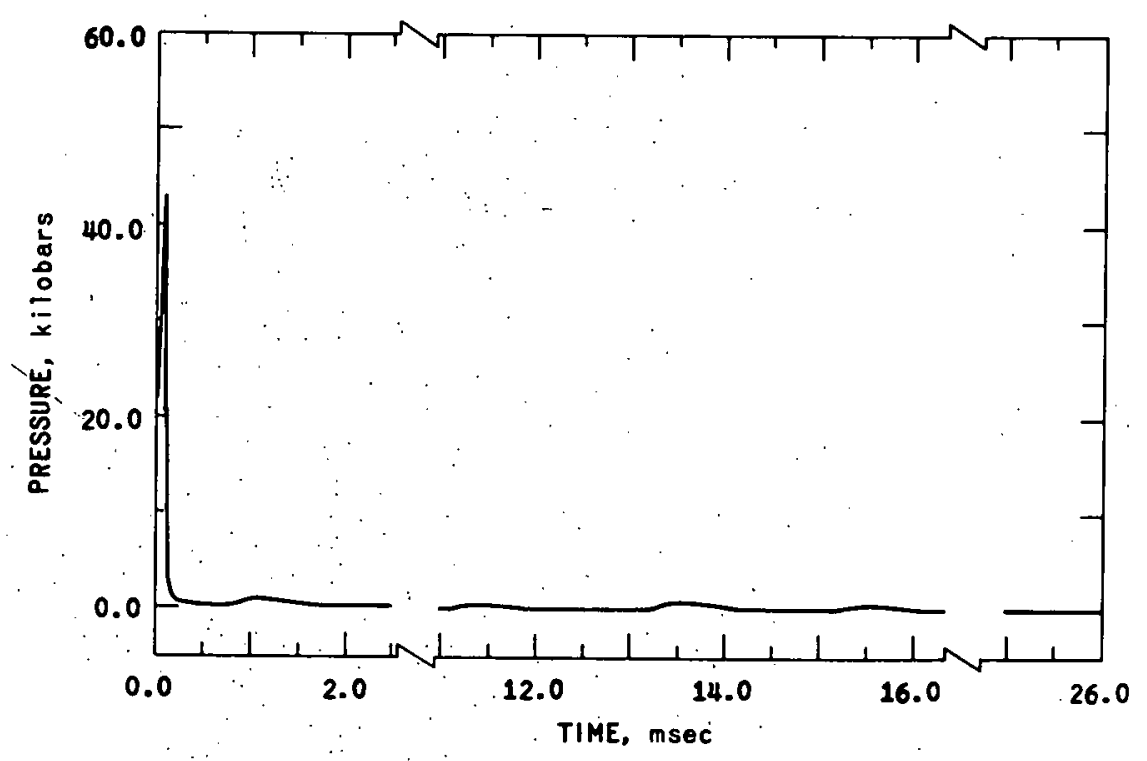

Fig. 27. Pressure-TimeCurve for the Center of the Gas Bubble

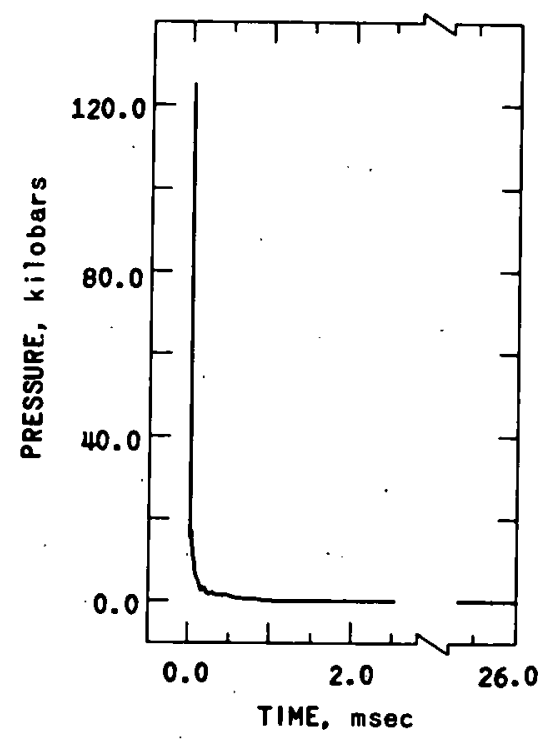

Fig. 28: Pressure-TimeCurve for the TNT at the TNT-Water Interface

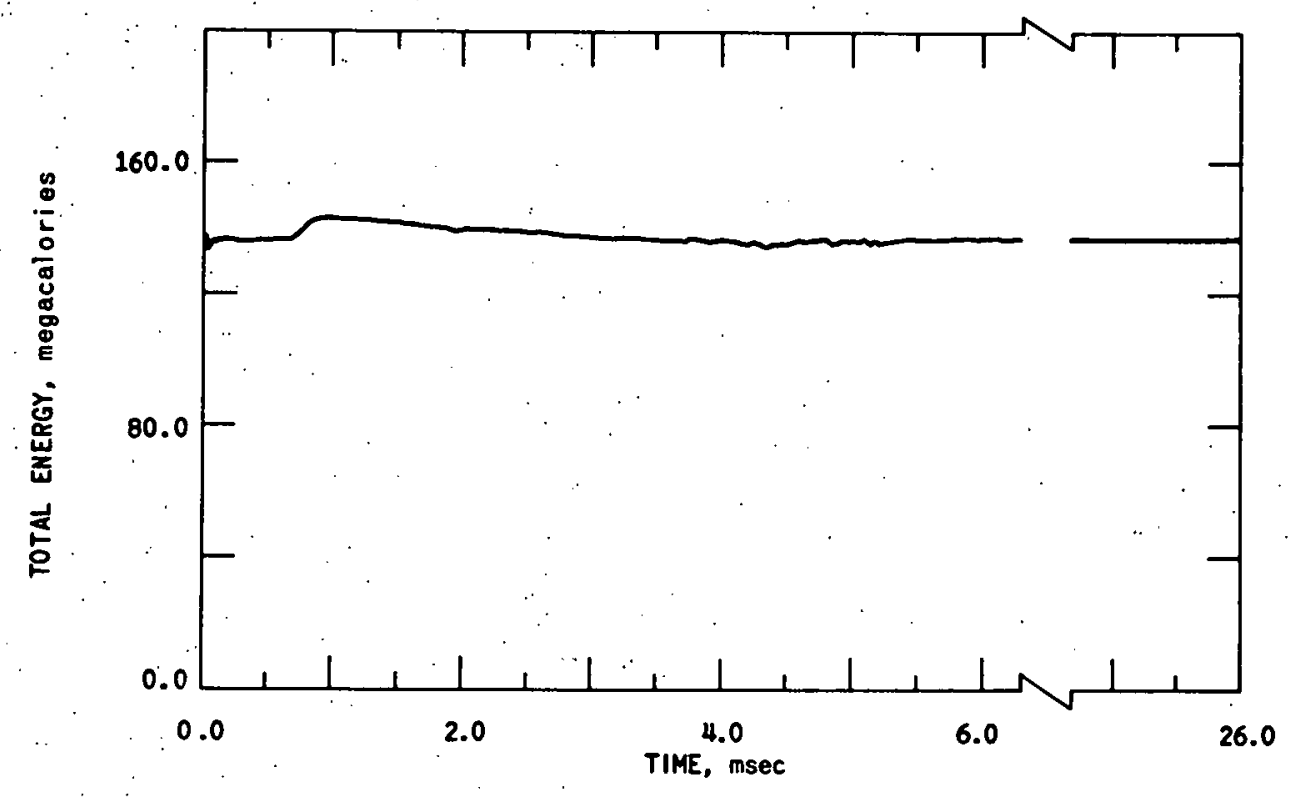

Fig. 29. Total Energy of the System as a Function of Time 


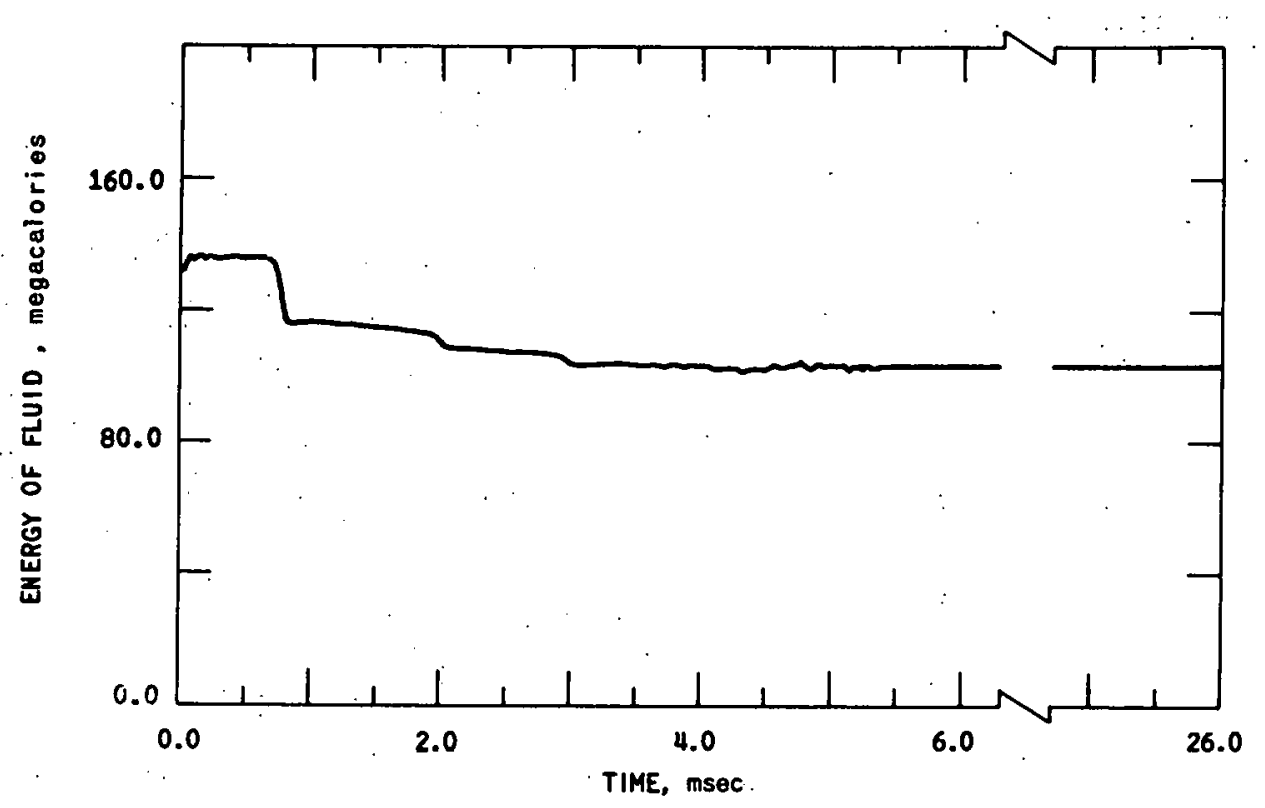

Fig. 30. Energy Associated with the Fluid as a Function of Time

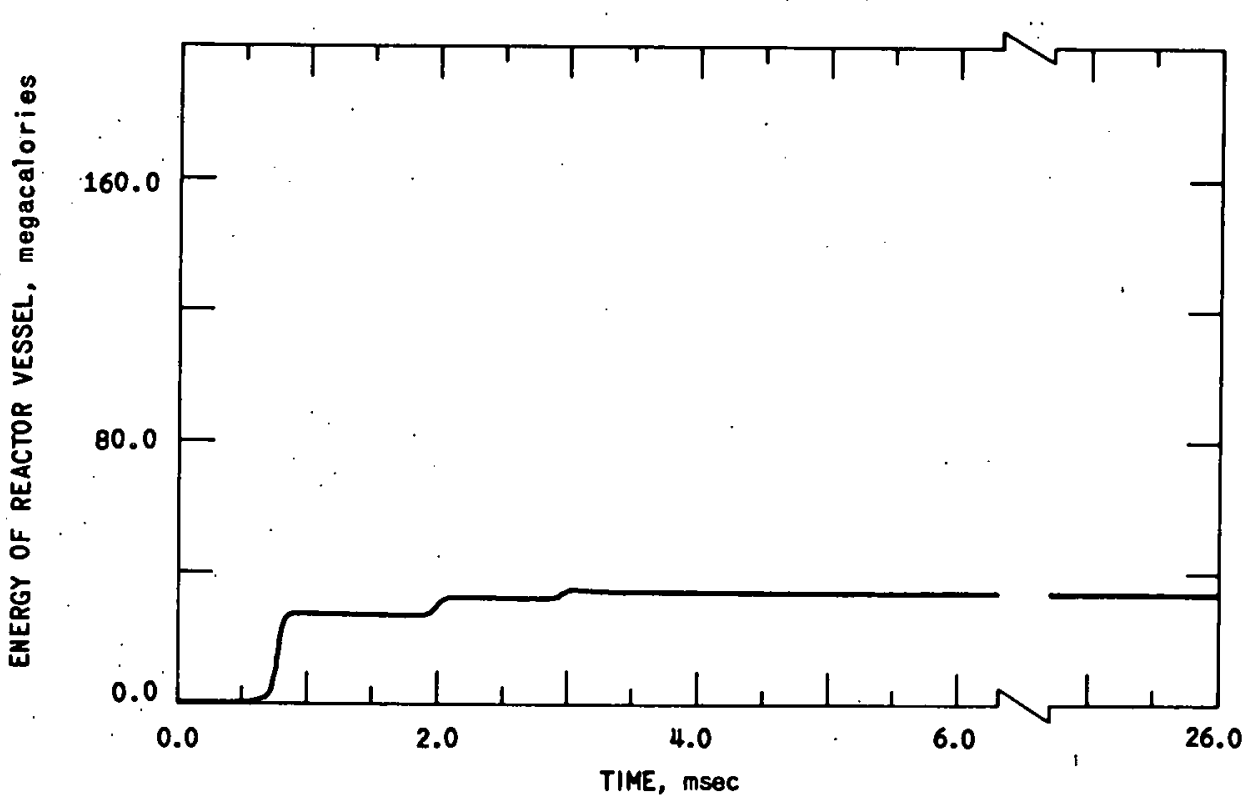

Fig. 31. Energy Associated with the Reactor Vessel as a Function of Time 


\section{DISCUSSION OF RESULTS}

A. Comparison of Results

Computer results for the simulated sodium reactor installation without the reactor vessel are compared to those results obtained with the reactor vessel by use of the following figures:

1. The pressure-time curve for the center of the gas bubble (Figs. 17 and 27).

The pressure at the center of the gas bubble is. virtually unaffected by the addition of the reactor vessel to the system.

2. The pressure-time curve for the TNT at the TNT-water interface (Figs. 10 and 28).

The pressure in the TNT at the TNT-water interface is virtually unaffected by the addition of the reactor vessel to the system.

3. The pressure-time curve for the water at the TNT-water interface (Fig.s. 15 and 26).

The pressure in the water at the TNT-water interface is virtually unaffected.by the addition of the reactor vessel to the system.

4. The location-time curve for the TNT-water interface (Figs. 12 and 22).

In a minor way, the motion of the TNT-water interface is affected by, the addition of the reactor vessel to the system. The period of the second bubble pulsation is increased because of the retarding action caused by the resistance of the reactor vessel. The maximum size of the gas bubble is virtually unaffected by the addition of the reactor vessel.

5. The pressure-time curve for the water at the reactor vessel (water-argon interface). (Figs. 14 and 25).

The pressure history. for the water at the reactor vessel or water-argon-interface is changed considerably. with the addition of the reactor vessel to the system. Because of the resistance of the reactor vessel, the first pressure peak $(t=0.75 \mathrm{msec})$, which is due to the shock wave, increases from $1^{+}$to $3^{-} \mathrm{kb}$. Also, the peak pressures due to the fluid momentum are displaced from 4.5 and $20 \mathrm{msec}$ to 5 and $23 \mathrm{msec}$, respectively. The magnitudes of these two peak pressures are virtually unchanged. 
6. The location-time curve for the reactor vessel (water-argon interface) (Figs. 13 and 23).

The motion of the boundary separating the water and the argon is greatly affected.by the addition of the reactor vessel to the system. The boundary is. slowed down because of the resistance of the reactor vessel. This results in a longer period for the second pulsation.

7. The pressure-time curve for the inside face of the concrete vessel (Fig.s. 11 and 21 ).

The addition of the reactor vessel to the system has resulted in three noticeable differences between the two pressure-time curves for the inside face of the concrete vessel: (a) The pressure peak at $2.0 \mathrm{msec}$ (Fig. 11) has been eliminated by the reactor vessel as a result of the resistance of the reactor vessel, (b) the maximum pressure has been de-. creased, and (c) the period of the second pressure peak has been increased.

8. The maximum pressure in the system outside of the gas bubble (Figs. 16 and 24).

These graphs are presented for information only. and 29).

9. The total energy in the system as a function of time (Figs. 18

The system analyzed in this problem constitutes a closed energy system. Therefore, the total energy in the system should remain constant. These two graphs depict energy conservation to within the accuracy of the finite-difference solution.

Figures 30 and 31 are presented to show the way in. which the various energy components vary.

B. General Discussion of Results

Figure 31 shows that the reactor vessel removes a substantial amount of energy from the fluid. The maximum reactor vessel energy is 33.35 Mcal. The total energy in the system is $136.60 \mathrm{Mcal}$. Thus, the energy of the reactor vessel represents $24.4 \%$ of the total energy. The energy remaining: in the fluid is thereby decreased by this amount, and thus the effect of the destructive component on the concrete containment vessel is diminished.

The impulse on the concrete containment vessel is $2,066,292 \mathrm{gm}$ $\mathrm{cm} / \mathrm{sec} / \mathrm{sq} \mathrm{cm}$. The resulting maximum strain rate is $9.77 \mathrm{sec}^{-1}$. This corresponds to a $20.7 \%$ decrease compared to the analysis made without. the reactor vessel. 


\section{CONCLUSION}

It can be concluded from the results obtained from this solution that the reactor vessel is a very good energy-absorbing device and should be included as part of the primary containment system. The addition of the reactor vessel to the system reduces the effect that the destructive component produces on the concrete structure as compared to the effect produced without a reactor vessel. Thus, the use of the static properties of the steelistrands for design becomes a better approximation.

The incorporation of the Tait form of the equation of state for the water into the computer program decreases the computer time required for the solution with virtually no change in the accuracy of the solution.

It is known that the stress in a strain-hardening. steel like Type 304 stainless is a function of strain $\epsilon$ and the strain rate $\dot{\epsilon} ; i_{\circ}$ e.,

$$
\sigma=\sigma(\epsilon, \dot{\epsilon})
$$

In this problem, the static properties of the material were used as a first approximation. To refine the solution, it is necessary to have a function relating the strain rate and the dynamic yield stress similar to that given for mild steel,*

$$
\sigma_{\mathrm{d}}=\sigma_{\mathrm{y}}\left[\left(\frac{\dot{\epsilon}}{40.4}\right)^{0.2}+.1\right],
$$

where

$$
\begin{aligned}
& \sigma_{\mathrm{d}}=\text { dynamic yield stres.s, psi; } \\
& \sigma_{\mathrm{y}}=\text { static yield stress, psi; }
\end{aligned}
$$

and

$$
\dot{\epsilon}=\text { strain rate, } \sec ^{-1} \text {. }
$$

A function similar to Eq. 94, together with a linear strain-hardening function, could be used to obtain a more exact true stress-strain curve for the conditions to which the reactor vessel is subjected. The strain rate can be obtained at any given time from the relationship

$$
\dot{\epsilon}_{\mathrm{c}}=\frac{\mathrm{u}}{\mathrm{r}_{0}},
$$

*See Ref. 23, page 38. 
where $u$ and $r_{0}$ are the velocity at time $t$ and the initial radius of the $r e-$ actor vessel, respectively. The effective strain rate, $\dot{\epsilon}$, obtained from an expression similar to Eq. 78. is given as

$$
\dot{\epsilon}=2 \dot{\epsilon}_{\mathrm{c}} \text {. }
$$

A very important factor in the analysis.is the thickness of the argon layer in comparison to the allowable increase in the radius of the reactor vessel before rupture. The reactor vessel must not be allowed to impinge against the concrete vessel while retaining its.integrity, as this. would cause adverse effects. Thus, the thickness of the argon layer must be correlated to the plastic deformation of the vessel.

Further work in the nuclear-reactor containment field on this concept should include (1) a more reliable equation of state for the argon, (2) optimization of the computer program as to the zone widths used.in the solution, and (3) extension of the analysis to a two-dimensional system, which resembles more closely the actual reactor system. The fracture criteria for the reactor vessel should be based upon the strain rate as. well as the total strain. It is also necessary to obtain a new solution for distribution of the pressure, particle velocity, etc., for TNT by. the use of high-speed computers and present explosive technological data. 
APPENDIX A

Tables of Experimental Data

Extracted from References

TABLE XI. Spherical Detonation Wave in $\mathrm{TNT}^{\mathrm{a}}$

\begin{tabular}{|c|c|c|c|c|c|c|c|}
\hline$r / R$ & $\xi$ & $\psi$ & $c / U$ & $f$ & $u / U$ & p. $\times 10^{-10}$ & $\rho$ \\
\hline 1.0 & 0.2424 & 0.320 & 0.7575 & 2.60 & 0.2424 & 15.00 & 2.000 \\
\hline 0.99 .904 & 0.230 & 0.3084 & 0.742 & 2.06 & 0.230 & 14.45 & 1.972 \\
\hline 0.99632 & 0.220 & 0.2986 & 0.733 & 1.80 & 0.219 & 13.90 & 1.942 \\
\hline 0.99271 & 0.210 & 0.2874 & 0.724 & 1.20 & 0.208 & 13.34 & 1.928 \\
\hline 0.9885 & 0.20 & 0.2748 & .0 .719 & 1.00 & 0.1977 & 12.68 & 1.880 \\
\hline 0.9821 & 0.19 & 0.2612 & 0.714 & 0.70 & 0.1866 & 12.11 & 1.850 \\
\hline 0.9744 & 0.18 & 0.2469 & 0.710 & 0.60 & 0.1754 & 11.09 & 1.797 \\
\hline 0.9656 & 0.17 & 0.2323 & 0.708 & 0.60 & 0.16415 & 10.59 & 1.773 \\
\hline 0.9557 & 0.16 & 0.2177 & 0.702 & 0.60 & 0.1529 & 9.44 & 1.709 \\
\hline 0.9448 & 0.15 & 0.2028 & 0.700 & 0.62 & 0.14172 & 8.91 & 1.683 \\
\hline 0.9320 & 0.14 & 0.1879 & 0.694 & 0.80 & 0.1305 & 7.94 & 1.639 \\
\hline 0.9178 & 0.13 & 0.1737 & 0.688 & 1.45 & 0.1193 & 7.08 & 1.595 \\
\hline 0.8997 & 0.12 & 0.1601 & 0.675 & 1.97 & 0.1080 & 6.46 & 1.562 \\
\hline 0.8804 & 0.11 & 0.1468 & 0.659 & 2.52 & 0.09684 & 5.875 & 1.531 \\
\hline 0.8577 & 0.10 & 0.1337 & 0.641 & 3.00 & 0.08577 & $5.43_{3}$ & 1.506 \\
\hline 0.8275 & 0.09 & 0.1205 & 0.618 & 3.40 & 0.07448 & 4.84 & 1.468 \\
\hline 0.7960 & 0.08 & 0.1071 & 0.596 & 3.88 & 0.06368 & $4.41_{6}$ & 1.440 \\
\hline 0.7584 & 0.07 & 0.09350 & 0.568 & 4.22 & 0.05309 & 3.98 & 1.407 \\
\hline 0.7148 & 0.06 & 0.07966 & 0.538 & 4.50 & 0.04289 & $3.56_{5}$ & 1.372 \\
\hline 0.6668 & 0.05 & 0.06514 & 0.512 & 4.65 & 0.03334 & 3.236 & 1.342 \\
\hline 0.6166 & 0.04 & 0.05084 & 0.487 & 4.72 & 0.02466 & $2.95_{1}$ & 1.316 \\
\hline 0.5672 & 0.03 & 0.03673 & 0.461 & 4.74 & 0.01702 & 2.66 & 1.285 \\
\hline 0.5186 & 0.02 & 0.02327 & 0.446 & 4.70 & 0.01037 & 2.48 & 1.265 \\
\hline 0.4950 & 0.015 & 0.01695 & 0.441 & 4.70 & 0.00741 & 2.43 & 1.259 \\
\hline 0.4723 & 0.010 & 0.01096 & 0.430 & 4.66 & 0.00472 & 2.34 & 1.249 \\
\hline 0.4474 & 0.005 & 0.00527 & 0.425 & 4.64 & 0.00224 & 2.29 & 1.244 \\
\hline 0.418 & 0 & 0 & 0.418 & 4.60 & 0 & 2.19 & 1.233 \\
\hline
\end{tabular}

axtracted from Ref. 15. The figures in columns 4, 7, and 8 are taken from an unpublished report by $\mathrm{H}$. Jones. They are not identical with the revised figures published by Jones and Miller (Ref.10, Table 3, p.497), but Taylor decided the difference was not sufficiently great to warrant the recalculation of the spherical detonation wave.

The detonation velocity, $U$, has the value $638,000 \mathrm{~cm} / \mathrm{sec}$ based on a density, $\rho$, of the packed TNT of $1.51 \mathrm{gm} / \mathrm{cm}^{3}$; the unit of pressure, $\mathrm{p}$, is dynes $/ \mathrm{cm}^{2}$. 
TABLE XII. Shock-wave and Thermodynamic Data for the Water Hugoniot Centered at $20^{\circ} \mathrm{C}$ and $1 \mathrm{~atm}^{\mathrm{a}}$

\begin{tabular}{|c|c|c|c|c|c|c|c|c|}
\hline $\begin{array}{l}\mathrm{P}, \\
\mathrm{kb}\end{array}$ & $\begin{array}{c}V \\
\mathrm{~cm}^{3} / \mathrm{gm}\end{array}$ & $\begin{array}{l}\mathrm{T}, \\
{ }^{\circ} \mathrm{C}\end{array}$ & $\begin{array}{c}\mathrm{U}_{\mathrm{s}} \\
\mathrm{km} / \mathrm{sec}\end{array}$ & $\begin{array}{c}\mathrm{U}_{\mathrm{p}} \\
\mathrm{km} / \mathrm{sec}\end{array}$ & $\mathrm{cm} / \mathrm{sec}$ & $\begin{array}{c}\Delta \mathrm{S} \\
\mathrm{cal} / \mathrm{gm} / \mathrm{deg}\end{array}$ & $\begin{array}{c}\Delta E \\
\mathrm{cal} / \mathrm{gm}\end{array}$ & $\begin{array}{c}\Delta \mathrm{H} \\
\mathrm{cal} / \mathrm{gm}\end{array}$ \\
\hline 10 & 1.0018 & 20 & 1.483 & 0 & 1.483 & 0 & 0 & 0 \\
\hline 5 & 0.8773 & 36 & 2.008 & 0.250 . & 2.350 & 0.005 & 7.4 & 112 \\
\hline 10 & 0.8204 & 54 & 2.352 & 0.426 & 2.800 & 0.018 & 21.7 & 218 \\
\hline 15 & 0.7845 & 74 & 2.632 & 0.571 & 3.130 & 0.038 & 38.9 & 320 \\
\hline 20 & 0.7583 & 96 & 2.871 & 0.698 & 3.390 & 0.062 & 58.2 & 420 \\
\hline 25 & 0.7378 & 121 & 3.083 & 0.812 & 3.611 & 0.087 & 78.8 & 519 \\
\hline 30 & 0.7207 & 145 & 3.273 & 0.918 & 3.810 & 0.114 & 100.7 & 617 \\
\hline 40 & 0.6940 & 196 & 3.611 & 1.110 & 4.114 & 0.169 & 147.0 & 810 \\
\hline 50 & 0.6735 & 251 & 3.910 & 1.281 & 4.330 & 0.224 & 196.0 & 1000 \\
\hline 60 & 0.6561 & 310 & 4.173 & 1.440 & 4.513 & 0.276 & 247.7 & 1188 \\
\hline 70 & 0.6414 & 372 & 4.415 & 1.588 & 4.666 & 0.326 & 301.2 & 1373 \\
\hline 80 & 0.6287 & 436 & 4.639 & 1.728 & 4.795 & 0.374 & 356.4 & 1558 \\
\hline 90 & 0.6175 & 502 & 4.848 & 1.860 & 4.907 & 0.420 & 413.0 & 1740 \\
\hline 100 & 0.6075 & 570. & 5.045 & $1.986^{\circ}$ & 5.015 & 0.463 & 470.8 & 1922 \\
\hline 110 & 0.5980 & 638 & 5.228 & 2.108 & 5.113 & 0.504 & 530.4 & 2101 \\
\hline 120 & 0.5893 & 710 & 5.404 & 2.225 & 5.214 & 0.543 & 591.1 & 2280 \\
\hline 130 & 0.5813 & 781. & 5.570 & 2.338 & 5.295 & 0.580 & 652.7 & 2457 \\
\hline 1.40 & 0.5740 & 854 & 5.731 & $2: 447$ & 5.380 & 0.615 & 751.2 & 2634 \\
\hline 150 & 0.6558 & 927 & 5.883 & 2.554 & 5.462 & 0.649 & 779.1 & 2810 \\
\hline 170 & 0.5538 & 1074 & 6.160 & 2.760 & 5.626 & 0.712 & 909.4 & 3158 \\
\hline 190 & 0.5420 & 1223 & 6.428 & 2.956 & 5.781 & 0.771 & 1043.2 & 3503 \\
\hline 200 & 0.5363 & 1297 & 6.567 & 3.051 & 5.856 & 0.798 & 1111.7 & 3673 \\
\hline 210 & 0.5310 & 1371 & $6: 679$ & 3.144 & 5.928 & 0.825 & 1180.6 & 3844 \\
\hline 230 & $0.5209^{\circ}$ & 1520 & 6.916 & 3.326 & 6.072 & 0.876 & 1320.7 & 4182 \\
\hline 250 & 0.5112 & 1667 & 7.151 & 3.502 & 6.211 & 0.923 & 1464.5 & 4517 \\
\hline 300 & 0.4897 & 2037 & 7.668 & 3.920 & - & 1.031 & 1834.5 & 5343 \\
\hline 350 & 0.4705 & 2407 & 8.131 & 4.312 & - & 1.127 & 2220.5 & 6153 \\
\hline 400 & 0.4530 & 2777 & 8.552 & 4.685 & - & 1.212 & 2621.3 & 6949 \\
\hline 450 & 0.4371 & 3147 & 8.943 & 5.041 & - & 1.290 & 3034.3 & 7732 \\
\hline
\end{tabular}

axtracted from Ref. 13. 


\section{APPENDIX B}

Description of the Miscellaneous Computer Programs

1. Least-squares Curve-fitting Program

The analytic fits to experimental data were all obtained by a leastsquares curve-fitting program adapted to the CDC-160-A computer. This computer program produced a least-squares polynomial fit to a set of discrete data by the use of orthogonal polynomials.* This program performed the least-squares operations for four types of polynomial forms:
a. Polynomial: $\mathrm{Y}=\mathrm{A}+\mathrm{BX}+\mathrm{CX^{2 }}+\ldots$
b. Exponential: $Y=\exp \left(A+B X+C X^{2}+\ldots\right)$.
c. Power: $Y=\exp \left[A+B(\ln X)+C(\ln X)^{2}+\ldots\right]$.
d。 Logarithmic: $Y=A+B(\ln X)+C(\ln X)^{2}+\ldots$.

The form that resulted in the best fit to each set of data was used.

\section{Program for CalComp 580. Plotter}

The graphical representation of the computer results was obtained by the use of a plotting subroutine** adapted to the CDC-3600 computer. The required output from the main.computer program was saved on a separate magnetic tape. The information on this tape was transformed to appropriate instructions for a CalComp 580. plotter.

All the graphs resulting from this analysis were drawn in original form by a CalComp 580 plotter. These graphs were then traced by a draftsman and reduced photographically to the form. presented in this report.

\section{Program for the Impulse}

The area under the pressure-time curve was obtained by the use of a program written for the CDC-3600 computer. This program was based on the trapezoid rule for performing the numerical integration. The area was computed from $t_{1}$, the time at which the pressure on the concrete first exceeded $P_{0}$, to $t_{2}$, the time at which the computer solution was ended.

The magnitude of the impulse obtained by the use of this computer program is

$$
\text { Impulse }=2,607,150 \mathrm{gm}-\mathrm{cm} / \mathrm{sec} / \mathrm{cm}^{2} \text {. }
$$

* The method was taken from a paper by Forsythe, G. E., Generation and Use of Orthogonal Polynomials. for Data Fitting with a Digital Computer, J. Soc. Indust. Appl。Math.6 (1957).

*** Technical Memorandum No. 70, ANL, Off-Line Plotting Techniques Using CalComp Magnetic Tape Plotting System 580, LeVee, C. G., and Ohde, J. A. (Apri.1 20, 1964). 


\section{APPENDIX C}

\section{Equations}

1. Equations for the Speed of Sound
a. TNT

The speed of sound in the TNT explosion products is determined by an analytic fit to the data contained in columns 4 and 7 of Table. XI of the form

$$
\mathrm{c}_{\mathrm{TNT}}=183556.0+49547.0 . \mathrm{P}-2108.0 . \mathrm{P}^{2}
$$

where $P$ and $c$ are in dynes $/ \mathrm{cm}^{2}$ and $\mathrm{cm} / \mathrm{sec}$, respectively。

\section{b. Water}

The speed of sound in the water is determined by an analytic fit to the data contained in columns. 1 and 6 of Table X.II of the form

$$
c_{\text {water }}=256906.0+3853.0 \mathrm{P}-.13 .0 \mathrm{P}^{2} \text {, }
$$

where $P$ and $c$ are in $k b$ and $c m / s e c$, respectively.

$$
\text { c. Argon }
$$

equation:*

The speed of sound in the argon is determined by the following

$$
c_{\text {argon }}=(\gamma P V)^{1 / 2},
$$

where $P$ and $V$ are in dynes $/ \mathrm{cm}^{2}$ and $\mathrm{cm}^{3} / \mathrm{gm}$, respectively, and $\gamma$, the ratio of the specific heats, has the value 1.66 .

2. Equation:for Determining the Shock Speed, $U_{S}$, in the Water

In an.iterative process involving finite-difference equations, the number of iterations can be made relatively small by making a good initial guess for the parameter involved. In the determination of the shock speed in the water, the initial value was obtained by an analytic fit to the data contained in columns 1 and 4 of Table XII of the form

$$
\mathrm{U}_{\mathrm{S}}=1.07073+0.05486 \mathrm{P}-0.00022 \mathrm{P}^{2}
$$

where. $P$ and $U_{S}$ are in $\mathrm{kb}$ and $\mathrm{km} / \mathrm{sec}$, respectively.

\footnotetext{
* This equation can be found in any elementary physics book. See for example, Hausmann, E., and Slack, E. P., Physics, Third Edition (1948).
} 
3. Equation for the Internal Energy of the Argon

The equation of state for the argon is of the form

$$
P=\frac{R T}{V^{2}}\left(V+B_{0}\right)-\frac{A_{0}}{V^{2}}\left(1-\frac{a}{V}\right) \text {. }
$$

From thermodynamics, the change in specific internal energy can be expressed in terms of temperature and volume changes as

$$
d E=\left(\frac{\partial E}{\partial T}\right)_{V} d T+\left(\frac{\partial E}{\partial V}\right)_{T} d V
$$

Als o from thermodynamics,

$$
\left(\frac{\partial E}{\partial T}\right)_{V}=C_{v}
$$

and

$$
\left(\frac{\partial E}{\partial V}\right)_{T}=T\left(\frac{\partial P}{\partial T}\right)_{V}-P
$$

Therefore, by substitution, Eq. 102 becomes

$$
d E=C_{V} d T+\left[T\left(\frac{\partial P}{\partial T}\right)_{V}-P\right] d V
$$

By differentiating Eq.. 101, one obtains

$$
\left(\frac{\partial P}{\partial T}\right)_{\dot{V}}=\frac{\Omega}{V^{2}}\left(V+B_{0}\right)
$$

Substitution of Eqs. 101 and 104 into Eq. 103 gives the required equation for the internal energy of the argon:

$$
d E=C_{v} d T+\left[\frac{A_{0}}{V}\left(1-\frac{a}{V}\right)\right] d V .
$$

4. Transformation of the Equations for the Water

The following equations have been obtained from pages 28-30:

$$
\begin{aligned}
& \mathrm{H}(\mathrm{P}, \mathrm{V})=\mathrm{H}_{\mathrm{h}}(\mathrm{P})+\xi(\mathrm{P})\left[\mathrm{V}-\mathrm{V}_{\mathrm{h}}(\mathrm{P})\right] \\
& \mathrm{V}_{1} / \mathrm{V}_{0}=\left(\mathrm{U}_{\mathrm{S}}-\mathrm{U}_{\mathrm{p}}\right) / \mathrm{U}_{\mathrm{s}},
\end{aligned}
$$




$$
\begin{aligned}
& P_{1}-P_{0}=U_{s} U_{p} / V_{0}, \\
& H_{1}-H_{0}=\frac{1}{2}\left(P_{1}-P_{0}\right)\left(V_{0}+V_{1}\right), \\
& U_{S}-1.483=25.306 . \log _{10}\left(1+U_{p} / 5.190\right), \\
& \log _{10} \xi=2.17943+0.0030338 P,
\end{aligned}
$$

and

$$
E=H-P V
$$

The units used for the parameters in Eqs. 106-112 are as follows:

\begin{tabular}{ll} 
Symbol & Unit \\
\hline P, $\xi$ & $\mathrm{kb}$ \\
$\mathrm{H}, \mathrm{E}$ & $\mathrm{cal} / \mathrm{gm}$ \\
$\mathrm{V}$ & $\mathrm{cm}^{3} / \mathrm{gm}$ \\
$\mathrm{U}$ & $\mathrm{km} / \mathrm{sec}$
\end{tabular}

By. considering the units, Eqs. 106 and 112 become

$$
\begin{aligned}
& \mathrm{H}=\mathrm{H}_{\mathrm{h}}+\xi\left(\mathrm{V}-\mathrm{V}_{\mathrm{h}}\right) 23.8892 \\
& \mathrm{E}=\mathrm{H}-(\mathrm{PV}) 23.8892 .
\end{aligned}
$$

By taking antilogs and simplifying, Eq. 110. becomes

$$
\mathrm{U}_{\mathrm{p}}=4.53493\left(1.0953^{\left.\mathrm{S}_{-}-1.1444\right)}\right.
$$

By. considering the units and substituting for $U_{p}$ (Eq.. 1i5), Eq. 108. becomes

$$
\mathrm{U}_{\mathrm{S}}\left(1.0953^{\left.\mathrm{U}_{\mathrm{S}}-1.1444\right)}=0.02209 \mathrm{P}\right.
$$

where $P_{0}$ and $V_{0}$ have been replaced by the values. zero and 1.0018 , respectively. becomes

For the Hugoniot curve, $V_{1}=V_{h}$ and $H_{1}=H_{h}$, so that Eq. 107

$$
\cdot \mathrm{V}_{\mathrm{h}}=1.0018\left(1-\mathrm{U}_{\mathrm{p}} / \mathrm{U}_{\mathrm{s}}\right)
$$


and, by considering the units and choosing $\mathrm{H}_{0}=0$, Eq. 109, becomes

$$
\mathrm{H}_{\mathrm{h}}=11.9446 \mathrm{P}\left(1.0018+\mathrm{V}_{\mathrm{h}}\right) \text {. }
$$

By taking antilogs and simplifying, Eq. 111 becomes

$$
\xi=151.16\left(10^{0.0030338 \mathrm{P}}\right) \text {. }
$$

Equations 51-57 represent Eqs. 113-119, respectively.

5. The Equation.for the Lagrangean Coordinates

For a spherical shell with an inside radius and an outside radius designated $r_{1}$ and $r_{2}$, respectively, and a density $\rho_{0}$, the mass of the shell is given by

$$
\mathrm{m}=\frac{4}{3} \pi \rho_{0}\left(\mathrm{r}_{2}^{3}-\mathrm{r}_{1}^{3}\right)
$$

Similarly, for a spherical shell of radii $R_{1}$ and $R_{2}$ and density $\rho$, the mass of the shell is given by

$$
M=\frac{4}{3} \pi \cdot \rho\left(\mathrm{R}_{2}^{3}-\mathrm{R}_{1}^{3}\right)
$$

If the masses of the two spherical shells are equal, then

$$
\rho_{0}\left(r_{2}^{3}-r_{1}^{3}\right)=\rho\left(R_{2}^{3}-R_{1}^{3}\right) \text {. }
$$

If the terms on the right side of Eq. 122 are associated with the actual physical system, i.e., the finite-difference net, at time $t=0$, then the terms on the left side are associated with the standard reference configuration of density $\rho_{0}$.

The Lagrangean coordinates are calculated by Eq. 122. The first zone of fluid, which is at the center of the system, is a small sphere. For this zone, $r_{1}=R_{1}=0$, and therefore the Lagrangean coordinate of interface 2 is

$$
\mathrm{r}_{2}=\frac{\rho}{\rho_{0}} \mathrm{R}_{2}
$$

The Lagrangean coordinate, $r_{2}$, becomes the inside radius in the standard reference configuration for the next outer zone of fluid, which is a spherical shell. Hence, the Lagrangean coordinate of interface 3 is 


$$
r_{3}=\left[r_{2}^{3}+\frac{\rho}{\rho_{0}}\left(R_{3}^{3}-R_{2}^{3}\right)\right]^{1 / 3}
$$

The process is repeated until all the Lagrangean coordinates have been calculated, i.e., until the entire physical system is transformed to the standard reference configuration.

The finite-difference form of Eq. 122 used for the calculation of the Lagrangean coordinates is

$$
R(J)=\left\{R(J-1)^{3}+\frac{i V_{0}}{V(J-1)}\left[\operatorname{RR}(J, 1)^{3}-\operatorname{RR}(J-1,1)^{3}\right]\right\}^{1 / 3} .
$$

where $R(J-1)$ and $R(J)$ are the Lagrangean coordinates representing the radii of the zone interfaces in the standard reference configuration, and $R R(J-1,1)$ and $R R(J, 1)$ are the Eulerian coordinates representing the radii of corresponding zone interfaces. in the actual physical system at time $\mathbf{t}=0$. 


\section{APPENDIX D}

Comparison of Computer Results. with Those Given by the Tait Equation

The adiabatic Tait form of the equation of state for water ${ }^{4}$ is

$$
P=3.047 \cdot\left[\left(\frac{1.0018}{V}\right)^{7.15}-1\right]
$$

for the pressure range $0<P<25 \mathrm{~kb}$ 。

Various values for the specific: volume and the associated values for the pressure have been extracted from the computer results. given in Table III and are shown in Table XIII. The values for the volumes wereused in Eq. 1:26 to obtain the corresponding pressures. These values of volume and pressure are also given in Table XIII.

TABLE XIII. Pressure-Volume Data for Water

\begin{tabular}{ccccc}
\hline Computer Solution & & Equation 126 & \% \\
\cline { 1 - 4 } $\begin{array}{c}\text { Spec. Vol, } \\
\mathrm{cm}^{3} / \mathrm{gm}\end{array}$ & $\begin{array}{c}\text { Pressure } \\
\mathrm{kb}\end{array}$ & $\begin{array}{c}\text { Spec. Vol, } \\
\mathrm{cm}^{3} / \mathrm{gm}\end{array}$ & $\begin{array}{c}\text { Pressure, } \\
\mathrm{kb}\end{array}$ & $\begin{array}{c}\text { Diff } \\
\text { in }\end{array}$ \\
\hline 0.7676 & 24.162 & 0.7676 & 17.404 & 38.8 \\
0.7753 & 16.962 & 0.7753 & 15.991 & 6.06 \\
0.8019 & 12.358 & 0.8019 & 11.914 & 3.72 \\
0.8427 & 7.649 & 0.8427 & 7.447 & 2.70 \\
0.9079 & 3.174 & 0.9079 & 3.111 & 2.02 \\
0.9614 & 1.057 & 0.9614 & 1.042 & 1.44 \\
0.9808 & 0.503 & 0.9808 & .0 .500 & 0.60 \\
\hline
\end{tabular}

For pressures below $16 \mathrm{~kb}$, there is good agreement between the computer results and the values given by Eq. 126. Therefore, the adiabatic Tait form of the equation of state for water. (Eq. 126) could have been used in the computer solution when the peak.pressure in the shock front dropped below $16 \mathrm{~kb}$. 


\section{APPENDIX E}

\section{Calculations for the Concrete'Vessel}

1. Mass per Unit Area of the Inside Surface

The mass per unit area, $\mathrm{m}$, is given by $m=\frac{\text { Total Mass of Concrete }}{\text { Area of Inside Surface }}$

For $\underline{r}_{i}=210 \mathrm{~cm}, r_{0}=390 \mathrm{~cm}$; and $\rho=2.663 \mathrm{gm} / \mathrm{cm}^{3}$, one obtains:

a. The area of the inside surface, $A=5.54,178 \mathrm{~cm}^{2}$;

b. The volume of concrete; $V=209,682,950 \mathrm{~cm}^{3}$;

c. The total mass of concrete, $\mathrm{M}=558,385,695 \mathrm{gm}$.

Hence, the mass per unit area is $\mathrm{m}=1007.59 \mathrm{grm} / \mathrm{cm}^{2}$.

2. Calculation for the Allowable Internal Pressure

The tangential stress in the concrete, based upon the equation. from elasticity* for a spherical container under internal pressure, is given by

$$
\sigma_{t}=\frac{P_{i a^{3}}}{2 R^{3}} \frac{2 R^{3}+b^{3}}{b^{3}-a^{3}},
$$

where $\sigma_{t}$ is the stress in the tangential direction, $P_{i}$ is the internal pressure, $a$ and $b$ are the inside and outside radii, respectively, and $R$ is the radial coordinate of the point of stress.

The allowable internal pressure, taken as that internal pressure for which the tangential stress at the outside surface equals the allowable stress, is given by

$$
\left.P_{i}\right|_{R=b}=\frac{2}{3}\left(\sigma_{t}\right)\left[\left(\frac{b}{a}\right)^{3}-1\right] \text {. }
$$

For $\sigma_{t}=400$ psi; the allowable internal pressure $\cdot$ is

$$
P=0.0992 \mathrm{~kb} \text {. }
$$

\footnotetext{
* See Timoshenko, S., and Goodier, J., Theory of Elasticity, Second Edition, 1951, p. 359.
} 


\section{APPENDIX F \\ Energy Calculations}

1. Energy Released by the Detonation of TNT

The energy released by the detonation of solid TNT can be determined if the appropriate information about the gaseous explosion products is known. The required information for the gaseous products of detonation for TNT of density $1.5 \mathrm{gm} / \mathrm{cm}^{3}$ is given in Table XIV. In addition, for the solid TNT, the heat of formation is $1.3 .0 \mathrm{kcal} / \mathrm{mole}$, and the molecular weight is $227 \mathrm{gm}$. Thus, by converting the units, the heat of formation of solid TNT is $57.30 \mathrm{cal} / \mathrm{gm}$.

TABLE XIV. Information about the Products of Detonation of TNTa

\begin{tabular}{lccc}
\hline Product & $\begin{array}{c}\text { Quantity, } \\
\text { moles/kg }\end{array}$ & $\begin{array}{c}\text { Heat of Formation, } \\
\text { kcal/mole }\end{array}$ & $\begin{array}{c}\text { Energy Released, } \\
\text { cal/gm }\end{array}$ \\
\hline $\mathrm{CO}$ & 8.7 & +26.4 & 229.68 \\
$\mathrm{CO}_{2}$ & 6.5 & +94.05 & 611.32 \\
$\mathrm{H}_{2}$ & 1.6 & 0 & 0 \\
$\mathrm{H}_{2} \mathrm{O}$ & 4.6 & +57.80 & 265.88 \\
$\mathrm{~N}_{2}$ & 6.6 & 0 & .0 \\
$\mathrm{CH}_{4}$ & 2.4 & +17.89 & 42.94 \\
$\mathrm{C}$ & 13.1 & 0 &. .9 \\
\hline
\end{tabular}

a The information in this table is extracted from Table 12.18a (page 310) and Table ii.5 (pages 404-405) of Cook, M. A., The Science of High Explosives, Reinhold Publishing Corporation, New York (1958).

The energy released by detonation of TNT is given as

$$
\dot{U}=\Sigma U_{\text {Products }}-U_{\text {Solid }} \mathrm{TNT}=1092.52 \mathrm{cal} / \mathrm{gm} \text {. }
$$

In this problem, $a_{0}=30 \mathrm{~cm}$, so that the mass of explosive is given as

$$
\mathrm{M}_{\mathrm{TNT}}=169,645 \mathrm{gm} \text {. }
$$

Therefore, the total energy released by the explosive charge is

$$
\mathrm{U}=1092.52 \times 169,645=185,124,000 \mathrm{cal} \text {. }
$$

2. Initial Kinetic Energy of the Concrete Mass

The initial kinetic energy of the concrete mass, as a result of the impulse, is given by

$$
\mathrm{K} . \mathrm{E} .=\frac{1}{2} \cdot \mathrm{Mv}_{\mathrm{r}}^{2} \text {. }
$$


The initial radial velocity, as given by Eq.. 67, is

$$
\mathrm{v}_{\mathrm{r}}=\frac{\mathrm{I}}{\mathrm{m}}=2590 \mathrm{~cm} / \mathrm{sec}
$$

For the total mass $M=558,385,695 \mathrm{gm}$, the initial kinetic energy is given as

$$
\text { K.E. }=18.36445 \times 10^{i 4} \text { dyne-cm }=43,871,100 \text { cal. }
$$

3. Comparison of Energies

The energies that have been determined are as follows:

a. The total energy released by the TNT: $185,124,000 \mathrm{cal}$.

b. The total energy of the detonation products* at time $t=0: 126,128,500$ cal.

c. The initial kinetic energy of the concrete mass: $43,871,100$ cal.

The initial kinetic energy of the concrete mass represents $23.7 \%$ of the total energy released by the detonation process and $34.8 \%$ of the energy in the detonation products at time $\mathrm{t}=0$.

*Obtained from Table II as ETNT $=5.2797292 \times 10^{15}$ dyne-cm. 


\section{APPENDIX G \\ Miscellaneous Considerations}

1. Calculation of the Gas Constant, $Q$, for the Detonation Products

The equation of state for the detonation products is given by Eq. 29 as

$$
P V=R T+0.6490 P-\left(0.2712 \times 10^{-11}\right) P^{2}+\left(0.6199 \times 10^{-23}\right) P^{3} .
$$

The conditions immediately, behind the detonation front, as given by Taylor, are

$$
\begin{aligned}
& P=15.00 \times 10^{10} \text { dynes } / \mathrm{cm}^{2} \\
& V=0.500 \mathrm{~cm}^{3} / \mathrm{gm},
\end{aligned}
$$

and

$$
\mathrm{T}=3400^{\circ} \mathrm{K}
$$

Thus, the value of the gas constant, $R$, for the detonation products is given as

$$
R=5,217,660 \text { dyne }-\mathrm{cm} / \mathrm{gm}-{ }^{\circ} \mathrm{K} \text {. }
$$

2. Calculations for the Allowable $\Delta t^{\prime} s$ at $t=0$

The minimum allowable time increment for each fluid media is as follows:

a. TNT

For $\Delta R=1.0 \mathrm{~cm}, P=12.45 \times 10^{10}$ dynes $/ \mathrm{cm}^{2}$, and $c=473,670 \mathrm{~cm} / \mathrm{sec}$, the time increment is given as

$$
\Delta t \leq 0.0000006 \text { sec. }
$$

Therefore, DTTEST for the TNT products is taken as 0.0000005 sec.

\section{b. Water}

For $\Delta R=10.0 \mathrm{~cm}, P=1.013274 \times 10^{6}$ dynes $/ \mathrm{cm}^{2}$, and c. $=145,000 \mathrm{~cm} / \mathrm{sec}$,

$$
\Delta t \leq 0.0000206
$$

Therefore, DTTEST for the water is taken as $0.0000100 \mathrm{sec}$. 


\section{c. Argon}

For $\Delta \mathrm{R}=15.0 \mathrm{~cm}, \mathrm{P}=1.013274 \times 10^{6}$ dynes $/ \mathrm{cm}^{2}$, and $c=: 33,100 \mathrm{~cm} / \mathrm{sec}$,

$$
\Delta t \leq 0.0001360 \text {. }
$$

Therefore, DTTEST for the argon is taken as $0.00010000 \mathrm{sec}$.

The allowable time increment for the finite-difference calculations is governed by that for the TNT products and is taken as

DELT $=0.0000005 \mathrm{sec}$.

3. Pictorial Representation for the $\Delta \mathrm{r}^{\prime} \mathrm{s}$

The pictorial representation for the $\Delta \mathrm{r}$ 's is shown in Fig. 32 :

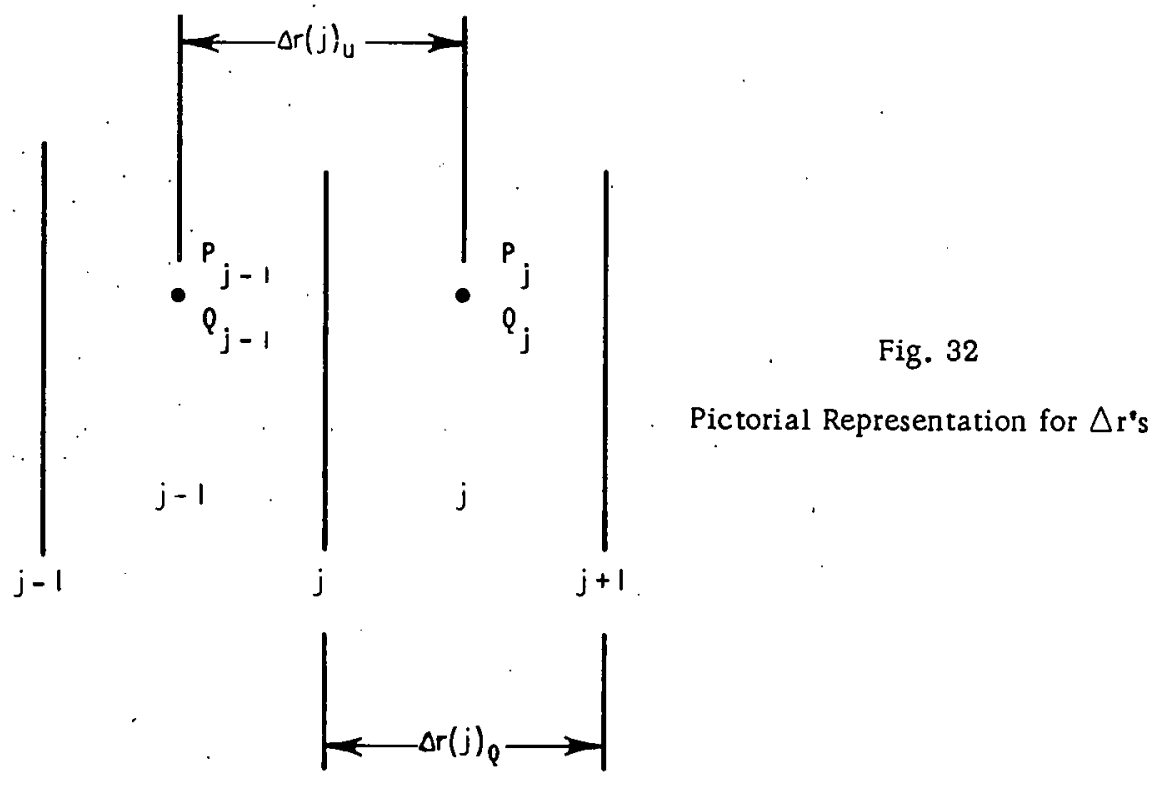




\section{ACKNOW LEDGMENT}

We.wish to express our appreciation to Dr. T. H. Hughes, Ap-plied Mathematics Division, ANL, for his very valuable advice and consultation; to Mr. M. R. Kraimer, Applied Mathematics Division, ANL, and Mr. R. E. Grench, Reactor Engineering. Division, ANL, for their help in the computer programming; and to the other members of the Engineering Mechanics Section, Reactor Engineering. Division, AN L, for their valuable comments. 


\section{REFERENCES}

1. Fistedis, S. H.; "A New Reactor Containment Concept by Energy Absorption," Nuclear Engineering and Design, Vol: 3, North Holland Publishing Company, Amsterdam, Holland (1966)。

2. Bethe, H. A., Testimony in the Matter of Power Reactor Development Company, U. S. Atomic Energy Commission. Docket No. 50-16.

3. Brode, H. L.; Blast Wave from a Spherical.Charge, The Physics of Fluids 2; No. 2, p. 217 (1959):

4. Brode, H. L., Numerical Solutions of Spherical Blast Waves, J. Appl. Phys. 26, No. 6, p。 766 (1955)。

5. Cole, R. H., Underwater Explosions, Princeton University Press, Princeton, New Jersey (1948)。

6. Cortrell, W. B., and Savolainen, A. W., U. S. Reactor Containment Technology, Vol. I, Oak Ridge National Laboratory (1965).

7. Courant, R., and Friedrichs, K. O., Supersonic Flow and Shock Waves, Interscience Publishers, Inc., New York (1948).

8. Dodge, B. F., Chemical Engineering Thermodynomics, McGraw-Hill Book Company, Inc., New. York (1944).

9. Hirschfelder, J. 0., Curtiss, F. C., and Bird, B. R., Molecular Theory of Gases and Liquids, John Wiley \& Sons, Inc., New York (1954).

10. Jones, H., and Miller, A. R., The Detonation of Solid Explosives: The Equilibrium Conditions in the Detonation Wave-Front and the Adiabatic Expansion of the Products of Detonation, Proc. Roy. Soc. (London) 194, 480 (1948).

11. K1inger, R. F., Effect of Rate of Strain on the Tensile Properties of SAE 4340 Steel, WADC-TR-53-507, Wright Air Development Center (1955)。

12. Owczarek, J. A., Fundomentals of Gas Dynomics, International Textbook Co., Scranton, Pa. (1964)。

13. Rice, M. H., and Walsh, J. M., Equation of State of Water to 250 Kilobars, J. Chem. Phys. 26, No. 4, 824 (1957).

14. Richtmeyer, R. D., Difference Methods for Initial-Value Problems, Interscience Publishers, Inc., New York (1957).

15. Taylor, Geoffrey, The Dynomics of the Combustion Products Behind Plane and Spherical Detonation Fronts in Explosives, Proc. Roy. Soc. (London) 200,235 (1950).

16. Von Neumann, J., and Richtmeyer, R. D., A Method for the Numerical Calculation of Hydrodynamic Shocks, J. Appl. Phys. 21, 232 (1950).

17. Yakovlev, Yu. S., The Hydrodynamics of an Explosion, FTD-TT-63-381/1+2, English Translation by Translation Division, Foreign Technology Division, Wright Patterson Air Force Base, Ohio.

18. Walsh, J. M., and Rice, M. H., Dynamic Compression of Liquids from Measurements on Strong Shock Waves, J. Chem. Phys.. 26, Nọ. 4, p. 815 (1957). 
19.* Kirkwood; J. G:, and Bethe, H. A., Basic Propagation Theory, OSRD 588 (1942).

20.* Kirkwood, J.G., and Brinkley, S. R., Jr., Theory of the Propagation of Shock Waves from Explosive Sources in Air and Water, OSRD 4814 (1945).

21.* Penney, W. G., British Report RC-142 (1941).

22 :* Penney, W. G., and Dasgupta, H. K., British Report RC-333 (1942).

23. Wise, W. R., Jr., and Proctor, J. F., NOLTR 63-140, Explosion Containment Laws for Nuclear Reactor Vessels, United States Naval Ordnance Laboratory, White Oak, Maryland (1965).

*Copies of Refs. 19-22 could not be located by the authors.: However, the necessary information from each is found in Ref. 4. 